\title{
Sustainability Product Properties in Building Information Models
}

Kristine Fallon Associates, Inc.

September 2012

11 East Adams Street, Suite 1100

Chicago, IL 60603

Prepared under Cooperative Research and Development Agreement CRADA-07-CERL-02 under the supervision of

E. William East, Project Manager (CEERD-CF-N)

Construction Engineering Research Laboratory

US Army Engineer Research and Development Center

2902 Newmark Drive

Champaign, IL 61822 



\section{Sustainability Product Properties in Building Information Models}

Kristine K. Fallon, Robert A. Feldman, Julia Greenberger, and Gregory R. Williams

Kristine Fallon Associates, Inc.

11 East Adams Street, Suite 1100

Chicago, IL 60603

Holly J. Genc, Lourdes M. Gonzalez, and Josh Greenfield

Primera Engineers, Ltd.

100 South Wacker Drive, Suite 700

Chicago, Illinois 60606

Final report

Approved for public release; distribution is unlimited.

\footnotetext{
Prepared for US Army Corps of Engineers

Washington, DC 20314-1000

Under CRADA-07-CERL-02

Monitored by Construction Engineering Research Laboratory US Army Engineer Research and Development Center 2902 Newmark Drive, Champaign, IL 61822
} 


\section{Abstract}

There are currently several competing efforts to define and measure sustainability. To date, no single concept of facility sustainability is widely accepted as being definitive because the term is often loosely used to define the particular environmental and social goals of any given sustainability proponent. This work looks beyond an abstract definition of facility sustainability and proposes a set of product properties that can be measured to represent the natural resources consumed to produce and operate facility assets.

Development of this set of sustainability properties included a review of prominent tools and systems for assessing facility sustainability, including contributions by industry experts. The project also included analysis of how sustainability product properties may be integrated with Building Information Modeling (BIM) technology to improve US Army facilities. The report includes sustainability properties for 56 building elements, which have been incorporated into building property templates for use in BIM models.

DISCLAIMER: The contents of this report are not to be used for advertising, publication, or promotional purposes. Citation of trade names does not constitute an official endorsement or approval of the use of such commercial products. All product names and trademarks cited are the property of their respective owners. The findings of this report are not to be construed as an official Department of the Army position unless so designated by other authorized documents. 


\section{Contents}

Abstract.................................................................................................................................. if

List of Figures and Tables ..................................................................................................vi

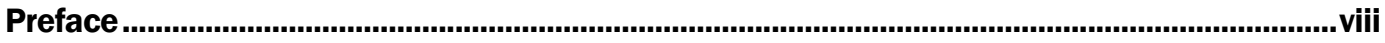

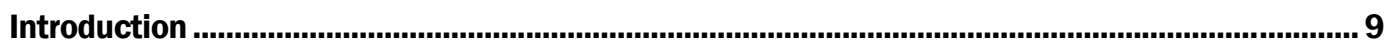

1 Guiding Principles for High Performance and Sustainable Buildings..................................12

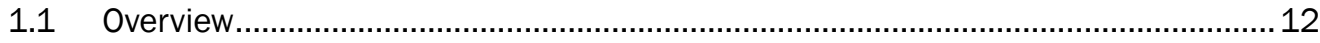

1.2 Employ integrated design principles ................................................................ 13

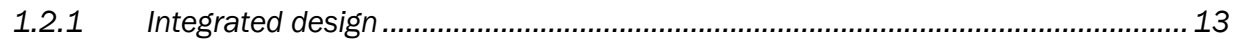

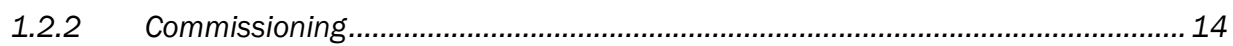

1.3 Sustainable sites ..................................................................................... 14

1.3.1 Select appropriate sites................................................................................. 15

1.3.2 Control erosion, sedimentation, and water quality ............................................... 15

1.3.3 Provide alternative transportation ....................................................................... 16

1.3.4 Minimize site and habitat disturbance .............................................................. 17

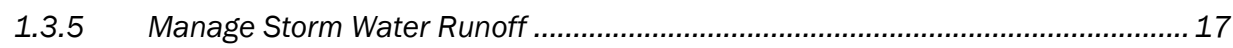

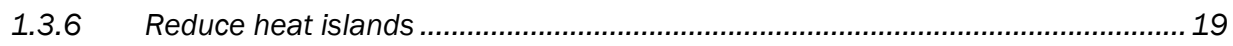

1.4 Protect and conserve water ........................................................................ 19

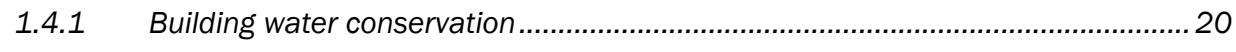

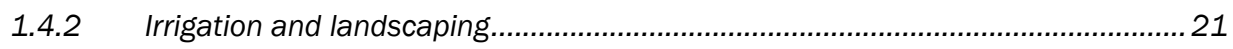

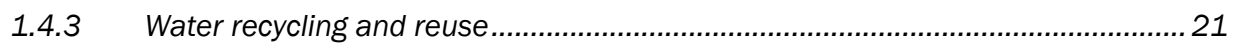

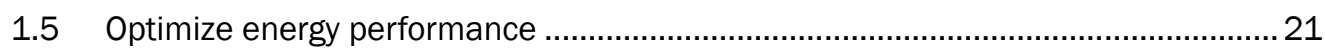

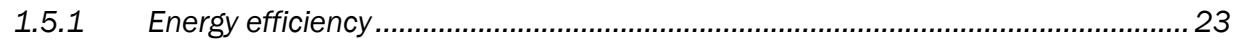

1.5.2 Onsite renewable energy ............................................................................. 23

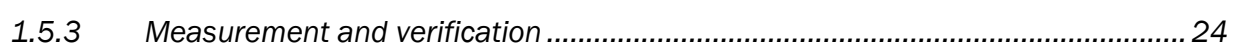

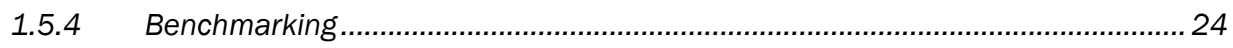

1.6 Reduce environmental impact of materials .................................................. 24

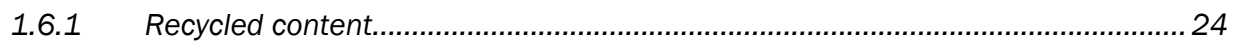

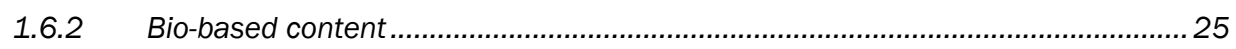

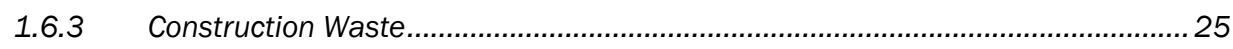

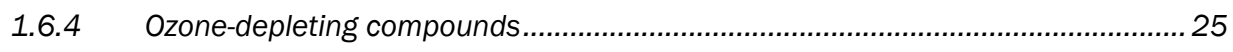

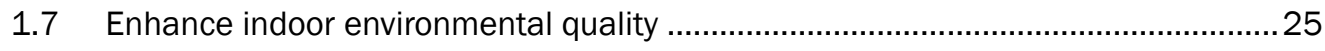

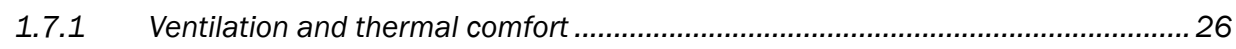

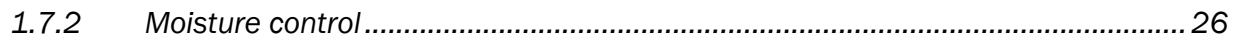

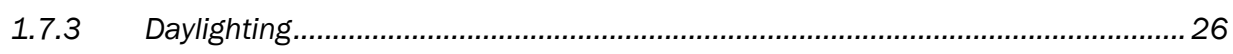

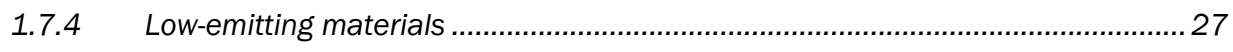

1.7.5 Protect indoor air quality during construction .......................................................2 27

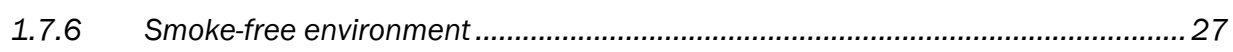

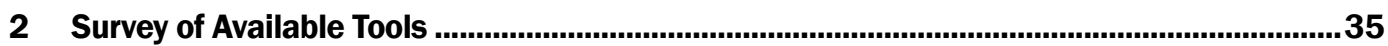




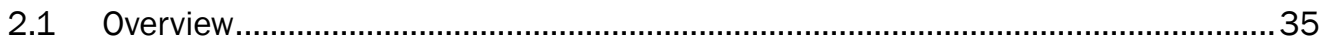

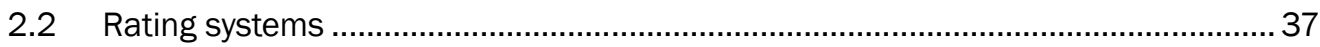

2.2.1 Leadership in Environmental and Energy Design (LEED).................................. 37

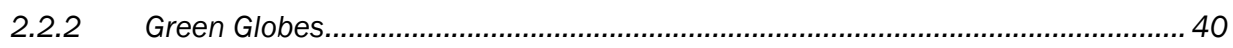

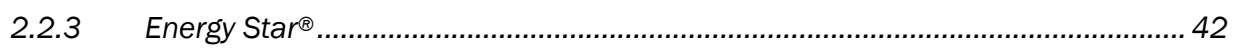

2.2.4 Green Guide for Health Care and LEED for Healthcare........................................ 44

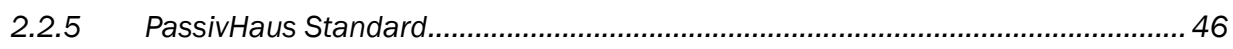

2.3 Compliance programs ................................................................................... 48

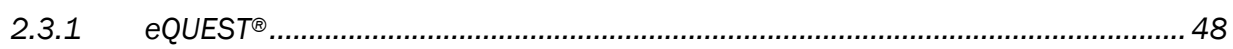

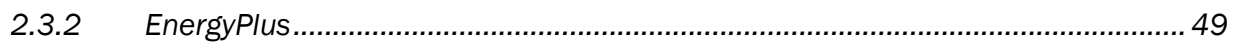

2.3.3 Building for Environmental and Economic Sustainability (BEES) ........................49

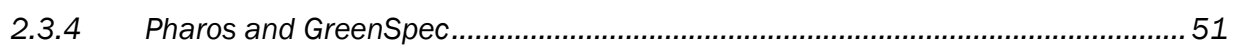

2.4 Comparison of the rating systems.................................................................... 51

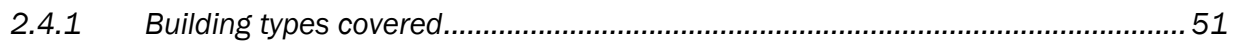

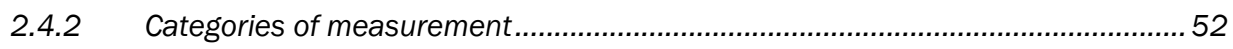

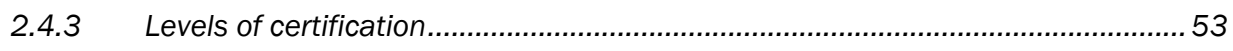

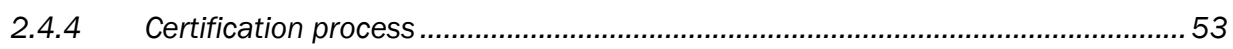

2.5 Tool capabilities required for support of Guiding Principles ...................................53

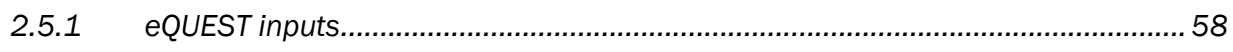

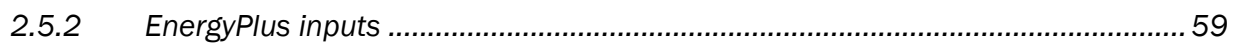

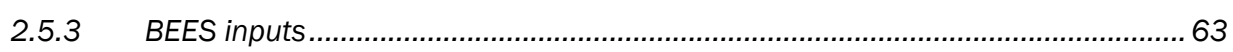

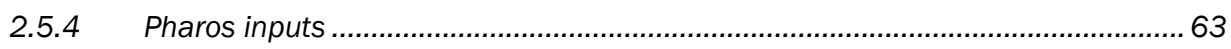

3 Sustainability Tool Capability Gaps ....................................................................................64

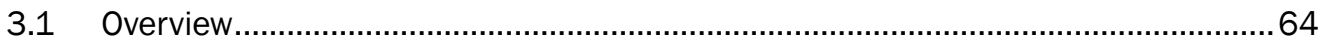

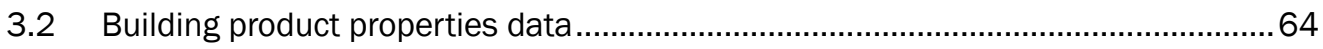

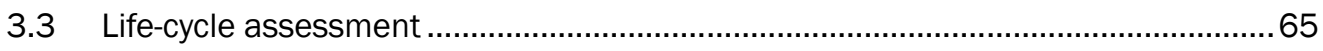

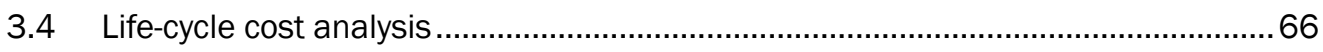

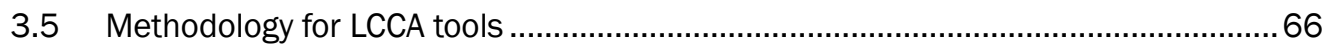

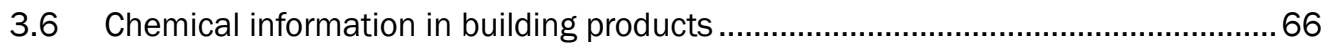

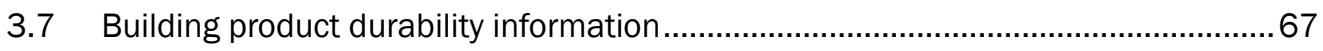

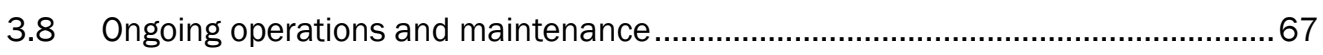

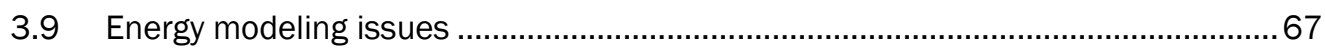

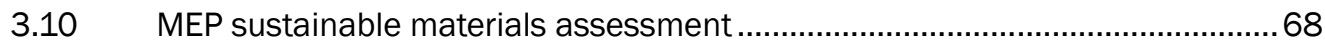

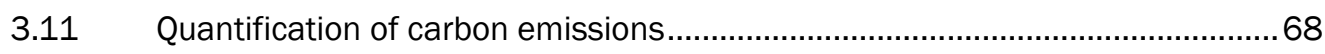

3.12 Benchmarking building performance .......................................................69

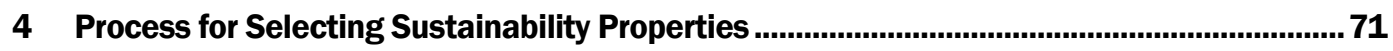

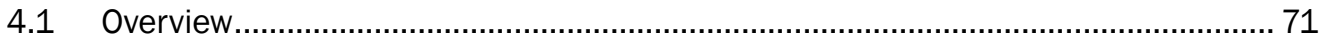

4.2 Step 1: Learn from precedent efforts................................................................ 72

4.2.1 Specifiers' Properties information exchange ......................................................... 72

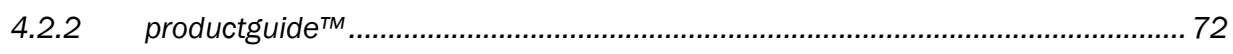

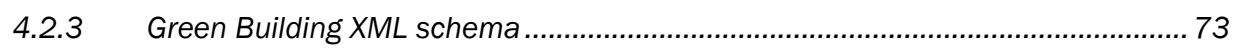

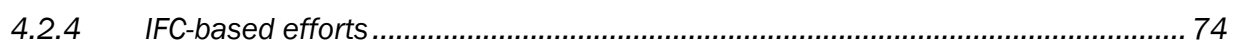

4.3 Step 2: Select product categories and types .................................................... 75

4.4 Step 3: Develop draft set of sustainability properties........................................... 76 
4.4.1 Document relevant sustainability properties from precedent projects ................. 76

4.4.2 Convene discipline-specific sustainability experts ............................................. 77

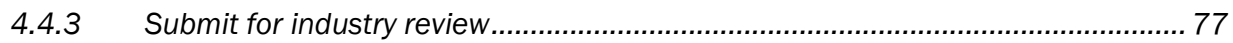

4.5 Sustainability properties not included .............................................................. 78

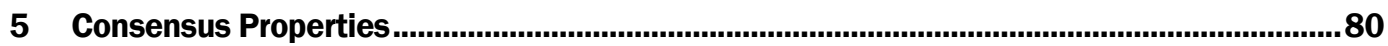

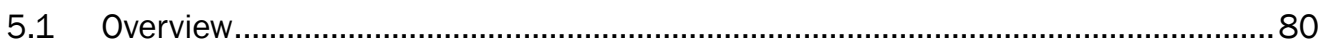

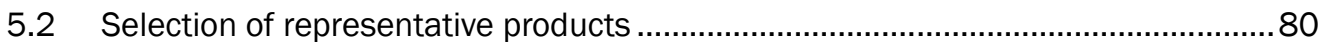

5.3 Sustainability property comparisons .............................................................. 81

5.4 Outside review of the sustainability properties ................................................... 81

5.5 Creation of IFC and COBie templates ........................................................ 82

5.6 Importation of sustainability properties into the Revit experimental building

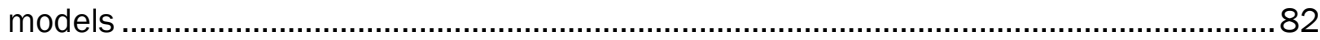

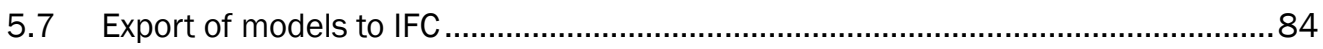

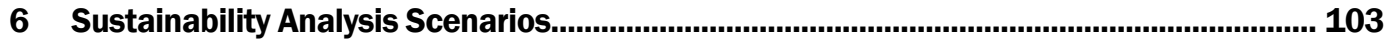

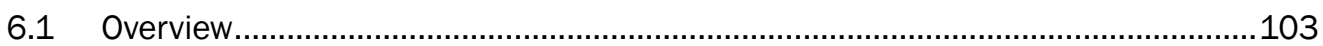

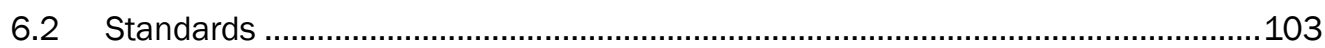

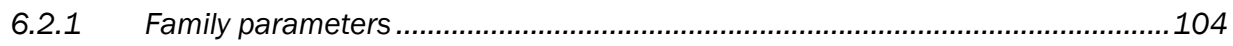

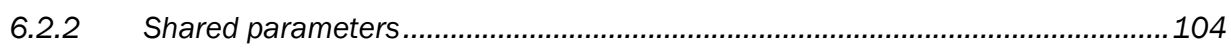

6.2.3 Sustainability requirements ............................................................................ 104

6.3 Scenario 1: LEED Water Efficiency Credit 3-Water Use Reduction .......................105

6.4 Scenario 2: LEED Sustainable Sites Credit 7.2-Heat Island Effect - Roof.............107

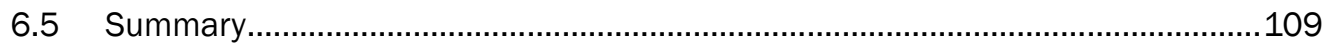

7 Adding Sustainability Properties to IFC Model Through COBie Spreadsheet.................... 110

7.1 Overview...................................................................................................... 110

7.2 Procedure .................................................................................................... 110

7.3 Demonstration .................................................................................... 111

7.4 Conversion issues..................................................................................... 113

7.4.1 Loss of model geometry ........................................................................... 113

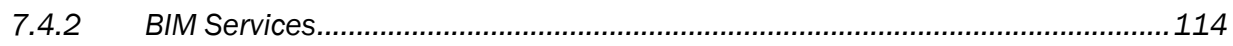

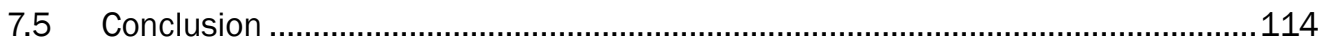

Appendix A: Proceedings of the ERDC-CERL Sustainability Product Properties

Workshop................................................................................................................ 116

Appendix B: Extended Building Information Templates........................................................... 203

Report Documentation Page 


\section{Figures and Tables}

\section{Figures}

Figure 5-1. Sample additional attribute rows in a COBie spreadsheet.

Figure 5-2: Revit parameter properties dialog box showing the Lamp Efficiency property applied to Lighting Fixtures

Figure 6-1. Parameter properties dialog. 104

Figure 6-2. Reproduction of table from 2009 edition of LEED Reference Guide for Green Building Design and Construction. 105

Figure 6-3. Duplex A, total annual water usage schedule............................................................106

Figure 6-4. Duplexes A and B, plumbing fixtures. ....................................................................106

Figure 6-5. Duplex B, total annual water usage schedule...........................................................106

Figure 6-6. Baseline SRI requirements-Table from 2009 LEED reference guide............................ 107

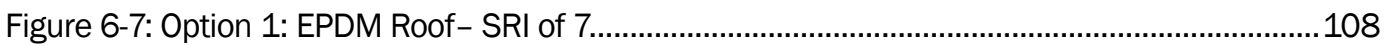

Figure 6-8: Option 2: TPO Roof-SRI of 111 ........................................................................108

Figure 6-9. Option 1-EPDM roofing schedule....................................................................... 108

Figure 6-10. Option 2-TPO roofing schedule.........................................................................108

Figure 7-1. COBie Properties of fixture in Solibri...........................................................................111

Figure 7-2. COBie spreadsheet Attributes tab..........................................................................112

Figure 7-3. Sustainability properties information...................................................................113

Figure 7-4. IFC MEP model in Solibri after export from Revit......................................................114

Figure 7-5. IFC MEP model after BIM Services conversion from COBIE to IFC. ...............................114

\section{Tables}

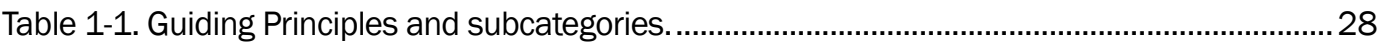

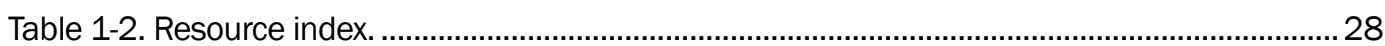

Table 1-3. Guiding Principles sections relevant to source documents (listed according to

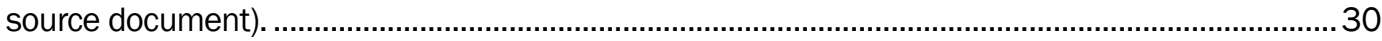

Table 1-4. Source documents related to individual Guiding Principles (listed according to

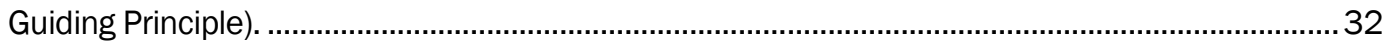

Table 1-5. Comparison of LEED ${ }^{\circledR}$ categories and Guiding Principles.................................................34

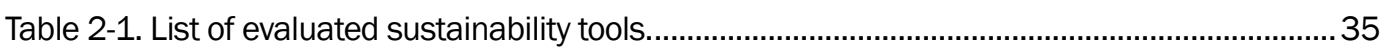

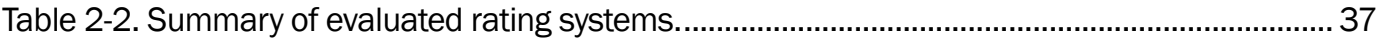

Table 2-3. Tool summary-compliance programs...................................................................... 48

Table 2-4. Summary of tool types required for Army sustainability initiatives..................................54

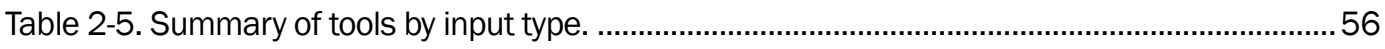

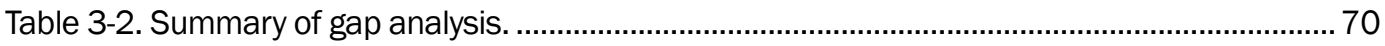

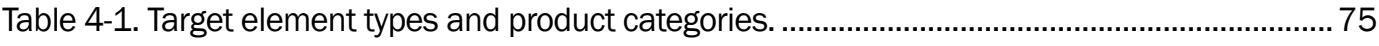

Table 4-2. Window sustainability properties from multiple sources................................................... 76 
Table 4-3. Sustainability Properties Suggested But Not Included in Templates. ..............................79

Table 5-1. Target Element Types and Product Categories............................................................... 85

Table 5-2. Sample products by Category and Element Type.......................................................... 85

Table 5-3. Sample of a property comparison for a window............................................................. 87

Table 5-4: Proposed Sustainability Properties...................................................................................... 88

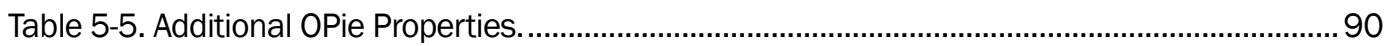

Table 5-6. Additional SPie and sustainability properties from CSI review...........................................94

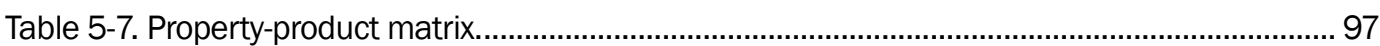




\section{Preface}

This report was prepared by Kristine Fallon Associates for the US Army Engineering Research and Development Center, Construction Engineering Research Laboratory (ERDC-CERL) under Cooperative Research and Development Agreement CRADA-07-CERL-02, "Cooperative Research And Development Agreement Between US Army Engineer Research and Development Center - Construction Engineering Laboratory and National Institute Of Building Sciences." The technical reviewer was Dr. E. William East, CEERD-CF-N.

The work was supervised and monitored by the Engineering Processes Branch (CF-N) of the Facilities Division (CF), US Army Engineer Research and Development Center - Construction Engineering Research Laboratory (ERDC-CERL). At the time of publication, Donald K. Hicks was Chief, CEERD-CF-N; L. Michael Golish was Chief, CEERD-CF; and Martin J . Savoie, CEERD-CV-ZT, was the Technical Director for Installations. The Deputy Director of ERDC-CERL was Dr. Kirankumar Topudurti and the Director was Dr. Ilker Adiguzel.

The following individuals are acknowledged for their significant contributions to this work:

- Dr. Vladimir Bazjanac, Lawrence Berkeley National Laboratory, Berkeley, CA

- Paul Bertram, Kingspan Insulated Panels, Inc., De Land, FL

- Mark Kalin, Kalin Associates, Inc., Newton, MA

- J ohn Kennedy, Autodesk, Inc., San Rafael, CA

- Arol Wolford, SmartBIM, Norcross, GA.

COL Kevin J . Wilson was the Commander of ERDC, and Dr. J effery P. Holland was the Director. 


\section{Introduction}

\section{Background}

Since FY08 (DoD Memorandum, "Sustainable Design and Development Policy Update - SPiRiT to LEED Transition") the Army has been using the US Green Building Council (USGBC) Leadership in Energy and Environmental Design (LEED) rating system for the Military Construction program. Projects starting in FY08 have been required to meet LEED-NC (New Construction), v2.2 requirements for compliance with a Silver Level certification. Residential Housing projects are similarly required to follow the LEED for Homes rating system as their standard to show compliance for sustainability. All major renovation projects exceeding \$7.5 million are required to follow the LEED EBOM (Existing Buildings, Operation and Maintenance) rating system to show compliance at the Certified Level. Actual documentation through the USGBC (Green Building Certification Institute - GBCI, is their American National Standards Institute (ANSI) compliant certification arm) certification is not required. Projects are jointly reviewed by an internal appointed team to determine compliance.

As of 25 October 2010, the DoD Memorandum, "Department of Defense Sustainable Buildings Policy" stated that all new construction and major renovations are required to follow the Guiding Principles in the High Performance and Sustainable Buildings MOU, in addition to the existing regulations that require LEED Silver compliance. This document also states that beginning in FY12 for projects in the planning stage (not yet in full design), the sum of energy and water efficiency credits shall equal or exceed $40 \%$ of the points required for a LEED-Silver, v2.2 (or equal) rating. This additional requirement highlights Army's focus on the importance of pursuing additional energy-and water-related credits. Some of the strategies that may be used to meet these goals in these areas will be the use of alternative energy sources, cool roofs and day lighting strategies.

A very important element of the Army's requirements is the need to evaluate each sustainability strategy using a life-cycle cost analysis. This is a requirement of the Guiding Principles for Federal Leadership in High Performance and Sustainable Buildings. It is not something that is formally required as part of LEED. Every sustainability measure discussed in this 
report is subjected to a life-cycle cost analysis to determine if it is cost effective for the project.

There are currently several competing efforts to define and measure sustainability. To date, no single approach to the issue of sustainability is widely accepted as being definitive because the term "sustainability" is often loosely used to define the particular environmental and social goals of a speaker or organization at a given time. Instead of addressing the abstract question "What is sustainability?", this work attempted to identify a set of quantifiable product properties that can be measured to represent the natural resources consumed to produce and use facility assets.

\section{Objectives}

The objective of this project was to develop, document, and create examples of a proposed model for the specification, delivery, and measurement of sustainability information about US Army building projects in Building Information Models (BIMs).

\section{Approach}

This study addresses three types of common Army buildings using experimental building models previously developed for officer housing, administrative offices, and clinics. ${ }^{1}$

A workshop was convened with invited building industry experts to define a minimum set of sustainability properties needed for BIM data exchanges for Architectural Elements/ Finishes, Mechanical Equipment, Electrical Equipment, and Water Systems (see Appendix A for the workshop proceedings). These properties were then used to illustrate the delivery of lifecycle sustainability information through the BIM environment and perform a model-checking demonstration.

In developing requirements for a sustainability data exchange, the authors reviewed the Federal Memorandum of Understanding entitled "Guiding Principles for Federal Leadership in High Performance and Sustainable Buildings." They also surveyed currently available sustainability rating sys-

1 Johnson, Mark, and Kristine K. Fallon. September 2011. Experimental Building Information Models. ERDC/CERL CR-11-2. Champaign, IL: US Army Engineer Research and Development Center, Construction Engineering Research Laboratory. 
tems and data properties, assessing them for capability gaps that should be filled in a sustainability data exchange specification for buildings. 


\section{Guiding Principles for High Performance and Sustainable Buildings}

\subsection{Overview}

This chapter summarizes current sustainability requirements placed on Army facilities. The focus is specifically on certain very common building types currently planned by the Army: single-family residential, low-rise multifamily residential, office and medical facilities. This review includes federal, agency, and department regulations and public law.

The Guiding Principles were created to help implement common strategies across governmental facilities to develop High Performance and Sustainable Buildings. They were established on J anuary 24, 2006 through a Memorandum of Understanding (MOU) committing the Federal government to designing, constructing, and operating its facilities in an energyefficient and environmentally sustainable manner, consistent with Federal agency missions. The MOU encourages the use of life-cycle concepts, consensus-based standards, and performance measurement and verification methods that lead to sustainable buildings. It also establishes the five Guiding Principles for High Performance and Sustainable Buildings that all Executive Branch agencies are to follow in the design, construction, and commissioning of federal buildings.

Executive Order (EO) 13423, "Strengthening Federal Environmental, Energy, and Transportation Management" (J anuary 24, 2007) instructs Federal agencies to conduct their environmental, transportation, and energyrelated activities under the law in support of their respective missions in an environmentally, economically and fiscally sound, integrated, continuously improving, efficient, and sustainable manner. EO 13423 consolidates prior "Greening the Government" Executive Orders and integrates the sustainable practices of those orders into a cohesive approach to environmental, energy, and transportation management. Executive Order 13423 requires Federal agencies to lead by example in advancing the nation's energy security and environmental performance. One of the sustainable environmental and energy practices of Executive Order 13423 is compliance with the High Performance and Sustainable Buildings principles of the Federal Leadership in High Performance and Sustainable Buildings 
Memorandum of Understanding in the design, construction and/ or major renovation, and commissioning of federal buildings.

The Guiding Principles translate this into six sustainable practices: employ integrated design principles, use sustainable sites, protect and conserve water, optimize energy performance, reduce environmental impact of materials, and enhance indoor environmental quality. These categories are listed and divided into subcategories in Table 1-1. Table 1-2 and supporting text describe all significant policy and standards sources related to the Guiding Principles, and Table 1-3 through Table 1-5 show the specific interconnections between the Guiding Principles and source documents. (The tables are shown at the end of this chapter.)

The text summarizes the requirements and policies for the major sustainability elements included in Army policies and regulations. These elements use both qualitative and quantitative metrics to help establish and assess the level of sustainability. This information is used to establish the level of sustainability properties for materials to be used by the Army.

\subsection{Employ integrated design principles}

\subsubsection{Integrated design}

The integrated design process, also known as the "whole building approach," is one of the first steps in developing a sustainable building. It requires participation of every team member to resolve issues, establish objectives and create a cohesive design. This needs to happen from the planning phase all the way through construction. Team members may include the Owner, Facility Users, Architect, Engineers, Contractors, Commissioning Agent, and Environmental and Energy Consultant. This approach is a powerful tool that can result in creative solutions and a multitude of benefits that would not be realized by isolated team members. This Integrated Design Process is also required by the Guiding Principles MOU.

Performance goals for siting, energy, water, materials and indoor environmental quality along with other comprehensive design goals shall be establish by the Integrated Project Team at the project planning and programming stage. The outcome of the project will be most affected by the decisions made in this early stage, as well as have the greatest impact upon facility life-cycle costs. Incorporation of these goals throughout the design 
and lifecycle of the building also needs to occur for a successful project. Department of Defense (DoD) Form 1391 was created to document this process of goal setting and project planning. This form is a requirement for all projects, but by completing this form you can document the results of a collaborative effort by the Project Team during a planning/ programming charrette.

The Integrate Design requirements are part of the Guiding Principles, stemming from DOE Order 413.3A, "Program and Project Management for the Acquisition of Capital Assets." It states that all projects must have an Integrated Design Team. The Guiding Principles refer to the Whole Building Design Guide (www.wbdg.org) for instruction on how to set up the integrated project team, as well as, ongoing maintenance throughout all stages of a project's planning and execution.

\subsubsection{Commissioning}

The Army's Sustainability Policy also requires Building Commissioning as part of any new construction project or major renovation. A commissioning plan is produced by a qualified Commissioning Agent at the beginning stage of each project. It captures the project requirements and identifies the project's commissioning goals. Most importantly, it determines what building components, systems and equipment will be verified for proper performance, ensuring that the design requirements are met. The size and complexity of the project will determine the extent of the commissioning scope. For large and/ or high risk projects, the Army requires that the Commissioning Agent ( $\mathrm{CxA}$ ) be hired directly by the government. For lower risk projects, the CxA may be hired through the prime contractor. Small, low risk projects may use the Contractor's Quality Control Manager as the CXA.

\subsection{Sustainable sites}

The site should be developed to optimize its potential by taking advantage of the natural site features, minimizing impacts of the built structure on the environment, and implementing passive solar heating and cooling, daylighting, and natural ventilation. Sustainable site design is a process of intervention involving the location of circulation, structures, and utilities. The process encompasses many steps from planning to construction, including initial inventory, assessment, alternative analysis, detailed design, and construction procedures and services. Key strategies for sustainable 
sitesare to (1) select appropriate sites, (2) control erosion, sedimentation, and water quality, (3) provide alternative transportation, (4) minimize site and habitat disturbance, (5) manage storm water runoff, and (6) reduce heat Islands.

\subsubsection{Select appropriate sites}

Selecting an appropriate site is one the first sustainable strategies to be implemented on a project. When selecting the site there are several features in or near the area that should be considered. Sites that have sensitive elements and restrictive land types, such as prime farmland or wetlands, should be avoided. Sustainable site design reinforces the holistic character of a landscape. It conveys appreciation of and respect for the interrelationships of a site, illuminating the interconnection of all parts through responsive design. A site that is classified as a brownfield or has existing buildings is a more sustainable choice than undeveloped land. By choosing a site in an urban setting, the facility can take advantage of mass transportation, existing infrastructure, and existing services in the surrounding community, and development density. When developing on an existing or new Base, Installation or Campus it is highly recommended to develop a sustainable master plan for guidance on the current and future projects.

Grouping facilities close together on a site, if possible, creates density and maximizes open space. Density will help conserve resources by sharing them among facilities. Sites near existing utility corridors require shorter extension of utilities to the new facility, resulting in lower costs and shorter distances.

Brownfields are sites that are not currently usable due to contamination from previous developments. Remediating a brownfield for a new facility is a commendable sustainability practice by bringing a piece of land back to use and conserving existing natural sites, as well as creating a healthier habitat for native species in the area.

\subsubsection{Control erosion, sedimentation, and water quality}

Construction activities, as well as rain and wind, contribute to soil erosion, sedimentation and pollution. Developing an erosion and sediment control plan and pollution prevention plan is necessary to prevent these negative impacts on the site. The Army's requirement is the 2003 EPA Construction 
General Permit, or local code if more stringent, which has requirements for the erosion and sediment control plan outlined. It describes the steps required for a Phase I and II of the National Pollutant Discharge Elimination System (NPDES). A permit is only required for site larger than 1 acre, but these measure are important for all sites. These requirements include measures to prevent the following:

- loss of soil during construction by wind erosion and stormwater runoff, including the protection of topsoil by stockpiling

- sedimentation of storm sewers or receiving streams

- pollution of air with dust and particulate matter.

Strategies to prevent the outcomes listed above include:

- temporary seeding, permanent seeding and mulching

- silt fence at project perimeter

- filter fabric at existing catch basins

- temporary gravel roads at entrance to site

- regular inspection of these measures to make sure they stay in place throughout construction.

Pollution prevention on the site includes Integrated pest management, a green cleaning program and elimination of hazardous material discharge into storm water systems. Integrated pest management requires environmentally friendly products to reduce groundwater pollution which impacts operations and maintenance procedures for pest control. Green cleaning programs are set up to make sure only cleaning products that are better for the environment are used throughout the facility. The Army also requires where hazardous discharge is a possibility, wet detention ponds or oil grit separators need to be installed to filter surface water runoff. These site elements filter the discharge through physical, biological or mechanical processes. These items are an important part of the LEED EBOM rating system and can also be used to show compliance for the Innovation and Design credits for the LEED BD+C rating system.

\subsubsection{Provide alternative transportation}

Sites that have several mass transit options available within walking distance of the facility help encourage occupants to utilize these options instead of driving vehicles to and from the site. Selecting sites with these features is preferred. These transit options can be provided by a local entity 
or developed by the facility. By siting the facility next to these resources, smaller onsite parking lots can be planned. Encouraging car or van pooling can provide additional benefits for no additional costs.

Where parking onsite is planned, as well as roads and walkways, porous paving can be used to decrease stormwater runoff. Include preferred carpool parking spots, preferred low-emitting/ fuel-efficient vehicle parking spots, bike racks and telecommuting as options to promote good transportation habits among facility-users.

\subsubsection{Minimize site and habitat disturbance}

The ability to minimize site and habitat disturbance provides benefits which include reducing building and paving footprints and limiting site disturbance to a minimal area around the building perimeter. Selecting a site in areas of high density where buildings can be located adjacent to existing infrastructure also minimizes the disturbance created by construction projects where new or relocated utilities are required. Light pollution, caused by both site lighting and excessive or unshielded interior lighting, is also considered a habitat disturbance to be prevented or reduced.

Reducing light pollution guidance is provided in UFC 03-530-01, "Interior and Exterior Lighting and Controls," based on Illuminating Engineering Society of North America's (IESNA) "Lighting Handbook Reference and Application, 9th Edition." Recommended measures include:

- Select fully shielded luminaires or IESNA full cutoff type for area and roadway lighting

- Provide uniform low glare lighting

- Do not over light exterior areas

- Control lighting with time clocks, photocells, and motion sensors such that lighting is only energized when needed - both exterior and interior lighting.

\subsubsection{Manage Storm Water Runoff}

The Army uses low-impact development (LID) for a sustainable storm water management strategy. LID is a holistic approach to site design, as well as overall sustainable design. This strategy controls water at the source, rainfall and storm water runoff. The main difference between LID and conventional systems is the concept of keeping the water onsite to return 
to the groundwater rather than being carried away by a storm drain piping system to a large storm water management facility. To achieve this goal, the rate of storm water runoff, the pollutants in the water and recharge of water into the ground have to be addressed. There are a variety of methods which can be utilized to reach the goal of LID including use of structural and non-structural elements to maintain the site in predevelopment condition to the maximum extent and to distribute and collect stormwater and rainfall.

LID takes conventional design strategies to the next level, by using all surfaces, both natural and hardscape, to their best advantages to meet the end goals of storm water management. Below are some of the more typical techniques that are used in practice:

- permeable paving to reduce imperviousness

- landscaping to break up expanses of impervious surfaces

- vegetated areas to help filter runoff and return it to the groundwater

- located vegetated areas near parking areas, building and other impervious areas to slow runoff, filter out pollutants and facilitate infiltration

- avoid curbs and gutters in parking areas and roadways onsite that deter storm water flow to vegetated areas

- reduce roadway widths

- bio retention cells

- vegetated swales

- infiltration trenches

- dry cells

- design grading to lengthen flow paths for increased runoff travel, which will modify the peak flow rate

- disconnect impervious areas

- maintain natural drainage patterns to keep flow paths dispersed

- divert storm water from roofs to vegetated areas or to collection devices

- subsurface retention facilities, or cisterns, to capture rainwater for reuse in irrigation and non-potable uses

- vegetated roofs

- native and adaptive plants, which require less irrigation and are appropriate for the region. 


\subsubsection{Reduce heat islands}

Urban area temperatures can be elevated by structures and pavements that are not sensitive to sustainable design, due to materials that absorb heat. This not only affects microclimates and natural habitats, but also increases summertime peak energy demands, air conditioning costs, air pollution and greenhouse gas emissions, heat-related illness and mortality, and water quality. Approaches include:

- use of trees and vegetation for shading and evapotranspiration

- green roofs-vegetated roofs that cover the roof membrane, providing the same benefits of vegetation on the site.

- cool roofs-highly reflective and emissive materials that can remain approximately $50-60^{\circ} \mathrm{F}\left(28-33^{\circ} \mathrm{C}\right)$ cooler than traditional materials during peak summer weather

- cool pavements-reflective pavements increase the albedo of the surface to limit heat gain

- permeable pavers permit evaporative cooling when the pavement is moist, helping to keep it cool

- reduce the need to pave

- canopies that incorporate solar panels in parking lots.

\subsection{Protect and conserve water}

Executive Order 13123 and the Energy Policy Act of 1992 require Federal agencies to install cost-effective water conservation measures in their facilities but do not include water conservation goals. Executive Order 13423 requires agencies to reduce water consumption intensity by 2 percent annually through 2015.

Based on these policies, the Army requires a facility water management plan for their new and existing facilities based on the Federal Energy Management Program's (FEMP) Facility Water Management Planning Guidelines and Ten Best Management Practices for Water Conservation. Key strategies include using potable water efficiently and reusing or recycling water onsite.

The Guiding Principles require indoor potable water usage to achieve a minimum of 20 percent water use savings as compared to the baseline, after meeting the Energy Policy Act of 1992 fixture performance requirements. For outdoor water, a 50 percent potable water use reduction over 
conventional landscaping and irrigation installations is desired. Water reuse and recycling and plant selection are suggested strategies. Storm water runoff and polluted site water runoff also require reduction measures. Refer to Sustainable Sites for more detail on storm water runoff.

A Military Handbook on Water Conservation was published in 2007 to provide guidance on implementation of the requirements. It specifically addresses creating a Water Conservation Plan. Some of the water-saving measures suggested for the Army are listed below.

\subsubsection{Building water conservation}

Numerous opportunities are available, including:

- Provide water conservation awareness training to building occupants.

- Provide low-flow plumbing fixtures and shorter shower times.

- Reduce excessive backwashing, well discharges, and leaks from the water well and treatment plant (the water supply source).

- Prepare a leak detection program to eliminate water being wasted before it ever reaches its intended purpose.

- Provide metering of the distribution system to determine where your major water users reside. this is most effective for applications where a tenant is paying for their water.

- Reduce water pressure to no more than 50-60 pounds per square inch (psi) (345-414 kiloPascals (kPa)).

- Consider eliminating water softeners where not needed, e.g., geographical areas where the tap water is not excessively hard, and for applications such as drinking, landscaping, and toilet flushing.

- Review HVAC water requirements.

- Locate water heaters close to the end-use devices. Install an autosetback control.Install a 360 degree loop heat trap or anti-convection valve to keep water driven by convection from traveling from the water heater. Include a hot water recovery system to minimize the loss of leftover hot water in the distribution pipes by drawing it back to the tank. Use tankless water heaters where continuous hot water is required for discrete and known periods of time

- Exploit unique opportunities for water conservation in medical facilities related to specialized equipment including $x$-ray machines, autoclaves and sterilizers

- Regularly inspect and maintain building equipment to detect leaks and malfunctions and prevent extended times of water losses 


\subsubsection{Irrigation and landscaping}

Irrigation and landscaping is a major source of water waste. The "U.S. Air Force Landscape Design Guide” and AWWA's “Water-Efficient Landscape Guidelines" include many approaches:

- rain sensors that shut off automatic irrigation systems in response to rainfall

- properly programmed automatic in-ground irrigation systems

- native, drought-tolerant and adaptive turf and plants for landscaping that do not require a permanent irrigation system

- graywater or rainwater collection for irrigation where feasible.

Maintenance and scheduling guidelines are also provided in these guides, such as adjusting automated controls when the seasons change, water deeply and infrequently, water in the morning, use mulches, control weeds

\subsubsection{Water recycling and reuse}

Implement these practices for:

- for irrigation

- for flushing toilets and urinals

- cooling tower make-up water.

\subsection{Optimize energy performance}

Executive Order 13423 and the Energy Policy Act of 2005 require Federal agencies to install cost-effective energy conservation measures in their facilities. The Army Corps of Engineers requires energy consumption levels that are a minimum of 30 percent better than ASHRAE 90.1-2004. Energy consumption levels for both the baseline building and proposed building shall be determined by using the Performance Rating Method found in ASHRAE Standard 90.1. Appendix $G$ except the formula for calculating the Performance Rating. The Army's requirement for this calculation is available in UFC-3-400-01, "Energy Conservation." This document requires an Energy Compliance Audit performed by various professionals on the design team, including a narrative written by the Lead Project Architect, Lead Project Mechanical Engineer, and the Lead Project Electrical Engineer. 
New single-family housing and low-rise (3 stories or less) multifamily residential buildings shall be designed and constructed in accordance with CFR Title 10 CFR Part 435. Specifically, residential buildings shall achieve an energy consumption level that is at least 30 percent below the International Code Council (ICC) International Energy Conservation Code. Energy consumption levels for both the baseline building and proposed building shall be determined by using the Simulated Performance Alternative found in the ICC International Energy Conservation Code. For all building types, if a minimum of 30 percent energy consumption savings cannot be achieved in a life-cycle cost-effective manner, the maximum savings level that is life-cycle cost-effective shall be achieved.

All energy consuming products shall be either Energy Star-qualified or FEMP-recommended. These products are in the upper 25 percent of energy efficiency in their class. These purchasing requirements are codified by FAR Part 23. All energy consuming products shall also be designated as using "low standby power" as required by Executive Order 13221.

Specific to the Guiding Principles, the design team must establish a whole building performance target that takes into account the intended use, occupancy, operations, plug loads, other energy demands, and design to earn the Energy Star ${ }^{\circledR}$ targets for new construction and major renovation where applicable. Based on the EO 13423, for new construction, the Guiding Principles require an energy reduction of of 30 percent compared to the baseline building performance rating per the American National Standards Institute (ANSI)/American Society of Heating, Refrigerating and AirConditioning Engineers, Inc., (ASHRAE)/ Illuminating Engineering Society of North America (IESNA) Standard 90.1-2007, Energy Standard for Buildings Except Low-Rise Residential. (Note that EO 13423 refers to the 2004 standard) Furthermore, for major renovations, the Guiding Principles also sets a standard for energy use reduction of 20 percent below prerenovations 2003 baseline, and for laboratory spaces, designers may use the Labs21 Laboratory Modeling Guidelines. The Guiding Principles require standard purchasing policies, constructions specifications, or proof of purchase on required projects to show that Energy Star ${ }^{\circledR}$ and FEMPdesignated Energy Efficient Products were used, where available.

The key strategies for conserving energy include energy efficiency in buildings, use of onsite renewable energy or green power, measurement and verification and benchmarking. 


\subsubsection{Energy efficiency}

The basics in designing an energy-efficient, high-performance building include:

- integrating the building with the site

- using renewable and/ or distributed energy resources

- optimizing the building envelope

- specifying efficient lighting and appliances

- specifying correctly-sized heating, ventilating, and air-conditioning (HVAC) systems

- recovering waste energy

- developing appropriate system control strategies.

The use of energy modeling programs early in the design process will help to guide architectural and engineering decisions to achieve the energy use goals defined in the planning stage.

\subsubsection{Onsite renewable energy}

The Army promotes the purchase of bulk green power or generating power onsite. Green power sources are clean and rapidly renewable, such as wind, solar, geothermal, biomass, and small hydroelectric. The EPAct 2005 defines renewable as electric energy generated from solar, wind, biomass, landfill gas, ocean (including tidal, wave, current, and thermal), geothermal, and municipal solid waste. The Energy Independence and Security Act of 2007 (EISA), Section 523 requires 30\% of the hot water demand in new Federal buildings (and major renovations) be met with solar hot water equipment, stipulated by the Guiding Principles provided it is life-cycle cost-effective. It also requires the reduction of fossil fuel consumption relative to the 2003 baseline by $55 \%$ by 2010 , $65 \%$ by $2015,80 \%$ by 2020 and $100 \%$ by 2030 . The Guiding Principles require life-cycle cost analysis be done for all viable onsite renewable energy sources, as set forth in Executive Order 13423. When they are lifecycle cost-effective, renewable energy strategies should be implemented.

The Renewable Energy Working Group (REWG), led by FEMP, was set up to provide guidance on what counts toward the renewable energy goals for federal facilities. Only electricity from renewable resources counts towards EPAct 2005 renewable energy goals as modified by EO 13423, and the facility must use the renewable energy it produces. EO 13423 requires "new" 
renewable energy. This has been defined as renewable energy coming from facilities placed in service after J anuary 1, 1999. Purchasing renewable energy credits (RECs) also counts toward the goals.

\subsubsection{Measurement and verification}

The Guiding Principles refer to the EPAct 2005, requiring building level utility meters to track and continuously optimize performance. Monitoring of project performance starts in the planning phases and lasts throughout the life of the building. At the very beginning, quality assurance plans and procedures must be created that will provide a reference for use by everyone from designers to the building's end user. The sequence of operation and the systems parameters to be measured are defined in the design phase. The commissioning phase ensures that these systems work properly from the start. Once occupied, the building's operations and maintenance program continues to monitor the building through building automation system, energy management systems, and/ or direct digital controls for all systems affecting energy efficiency.

\subsubsection{Benchmarking}

The Army requires annual reporting of their buildings' energy and water usage data. Per the Energy Policy Act of 2005, Federal agencies must have advanced metering capability (hourly measurements of electricity consumption and daily data reports, at a minimum) by October 1, 2012.

\subsection{Reduce environmental impact of materials}

Executive Order 13423 directs Federal agencies to use recycled content, bio based products, environmentally preferable products, and reduce the quantity of toxic and hazardous chemicals and materials acquired, used, or disposed of by the agencies.

\subsubsection{Recycled content}

The Guiding Principles require products meeting or exceeding EPA's recycled content recommendations. The EPA's recommendations list specifies products and percentage of recycled content for that product. For other products, specify materials with recycled content when practicable. 


\subsubsection{Bio-based content}

For bio-based products, the Guiding Principles direct one to the USDA recommendations. For other products, use bio based products made from rapidly renewable resources and certified sustainable wood products.

\subsubsection{Construction Waste}

The DoD Memorandum "Sustainable Management of Waste in Military Construction, Renovation, and Demolition Activities," dated February 6, 2006 requires $50 \%$ diversion of construction and demolition waste from landfills. This is calculated by weight. Contractors are required to provide a C and D Waste Management Plan. Project cost estimates must include expenses to include these services.

\subsubsection{Ozone-depleting compounds}

The Significant New Alternatives Policy (SNAP) program is EPA's program to evaluate and regulate substitutes for ozone-depleting chemicals being phased out under the stratospheric ozone protection provisions of the Clean Air Act (CAA). To meet the Executive Order 13423 objectives, use alternatives to ozone-depleting substances to the maximum extent possible per SNAP and do not use CFC containing Halon systems in fire suppression.

\subsection{Enhance indoor environmental quality}

Invariably, healthy and comfortable environments will enable occupants to better perform assignments to meet their service's mission. The Guiding Principles require for both new and existing facilities several items to meet the requirements to enhance indoor environmental quality including providing ventilation and thermal comfort, employing moisture control strategies, maximizing daylighting and lighting controls, minimizing the interior emissions of materials during and after construction, utilizing integrated pest control strategies and prohibiting smoking within and around buildings.

Key strategies for creating and maintaining a healthy and productive indoor environment include the following:

- Provide adequate levels of ventilation as determined by ASHRAE 62.1 
- Minimize impacts on indoor air quality by following preventative measures during Construction.

- Do not use materials with high volatile organic compounds (VOC) with the building's envelope.

- Control disturbing odors and contaminants.

- Provide occupants with the ability to control their own environment by providing both individual lighting controls and thermal controls.

- Maximize the use of daylighting strategies to minimize energy, and plan so all regularly occupied spaces have access to views and daylight.

- Ensure that acoustical privacy is provided, and noise transmission minimized.

\subsubsection{Ventilation and thermal comfort}

Meet the current ASHRAE Standard 55-2004, "Thermal Environmental Conditions for Human Occupancy," including continuous humidity control within established ranges per climate zone, and ASHRAE Standard 62.12004, "Ventilation for Acceptable Indoor Air Quality." There are several prerequisites in LEED rating systems which specifically address this category which must also be taken into account when establishing the basis of design. Carbon dioxide sensors are preferred in large group spaces to provide operational control so that the right amount of fresh air is delivered.

\subsubsection{Moisture control}

Establish and implement a moisture control strategy for controlling moisture flows and condensation to prevent building damage and mold contamination. Use best practices for the envelope enclosure and provide proper site preparation to ensure that all moisture drains away from building's perimeter.

\subsubsection{Daylighting}

Achieve a minimum of daylight factor of 2 percent (excluding all direct sunlight penetration) in 75 percent of all space occupied for critical visual tasks. Provide automatic dimming controls or accessible manual lighting controls, and appropriate glare control. This daylighting strategy improves overall energy performance of your facility, and can provide increased quality of light available for these tasks. Strategies such as light shelves can help bring this light further in to the building's perimeter. 


\subsubsection{Low-emitting materials}

Specify materials and products with low pollutant emissions, including adhesives, sealants, paints, carpet systems, and furnishings. The levels are determined by the South Coast Air Quality Management System (SCAQMD) Rule \#1186. Consider removing asbestos containing materials during renovation or encapsulating it so that further migration is impossible. Also develop radon strategies in applicable areas. All areas of the building that will permanently house chemical materials should be constructed to create safe, convenient, and secure storage spaces.

\subsubsection{Protect indoor air quality during construction}

Follow the recommended approach of the Sheet Metal and Air Conditioning Contractor's National Association (SMACNA) 'Indoor Air Quality Guidelines for Occupied Buildings under Construction" (1995). After construction and prior to occupancy, conduct a flush-out of the entire facility with maximum outdoor air temperature and humidity consistent with the parameters established during design. This plan should be developed by the Contractor based on the parameters developed from the designed systems. Schedule material deliveries to minimize moisture exposure, and provide additional ventilation if materials contain high levels of VOCs.

\subsubsection{Smoke-free environment}

LEED requires that any building pursuing certification prohibits smoking with 25 feet of any entrance to the facility, outdoor air intakes and within the building proper. This requirement is a prerequisite for the rating systems. Many local jurisdictions also have regulations regarding nosmoking, however the LEED requirements are more stringent in many cases and need to be followed to meet the LEED prerequisites. 
Table 1-1. Guiding Principles and subcategories.

\begin{tabular}{|c|c|}
\hline Guiding Principle - Category & Subcategory \\
\hline \multirow[t]{2}{*}{ Employ Integrated Design Principles } & Integrated Design \\
\hline & Commissioning \\
\hline \multirow[t]{5}{*}{ Sustainable Sites } & Select Appropriates Sites \\
\hline & Provide Alternative Transportation \\
\hline & Minimize Site and Habitat Disturbance \\
\hline & Manage Storm Water Runoff \\
\hline & Reduce Heat Islands \\
\hline \multirow[t]{3}{*}{ Protect and Conserve Water } & Building Water Conservation \\
\hline & Irrigation and Landscaping \\
\hline & Water Recycling and Re-use \\
\hline \multirow[t]{4}{*}{ Optimize Energy Performance } & Energy Efficiency \\
\hline & Onsite Renewable Energy \\
\hline & Measurement and Verification \\
\hline & Benchmarking \\
\hline \multirow[t]{4}{*}{ Reduce Environmental Impact of Materials } & Recycled Content \\
\hline & Bio-Based Content \\
\hline & Construction Waste \\
\hline & Ozone Depleting Compounds \\
\hline \multirow[t]{6}{*}{ Enhance Indoor Environmental Quality } & Ventilation and Thermal Comfort \\
\hline & Moisture Control \\
\hline & Daylighting \\
\hline & Low-Emitting Materials \\
\hline & Protect Indoor Air Quality during Construction \\
\hline & Smoke Free \\
\hline
\end{tabular}

Table 1-2. Resource index.

\begin{tabular}{|l|l|l|l|}
\hline Source & Document Name & Reference & Date \\
\hline UFC & Energy Conservation & UFC-3-400-01 & $08 / 2008$ \\
\hline UFC & Sustainable Development & UFC-4-030-01 & $12 / 21 / 2007$ \\
\hline DoD & $\begin{array}{l}\text { Sustainable Design and Development } \\
\text { Policy Update -SPiRiT to LEED Transition }\end{array}$ & DoD Memorandum & $01 / 05 / 2006$ \\
\hline DoD & $\begin{array}{l}\text { Sustainable Design and Development } \\
\text { Policy Update - Life-cycle cost }\end{array}$ & $\begin{array}{l}\text { DoD } \\
\text { Memorandum }\end{array}$ & $04 / 27 / 2007$ \\
\hline ARMY & $\begin{array}{l}\text { The US Army Energy and Water Campaign } \\
\text { Plan for Installations }\end{array}$ & & $08 / 01 / 2006$ \\
\hline DoD & $\begin{array}{l}\text { Department of Defense Sustainable } \\
\text { Buildings Policy }\end{array}$ & DoD Memorandum & $10 / 25 / 2010$ \\
\hline DOE & Guiding Principles for Federal Leadership & DOE & $01 / 2006$ \\
\hline
\end{tabular}




\begin{tabular}{|c|c|c|c|}
\hline Source & Document Name & Reference & Date \\
\hline & $\begin{array}{l}\text { in High Performance and Sustainable } \\
\text { Buildings }\end{array}$ & & \\
\hline $\mathrm{DOE}$ & $\begin{array}{l}\text { Program and Project Management for the } \\
\text { Acquisition of Capital Assets }\end{array}$ & DOE Order 413.3A & $11 / 17 / 2008$ \\
\hline WBDG & $\begin{array}{l}\text { Technical Guidance: Sustainable } \\
\text { Sites/Smart Growth }\end{array}$ & EO 13423 & \\
\hline EPA & $\begin{array}{l}\text { National Pollution Discharge Elimination } \\
\text { System }\end{array}$ & & \\
\hline UFC & Interior and Exterior Lighting and Controls & UFC 3-530-01 & $12 / 10 / 2010$ \\
\hline IESNA & $\begin{array}{l}\text { IESNA Recommended Practice Manual: } \\
\text { Lighting for Exterior Environments }\end{array}$ & IES RP-33-99 & 02/01/1999 \\
\hline WBDG & $\begin{array}{l}\text { Technical Guidance: Stormwater Run-off } \\
\text { Mitigation }\end{array}$ & & \\
\hline UFC & Low Impact Development Manual & UFC 3-210-10 & $11 / 15 / 2010$ \\
\hline EPA & $\begin{array}{l}\text { Reducing Urban Heat Islands: } \\
\text { Compendium of Strategies }\end{array}$ & & $10 / 2008$ \\
\hline FR & $\begin{array}{l}\text { Greening the Government through } \\
\text { Leadership in } \\
\text { Environmental Management }\end{array}$ & EO 13123 & $04 / 02 / 2002$ \\
\hline FR & $\begin{array}{l}1997 \text { Military Handbook on Water } \\
\text { Conservation }\end{array}$ & & \\
\hline FR & $\begin{array}{l}\text { Energy Efficiency and Water Conservation } \\
\text { at Federal Facilities }\end{array}$ & EO 12902 & 03/08/1994 \\
\hline FR & $\begin{array}{l}\text { Strengthening Federal Environmental, } \\
\text { Energy, and Transportation Management }\end{array}$ & EO 13423 & $01 / 24 / 2007$ \\
\hline Air Force & U. S. Air Force Landscape Design Guide & & \\
\hline AWWA & Water-Efficient Landscape Guidelines & & \\
\hline WBDG & $\begin{array}{l}\text { Executive Order } 13423 \text { Technical } \\
\text { Guidance: Ozone Depleting Compounds }\end{array}$ & & \\
\hline ASHRAE & $\begin{array}{l}\text { ASHRAE Standard 90.1-2007, Energy } \\
\text { Standard for Buildings Except Low-Rise } \\
\text { Residential Buildings }\end{array}$ & ASHRAE Standard 90.1-2007 & 2007 \\
\hline ASHRAE & $\begin{array}{l}\text { ASHRAE: Standard 62.1-2004, Ventilation } \\
\text { for Acceptable Indoor Air Quality }\end{array}$ & ASHRAE Standard 62-1999 & 2004 \\
\hline ASHRAE & $\begin{array}{l}\text { ASHRAE: Standard 55-2004, Thermal } \\
\text { Environmental Conditions for Human } \\
\text { Occupancy }\end{array}$ & ASHRAE Standard 55-2004 & 2004 \\
\hline USC & $\begin{array}{l}\text { Energy Efficient Standards for the Design } \\
\text { and Construction of New Federal and } \\
\text { Commercial and Multifamily High Rise } \\
\text { Residential Buildings }\end{array}$ & USC Title 10, Part 433 & $12 / 04 / 2006$ \\
\hline USC & $\begin{array}{l}\text { Energy Efficient Standards for New } \\
\text { Federal Low-rise Residential Buildings }\end{array}$ & USC Title 10, Part 435 & $12 / 04 / 2006$ \\
\hline USC & $\begin{array}{l}\text { Federal Energy Management and } \\
\text { Planning Programs, Subpart A - } \\
\text { Methodology and Procedures for Life-cycle } \\
\text { cost Analysis }\end{array}$ & USC Title 10, Part 436 & $12 / 04 / 2006$ \\
\hline FR & Energy Efficient Standby Power Devices & EO 13221 & $08 / 02 / 2001$ \\
\hline Congress & $\begin{array}{l}\text { Energy Independence and Security Act of } \\
2007\end{array}$ & & $01 / 04 / 2007$ \\
\hline ICC & ICC International Energy Conservation & & 2009 \\
\hline
\end{tabular}




\begin{tabular}{|c|c|c|c|}
\hline Source & Document Name & Reference & Date \\
\hline & Code & & \\
\hline EPA & $\begin{array}{l}\text { EPA Significant New Alternatives Program } \\
\text { (SNAP) }\end{array}$ & SNAP & \\
\hline DOE, FEMP & $\begin{array}{l}\text { Renewable Energy Requirement } \\
\text { Guidance for EPACT } 2005 \text { and Executive } \\
\text { Order } 13423\end{array}$ & & $01 / 28 / 2008$ \\
\hline DoD & $\begin{array}{l}\text { Sustainable Management of Waste in } \\
\text { Military Construction, Renovation, and } \\
\text { Demolition Activities }\end{array}$ & DoD Memorandum & $02 / 06 / 2006$ \\
\hline WBDG & $\begin{array}{l}\text { Executive Order } 13423 \text { Technical: Low- } \\
\text { Emitting Materials. }\end{array}$ & & \\
\hline EPA & $\begin{array}{l}\text { EPA's Comprehensive Procurement } \\
\text { Guidelines }\end{array}$ & & \\
\hline USDA & Biobased products & www.biopreferred.gov & \\
\hline EPA & EPA's EPP database & www.epa.gov/epp & \\
\hline
\end{tabular}

Table 1-3. Guiding Principles sections relevant to source documents (listed according to source document).

\begin{tabular}{|c|c|c|c|c|c|c|c|}
\hline Document Name & 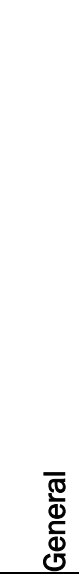 & 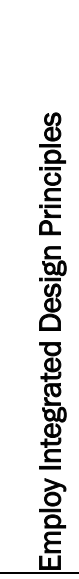 & 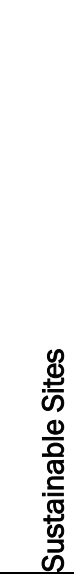 & 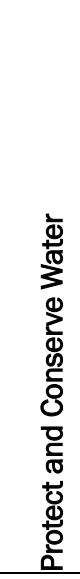 & 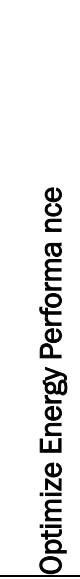 & 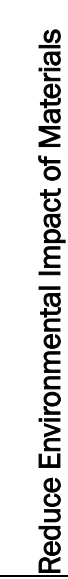 & 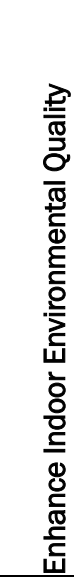 \\
\hline $\begin{array}{l}\text { EO 13423, "Strengthening Federal } \\
\text { Environmental, Energy, and } \\
\text { Transportation Management" }\end{array}$ & & $\mathrm{X}$ & & $\mathrm{x}$ & $\mathrm{X}$ & $\mathrm{X}$ & $x$ \\
\hline UFC-3-400-01, “Energy Conservation” & & & & & $x$ & & \\
\hline $\begin{array}{l}\text { UFC-4-030-01, “Sustainable } \\
\text { Development” }\end{array}$ & & $\mathrm{X}$ & $X$ & $\mathrm{x}$ & $\mathrm{X}$ & $\mathrm{X}$ & $x$ \\
\hline $\begin{array}{l}\text { Sustainable Design and Development } \\
\text { Policy Update -SPiRiT to LEED Transition }\end{array}$ & $X$ & & & & & & \\
\hline $\begin{array}{l}\text { Sustainable Design and Development } \\
\text { Policy Update - Life-cycle cost }\end{array}$ & $X$ & & & & & & \\
\hline $\begin{array}{l}\text { The US Army Energy and Water } \\
\text { Campaign Plan for Installations }\end{array}$ & & & & $\mathrm{x}$ & $\mathrm{X}$ & & \\
\hline $\begin{array}{l}\text { Department of Defense Sustainable } \\
\text { Buildings Policy }\end{array}$ & $x$ & & & & & & \\
\hline $\begin{array}{l}\text { Guiding Principles for Federal Leadership } \\
\text { in High Performance and Sustainable } \\
\text { Buildings }\end{array}$ & & $\mathrm{X}$ & & $\mathrm{x}$ & $\mathrm{X}$ & $\mathrm{X}$ & $X$ \\
\hline
\end{tabular}




\begin{tabular}{|c|c|c|c|c|c|c|c|}
\hline Document Name & 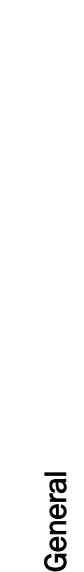 & 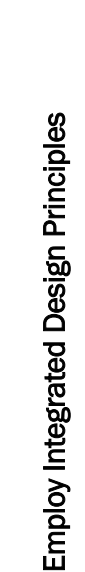 & 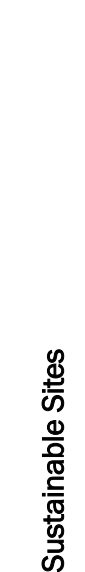 & 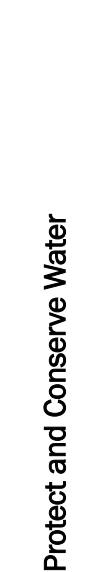 & 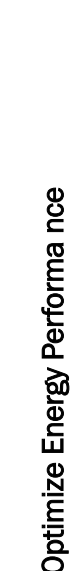 & 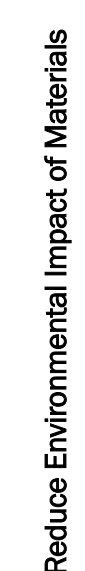 & 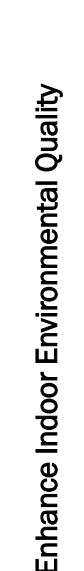 \\
\hline $\begin{array}{l}\text { DOE 0. 413.3A: Program and Project } \\
\text { Management for the Acquisition of } \\
\text { Capital Assets }\end{array}$ & & $x$ & & & & & \\
\hline $\begin{array}{l}\text { WBDG: Technical Guidance: Sustainable } \\
\text { Sites/Smart Growth }\end{array}$ & & & $x$ & & & & \\
\hline 2003 EPA Construction General Permit & & & $x$ & & & & \\
\hline $\begin{array}{l}\text { National Pollution Discharge Elimination } \\
\text { System }\end{array}$ & & & $x$ & & & & \\
\hline $\begin{array}{l}\text { UFC 3-530-01, "Interior and Exterior } \\
\text { Lighting and Controls" }\end{array}$ & & & $x$ & & & & \\
\hline $\begin{array}{l}\text { IESNA Recommended Practice Manual: } \\
\text { Lighting for Exterior Environments }\end{array}$ & & & $x$ & & & & \\
\hline $\begin{array}{l}\text { USACE Sustainable Design and } \\
\text { Development Resources: } \\
\text { Sustainable Sites: Light Pollution } \\
\text { Reduction }\end{array}$ & & & $x$ & & & & \\
\hline $\begin{array}{l}\text { WBDG Technical Guidance: Stormwater } \\
\text { Run-off Mitigation }\end{array}$ & & & $x$ & & & & \\
\hline EPA Low Impact Development Manual & & & $x$ & & & & \\
\hline $\begin{array}{l}\text { EPA Reducing Urban Heat Islands: } \\
\text { Compendium of Strategies }\end{array}$ & & & $X$ & & & & \\
\hline $\begin{array}{l}\text { EO 13123, "Greening the Government } \\
\text { through Leadership in Environmental } \\
\text { Management" }\end{array}$ & $x$ & & & & & & \\
\hline $\begin{array}{l}1997 \text { Military Handbook on Water } \\
\text { Conservation }\end{array}$ & & & & $x$ & & & \\
\hline $\begin{array}{l}\text { Energy Efficiency and Water Conservation } \\
\text { at Federal Facilities }\end{array}$ & & & & $x$ & & & \\
\hline U. S. Air Force Landscape Design Guide & & & & $\mathrm{x}$ & & & \\
\hline Water-Efficient Landscape Guidelines & & & & $x$ & & & \\
\hline $\begin{array}{l}\text { Executive Order } 13423 \text { Technical } \\
\text { Guidance: Ozone Depleting Compounds }\end{array}$ & & & & & & $x$ & \\
\hline $\begin{array}{l}\text { ASHRAE Standard 90.1-2007, Energy } \\
\text { Standard for Buildings Except Low-Rise } \\
\text { Residential Buildings }\end{array}$ & & & & & $x$ & & \\
\hline $\begin{array}{l}\text { Energy Efficient Standards for the Design } \\
\text { and Construction of New Federal and } \\
\text { Commercial and Multifamily High Rise }\end{array}$ & & & & & $x$ & & \\
\hline
\end{tabular}




\begin{tabular}{|c|c|c|c|c|c|c|c|}
\hline Document Name & $\begin{array}{l}\bar{\sigma} \\
\bar{\Phi} \\
\bar{\Phi} \\
\bar{\Phi}\end{array}$ & 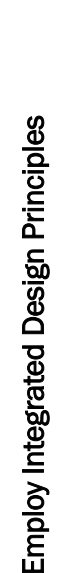 & 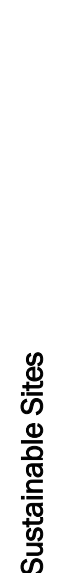 & 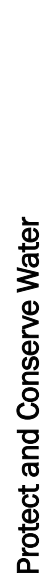 & 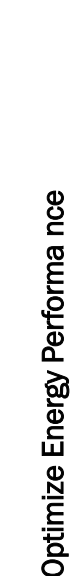 & 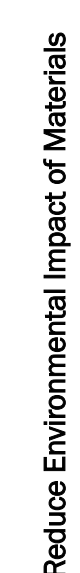 & 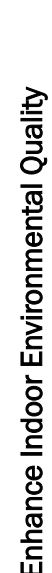 \\
\hline \multicolumn{8}{|l|}{ Residential Buildings } \\
\hline $\begin{array}{l}\text { Energy Efficient Standards for New } \\
\text { Federal Low-rise Residential Buildings }\end{array}$ & & & & & $X$ & & \\
\hline $\begin{array}{l}\text { Federal Energy Management and } \\
\text { Planning Programs, Subpart A - } \\
\text { Methodology and Procedures for Life- } \\
\text { cycle cost Analysis }\end{array}$ & & & & & $X$ & & \\
\hline Energy Efficient Standby Power Devices & & & & & $\mathrm{X}$ & & \\
\hline $\begin{array}{l}\text { Energy Independence and Security Act of } \\
2007\end{array}$ & & & & & $X$ & & \\
\hline $\begin{array}{l}\text { ICC International Energy Conservation } \\
\text { Code }\end{array}$ & & & & & $X$ & & \\
\hline $\begin{array}{l}\text { EPA Significant New Alternatives Program } \\
\text { (SNAP) }\end{array}$ & & & & & $X$ & & \\
\hline $\begin{array}{l}\text { Renewable Energy Requirement } \\
\text { Guidance for EPACT } 2005 \text { and Executive } \\
\text { Order } 13423\end{array}$ & & & & & $x$ & & \\
\hline $\begin{array}{l}\text { Sustainable Management of Waste in } \\
\text { Military Construction, Renovation, and } \\
\text { Demolition Activities }\end{array}$ & & & & & & $X$ & \\
\hline $\begin{array}{l}\text { EPA's Comprehensive Procurement } \\
\text { Guidelines }\end{array}$ & & & & & & $X$ & \\
\hline $\begin{array}{l}\text { USDA's Biobased products } \\
\text { recommendations }\end{array}$ & & & & & & $X$ & \\
\hline EPA's EPP database & & & & & & $\mathrm{X}$ & \\
\hline
\end{tabular}

Table 1-4. Source documents related to individual Guiding Principles (listed according to Guiding Principle).

\begin{tabular}{|l|}
\hline Guiding Principle - Employ Integrated Design Principles \\
\hline EO 13423, "Strengthening Federal Environmental, Energy, and Transportation Management" \\
\hline UFC-4-030-01, "Sustainable Development” \\
\hline DOE 0. 413.3A: Program and Project Management for the Acquisition of Capital Assets \\
\hline
\end{tabular}

\section{Guiding Principle - Protect and Conserve Water}

EO 13423, "Strengthening Federal Environmental, Energy, and Transportation Management" 


\begin{tabular}{|l|}
\hline UFC-4-030-01, “Sustainable Development” \\
\hline The US Army Energy and Water Campaign for Installations \\
\hline 1997 Military Handbook on Water Conservation \\
\hline Energy Efficiency and Water Conservation at Federal Facilities \\
\hline U. S. Air Force Landscape Design Guide \\
\hline Water-Efficient Landscape Guidelines \\
\hline
\end{tabular}

\begin{tabular}{|l|}
\hline Guiding Principle - Optimize Energy Performance \\
\hline EO 13423, “Strengthening Federal Environmental, Energy, and Transportation Management” \\
\hline UFC-400-01, “Energy Conservation” \\
\hline UFC-4-030-01, “Sustainable Development” \\
\hline The US Army Energy and Water Campaign for Installations \\
\hline ASHRAE Standard 90.1-2007, Energy Standard for Buildings Except Low-Rise Residential Buildings \\
\hline Energy Efficient Standards for the Design and Construction of New Federal and Commercial and Multifamily High Rise \\
Residential Buildings \\
\hline Energy Efficient Standards for New Federal Low-rise Residential Buildings \\
\hline Federal Energy Management and Planning Programs, Subpart A - Methodology and Procedures for Life-cycle cost Analysis \\
\hline Energy Efficient Standby Power Devices \\
\hline Energy Independence and Security Act of 2007 \\
\hline ICC International Energy Conservation Code \\
\hline EPA Significant New Alternatives Program (SNAP) \\
\hline Renewable Energy Requirement Guidance for EPACT 2005 and Executive Order 13423 \\
\hline
\end{tabular}

\section{Guiding Principle - Reduce Environmental Impact of Materials}

EO 13423, "Strengthening Federal Environmental, Energy, and Transportation Management" UFC-4-030-01, "Sustainable Development"

Executive Order 13423 Technical Guidance: Ozone Depleting Compounds

Sustainable Management of Waste in Military Construction, Renovation, and Demolition Activities

EPA's Comprehensive Procurement Guidelines

USDA's Biobased products recommendations

EPA's EPP database

\section{Guiding Principle - Enhance Indoor Environmental Quality}

EO 13423, "Strengthening Federal Environmental, Energy, and Transportation Management"

UFC-4-030-01, "Sustainable Development"

\begin{tabular}{|l|}
\hline LEED® Principle - Sustainable Sites \\
\hline UFC-4-030-01, “Sustainable Development” \\
\hline WBDG: Technical Guidance: Sustainable Sites/Smart Growth \\
\hline 2003 EPA Construction General Permit \\
\hline National Pollution Discharge Elimination System \\
\hline UFC 3-530-01, “Interior and Exterior Lighting and Controls” \\
\hline IESNA Recommended Practice Manual: Lighting for Exterior Environments \\
\hline USACE Sustainable Design and Development Resources: \\
\hline
\end{tabular}


Sustainable Sites: Light Pollution Reduction

WBDG Technical Guidance: Stormwater Run-off Mitigation

EPA Low Impact Development Manual

EPA Reducing Urban Heat Islands: Compendium of Strategies

Table 1-5. Comparison of LEED ${ }^{\circledR}$ categories and Guiding Principles.

\begin{tabular}{|l|l|}
\hline LEED $\mathbb{}$ & Guiding Principles \\
\hline Sustainable Sites & N/A \\
\hline N/A & Employ Integrated Design Principles \\
\hline Water Efficiency & Protect and Conserve Water \\
\hline Energy and Atmosphere & Optimize Energy Performance \\
\hline Materials and Resources & Reduce Environmental Impact of Materials \\
\hline Indoor Environment Quality & Enhance Indoor Environmental Quality \\
\hline
\end{tabular}




\section{Survey of Available Tools}

\subsection{Overview}

This chapter evaluates current sustainability tools available on the commercial market. It compares several tools related to facility design and sustainability ratings. Interviews with recognized industry experts and review of existing technical scientific literature contribute to the findings in this chapter. Table 2-1 lists the sustainability tools evaluated for this project.

Table 2-1. List of evaluated sustainability tools.

\begin{tabular}{|c|c|c|c|c|}
\hline Tool & Type & Current Version & Developer & Website \\
\hline $\begin{array}{l}\text { Leadership in } \\
\text { Environmental and } \\
\text { Energy Design (LEED) }\end{array}$ & $\begin{array}{l}\text { Rating } \\
\text { System }\end{array}$ & $\begin{array}{l}\text { LEED 2009, also known as LEED } \\
\text { v3.0 }\end{array}$ & USGBC/GBCI & $\begin{array}{l}\text { www.usgbc.org } \\
\text { www.leedonline.com }\end{array}$ \\
\hline Green Globes & $\begin{array}{l}\text { Rating } \\
\text { System }\end{array}$ & $\begin{array}{l}\text { Online Tool and ANSI/GBI 01- } \\
\text { 2010Pilot Program }\end{array}$ & GBI & www.greenglobes.com \\
\hline Energy Star & $\begin{array}{l}\text { Rating } \\
\text { System }\end{array}$ & March 2011 Update & DOE & www.energystar.gov \\
\hline $\begin{array}{l}\text { Green Guide for Health } \\
\text { Care (GGHC) }\end{array}$ & $\begin{array}{l}\text { Rating } \\
\text { System }\end{array}$ & $\begin{array}{l}\text { Version } 2.2(01 / 2007 \text { for Design } \\
\text { and Construction Section. } \\
\text { 12/2008 for Operations Section) }\end{array}$ & $\begin{array}{l}\text { Center for Maximum } \\
\text { Potential Building Systems }\end{array}$ & www.gghc.org \\
\hline PassivHaus & $\begin{array}{l}\text { Rating } \\
\text { System }\end{array}$ & PHPP 20071.2 (Spring 2010) & $\begin{array}{l}\text { PassivHaus Institut } \\
\text { PHIUS }\end{array}$ & $\begin{array}{l}\text { www.passivehouse.us/passiveHo } \\
\text { use/PHIUSHome.html }\end{array}$ \\
\hline eQUEST & $\begin{array}{l}\text { Compliance } \\
\text { Tool }\end{array}$ & v3.64 (8/25/2010) & $\begin{array}{l}\text { James J. Hirsch and } \\
\text { Associates }\end{array}$ & www.doe2.com/equest \\
\hline EnergyPlus & $\begin{array}{l}\text { Compliance } \\
\text { Tool }\end{array}$ & v6.0.0 (10/18/2010) & $\begin{array}{l}\text { US DOE, LBL, } \\
\text { UIUC, CERL }\end{array}$ & www.energyplus.gov \\
\hline $\begin{array}{l}\text { Building for } \\
\text { Environmental and } \\
\text { Economic } \\
\text { Sustainability (BEES) }\end{array}$ & $\begin{array}{l}\text { Compliance } \\
\text { Tool }\end{array}$ & $\begin{array}{l}\text { BEES Online } \\
2010\end{array}$ & NIST & $\begin{array}{l}\text { www.nist.gov/el/economics/BEE } \\
\text { SSoftware.cfm }\end{array}$ \\
\hline Pharos & $\begin{array}{l}\text { Compliance } \\
\text { Tool }\end{array}$ & Online Tool & Healthy Building Network & www.pharosproject.net/ \\
\hline GreenSpec & $\begin{array}{l}\text { Compliance } \\
\text { Tool }\end{array}$ & Online Tool is updated weekly & GreenBuilding, LLC & www.buildinggreen.com/menus/ \\
\hline
\end{tabular}

Sustainability tools provide a defined way to measure a building's level of sustainability. They can also help to evaluate a building's design in relation to its environmental performance. Two types of sustainability tools are evaluated in this chapter: (1) rating systems and (2) compliance programs. A rating system is not a scientifically validated tool, but a recommenda- 
tion of thresholds and goals for a wide range of sustainable technical domains. A compliance program is a scientifically validated tool applied to a specific technical domain such as energy performance, daylighting, etc. Compliance programs are often used in conjunction with rating systems to establish technical baseline requirements.

A substantial list of sustainability tools was developed as an initial starting point for this evaluation. Since the developed list provided a large amount of variation in terms of usability and technical input required, the team decided that a more focused list was required to complete the in-depth evaluation required by this program. An online survey was created and distributed to our panel of industry experts, as an initial data gathering method. In narrowing down the long list of sustainability tools to include in this chapter, it was also important to gather input from questionnaires and phone interviews with the panel.

Green rating systems were created to provide a uniform method of measuring green product design, promote sustainability in buildings, and define the term "green." These are sometimes invoked to make false claims of green buildings (called greenwashing). The best way to avoid false claims is to use an independently developed rating system. The rating system serves as a checklist to ensure that a project actually meets environmental protection, energy reduction, and other sustainability goals.

Most sustainability rating systems include a level of certification by assigning credits or points for each sustainable practice employed by the design. It is a comprehensive evaluation of the whole project including goals such as sustainable sites, water savings, energy performance, indoor air quality and materials. This assigns a uniform rating or score to a building for comparison to other buildings using the same rating system.

Compliance programs typically target a specific sustainability goal rather than an entire project. For example, EnergyPlus is software used to model energy and water use in buildings. This allows for optimization of the building design to use less energy and water. This type of scientifically validated tool can be used to reach specific goals within the chosen rating system. 


\subsection{Rating systems}

A summary of the rating systems evaluated for this project is provided in Table 2-2. Each tool is discussed in the text that follows.

Table 2-2. Summary of evaluated rating systems.

\begin{tabular}{|c|c|c|c|c|}
\hline & Year & Building Types & Categories of Measurement & Levels \\
\hline LEED & 2000 & $\begin{array}{l}\text { New Construction and Major Renovations, } \\
\text { Existing Buildings: Operations and } \\
\text { Maintenance, Commercial Interiors, Core and } \\
\text { Shell, Schools, Retail, Healthcare, Homes, } \\
\text { Neighborhood Development }\end{array}$ & $\begin{array}{l}\text { Sustainable Sites, Water Efficiency, Energy and } \\
\text { Atmosphere, Materials and Resources, Indoor } \\
\text { Environmental Quality, Innovation and Design }\end{array}$ & $\begin{array}{l}\text { Certified } \\
\text { Gold } \\
\text { Silver } \\
\text { Platinum }\end{array}$ \\
\hline $\begin{array}{l}\text { Green } \\
\text { Globes }\end{array}$ & 2000 & $\begin{array}{l}\text { New Construction, Continual Improvement of } \\
\text { Existing Buildings }\end{array}$ & $\begin{array}{l}\text { Project Management, Site, Energy, Water, Materials } \\
\text { and Resources, Emissions, Effluents, and Pollution } \\
\text { Reduction, Indoor Air Quality }\end{array}$ & $\begin{array}{l}1 \text { Globe } \\
2 \text { Globes } \\
3 \text { Globes } \\
4 \text { Globes }\end{array}$ \\
\hline Energy Star & 1995 & $\begin{array}{l}\text { Bank/Financial Institution, Courthouses, Data } \\
\text { Centers, Hospitals (Acute Care and } \\
\text { Children's), Hotels/Motels, Houses of } \\
\text { Worship, K-12 Schools, Medical Offices, } \\
\text { Offices, Residence Halls/Dormitories, Retail } \\
\text { Stores, Senior Care, Supermarkets/Grocery } \\
\text { Stores, Warehouses (Refrigerated and } \\
\text { Unrefrigerated) }\end{array}$ & Energy Efficiency, Water Consumption & $\begin{array}{l}\text { Certified } \\
\text { (Pass or Fail) }\end{array}$ \\
\hline $\begin{array}{l}\text { Green } \\
\text { Guide for } \\
\text { Health } \\
\text { Care }\end{array}$ & 2003 & $\begin{array}{l}\text { Healthcare related facilities including: } \\
\text { New buildings } \\
\text { Building Additions } \\
\text { Major Renovations } \\
\text { Existing Buildings }\end{array}$ & $\begin{array}{l}\text { Construction Categories: integrated design, sustainable } \\
\text { sites, water efficiency, energy and atmosphere, } \\
\text { materials and resources, environmental quality, and } \\
\text { innovation and design } \\
\text { Operations Categories: integrated operations and } \\
\text { education, sustainable sites management, } \\
\text { transportation operations, facilities management, } \\
\text { chemical management, waste management, } \\
\text { environmental services, food service, environmentally } \\
\text { preferable purchasing, innovation in operations }\end{array}$ & N/A \\
\hline PassivHaus & 1996 & $\begin{array}{l}\text { Residential } \\
\text { (although other building types can be applied) }\end{array}$ & $\begin{array}{l}\text { Airtightness, Passive Solar Energy, Superinsulation, } \\
\text { Advanced Window Technologies, Ventilation, Space } \\
\text { Heating, Energy Efficient Building Components }\end{array}$ & $\begin{array}{l}\text { Certified } \\
\text { (Pass or Fail) }\end{array}$ \\
\hline
\end{tabular}

\subsubsection{Leadership in Environmental and Energy Design (LEED)}

LEED is one of the two most common green rating systems used in the United States. The first version of LEED was rolled out in 2000 by the US Green Building Council. Its development was strongly influenced by the already established UK system, Building Research Establishment Environmental Assessment Method (BREEAM). There are a variety of rating systems within LEED which vary based on project type. Each rating system is created through a consensus-based process. LEED committees, consisting of a varied group of volunteers in the building and construction industry, lead the effort with input from technical advisory groups (TAG). 
LEED stakeholders are provided an opportunity to review and comment on the draft of a new or revised rating system and USGBC members vote on final draft versions prior to publication. This system is used internationally and currently represents 41 countries.

The rating systems are grouped into New Construction and Major Renovations (NC), Existing Buildings: Operations and Maintenance (EBOM), Commercial Interiors (CI), Core and Shell (CS), Schools (SCH), Retail, Healthcare (HC), Homes and Neighborhood Development (ND).

Five key categories of measurement include Sustainable Sites, Water Efficiency, Energy and Atmosphere, Materials and Resources and Indoor Environmental Quality. Each of these categories is made up of credits of varying point values. They are weighted depending on the level of achievement or simply the importance of the credit to sustainable impact. For instance, improving a building's energy efficiency by 35\% above the ASHRAE 90.1 standard will obtain more points than installing bike racks. Although both are encouraged, reducing energy use is a larger achievement, thus awarded more points. Up to four "bonus" points, called "Regional Points" are given based on a building site's US ZIP code. The USGBC has recognized that different regions have different areas of priority based on local condition, e.g. arid areas of the country have a greater emphasis on water conservation. Those credits that are considered most important to a region will give the project an extra point when achieved.

The LEED rating systems go up to 110 points and four levels of certification, as shown below:

$\begin{array}{ll}\text { LEED Certified } & 40 \text { to } 49 \text { Points } \\ \text { LEED Silver } & 50 \text { to } 59 \text { Points } \\ \text { LEED Gold } & 60 \text { to } 79 \text { Points } \\ \text { LEED Platinum } & 80+\text { Points }\end{array}$

The LEED certification process is through the GBCI (Green Building Certification Institute). Having a project certified demonstrates that an independent, third-party has verified the green performance measures. There are four basic steps in the LEED certification process, including registration, application, review and certification. The first step is to register the project online (www.leedonline.com). This will provide access to the tools and resources necessary to submit a LEED application for project certification. 
The second step is the documentation process. Each project team member can be given access to the project at online to upload and complete the credit template that they are assigned. Each credit being pursued has unique template information to be entered and back-up documentation to be uploaded. After all the required documentation is assembled and uploaded, it is submitted for review.

Depending on the LEED system being used, there are multiple options for submitting a project. Under the Building Design and Construction system (including NC, CS and SCH projects), a split-design and construction review takes place in up to four phases: (1) the preliminary design review, (2) final design review (optional), (3) preliminary construction review, and (4) final construction review (optional). Phase 1 requires the project information forms, prerequisites and at least one design credit. At this review phase, all submitted items are pending (needs clarification), anticipated (to be approved at final completion of construction phase) or denied (does not meet intent of credit). Technical feedback and requests for clarification are provided where appropriate by the reviewers. The project team can opt to accept the results of the phase 1 review or submit revised documentation for pending credits for a phase 2 final design review. The same options are provided for the construction phase of the review. Yet another review option is the Combined Design and Construction Review. This option has up to two phases: (1) preliminary review which can be accepted as final or resubmitted for (2) final review based on the same process as above. After final review for any process, a team can submit for an appeal review of any denied credits for an additional fee.

The fourth and final step is certification. Once all review results are accepted, the project will receive a certificate of registration. They may order a plaque for displaying their LEED certification, including level achieved. The Owner can opt to have their project listed in the online LEED project directory. Photographs and other documentation, also at the Owner's option, can be included in the Department of Energy's High Performance Buildings Database.

LEED 2012 (the working name for the version in development) is slated for release in November 2012. It is not guaranteed that all items in the draft will remain in the new release, but the following is a summary of some of the large scale changes and additions: 
- Integrated Process is a new category, encouraging practices, such as, design charrettes, material life cycle assessments and conceptual design phase energy modeling.

- Energy savings calculated under Option 1 of Minimum Energy Performance: Whole Building Energy Simulation will change, recognizing the difficulty of measuring whole building energy performance. Energy cost alone is used to measure energy performance in LEED 2009.The new version proposes both energy cost and source Energy Use Intensity (EUI). The same 10\% improvement over a baseline is maintained in the new draft, but it references ASHRAE 90.1-2010, which is estimated to be about $20 \%$ more stringent than the 2004 version.

- Acoustics Performance is added under the Indoor Environmental Quality category.

- A new category called Performance is added that replaces the commissioning credits and prerequisites that are currently under the Energy and Atmosphere category. This section includes two new prerequisites, Water Metering and Reporting and Building Level Metering.

- Another new credit under the Performance category is Reconcile Design and Actual Energy Performance, which is intended to provide verification of the project's energy claims in the Optimize Energy Performance credit.

\subsubsection{Green Globes}

Green Globes is also one of the most common green rating systems used in the United States. It stems from BREEAM Canada in 1996, but the Green Globes moniker was established when the online tool became available in the year 2000. More than 35 individuals from green industries contributed to its creation. In the United States, Green Globes is operated by the Green Building Initiative (GBI), which employs a consensus-based process for updating this standard, involving users, producers, interested parties and non-governmental organizations. This system is used in Canada and the United States. The GBI, which has been an accredited ANSI standards developer since 2005, published the Green Globes as ANSI/ GBI 01-2010, "Green Building Assessment Protocol for Commercial Buildings." The standard was created by a technical committee of 30 people, including users, generally interest parties and building product manufacturers. This base group is supported by technical experts in working subcommittees. Development of the standards also included periodic opportunities for public comment; however the process for modification to the online tool does not appear to be transparent. 
There are two programs for Green Globes: (1) Green Globes for New Construction (NC) and (2) Green Globes for Continual Improvement of Existing Buildings (CIEB). Within these two paths, any building type can be accommodated. Major Renovation projects also fall under the NC program.

There are seven areas that are addressed in a Green Globes assessment. These areas, or sections, include Project Management, Site (for NC only), Energy Water, Materials and Resources, Emissions, Effluents, and Pollution Reduction and Indoor Air Quality. Each section has a series of questions that are answered by the applicant. Each question has a set number of points assigned to it. The resulting level of certification is dependent on the percentage of points the applicant is awarded. Currently, points are given to the project for completing a life-cycle assessment for the building assemblies and materials.

Green Globes has a weighted point system with the largest number of points available for energy performance. It has up to 1,000 points and four levels of certification, as shown below:

$\begin{array}{ll}1 \text { Globe } & 35 \% \text { to } 54 \% \text { of Points } \\ 2 \text { Globes } & 55 \% \text { to } 69 \% \text { of Points } \\ 3 \text { Globes } & 70 \% \text { to } 84 \% \text { of Points } \\ 4 \text { Globes } & 85 \% \text { to } 100 \% \text { of Points }\end{array}$

After achieving at least 35\% of the available points, a project can request a Green Globes third-party assessment. A Green Globe Assessor is assigned to the project by GBI. This person is an independent third-party with expertise in green building design, engineering, construction and facility operations, approved through GBI's training program. The assessor reviews building documentation and conducts an onsite walk through.

Further integration of LCA into Green Globes is anticipated so that the cradle-to-grave environmental impacts of alternate designs can be compared more easily. The GBI is in the process of evaluating various building assemblies using established LCA methodology. The results of GBI evaluations will be added to Green Globes, giving design teams the ability to select highly ranked assemblies, which in turn receive more points in the rating system. 


\subsubsection{Energy Star ${ }^{\circledR}$}

The US Environmental Protection Agency (EPA) and the US Department of Energy (DOE) partnered in 1996 to promote and advance the Energy Star program. The Energy Star label had already been applied to qualifying energy efficient products through the EPA's voluntary program, and in 1995 Energy Star for Buildings was introduced. The goals of the Energy Star program are to protect the environment by promoting energy efficient products and energy saving measures, as well as, benefits to the building owner's bottom line. It provides a means for owners to measure a building's performance with the use of an online tool called Portfolio Manager. Over 20,000 public and private organizations have contributed to creating the tools and standards for the Energy Star program.

Energy Star for Buildings can be applied to commercial and industrial buildings that meet the rating system's criteria. This criteria fall into three categories: building designation, operating characteristics, and energy data. The building designations are based on more than $50 \%$ of gross floor area being used for a specific purpose. The designations are as follows:

- Bank/ Financial Institution

- Courthouse

- Data Center

- Hospital

- Hotel

- House of Worship

- K-12 School

- Medical Office

- Municipal Wastewater Treatment Plant

- Office

- Residential Hall/ Dormitory

- Retail Store

- Senior Care Facility

- Supermarket

- Warehouse.

The operating characteristics must fall into the same pattern for comparison among the peer group. The building must have an area of at least $5,000 \mathrm{SF}$, unless it is a hospital, which must be at least 20,000 SF and no more than 5,000,000 SF. Offices must have at least one computer in use and have more than $50 \%$ average annual occupancy. Hospitals must have 
at least 16 licensed beds but no more than 1,510 beds and no more than 40 floors. The energy data entered in Portfolio Manager must account for all energy use (regardless of fuel type) in the building. It must include at least 11 full consecutive calendar months of energy data for all active meters. If there are multiple meters, there must be 11 consecutive and overlapping months. No individual electrical meter entry can be for a period longer than 65 days. After all the above criteria is met and entered in Portfolio Manager, a rating is of 1- 100 is designated for the building. The building must have a rating of 75 or higher to qualify for Energy Star.

Energy Star for Buildings focuses on energy use. Portfolio Manager is an energy management tool that allows users to track and assess energy and water consumption for a building, or a portfolio of several buildings. Once energy and water usage is entered in Portfolio Manager, a benchmark can be set to measure improvement over time. It is also a way to easily identify opportunities for energy savings.

The energy performance rating that is generated by Portfolio Manager is on a scale of 1- 100 in relation to similar buildings across the country. A rating of 75, for example, indicates that the building performs better than $75 \%$ of similar buildings in the nation. This rating is based on source energy (versus site energy) and takes into account the local climate and specific operating characteristics of the building. The basis is used as a means to directly compare different types of energy, represented in differing units of measure. Site energy includes primary energy (raw fuel such as natural gas, electricity, potable water) and secondary energy (energy product of raw fuel - energy from pumps or chillers, etc.). These two items are not directly comparable; therefore they are converted into an equivalent unit of measure, "source energy." Also, Portfolio Manager's energy rating is not the same rating as the Energy Star rating for the building. The Energy Star rating is determined by how an applicant rates against data on buildings collected by the Commercial Building Energy Consumption Survey (CBECS), which is a national survey updated every 4 years. Energy Star is award for a specific year. Once earned, a building can reapply for the Energy Star label every year based on the date of the last energy data provided in the previous application. A bronze plaque illustrating the building's achievement is available and states the year it was awarded.

The process for earning the Energy Star label requires the involvement of a licensed architect or engineer. After all the required information is entered 
in Portfolio Manager, a Statement of Energy Performance (SEP) and Data Checklist are generated. These two pieces of documentation require a stamp and/ or signature by the licensed professional, who is required to perform a site visit and verify all the reported information. Verification that all energy use is tracked correctly, the building characteristics are reported accurately, and industry standards for the building's functionality and indoor environment criteria are met must be performed by the architect or engineer. No known updates are published for Energy Star at this time.

\subsubsection{Green Guide for Health Care and LEED for Healthcare}

The Green Guide for Health Care (GGHC) was created in 2003 by two groups: The Center for Maximum Potential Building Systems, and Healthcare without Harm. It was developed in response to a need for a green guide with performance metrics specific to healthcare. Volunteer steering committees and working groups are made up of designers, engineers, facility management, environmental and green building professionals with particular expertise in the healthcare sector. These volunteers aide in the creation and improvement of the GGHC's healthcare specific and health focused tools, technical guidance and educational resources. As updated versions are proposed for the GGHC based on new information brought forth from pilot programs, a period to collect public comments is provided to gain a broad spectrum of ideas in evolving their tools.

This metrics toolkit is specifically tailored for the unique characteristics of healthcare facilities, such as 24 hours per day/ 7 days per week operation. Intense energy and water usage, use of chemicals, and infection control requirements are a few other healthcare specific traits that the typical green rating system does not address. The GGHC is intended for use by a variety of building types within the medical field, mostly institutional occupancies as defined by building codes. GGHC recognizes that construction, operations and maintenance all play important roles in a healthy building environment. New buildings, additions, and major renovations can adopt the Green Guide for Health Care, whereas existing buildings extract the guide section, "Operations," as a stand-alone rating system.

Areas of measurement for construction are based on those found in the LEED checklist, with permission from USGBC. They have been modified to fit healthcare sector concerns. These categories include integrated design, sustainable sites, water efficiency, energy and atmosphere, materials 
and resources, environmental quality, and innovation and design. The operations section of the guide includes integrated operations and education, sustainable sites management, transportation operations, facilities management, chemical management, waste management, environmental services, food service, environmentally preferable purchasing, and innovation in operations.

Because the GGHC is a voluntary program there are no levels of certification. The point system provides a method for design and construction teams to track improvement. Existing facilities can view ongoing performance through the tools in the operation section of the guide. Construction projects can select items from the operation section to incorporate into policies to implement these O\&M strategies. These items can then be addressed through the facility's policy and protocol creation. In 2007, USGBC and GGHC partnered to develop tools and educational programs that support green healthcare building. USGBC administers the LEED for Healthcare certification process and the GGHC continues to provide healthcare specific green building guidance and tools.

Since the GGHC program is voluntary and self-certifying, there is not a certification process or application to undergo. Healthcare projects can register online with GGHC at www.gghc.org, participating in mutual benefits. The project team has a tool to track sustainability metrics and GGHC can use the data entered for research. At the applicant's option, the project can be provided as a case study for other projects. Registered projects contribute to GGHC published reports showing aggregated project data for use by the public. The information in these reports is anonymous. By providing this information on registered project performance, useful statistics are revealed, such as total square footage of GGHC projects, frequency of credit achievement based on project type, and geographic distribution.

USGBC's LEED for Healthcare (HC) launched in November 2010 after seven years of close collaboration with Green Guide for Health Care. Since a healthcare pilot program was completed by GGHC, the knowledge gleaned from that process was used to roll out the LEED-HC rating system without USGBC's typical pilot program. LEED-HC can be used to certify inpatient, outpatient and licensed long-term care facilities, medical offices, assisted living facilities and medical education and research centers. The full LEEDonline application and certification utilities are expected to become available by end of summer 2011. 


\subsubsection{PassivHaus Standard}

The PassivHaus Institut (PHI) was founded by Wolfgang Feist of the Institut für Wohnen und Umwelt in 1996. This was a direct result of a series of research projects, with the goal to provide ongoing development of the PassivHaus Standard (ISO 13790) and promote its use worldwide. PHI aims to significantly reduce a building's heat consumption energy usage by up to $90 \%$ when compared to traditional construction methods, but it is not just an energy tool. It is a construction concept the employs strategies for energy-efficient, comfortable, affordable, and ecological houses. The International Passive House Association (iPHA) was created as a communication initiative of the PassivHaus Institut, providing technical expertise, professional competence, independence and objectivity. The PassivHaus Institut developed the Passive House Planning Package (PHPP) as a design tool, including energy modeling, to help ensure that the building components used work together to achieve the desired result. The PHPP is continuously validated and refined based on measurements and new research results. As part of accompanying scientific research studies, measurements from more than 300 projects have so far been compared with calculation results.

Primarily implemented for residential structures, additional requirements have been included for certification of nonresidential structures. As described on the PassivHaus website

The Passive House is not an energy performance standard, but a concept to achieve highest thermal comfort conditions on low total costs - this is the correct definition: A Passive House is a building, for which thermal comfort (ISO 7730) can be achieved solely by post-heating or post-cooling of the fresh air mass, which is required to fulfill sufficient indoor air quality conditions (DIN 1946) - without a need for recirculated air.

Rather than defining categories of measurements, the standard sets criteria that define a Passive House. The main concepts include airtightness, passive solar energy, superinsulation, advanced window technologies, ventilation, space heating and energy-efficient building components (preferable those that are certified as Passive House suitable). Specifically, criteria for Passive House certification mandates; a maximum of $15 \mathrm{kWh} /(\mathrm{m} 2 \mathrm{a})$ for 
specific space heat demand, maximum of $10 \mathrm{~W} / \mathrm{m} 2$ heating load, maximum $0.6 \mathrm{~h}-1$ pressurization test result n50, and a maximum of 120 $\mathrm{kWh} /(\mathrm{m} 2 \mathrm{a})$ for entire specific primary energy demand. The current version, PHPP 2007 1.2, provides calculation spreadsheets, historical weather data, and many other tools as a guide for design.

Basic features that distinguish passive house construction include the following:

- All components of the exterior shell of the house are insulated to achieve a U-factor that does not exceed $0.15 \mathrm{~W} /\left(\mathrm{m}^{2} \mathrm{~K}\right)(0.026$ $\left.\mathrm{Btu} / \mathrm{h} / \mathrm{ft}^{2} /{ }^{\circ} \mathrm{F}\right)$.

- Passive use of solar energy is a significant factor in passive house design.

- Windows (glazing and frames, combined) should have U-factors not exceeding $0.80 \mathrm{~W} /\left(\mathrm{m}^{2} \mathrm{~K}\right)\left(0.14 \mathrm{Btu} / \mathrm{h} / \mathrm{ft}^{2} /{ }^{\circ} \mathrm{F}\right)$, with solar heat-gain coefficients around $50 \%$.

- Air leakage through unsealed joints must be less than 0.6 times the house volume per hour.

- Fresh air may be brought into the house through underground ducts that exchange heat with the soil. This preheats fresh air to a temperature above $5^{\circ} \mathrm{C}\left(41^{\circ} \mathrm{F}\right)$, even on cold winter days.

- Most of the perceptible heat in the exhaust air is transferred to the incoming fresh air (heat recovery rate over $80 \%$ ).

- Solar collectors or heat pumps provide energy for hot water.

- Low energy refrigerators, stoves, freezers, lamps, washers, dryers, etc. are indispensable in a passive house.

Certification is through a third-party building certifier that has been accredited by the PassivHaus Institut. The PPHP software provides the templates that can be used to submit the rigorous documentation required for approval. As of J anuary 2008, Passive House Institute US (PHIUS) has been authorized by the PassivHaus Institut as the official certifier of Passive Houses in the United States. The documentation must be examined at least once, although more can be required if necessary. It is recommended, but not required, to submit this documentation during the planning period of the project in order to allow for corrections and/ or suggestions for improvement to be more easily implemented. 
There is not a point structure for this system. A building either meets the Passive House Standard or it does not. The last update to the PHPP was issued in the spring of 2010, and no further documentation could be found regarding future updates underway at this time.

\subsection{Compliance programs}

The compliance tools reviewed for this project are summarized in Table $2-4$. The output from these programs serves as key technical input for some of the rating systems discussed in the previous section.

Table 2-3. Tool summary-compliance programs.

\begin{tabular}{|l|l|l|}
\hline Tool & Author/Developer & Function \\
\hline eQUEST & James J. Hirsch and Associates & Energy performance simulation \\
\hline EnergyPlus & $\begin{array}{l}\text { US DOE, Lawrence Berkeley National Laboratory, } \\
\text { University of Illinois at Urbana-Champaign, US Army } \\
\text { CERL, others }\end{array}$ & Energy performance simulation \\
\hline BEES & NIST & Life-Cycle Assessment Tool \\
\hline Pharos & Healthy Building Network & Life-Cycle Assessment Tool. Linked to GreenSpec. \\
\hline GreenSpec & GreenBuilding, LLC & $\begin{array}{l}\text { Product Directory. Indicates important sustainable attributes for } \\
\text { each product. Linked to Pharos. }\end{array}$ \\
\hline
\end{tabular}

\subsection{1 $\quad$ QQUEST ${ }^{\circledR}$}

The QUick Energy Simulation Tool (eQUEST) is a whole-building energy performance design tool. It is designed to be used from a project's beginning conceptual stages to final design. eQUEST is meant to be userfriendly for all team members, through the step-by-step guidance of a software wizard. There are three different software wizards for entering design inputs: schematic design, design development and detailed DOE-2 interface. The standard defaults for every input are based on California Title 24 building energy code.

Within eQUEST, DOE-2 performs an hourly simulation of your building design for a one-year period. It calculates heating or cooling loads for each hour of the year, based on the factors such as: walls, windows, glass, people, plug loads and ventilation. DOE- 2 also simulates the performance of: fans, pumps, chillers, boilers and other energy-consuming devices. During the simulation, DOE-2 also tabulates your building's projected energy use for various end uses such as: lighting, plug loads (computers, appliances, copiers, etc.), heating, cooling, ventilation and pumping. 
eQUEST offers several graphical formats for viewing simulation results, such as, estimated overall building energy on an annual or monthly basis. You also can compare the performance of alternative building designs. In addition, eQUEST allows you to perform multiple simulations and view the alternative results in side-by-side graphics. It offers: energy cost estimating, daylighting and lighting system control, and automatic implementation of common energy efficiency measures (by selecting preferred measures from a list).

\subsubsection{EnergyPlus}

EnergyPlus is a whole-building energy simulation program for modeling energy and water use, based on BLAST and DOE- 2 programs, combining the best capabilities and features from these two programs along with new capabilities. EnergyPlus comprises completely new code written in Fortran 90. Like BLAST and DOE-2, EnergyPlus is an energy analysis and thermal load simulation program. It models heating, cooling, lighting, ventilation, other energy flows, and water use. EnergyPlus is a simulation engine that is meant to be used with third-party user interface software.

EnergyPlus includes many integrated simulation capabilities: time steps less than 1 hour, modular systems and plant integrated with heat balancebased zone simulation, multi-zone air flow, thermal comfort, water use, natural ventilation, and photovoltaic systems. It is the intent of EnergyPlus to handle as many building and HVAC design options to calculate thermal loads and/ or energy consumption on a design day or an extended period of time. Currently, the program focuses on thermal aspects of buildings; however, other issues (water, electrical systems, etc.) are being explored for inclusion in future versions.

Integrated simulation also allows users to evaluate a number of processes that neither BLAST nor DOE-2 can simulate well. Some of the more important include realistic system controls, moisture adsorption and desorption in building elements, radiant heating and cooling systems and interzone air flow.

\subsubsection{Building for Environmental and Economic Sustainability (BEES)}

The Building for Environmental and Economic Sustainability (BEES) software is a web-based application that can guide a project in selecting cost-effective, environmentally-preferable building products. The NIST 
(National Institute of Standards and Technology) Engineering Laboratory developed BEES in 1997 and has maintained it as a downloadable software package. Today, it is online, enabling new products to be added as the information becomes available. BEES provides designers, builders and product manufacturers' science-based, technical data derived from consensus-based standards in a format that can be readily evaluated to make informed decisions on building product selection. As of May 2011 there were 230 different products included in the database.

The product information available through BEES includes actual environmental and economic performance data, which is measured using a life-cycle assessment (LCA) approach per the ISO 14040 series of standards. The life cycle of a product is analyzed from its start (raw material extraction), through mid-life (manufacture, transportation, installation, use), to its end (recycling and waste management). The ASTM standard life-cycle cost method is utilized for BEES. This includes initial, replacement, repair and maintenance, and disposal costs. The software takes these two metrics (environmental and economic) and uses the ASTM standard for Multi-Attribute Decision Analysis to produce a combined performance measurement. This measurement covers a 50-year period. UNIFORMAT II (an ASTM standard) is used to define and classify products listed in BEES.

The software is flexible for users by allowing a choice of methods to weigh the impacts. The impacts can range from global warming, smog, indoor air quality, human health, and fossil fuel depletion. The importance factors assigned to these impacts can be predefined weights chosen by BEES stakeholders or the Environmental Protection Agency Science Advisory Board or user-defined methods.

To perform a product evaluation using BEES, three main steps are completed:

1. Enter the product study parameters.

2. Select building products for comparison.

3. Review results.

Results are provided in the form of a product scoreThe lower the score, the better the environmental and economic performance. For future releases, NIST is developing an LCA calculator for entire buildings. The first phase 
of this project should be available in 2012 and will measure life-cycle operating energy. The next phase will include life-cycle carbon footprint, embodied energy, life-cycle impacts, and life-cycle cost effectiveness of whole buildings.

\subsubsection{Pharos and GreenSpec}

The Pharos Project is an online material-selection tool for building products created by the Healthy Building Network. Products are scored on several environmental and health impact categories, based on the product's makeup. Toxicity and health hazards are the focus. Healthy Building Network and GreenBuildings, LLC, the creators of GreenSpec, worked together to link Pharos with GreenSpec's building product directory. GreenSpec provides information on what green attributes are important for each product category, in addition to a list of green products. This list is generated using a life-cycle assessment, recognizing operational performance of a product (its impact on energy use, water use and building durability).

Pharos is not a compliance program, as defined in this chapter. It is not a scientifically validated tool, but a database of information for building products. It was included in this chapter because it was mentioned in several of the interviews.

\subsection{Comparison of the rating systems}

It is important to note that this discussion represents a "snapshot" because rating systems are constantly evolving, which in turn impacts the types of sustainability compliance tools that are developed. As some tools become obsolete, other tools are updated to meet the new demands of updated rating systems. New tools, as well, emerge when the evolving rating systems create a new need. This comparison addresses building types covered, metrics, certification levels, and certification processes.

\subsubsection{Building types covered}

Several rating systems offer a range of applications for specific building types while others are either very narrowly or broadly focused. LEED currently offers nine different applications (i.e., New Construction, Existing Buildings: Operations and Maintenance, Commercial Interiors, Core and Shell, Schools, Retail, Healthcare, Homes, Neighborhood Development). It also offers programs to address a campus setting, multiple buildings, and 
volume. The volume program can be used for owners with many buildings that are similar (prototypes), such as chain retail stores. Green Globes has two applications (New Construction and Continual Improvement of Existing Buildings) which can be assigned to any building type. Energy Star has a very specific list of building types, based on the most common that are in the database. They are continually updating to add more building types. GGHC is strictly for healthcare related buildings. PassiveHaus is intended for residential building, but can be applied to any other building type.

\subsubsection{Categories of measurement}

Categories of measurement, as well as how they measure, differ from one rating system to the next. All of the rating systems, including Energy Star, address energy performance and water efficiency. LEED, Green Globes and Green Guide for Health Care also include Sites, Materials and Resources and Indoor Environmental Quality. In addition, LEED has categories for Innovation in Design and Regional Priority. Green Globes has categories for Project Management and Emissions, Effluents, and Pollution Reduction. Green Guide for Health Care includes Integrated Design, as well as the categories under the Operations section. Green Globes and LEED also promote integrated design, but do not have a specific category heading for it or specific credits assigned. PassivHaus is the only rating system without defined categories.

Green Globes currently includes credits for acoustical performance and, optimized use of space and integrated design process. Both of these attributes are anticipated to be included in the LEED 2012 rating system, while LEED - Schools currently includes the acoustical performance requirements.

Green Globes recognizes all the mainstream forest certification systems, while LEED references only the Forest Stewardship Council's program. One criticism here is that some of the other systems do not match up to the stringency of FSC.

An important difference to note between Green Globes, LEED and PassivHaus is how energy consumption for buildings is measured. LEED requires the baseline energy model developed to the ASHRAE 90.1 standard. Green Globes requires EPA's Target Finder for comparison, which includes real building performance information within its database. PassivHaus claims to simplify the model while still getting accurate results 
by treating the whole building as one zone of energy calculation and using monthly energy balances in lieu of dynamic simulation with short time steps. The reason for this is that for the practical purpose of building design, employing already well-tested building concepts, the use of simplified, optimally adapted computing tools will reduce the probability of errors.

\subsubsection{Levels of certification}

Both LEED and Green Globes have four levels of certification, however Green Globes allows credits to be answered N/A, not applicable. These credits are detracted from the total available points without penalty. In the LEED rating systems, not all credits are meant for every project(nor can all projects even meet the minimum requirements necessary to register for LEED); however, credits that are not applicable are still included in the overall possible points. Every LEED project is up to 110 points, with the intent that no project can get 110 points. The top level of Platinum is achievable with 80 points, for this reason. GGHC, Energy Star and PassivHaus do not have levels of certification.

\subsubsection{Certification process}

The certification process for LEED, Green Globes, Energy Star and PassivHaus require some type of third-party verification. LEED has USGBC as its third-party reviewer, with a very transparent system in place for how credits evolve. Green Globes projects are verified by a Green Globes Certifier. PassivHaus buildings are approved by a PHI accredited building certifier. GGHC is a voluntary, self-certifying program.

\subsection{Tool capabilities required for support of Guiding Principles}

Before comparing the compliance programs it is necessary to evaluate what type of inputs are needed for programs supporting the Guiding Principles, and what kinds of tools can supply those inputs.

Table 2-4 was developed for this purpose and to facilitate the gap analysis that follows in Chapter 3. The table indicates which Guiding Principles need no supporting tools and which ones are supported by available tools. It also indicates where existing tools may be applicable but are not adequate, and which ones require a tool that does not exist at the current time. 
The legend for Table 2-4 follows:

- No tool needed to accomplish this strategy

- Tool is adequate to accomplish this strategy

- Tool exists, but is not adequate to accomplish this strategy

* Rather than looking at singular material properties, LCA Tools rate products based on their embodied environmental effects. Although this tool exists, it does not adequately assist in accomplishing the stated strategy.

$\square \quad$ No tool exists to assist in accomplishing this goal.

Note that the term LCA Tool, as used here, is defined as a tool for comparing LCA of different building products.

Table 2-4. Summary of tool types required for Army sustainability initiatives.

\begin{tabular}{|c|c|c|c|c|c|c|c|c|c|c|c|c|c|}
\hline $\begin{array}{l}\text { Guiding Principle } \\
\text { Category }\end{array}$ & Subcategory & 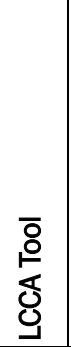 & 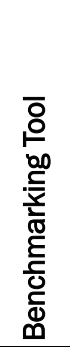 & 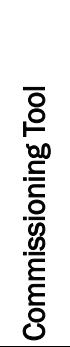 & $\begin{array}{l}\bar{\delta} \\
\stackrel{8}{8} \\
\text { in }\end{array}$ & 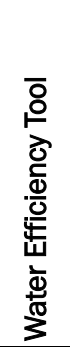 & 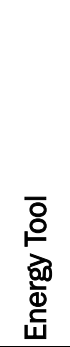 & $\begin{array}{l}\frac{*}{8} \\
\frac{\sigma}{\sigma} \\
\text { S }\end{array}$ & 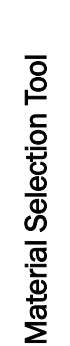 & 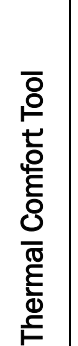 & $\begin{array}{l}\bar{\alpha} \\
\stackrel{\circ}{q} \\
\underline{q}\end{array}$ & 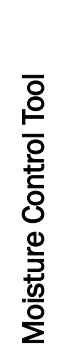 & 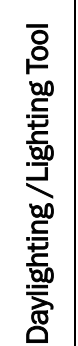 \\
\hline \multirow[t]{2}{*}{$\begin{array}{l}\text { Employ Integrated Design } \\
\text { Principles }\end{array}$} & Integrated Design & $\diamond$ & & & $\bullet$ & $\bullet$ & $\bullet$ & $\bullet$ & $\bullet$ & & $\bullet$ & & - \\
\hline & Commissioning & & • & - & & & & & & & & & \\
\hline \multirow[t]{5}{*}{ Sustainable Sites } & Select Appropriates Sites & $\bullet$ & & & & & & & & & & & \\
\hline & $\begin{array}{l}\text { Provide Alternative } \\
\text { Transportation } \bullet\end{array}$ & & & & & & & & & & & & \\
\hline & $\begin{array}{l}\text { Minimize Site and Habitat } \\
\text { Disturbance }\end{array}$ & & & & - & & & & & & & & \\
\hline & Manage Storm Water Runoff & $\bullet$ & & & - & & & & & & & & \\
\hline & Reduce Heat Islands & $\diamond$ & & & $\bullet$ & & & & & & & & \\
\hline \multirow[t]{4}{*}{$\begin{array}{l}\text { Optimize Energy } \\
\text { Performance }\end{array}$} & Energy Efficiency & $\diamond$ & $\bullet$ & & & & $\diamond$ & & & & & & \\
\hline & Onsite Renewable Energy & $\bullet$ & - & & & & $\diamond$ & & & & & & \\
\hline & Measurement and Verification & & $\bullet$ & & & & & & & & & & \\
\hline & Benchmarking & & • & & & & & & & & & & \\
\hline
\end{tabular}




\begin{tabular}{|c|c|c|c|c|c|c|c|c|c|c|c|c|c|}
\hline $\begin{array}{l}\text { Guiding Principle } \\
\text { Category }\end{array}$ & Subcategory & $\begin{array}{l}\bar{o} \\
\text { 엉 }\end{array}$ & 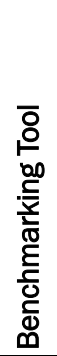 & 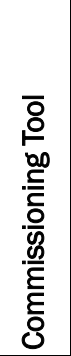 & $\begin{array}{l}\overline{8} \\
\stackrel{\circ}{0} \\
\bar{\omega}\end{array}$ & 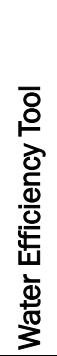 & $\begin{array}{l}\bar{\delta} \\
\stackrel{0}{0} \\
\bar{b} \overline{0} \\
\bar{w}\end{array}$ & $\begin{array}{l}\frac{*}{0} \\
\frac{0}{0} \\
\text { త్ }\end{array}$ & 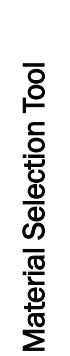 & 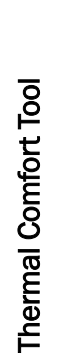 & $\begin{array}{l}\bar{\delta} \\
\stackrel{o}{\alpha} \\
\text { ơ }\end{array}$ & 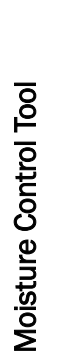 & 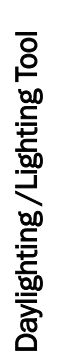 \\
\hline \multirow[t]{5}{*}{ Protect and Conserve Water } & $\begin{array}{l}\text { Building Water Conservation } \\
\text { (Indoor) }\end{array}$ & $\nabla$ & $\bullet$ & & & $\bullet$ & & & & & & & \\
\hline & $\begin{array}{l}\text { Irrigation and Landscaping } \\
\text { (Outdoor) }\end{array}$ & 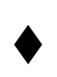 & $\bullet$ & & $\bullet$ & $\bullet$ & & & & & & & \\
\hline & $\begin{array}{l}\text { Water Recycling and Re-use } \\
\text { (Indoor/Outdoor) }\end{array}$ & $\diamond$ & & & & - & & & & & & & \\
\hline & Process Water & 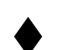 & & & & $\bullet$ & & & & & & & \\
\hline & Water Efficient Products & & & & & & & & & & & & \\
\hline \multirow[t]{6}{*}{$\begin{array}{l}\text { Enhance Indoor } \\
\text { Environmental Quality }\end{array}$} & $\begin{array}{l}\text { Ventilation and Thermal } \\
\text { Comfort }\end{array}$ & & & & & & & & & - & - & $\bullet$ & \\
\hline & Moisture Control & & & & & & & & & $\bullet$ & $\bullet$ & $\bullet$ & \\
\hline & Daylighting & & & & & & & & & & & & $\bullet$ \\
\hline & Low-Emitting Materials & & & & & & & $\star$ & 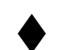 & & & & \\
\hline & $\begin{array}{l}\text { Protect Indoor Air Quality } \\
\text { during Construction }\end{array}$ & & & & & & & & & & $\bullet$ & & \\
\hline & Tobacco Smoke Control & & & & & & & & & & & & \\
\hline \multirow{5}{*}{$\begin{array}{l}\text { Reduce Environmental } \\
\text { Impact of Materials }\end{array}$} & Recycled Content & & & & & & & $\star$ & $\varphi$ & & & & \\
\hline & Bio-Based Content & & & & & & & $\star$ & $\varphi$ & & & & \\
\hline & $\begin{array}{l}\text { Environmentally Preferable } \\
\text { Products }\end{array}$ & & & & & & & 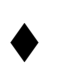 & & & & & \\
\hline & $\begin{array}{l}\text { Waste and Materials } \\
\text { Management }\end{array}$ & & & & & & & $\star$ & $\square$ & & & & \\
\hline & Ozone Depleting Compounds & & & & & & & $\star$ & $\square$ & & & & \\
\hline
\end{tabular}

Table 2-5 summarizes a wide range of sustainability tools, including the ones discussed previously in section 2.3, in terms of their capabilities for supplying inputs necessary for supporting the Guiding Principles. 
Table 2-5. Summary of tools by input type.

\begin{tabular}{|c|c|c|}
\hline Name of Tool & Type of Tool & Website \\
\hline ECONPACK (US Army COE) & LCCA Tool & www.hnd.usace.army.mil/paxspt/econ/econ.aspx \\
\hline $\begin{array}{l}\text { Building Life-Cycle Cost } \\
\text { Program (BLCC by NIST) }\end{array}$ & LCCA Tool & www.eere.energy.gov/femp/information/download_blcc.html \\
\hline $\begin{array}{l}\text { Life-Cycle Cost in Design } \\
\text { (LCCID) by CERL }\end{array}$ & LCCA Tool & $\begin{array}{l}\text { http://www.cecer.army.mil/facts/sheets/cf-55.pdf } \\
\text { http://www.cecer.army.mil/facts/sheets/PL31.html }\end{array}$ \\
\hline $\begin{array}{l}\text { ASHRAE: Service Life and } \\
\text { Maintenance Cost Database }\end{array}$ & LCCA Tool & http://xp20.ashrae.org/publicdatabase \\
\hline eVALUator ${ }^{\mathrm{TM}}$ & LCCA Tool & www.energydesignresources.com/resources/software-tools/evaluator.aspx \\
\hline $\begin{array}{l}\text { Sustainable Facilities Tool } \\
\text { (SF Tool by GSA) }\end{array}$ & $\begin{array}{l}\text { Integrated Design } \\
\text { Process Tool }\end{array}$ & http://www.sttool.org/ \\
\hline $\begin{array}{l}\text { BCA Templates (Building } \\
\text { Commissioning Assoc.) }\end{array}$ & Commissioning Tool & www.bcxa.org \\
\hline $\begin{array}{l}\text { California Commissioning } \\
\text { Collaborative Tools }\end{array}$ & Commissioning ToOI & www.cacx.org \\
\hline The Cx Assistant & Commissioning Tool & $\begin{array}{l}\text { http://www.energydesignresources.com/resources/software-tools/commissioning- } \\
\text { assistant.aspx }\end{array}$ \\
\hline Portfolio Manager & Benchmarking Tool & http://www.energystar.gov/index.cfm?c=evaluate_performance.bus_portfoliomanager \\
\hline Target Finder & Benchmarking Tool & http://www.energystar.gov/index.cfm?c=new bldg_design.bus target finder \\
\hline Watergy & Water Efficiency Tool & http://www.watergy.org/ \\
\hline LEED WEc3 Water Calculator & Water Efficiency Tool & www.leedonline.com \\
\hline $\begin{array}{l}\text { Sustainable Management } \\
\text { Approaches and } \\
\text { Revitalization Tools }\end{array}$ & Site Tool & www.smarte.org \\
\hline $\begin{array}{l}\text { Water-Energy Simulation } \\
\text { Tool (WEST) }\end{array}$ & Site/Energy Tool & http://dx.doi.org/10.1061/(ASCE)IS.1943-555X.0000036 \\
\hline $\begin{array}{l}\text { Low Impact Urban Design } \\
\text { Tools }\end{array}$ & Site Tool & http://www.lid-stormwater.net/index.html \\
\hline ecoSmart & Site Tool & www.ecosmart.gov \\
\hline $\begin{array}{l}\text { Green Building Studio } \\
\text { (Autodesk) }\end{array}$ & Energy Tool & http://usa.autodesk.com/adsk/servlet/pc/index?id=11179508 and sitelD=123112 \\
\hline EnergyPlus & Energy Tool & http://apps1.eere.energy.gov/buildings/energyplus/ \\
\hline QQUEST & Energy Tool & http://doe2.com/equest/ \\
\hline IES & Energy Tool & http://www.iesve.com/ \\
\hline Trane TRACE 700 & Energy Tool & www.trane.com/trace \\
\hline $\begin{array}{l}\text { Carrier Hourly Analysis } \\
\text { Program (HAP) }\end{array}$ & Energy Tool & www.commercial.carrier.com \\
\hline Revit (Autodesk) & BIM Tool & http://usa.autodesk.com/revit-architecture/ \\
\hline Project Vasari (Autodesk) & BIM Tool & http://labs.autodesk.com/utilities/vasari/ \\
\hline $\begin{array}{l}\text { ASHRAE's Thermal Comfort } \\
\text { Tool }\end{array}$ & Thermal Comfort Tool & $\begin{array}{l}\text { www.ashrae.org } \\
\text { (ASHRAE 55) }\end{array}$ \\
\hline
\end{tabular}




\begin{tabular}{|c|c|c|}
\hline Name of Tool & Type of Tool & Website \\
\hline $\begin{array}{l}\text { ASHRAE } 62.1 \text { Compliance } \\
\text { Software }\end{array}$ & IAQ Tool & www.ashrae.org \\
\hline CONTAM (NIST) & IAQ Tool & http://www.bfrl.nist.gov/IAQanalysis/CONTAM/index.htm (ASHRAE 62.1) \\
\hline MOIST (NIST) & Moisture Control Tool & https://engineering.purdue.edu/MOIST/ \\
\hline WUFI ORNL/IBP & Moisture Control Tool & www.ornl.gov/sci/btc/apps/moisture/ibpe_sof161.htm \\
\hline AGi32 & Lighting/Daylighting Tool & www.agi32.com \\
\hline DiaLUX & & www.dialux.com \\
\hline ElumTools & Lighting Tool & www.elumtools.com \\
\hline Desktop Radiance (LBL) & Daylighting Tool & http://radsite.lbl.gov/radiance/HOME.html \\
\hline $\begin{array}{l}\text { Building Design Advisor } \\
\text { (LBL) }\end{array}$ & Daylighting, Energy Tool & http://gaia.lbl.gov/BDA/ \\
\hline Autodesk Ecotect & $\begin{array}{l}\text { Energy, Thermal Comfort, } \\
\text { Daylighting Tool }\end{array}$ & http://usa.autodesk.com/adsk/serlet/pc/index?id=12602821 and sitelD=123112 \\
\hline $\begin{array}{l}\text { Specifiers' Properties } \\
\text { information exchange (SPie) }\end{array}$ & Material Selection Tool & http://wbdg.org/references/pg sptsearch.php \\
\hline $\begin{array}{l}\text { Federal Green Construction } \\
\text { Guide for Specifiers }\end{array}$ & Material Selection Tool & http://www.wbdg.org/design/greenspec.php \\
\hline BEES & LCA Tool* and LCCA Tool & http://www.nist.gov/el/economics/BEESSoftware.cfm \\
\hline PHAROS & Material Selection Tool & http://www.pharosproject.net/ \\
\hline Green Spec & Material Selection Tool & http://www.buildinggreen.com/menus/ \\
\hline $\begin{array}{l}\text { Recycled Content Product } \\
\text { Directory (searchable } \\
\text { database) }\end{array}$ & Material Selection Tool & www.calrecycle.ca.gov \\
\hline $\begin{array}{l}\text { USDA's Bio-Preferred } \\
\text { Catalogue (searchable } \\
\text { database) }\end{array}$ & Material Selection Tool & www.catalog.biopreferred.gov/bioPreferredCatalog \\
\hline $\begin{array}{l}\text { Environmental Impact } \\
\text { Estimator (ATHENA) }\end{array}$ & LCA Tool & http://www.athenasmi.org/tools/impactEstimator/ \\
\hline GaBi Software & LCA Tool & http://www.gabi-software.com/index.php?id=85 and L=6 and redirect=1 \\
\hline SimaPro LCA Software & LCA Tool & www.earthshift.com/software/simapro \\
\hline
\end{tabular}

Compliance programs require data to be input by the user to obtain accurate and useful results. These results, or outputs, are typically provided to show achievement of the rating system goals. There is a wide range of compliance programs and each program requires a unique set of inputs. This section will review the requirements for the four compliance programs that were highlighted in section 2.2: eQUEST, EnergyPlus, BEES and Pharos. 
A comprehensive list of every input possible for each compliance program is too vast for the scope of this task, since the primary focus of this project is sustainability product properties data. Instead, we have created input lists for the four compliance programs that highlight the critical inputs by category. These can then be used to help reach the ultimate goal of a useful list of product data requirements that manufacturers should provide specific to their products.

\subsubsection{QQUEST inputs}

\section{Architectural}

- Building square footage

- Envelope construction materials for all walls, floors, ceiling and roof

- Surface areas (by orientation)

- Fenestration U-value

- Fenestration shading coefficient (SC)

\section{Mechanical}

- HVAC zoning dictated by the mechanical design

- Design mechanical flow rates

- Equipment descriptions

- Temperature and Equipment Control sequences

\section{Electrical}

- Lighting equipment

\section{Internal Loads}

- Peak occupancy (by zone)

- Peak lighting (by zone)

- Peak equipment (by zone)

\section{Operations}

- Occupancy, lights, equipment schedules (per zone)

- Thermostat schedules (per zone)

- Outside air operations (per terminal system)

- Hot and cold deck temperatures (per terminal system) 
- Fan schedules (per terminal system)

- Fan kW (per terminal system)

- Lock-out schedules (per primary system)

\section{Economic}

- Utility schedules (all fuels)

- Equipment costs

- Life-cycle cost parameters

\subsubsection{EnergyPlus inputs}

EnergyPlus is a simulation engine that is meant to be used with thirdparty user interface software. A number of tools are available to create EnergyPlus input files (IDF). These include ECOTECT, EnergyPlugged, EP-GEO and EP-SYS, EP-Quick, ESP-r, and jEPlus. Tools for creating, editing, and running input files that come with EnergyPlus include IDF Editor and EP-Launch. The same inputs listed for eQUEST are used for most of the interface software for EnergyPlus, and therefore is not repeated in this section.

ECOTECT from Square One couples an intuitive 3D design interface with a comprehensive set of performance analysis functions (visualization, solar and daylighting analysis, shadows and shading, lighting design, thermal performance, UK building regulations, ventilation, and acoustic analysis) with interactive information displays. It also can export an EnergyPlus IDF file.

ECOTECT Inputs:

- Weather data and climate information

- Mechanical and electrical equipment load and consumption information

- Building geometry and envelope information-

o This would include U-value, solar heat gain coefficient, shading coefficients, etc.

- Many of these components may already exist from the Auto$\mathrm{CAD}$ or Revit file created.

- Utility rate and structure

EnergyPlugged is an Autodesk AutoCAD plug-in to create and edit EnergyPlus input files. EnergyPlugged was conceived to improve and 
speed up EnergyPlus model creation without losing control of it, preserving EnergyPlus flexibility and allowing errors to be found.

With EnergyPlugged you can:

- draw your tridimensional building in AutoCAD or import it from your favorite $\mathrm{CAD}$ program

- select each surface with a click and get the geometry data

- check potential relations between objects and select the one you need

- continue adding and editing EnergyPlus objects in the editor

- import datasets objects (schedules, internal gains, ...) in the same or in different layers

- exchange objects between layers

- convert values into SI and IP units

- add and edit comments to objects in the editor for future revisions

- save an .if file from each layer

- explore EnergyPlus simulation output files (.eso and .mtr)

- load only the EnergyPlus output variables you need

- graph each variable, navigate on the timeline, get each time step value into SI and IP units

- get maximum, minimum and other statistical data

- export variables in comma-separated values format

- compile reports to graph multiple series in each chart from the EnergyPlus output variables

- combine variables coming from the same or different files using series formulas

- save each report and re-use them to get same charts and data tables from different simulations.

The inputs for EnergyPlugged are:

- Building geometry information

- Location and climate

- Schedules (occupancy, lighting, equipment, etc).

- Fenestration (windows and doors) details

EP GEO and EP SYS are two spreadsheet-based interfaces that can complement the simple interface tools that are included in the standard EnergyPlus installation. 
EP GEO: A simple spreadsheet that uses a set of simple macros to create rectangular building geometry, windows, shading, infiltration, internal gains and temperature control (using 'purchased air'). Rectangular zones can be automatically created in an idf file by simply entering zone height, width and length. An offset in zone origin can be used to insert multiple zones in an existing file.

EP GEO inputs are:

- Length, width, and height of the zone (enclosed spaces)

- Relation of the zone to true North

- General location, sum of area, and shading information of windows.

- Building envelope construction (walls, floors, and roof)

- Internal heat gains

- Infiltration

- Thermostat schedule

EP SYS: This spreadsheet allows for creation of Purchased Air, Fan Coil and Variable air Volume systems in a large number of zones. The list of zones in an existing IDF file can be automatically imported and individual zones selected for insertion of one of the three basic types of systems available in the tool.

EP SYS inputs are:

- All information from EP GEO

- Zoning scheme for the mechanical system

- Temperature schedules

- Mechanical system type

EP-Quick creates input files for many different buildings using built in templates for the shape and zone layout. By using templates for commonly shaped buildings and zone layouts, the time needed to create an EnergyPlus input file is greatly reduced and it works for any sized building.

EP-Quick inputs are:

- Overall Geometry - depth, width

- Building - roof, floor, interior constructions 
- Defaults - default values used in "Floorplans"

- Internal Gain Types - lighting, people, schedules

- Floorplans - zones, exterior walls, windows, etc.

- Corners - locations of the building vertices

- Roof corners - locations of special roof vertices

ESP-r: In keeping with the philosophy of linking the ESP-r simulation suite to other modeling systems, users can now export to EnergyPlus an ESP-r model with materials, constructions, surfaces (all three and four sided surfaces as well as those including one window or one door - more complex surfaces are currently filtered out) and solar shading devices.

Boundary condition attributes are translated and the parent/ child relationship between opaque and transparent surfaces established. The exported models usually pass the EnergyPlus parser with no errors or with minor warnings.

Currently, approximate optical properties are established and schedules are not yet included. An update is anticipated for the geometric filters to match the current EnergyPlus release as well as including casual gain schedules in the near future.

ESP-r inputs are:

- Building Geometry

- Windows and Doors

- Lighting

- Shading features

- Façade-integrated photovoltaic modules

- Building Envelope

- Mechanical and Electrical equipment information

jEPlus: Parametric analysis is often needed for exploring design options, especially when a global optimization method is unavailable, or the optimization result is in doubt. Parametric analysis can also be applied to all design variables simultaneously, which forms an exhaustive search approach that, providing that the search grid is fine enough, will guarantee the global optimum solution. This is potentially a very useful method. 
In order to perform complex parametric analysis on multiple parameters with more than a handful of alternative values each, a tool to generate commands for the simulation model to run, and to collect results afterwards is needed. jEPlus has been developed as a parametric shell for EnergyPlus. It is written in J ava, therefore supports all Windows/ Mac/ Linux versions of EnergyPlus.

Briefly, to use jEPlus, user prepares an IDF template file by putting tags (special search strings) at the places of the parameters. jEPlus chooses the next set of values for the parameters according to the information provided by the user. It then searches the IDF template for the tags, replaces them with the new values, and saves it as a new IDF file. EnergyPlus is called to simulate the model. Results are post-processed with ReadVarsESO. exe to produce selected output in CSV format. jEPlus finally adds indices and tags to the results, so they can be searched or imported into databases. EP-Macro will be supported in the future.

jEPlus inputs are:

- Since the main purpose of the jEPlus is to provide a comparison of various design alternatives, the inputs of the program are limited by information that has already been provided.

\subsubsection{BEES inputs}

- Importance Weights (for economic and environmental performance measures)

- Discount Rate (excluding inflation, for converting future building product costs to their equivalent present value)The higher the discount rate, the less important to you are future building product costs; such as repair and replacement costs.

- Select specific product to compare alternatives

\subsubsection{Pharos inputs}

Pharos is a web-based material selection tool and therefore does not require similar software type inputs. It requires the user to select various building materials for comparison of attributes, focusing on toxicity. 


\section{Sustainability Tool Capability Gaps}

\subsection{Overview}

Telephone interviews and surveys were conducted with industry experts to gain perspective on the broad range of issues apparent with sustainability, as it relates to buildings. This chapter summarizes the findings of that work. Common themes repeatedly presented themselves, indicating areas for improvement.

The Army must follow Executive Orders pertaining to High Performance and Sustainable Building requirements. The technical gaps discussed in this section specifically relate to the sustainability tools available for meeting the stated goals of the Guiding Principles. The gaps identified include building product properties data, life-cycle assessment, life-cycle cost analysis, methodology for LCCA tools, chemical information in building products, building product durability information, ongoing operations and maintenance, energy modeling issues, MEP sustainable materials assessment, quantification of carbon emissions and benchmarking building performance.

\subsection{Building product properties data}

A key component of the project scope is to determine what sustainability product properties data are required from manufacturers, as it is currently not readily available. The range of applicable attributes is vast. Depending on the type of product being analyzed, a different set of properties data is required. This information can be considered input for the compliance tools and rating system tools.

One can typically find information regarding VOC levels, recycled content, chain of custody, for example, on the relevant building products. Gaps start to surface, when you get into specific material requirements that the Army has, such as, blast-resistant windows. The manufacturers do not have the information available that a design team needs. For instance, solar transmission coefficient of a triple-pane blast-resistant window is not known. 
Another example is location of raw material extraction for products. A lot of building products are not tracked all the way back to the location of raw material extraction. For LEED projects, in order to count a material as regional, the raw material extraction, harvesting or recovery, as well as the manufacture (place of final assembly)of the product must be within 500 miles of the project site. A manufacturer may procure raw materials from a variety of extraction sites, and the tracking of that material may or may not occur depending on the type of product. Certified wood has a chain-ofcustody and steel has recycled content that is always tracked, but not every product is tracked.

\subsection{Life-cycle assessment}

None of the green rating systems included in this review sufficiently addresses life cycle assessment (LCA) of building products. Green Globes does introduce users to the tools to perform LCA; however it only awards points for doing an LCA without guidance on the method to use or level of results. LEED had also considered the addition of the LCA in the current 2009 version (v3.0), but it was not incorporated into the final version.

LCA tools can be defined in two ways. There are tools for creating a LCA; however this chapter focuses on LCA tools that are decision support tools. LCA-based decision support tools (referred to as LCA tools throughout this document) use the information derived from LCA studies to provide a "score." These tools are region-specific, therefore a tool used in North America (ATHENA or BEES) will have different weightings for environmental impacts, as well as a different list of environmental impacts evaluated, than a UK tool (Envest). They also use different modeling approaches, however they all use embedded LCI data (life-cycle inventory analysis one step of an LCA study) to develop environmental midpoint indicators of design alternatives. Some LCA tools work at the whole-building level and assemblies level (ATHENA) while others work at building product and assemblies levels (BEES). BEES also includes Life-Cycle Costing Assessment within its score. The correct LCA tool is required based on the region and assessment level (whole-building, assembly or product). Ecopoints use the same principles to develop scores, but they are based on UK regionspecific weighting of environmental impacts.

The main problem with LCA is comparability of results. Each LCA tool has its own database of products, assemblies and/ or buildings. None of these are comprehensive. Each tool may be using a different methodology to de- 
termine a product's score. ATHENA and BEES both use ISO 14040 series standards for LCA methodology. Therefore, you can only compare items within the same tool to obtain an apples-to-apples comparisons.

\subsection{Life-cycle cost analysis}

Currently, the green rating systems discussed here do not include life-cycle cost analysis (LCCA), either. The Guiding Principles from the Department of Energy does require LCCA and we foresee this to be a continuing trend for true sustainability. For our team's assignment, understanding life-cycle costs is critical in an owner-operated, publicly funded scenario. A major barrier has been having good cost data to complete an accurate LCCA, especially as it relates to sustainability.

Although LCA may be very useful in determining the overall environmental impact of a construction product or system, it cannot determine which product is the most cost-effective or will work the best. LCCA, which focuses primarily on the direct economic impact of a product, may be more directly related to a product's durability as reflected in its service life.

\subsection{Methodology for LCCA tools}

There is a need for LCA tools to include LCCA. The LCA tool developers do see the need for integrating LCCA and have been working toward this goal. BEES is one of the LCA tools that does include LCCA. The issue here is developing an accepted methodology.

LCA-based Environmental Product Declarations (EPDs) do follow an accepted methodology by meeting ISO Standard 14025. To meet this standard, Product Category Rules (PCRs) must be created that are reviewed and verified by an outside expert. LCCA requires a widely accepted methodology, so that comparisons are accurate.

\subsection{Chemical information in building products}

The rating systems do address eliminating products with unacceptable VOC levels; however, the problem is rooted with the lack of requirements placed on chemicals in building products. There currently are not laws for building products to safeguard human health equivalent to food regulations, for example; and therefore toxicity of chemical is not always known. There are an estimated 80,000 chemicals used by manufacturers, yet only 
200 have required toxicity testing. Pharos, one of the public databases available, does help identify chemicals in building products, but it can only list the information, if it is made available by manufacturers. In some cases, the manufacturers are reluctant to provide all the chemical information, stating it is a trademarked or proprietary product. In other cases, manufacturers struggle to get adequate information on substances from their suppliers, especially for recycled feedstock.

\subsection{Building product durability information}

The Army builds its facilities to last 50 years or more. The span of a building product's useful life is one attribute of a sustainable product. Data for the long term reuse, recycling, and disposal implications for materials are often absent among the product data available.

LCCA, which focuses primarily on the direct economic impact of a product, can relate to a product's durability as reflected in its service life. Again, accurate data must be available regarding life-span of building products in order to obtain useful LCCAs. There are ASTM standards relating to durability, but this does not exist for every product. Where it does exist, the issue of comparable results is apparent. Direct comparison of the results on a test on one type of flooring product to another may be unachievable without a common methodology.

\subsection{Ongoing operations and maintenance}

Most of the discussed rating systems also do not address impacts associated with ongoing operations and maintenance of the facility. This is one of the most important tenets of sustainability and also helps offset the potential higher first costs associated with higher efficiency systems and metering. In conjunction with this added focus on operations and maintenance needs to be an understanding of an increase in training and education for those that operate and maintain these new systems, as well as educating those that occupy these spaces. This education component is a key tenet to the success of any sustainable project.

\subsection{Energy modeling issues}

Energy modeling is a very specialized field of expertise. Many times, young staff members are thrown into this realm and are typically not qualified, resulting in inaccuracies and false predictions of building performance. 
ASHRAE offers a certification program for energy modelers, called Building Energy Modeling Professional (BEMP) certification. There are currently approximately 180 BEMPs per ASHRAE's website. If clients start requiring certified modelers, this could yield better results.

The second issue is that building design is a dynamic process, and the energy modeling tools available are very static in nature. Although an energy model looks at a one-year-cycle, the Army Facilities are built with a 50year life span in mind. As time goes by, equipment efficiencies de-rate due to age, cleaning, maintenance and changes of operation. This is not accounted for in energy models.

The process for updating energy modeling software does not keep pace with the newest technologies, specifically HVAC system/ equipment technology. For example, eQUEST's current version cannot model Variable Refrigerant Flow (VRF) systems directly; outside calculations using data extrapolation from eQUEST to Excel is required.

\subsection{MEP sustainable materials assessment}

Although the research on architectural building products is not exhaustive, nor can it be due to the nature of the industry, more Life-Cycle Assessment has been done in this area as compared to mechanical, electrical and plumbing (MEP) equipment. In part, that is due to the complexity of this equipment. It has several components of varying make-up that require analysis. The green rating systems do no address MEP sustainable materials. The Materials and Resource section of LEED specifically states to exclude MEP equipment in the calculations for those credits. Items such as ductwork, piping and conduit could easily be included in these credits. For some building types, these kinds of elements are a large percentage of the construction cost.

\subsection{Quantification of carbon emissions}

Climate change is fuelled by greenhouse gas emissions, particularly carbon dioxide, which is a large by-product of buildings. Carbon emissions may be reduced in an indirect sense through most green rating systems, however, not in a manner that is easily quantified or open to accountability. Most energy efficiency savings credits within the rating systems, ask for results expressed in energy cost savings (not energy use savings), which is due the complexity of quantifying energy savings when several technologies are 
used and measured in different ways. Electricity, for example, comes from several sources (nuclear power, coal-fired power, wind, biomass, etc.). Each of these sources is measured differently. You also need to know what percentages of power are derived from each source, and electricity is only one piece of the intricate energy savings and carbon emissions calculation.

\subsection{Benchmarking building performance}

The most significant impact that green rating systems make for the design of high-performance buildings is heightened energy savings. Several articles have been published on the subject of whether or not all these certified buildings are actually performing as they have claimed. Currently, there is not a vehicle for accountability in this arena for most rating systems.

LEED 2012 proposes a credit under its new Performance category, titled Reconcile Design and Actual Energy Performance. This credit is intended to provide verification of the project's energy claims in the Optimize Energy Performance credit. The idea is that an annual report card can be provided to USGBC to obtain recertification and an updated plaque. Buildings that do not do this, would not be penalized, but will only be able to display a plaque with the year of initial certification. This same notion is accomplished with the Energy Star program by updating a building's plaque annually to reflect the current year, based on that year's performance. GGHC and LEED-EBOM do address benchmarking with either Energy Star Portfolio Manager or Energy Use Intensity (EUI) measurement.

The Army currently does not have a good way to measure how they are meeting sustainability goals. Building metering is one way to accomplish this and is required in the Guiding Principles for new projects. Building level electricity meters are required per EPAct 2005 Section 103. EISA Section 434 requires building level meters for natural gas and steam, if used. Water meters are encouraged for both indoor water use and outdoor water use. The issue is that the large existing building stock that belongs to the Army does not consistently have meters installed. 
Table 3-1. Summary of gap analysis.

\begin{tabular}{|c|c|c|}
\hline Technical Gap & Partial Inclusion or found elsewhere & Future Inclusion Anticipated \\
\hline Building Product Properties Data & SPie Project & SPie Project \\
\hline Life Cycle Assessment & $\begin{array}{l}\text { Green Globes directs users to LCA tools and } \\
\text { awards points just for using them. }\end{array}$ & $\begin{array}{l}\text { LEED } 2012 \text {, limited use. Green Globes is } \\
\text { working to further integrate LCA. }\end{array}$ \\
\hline Life-cycle cost Analysis & Guiding Principles & \\
\hline Methodology for LCCA Tools & BEES & Tool being developed by Sphere E \\
\hline Chemical Information in Building Products & Pharos & Further development of tools such as Pharos \\
\hline \multicolumn{3}{|l|}{ Building Product Durability Information } \\
\hline Ongoing Operations and Maintenance & $\begin{array}{l}\text { LEED-EBOM addresses O\&M, GGHC addresses } \\
\text { it. }\end{array}$ & LEED 2012 \\
\hline \multicolumn{3}{|l|}{ Energy Modeling Issues } \\
\hline \multicolumn{3}{|l|}{ MEP Sustainable Materials Assessment } \\
\hline \multicolumn{3}{|l|}{ Quantification of Carbon Emissions } \\
\hline Benchmarking Building Performance & $\begin{array}{l}\text { Energy Star does not mandate an updated } \\
\text { plaque every year, but Owners are encouraged } \\
\text { to do so }\end{array}$ & $\begin{array}{l}\text { LEED } 2012 \text { plans to incorporate a system } \\
\text { similar to Energy Star }\end{array}$ \\
\hline
\end{tabular}




\section{Process for Selecting Sustainability Properties}

\subsection{Overview}

A goal of this project was to engage the broad range of industry participants, especially specifiers and manufacturers, to move from traditional paper-based methods of defining and communicating building product data to an electronic, open standard approach. Due to the interest of a major industry organization - the Construction Specifications Institute (CSI) - in engaging actively in the project, it was decided during the national technical association meeting (see Appendix A) to change the method of providing industry input on sustainability properties from a series of discipline-specific working groups (architectural, mechanical, electrical and water systems) to initial definition of sustainability properties by the KFA/ Primera team followed by review and editing of the property sets by CSI's Technical Committee.

The target building elements for which sustainability properties are to be applied are:

- architectural elements-floor coverings, wall coverings, windows, doors, ceilings

- mechanical equipment—pumps, chillers, fan coil units, air handling units

- electrical equipment-lighting, panels, switches, outlets

- water systems-pumps, fixtures, pipes, valves

- exterior enclosure-roofing, cladding, foundations, shading elements.

Discipline-specific sustainability experts on the KFA/ Primera team developed the initial definition of sustainability properties, based on both research into precedent efforts and project experience. This draft set of sustainability properties was then be reviewed by CSI's Technical Committee. The KFA/ Primera team generated, and CSI subsequently reviewed and edited, 56 tables of product properties, which included sustainability properties of building products (architectural, mechanical, electrical, water and enclosure systems) used in typical Army facilities - apartments, offices and clinics. 
This chapter documents the process used to generate an initial set of the minimum sustainability properties for architectural, mechanical, electrical, water and enclosure systems - a US Sustainability Property Set-and to engage appropriate industry participants in technical review.

\subsection{Step 1: Learn from precedent efforts}

Although numerous groups have attempted to identify the sustainability characteristics and impacts of various building products and materials, few have attempted to define this information in a computable form. The focus of this project is to make sustainability assessment and analysis directly computable from a building information model (BIM). In this context, the following were identified as precedent efforts.

\subsubsection{Specifiers' Properties information exchange}

The principal precedent for the sustainability properties effort is the Specifiers' Properties information exchange (SPie), a project of the buildingSMART alliance. This project began in late 2007 with members of the Specifications Consultants in Independent Practice (SCIP) and Construction Specifications Institute (CSI), who developed product type templates from outline specifications. SPie now comprises a set of product templates that can be used by manufacturers to export product data into an open-standard format consumable by designers, specifiers, builders, owners, and operators, as well as Building Information Modeling software. For more information on SPie, see:

www.buildingsmartalliance.org/index.php/projects/ activeprojects/32

\subsection{2 productguide ${ }^{\mathrm{TM}}$}

In 2010, Engineer Research and Development Center (ERDC) worked with AEC3 UK to develop a tool to export the entire set of building product data from the IFC data model into a standard set of files in IFC, ifcXML, COBie formats; a property set report; and a product schedule report. For each generic type and system product, the corresponding Industry Foundation Class (IFC) model properties were exported for creation of a SPie property set. This effort produced 1,200 generic templates and is the basis for the current version of the productguide ${ }^{\mathrm{TM}}$, included in the National Institute of Building Sciences (NIBS) Whole Building Design Guide (WBDG), which can be found at: www.wbdg.org/ references/pg_spt.php. 
The SPie team received requests to include property sets related to sustainability and operations as well as specifications properties. These requests suggested the development of a comprehensive set of building product data requirements that could be included in the SPie templates to provide a richer set of building information, and facilitate and streamline manufacturers' provisioning of computable product descriptions to the range of building information consumers and analysis applications.

\subsubsection{Green Building XML schema}

The Green Building XML schema (gbXML) was developed to facilitate the transfer of building information stored in CAD building information models, enabling integrated interoperability between building design models and a wide variety of engineering analysis tools and models. gbXML has been in development since 1999, with the first schema published in 2000.

The gbXML schema is focused on describing a building's thermal load properties. Nevertheless, it does include elements that potentially can be used for sustainability analysis. Elements of interest include:

- AirLoop

- AirLoopEquipment

- Construction

- ExtEquip

- Glaze

- HydronicLoopEquipment

- IntEquip

- Layer

- Lighting

- LightingSystem

- Material

- Opening

- PeakDomesticHotWaterFlow

- Surface

- WindowType

These high-level elements have child elements that hold enough information about building features and MEP systems to be useful for sustainability analyses. For example, elements link (through ID elements) from a surface down to the material on the surface in the following chain: 


\section{Surface $\rightarrow$ Construction $\rightarrow$ Layer $\rightarrow$ Material}

The elements ExtEquip and IntEquip are used for external equipment and interior equipment, respectively. Both link to either an AirLoop or a HydronicLoop and include information about the equipment's cost, electric or fuel load, performance and efficiency.

The Lighting element references a LightingSystem element, which includes elements referencing the cost, lamp, lumens per lamp, input watts and coefficient of utilization.

Much of the information in gbXML elements relates to energy analyses, such as thermal conductivity factors, light transmittance values, air flows and so forth, so for more complete sustainability analyses, it might be necessary to add additional information, such as life-time information for classes other than Air Loop Equipment and Hydronic Loop Equipment (which already include age and life elements). For example, a floor can have a material (e.g., a carpet) assigned to its upper surface layer. That material has Recycled Content and Cost child elements, but does not have children to track the expected lifetime of the carpet.

\subsubsection{IFC-based efforts}

\subsubsection{Concept design-to-building performance analysis}

This Model View Definition (MVD) is designed to use a conceptual design BIM as the basis of energy analysis and simulation. The MVD builds off the basic space boundary definitions by adding information about materials and material layers on building surfaces and information about MEP systems, including the HVAC, Vertical Circulation, Electrical Power, Electrical Lighting, Cold Water, Hot Water, and Waste Water. The additional layer and MEP system mappings make this MVD of great interest for sustainability analyses using IFC as an interchange between the BIM and the analysis program.

\subsubsection{Other mappings}

Other BLIS MVD projects deal more with spaces and space boundaries for use in thermal simulations. Project VBL-007, Architectural Design to Thermal Simulation, deals entirely with spaces and space boundaries. Project HUT_HVAC-002, Space Requirements and Targets to Thermal Simu- 
lation, focuses on HVAC design and uses Space Types with additional information on air temperatures and quality, light and sound levels and power loads.

\subsection{Step 2: Select product categories and types}

Although 1,200 product type templates were available, it was not possible to specify and review appropriate sustainability properties for all within the project timeframemaking it necessary to select a subset of the templates.

In a previous project for the Engineer Research and Development CenterERDC-CERL CR-11-2, Experimental Building Information Models (September 2011) - KFA had produced building information models of three types of Army buildings: officer apartment housing, headquarter office, and clinic. These models contained all building elements-architectural, mechanical, electrical, water and enclosure systems-required for this study. ERDC concurred with a KFA team recommendation that the product templates to be enhanced with sustainability properties should correspond with the product types existing in the three experimental building information models. This would allow for effective testing and demonstration of the use of the sustainability properties in practice. Table 4- 1 identifies the product types and categories selected.

Table 4-1. Target element types and product categories.

\begin{tabular}{|c|c|c|c|c|c|}
\hline \multirow{2}{*}{$\begin{array}{l}\text { Element Type } \\
\text { Architectural Elements }\end{array}$} & \multicolumn{5}{|c|}{ Product Categories } \\
\hline & $\begin{array}{l}\text { Floor } \\
\text { coverings }\end{array}$ & Wall Coverings & Windows & Doors & Ceilings \\
\hline Mechanical Equipment & Pumps & Chillers & Fan Coil Units & $\begin{array}{l}\text { Air Handling } \\
\text { Units }\end{array}$ & \\
\hline Electrical Equipment & Lighting & Panels & Switches & Outlets & \\
\hline Water Systems & Pumps & Fixtures & Pipes & Valves & \\
\hline Exterior Enclosure & Roofing & Cladding & Foundations & $\begin{array}{l}\text { Shading } \\
\text { Elements }\end{array}$ & \\
\hline
\end{tabular}

In all, 56 product templates were extended with sustainability properties. These product templates are discussed in Chapter 5 and documented in Appendix B. 


\subsection{Step 3: Develop draft set of sustainability properties}

\subsubsection{Document relevant sustainability properties from precedent projects}

The next step was to merge the sustainability properties from multiple sources for each of the target product categories. This was a manual effort, inasmuch as the same property could be named differently by each source. It revealed many sustainability properties were already included in the Specifiers' Properties information exchange (SPie), particularly properties required for energy analysis. The team would not replicate these properties in the US Sustainability Property Set but only identify key sustainability properties not already included in SPie. This supports the assumption that development of a single, comprehensive set of building product properties would facilitate and streamline manufacturers' provisioning of computable product descriptions to the range of building information consumers and analysis applications -in this case: specifiers, energy analysts and LEED consultants. It also highlights the importance of the standardized naming of properties. Table 4-2 compares sustainability properties for the Window product type identified in various sources.

Table 4-2. Window sustainability properties from multiple sources.

\begin{tabular}{|l|l|l|l|}
\hline SPie Properties & gbXML Properties & DOE-2.2 Properties & MFR Performance Properties \\
\hline Infiltration & & & Air Infiltration \\
\hline ThermalTransmittance & U-value & U-Value & U-Factor \\
\hline VisibleLightReflectance & & Visible Reflectance & \\
\hline VisibleLightTransmittance & & Visible Transmittance & Visible Light Transmittance \\
\hline SolarAbsorption & & & \\
\hline SolarReflectance & Reflectance & Solar Reflectance & \\
\hline SolarTransmittance & Transmittance & Solar Transmittance & \\
\hline SolarHeatGainTransmittance & SolarHeatGainCoeff & Solar Heat Gain Coefficient & Solar Heat Gain Coefficient \\
\hline ShadingCoefficient & ShadingCoeff & Shading Coefficient & Shading Coefficient \\
\hline & & & Relative Heat Gain \\
\hline & & & Transmission Ultraviolet Energy (TUV) \\
\hline & & & Transmission Damage Function (TDW) \\
\hline & & & Performance Grade \\
\hline & & & Glaze Area \\
\hline LifeCyclePhase & & & \\
\hline ServiceLifeType & & & \\
\hline AssemblyPlace & & & \\
\hline AcquisitionDate & & & \\
\hline & & & \\
\hline & & & \\
\hline & & & \\
\hline
\end{tabular}

Once all candidate sustainability properties for each product type had been listed, they were compared to the SPie properties and the new sustainability properties were identified. The properties in this list were re- 
viewed against the IFC property sets and assigned to existing property sets where possible. New property sets were designated by appending “_ US” to the property set name. The root property set was called "Pset_Sustainability_US". Additional product-category specific property sets were designated "Pset_<ProductCategory>_Sustainability_US". The technical development of the property sets and templates is discussed in Chapter 5 and documented in Appendix B.

\subsubsection{Convene discipline-specific sustainability experts}

Primera Engineers, Ltd., a member of the project team, provided sustainability experts from all relevant disciplines: architectural, mechanical, electrical and plumbing. They met to review and discuss the initial draft product property templates. The templates were updated and underwent one additional review cycle before distribution to the CSI Technical Committee.

\subsubsection{Submit for industry review}

The Construction Specifications Institute (CSI) is a national association of more than 13,000 volunteers, including specifiers, architects, engineers, contractors, facility mangers, product representatives, manufacturers, owners and others who are experts in building construction and the materials used therein. The organization was founded in March 1948 by the specification writers of government agencies who came together to improve the quality of construction specifications. Today, CSI's mission is to advance building information management and education of project teams to improve facility performance. CSI, along with the Specifications Consultants in Independent Practice (SCIP), has been closely involved with the development of SPie.

CSI's Technical Committee oversees a number of formats and technical publications commonly used in the AECOO industry, including:

- MasterFormat ${ }^{\circledR}$

- UniFormat ${ }^{\mathrm{TM}}$

- Green Format ${ }^{\mathrm{TM}}$

- Uniform Drawing System (incorporated in the National CAD Standard)

- OmniClass $^{\mathrm{TM}}$ 
This committee agreed to review and edit the draft properties templates created through the KFA/ Primera team. This included review of all properties on the 56 templates, not just the sustainability properties. The review was facilitated by CSI President, Paul R. Bertram, Jr., FCSI, CDT, LEED AP, and Technical Services Director, Greg Ceton, CSI, CDT. Technical Committee reviewers were:

- Mark Kalin, FCSI, CCS, FAIA, LEED, Kalin Associates

- Thomas P. Lewis, AHC/ CDC, CSI, ASSA ABLOY Door Security Solutions

- Michael MacVittie, CSI, AIA, Allen + Philp Architects

- Steve Martin, CADworks

- Ric Master, AIA, CSI, USG Building Systems

- David Stutzman, CSI, CCS, AIA, SCIP, Conspectus

- Robert Weygant, CSI, CDT, Sumex Design

The contents of the 56 product property templates, after CSI review, are documented in Chapter 5.

\subsection{Sustainability properties not included}

The purpose of this project is to develop, document, and create examples of a proposed model for the specification, delivery, and measurement of sustainability information on United States Army building projects. Chapter 1 documents Army's sustainability policy and requirements. These requirements do not include Environmental Product Declarations (EPDs) at this time.

An Environmental Product Declaration (EPD) presents quantified environmental data for products or systems based on information from a Life Cycle Analysis (LCA) performed according to ISO standards. It includes information about the environmental impacts such as raw material acquisition, energy use and efficiency, content of materials and chemical substances, emissions to air, soil and water and waste generation.

One CSI reviewer recommended inclusion of product properties necessary for this type of life cycle analysis. These properties are shown in Table 4-3. 
Table 4-3. Sustainability Properties Suggested But Not Included in Templates.

\begin{tabular}{|l|l}
\hline EPD (Environmental Product Declaration) Metrics: & \\
\hline EPD - Carbon Footprint (Cradle to Gate) & kg CO2 equivalent/SF surface area \\
\hline EPD - Primary Energy (Cradle to Gate) & $\mathrm{MJ} / \mathrm{SF}$ surface area \\
\hline EPD - Acidification (Cradle to Gate) & $\mathrm{H}+$ moles/SF surface area \\
\hline EPD - Ozone Depletion (Cradle to Gate) & $\mathrm{kg} \mathrm{CFC-11} \mathrm{eq/SF} \mathrm{surface} \mathrm{area}$ \\
\hline EPD - Smog (Cradle to Gate) & $\mathrm{g}$ Nox eq/SF surface area \\
\hline & \\
\hline HPD (Healthy Product Declaration) Metrics & $\begin{array}{l}\text { PPB per California Department of Department of Health } \\
\text { Standard Practice for the Testing of Volatile Organic } \\
\text { Emissions from Various Sources Using Small-Scale } \\
\text { Environmental Chambers, }\end{array}$ \\
\hline HPD - VOC Emissions & $\begin{array}{l}\text { g/L less water per South Coast Air Quality Management } \\
\text { District (SCAQMD) Rule \#1168 }\end{array}$ \\
\hline HPD - VOC Content for non-solid materials & $\begin{array}{l}\text { Amount of Chemicals of Concern above defined health } \\
\text { threshold limits per CA Prop. 65 }\end{array}$ \\
\hline HPD - Chemicals of Concern & \\
\hline
\end{tabular}




\section{Consensus Properties}

\subsection{Overview}

As a result of the national technical association meeting documented in Appendix A, a group of industry domain experts was assembled to review and validate a minimum set of sustainability properties initially defined by the KFA/ Primera team for a small sample of building products used in typical Army buildings. The methodology used in selecting product properties was described in Chapter 4. The goal of this part of the study was to identify and propose a minimum set of sustainability properties for as set of building elements typically found in traditional army facilities as exemplified by the officer apartment, headquarters office and clinic building that were earlier created for ERDC-CERL.

The starting points for selecting building elements were the common object library developed for the three experimental Building Information Models (ERDC/CERL CR-11-2, Experimental Building Information Models) and the approximately 1200 products and assemblies in Version 1 of the Specifiers' Properties Information Exchange (SPie) templates. Building elements in the common object library representing a range of categories (Table 5-11) were matched to product templates in SPie.

Once the products were identified, a property comparison was made between different property schemas, including SPie, gbXML, DOE-2 and actual manufacturer-supplied product data. These comparisons resulted in the definition of minimal sustainability property sets.

For the final set of properties that were applied to the sample products, additional properties from the Operators Properties Information Exchange (OPie) were added.

\subsection{Selection of representative products}

The building elements in the common object library were sorted by the element types and product categories listed in Table 5- 1 . The goal was to identify about 60 comparable products from the 1200 SPie templates that

\footnotetext{
1 The tables appear after the conclusion of the text in this chapter.
} 
could be used to create and validate an initial set of sustainability properties. The 56 selected products are listed in Table 5-2.

\subsection{Sustainability property comparisons}

The next step in the process was to take the selected products and examine the sustainability-related properties that are in various existing schemas, including SPie, gbXML, DOE-2 and actual manufacturer-supplied product data. An example of such a comparison, for a window, is shown in Table 5-3.

From these comparisons, a minimum set of sustainability properties was extracted. The properties in this list were reviewed against the IFC property sets and assigned to existing property sets where possible (Table 5-4). New property sets were designated by appending “_US" to the property set name. The root property set was called "Pset_Sustainability_US". Additional product-category specific property sets were designated "Pset_<ProductCategory>_Sustainability_US." The property lists were then passed to domain specialists at Primera Engineers, who reviewed the lists and suggested revisions and additions, which were incorporated into the final list.

A total of 33 properties were identified by this process. Of these, a core set of 12 properties applies to all of the 56 selected building products. These properties are in Pset_Sustainability_US. The two properties in Pset_Material_Sustainability_US apply to materials in general. The remaining 19 properties apply to specific categories of products, such as the nine properties in Pset_LightFixture_Sustainability_US or the two properties for baths, showers, toilets and other Sanitary Terminal products in Pset_SanitaryTerminal_Sustainability_US.

\subsection{Outside review of the sustainability properties}

One outcome of the meeting documented in Chapter 3 was an agreement by the Construction Specification Institute to submit the 56 representative products to panels of their members for review and comment. Spreadsheets formatted to resemble the HTML version of the SPie templates were prepared for each of the 56 products. These spreadsheets included the original SPie properties, the added sustainability properties, and new OPie properties (Table 5-5). 
Comments from the reviewers were collated and additional properties were added to a number of products (Table 5-6). A matrix showing all of the new properties as applied to the 56 products is shown in Table 5-7.

Additional properties related to Environmental Product Declarations (EPD) and Healthy Product Declarations (HPD) were also suggested (Table 4-3). These properties were not added because the focus of this project is on the Army's sustainability policies and EPD/ HPD is not included in that policy. The suggested properties should be added to the SPie templates at a later date, however.

\subsection{Creation of IFC and COBie templates}

To create IFC versions of the SPie templates for the 56 selected products, the additional properties were added to the COBie.XLS spreadsheet version of each product's SPie template. New values were entered in the Name, Category, SheetName, RowName, Value, Unit, ExtObject, ExtIdentifier, Description, AllowedValues columns of the COBie Attribute tab for each property (Figure 5-1). Default enumerations and values, such as "Not Defined" or " $\mathrm{n} / \mathrm{a}$ " where added where necessary in order to allow the transformation to be completed. These spreadsheets were then converted to IFC and other formats by Nick Nisbet of AEC3 UK Ltd using the BIMServices Transform1 tool. The template files are available through the Specifiers' Properties Templates page of the Whole Building Design Guide ProductGuide $^{\mathrm{TM}}$ (http:// www.wbdg.org/references/pg spt.php).

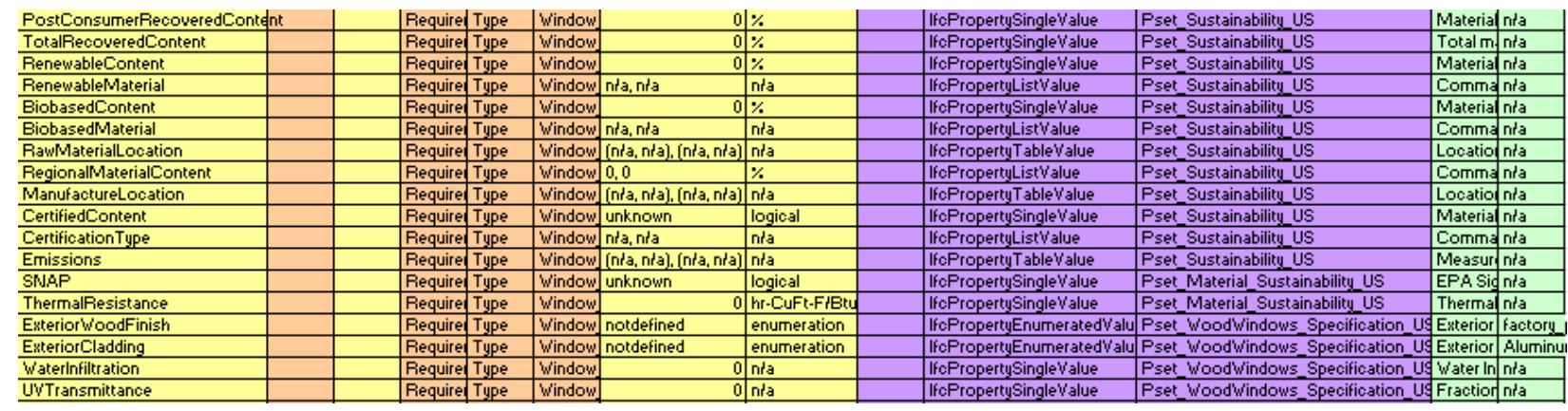

Figure 5-1. Sample additional attribute rows in a COBie spreadsheet.

\subsection{Importation of sustainability properties into the Revit experimental building models}

In an earlier ERDC/CERL project, KFA created three standardized building models ("experimental BIMs") in Autodesk Revit 2011, IFC and COBie formats. One part of the current project is to add the additional sustaina- 
bility properties to these models. The procedure that was used to create the Experimental BIMs is described in ERCD/CERL CR-11-2 (available for download from http://buildingsmartalliance.org/index.php/projects/commonbimfiles/).

Because (1) it is not possible to load individual building element families from IFC files into the default Revit template and retain the added COBie and Sustainability parameters and their values; (2) the Experimental BIM used specific Revit families that were different from the generic SPie products; and (3) the SPie templates did not--at the time--have any meaningful geometric representation, it was necessary to directly update the families in the Revit experimental models with the new parameters and create new IFC models from these Revit models.

The following procedure was used to add the sustainability parameters to the models:

1. The first Revit file-Duplex_A.rvt, the architectural model for the Duplex Apartment-was opened in Revit Architecture 2011.

2. New Revit Shared Parameters for each of the new sustainability properties were added to the COBieSharedParameters.txt file using the Revit Manage tab > Shared Parameters command. The resulting shared parameter file was saved as COBieandSustainability_SharedParameters.txt, available from http:// buildingsmartalliance.org/index.php/projects/commonbimfiles/ .

3. The new Shared Parameters were added to selected element categories using a proprietary custom add-in program. (Steps 2 and 3 can also be done using the Revit Manage tab > Project Parameters > Add command.)

4. A copy was made of the "COBie Types Schedule," a multi-category schedule in the Duplex Apartment model file, re-named "Sustainability Types Schedule" and updated to include the new parameters.

5. The new parameters were edited in the Schedule Properties dialog box to apply the parameters to the appropriate element categories in the model (Figure 5-2). 


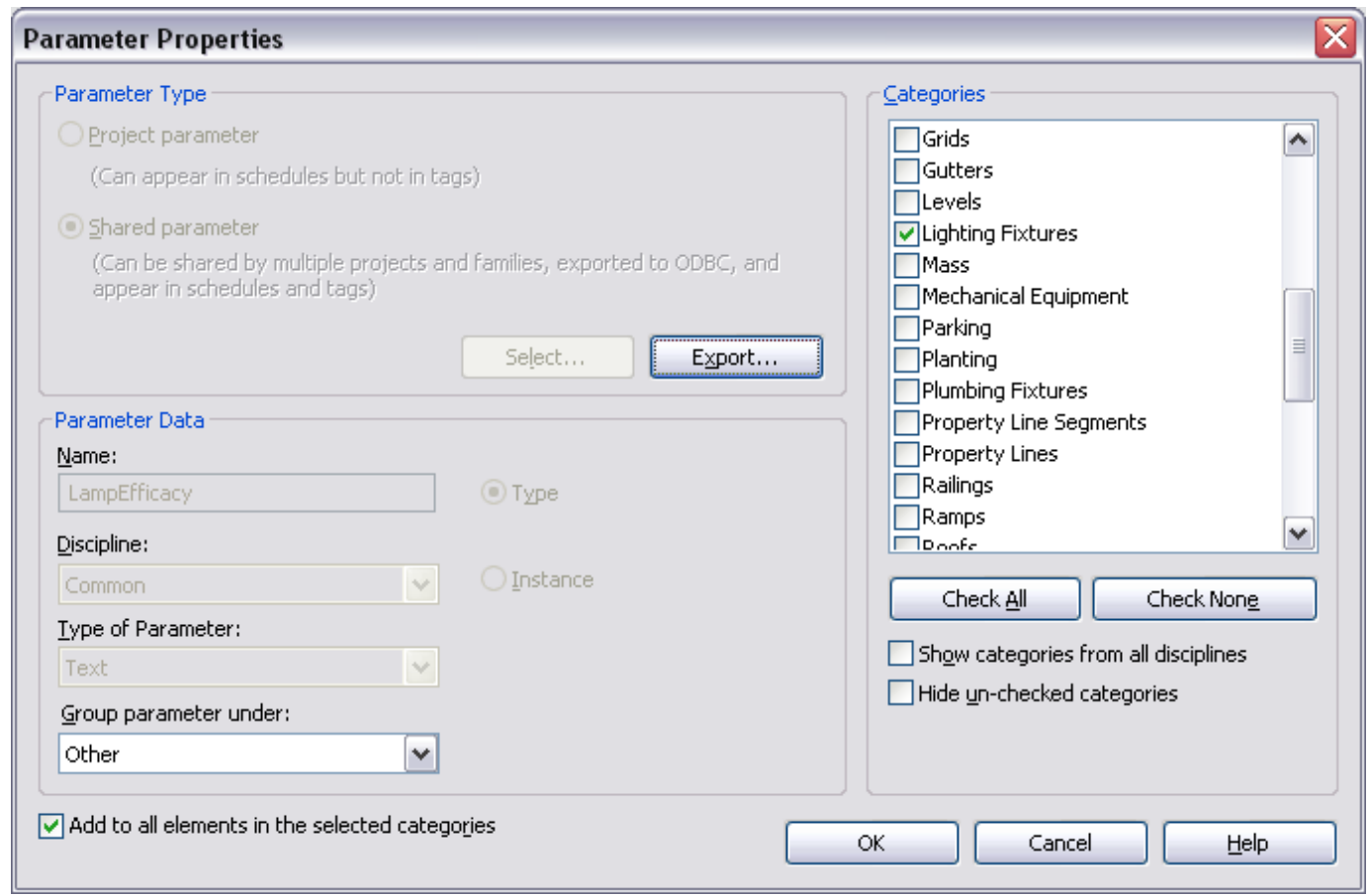

Figure 5-2: Revit parameter properties dialog box showing the Lamp Efficiency property applied to Lighting Fixtures

6. For the other models and the Revit Experimental BIM template (.RTE) files, the file was opened in Revit Architecture 2011 or Revit MEP 2011, depending on the discipline of the model, and the Sustainability Types Schedule was copied into it from the first model. Copying the schedule into the model applied the shared parameters to the building elements in the model.

\subsection{Export of models to IFC}

Once the new properties were added to the models and applied to the building elements in the models, the following procedure was used to export the models to IFC files:

1. In order to be able to export all of the parameters to IFC, default values were set using a proprietary custom add-in program.

2. The Revit model was saved as a new file.

3. The Revit model was exported to IFC using the IFC-exportlayers.txt file created for the Experimental BIM project. The IFC-exportlayers. txt file provides additional Revit-to-IFC mappings to enable correct export of the Revit elements and properties to IFC (see the Experimental BIM report for more details). 
Table 5-1. Target Element Types and Product Categories.

\begin{tabular}{|c|c|c|c|c|c|}
\hline \multirow{2}{*}{\begin{tabular}{|l} 
Element Type \\
Architectural Elements
\end{tabular}} & \multicolumn{5}{|c|}{ Product Categories } \\
\hline & $\begin{array}{l}\text { Floor } \\
\text { coverings }\end{array}$ & Wall Coverings & Windows & Doors & Ceilings \\
\hline Mechanical Equipment & Pumps & Chillers & Fan Coil Units & $\begin{array}{l}\text { Air Handling } \\
\text { Units }\end{array}$ & \\
\hline Electrical Equipment & Lighting & Panels & Switches & Outlets & \\
\hline Water Systems & Pumps & Fixtures & Pipes & Valves & \\
\hline Exterior Enclosure & Roofing & Cladding & Foundations & $\begin{array}{l}\text { Shading } \\
\text { Elements }\end{array}$ & \\
\hline
\end{tabular}

Table 5-2. Sample products by Category and Element Type.

\begin{tabular}{|c|c|c|}
\hline Type & Category & Element Template \\
\hline \multirow[t]{29}{*}{ Architectural } & Ceilings & Covering_CEILING_AcousticalPaneICeilings_US \\
\hline & Wall Coverings & Covering_MEMBRANE_Painting_US \\
\hline & \multirow[t]{5}{*}{ Floor Coverings } & Covering_FLOORING_CeramicTiling_US \\
\hline & & Covering_FLOORING_ResilientTileFlooring_US \\
\hline & & Covering_FLOORING_SheetCarpeting_US \\
\hline & & Covering_FLOORING_TileCarpeting_US \\
\hline & & Covering_FLOORING_WoodStripandPlankFlooring_US \\
\hline & \multirow[t]{17}{*}{ Enclosure } & Covering_CLADDING_AluminumSiding_US \\
\hline & & Covering_CLADDING_GypsumBoardAssemblies_US \\
\hline & & Covering_CLADDING_Sheathing_US \\
\hline & & Covering_MEMBRANE_AirBarriers_US \\
\hline & & Covering_MEMBRANE_EthylenePropyleneDieneMonomerRoofing_US \\
\hline & & Covering_ROOFING_AsphaltShingles_US \\
\hline & & Covering_ROOFING_SheetMetalRoofing_US \\
\hline & & Covering_ROOFING_VegetatedProtectedMembraneRoofing_US \\
\hline & & Footing_PAD_FOOTING_US \\
\hline & & Footing_STRIP_FOOTING_US \\
\hline & & Covering_INSULATION_BlanketInsulation_US \\
\hline & & Covering_INSULATION_Boardlnsulation_US \\
\hline & & Covering_INSULATION_PolymerBasedExteriorInsulationandFinishSystem_US \\
\hline & & CurtainWall_USERDEFINED_AluminumFramedEntrancesandStorefronts_US \\
\hline & & CurtainWall_USERDEFINED_GlazedAluminumCurtainWalls_US \\
\hline & & Wall_USERDEFINED_ConcreteUnitMasonry_US \\
\hline & & Wall_USERDEFINED_BrickMasonry_US \\
\hline & \multirow[t]{3}{*}{ Doors } & Door_DOOR_AluminumDoorsandFrames_US \\
\hline & & Door_DOOR_FlushWoodDoors_US \\
\hline & & Door_DOOR_HollowMetalDoorsandFrames_US \\
\hline & \multirow[t]{2}{*}{ Windows } & Window_SKYLIGHT_UnitSkylights_US \\
\hline & & Window_WINDOW_AluminumWindows_US \\
\hline
\end{tabular}




\begin{tabular}{|c|c|c|}
\hline Type & Category & Element Template \\
\hline & & Window_WINDOW_WoodWindows_US \\
\hline & & Window_WINDOW_VinyIWindows_US \\
\hline \multirow[t]{4}{*}{ Mechanical } & Chillers & Chiller_AIRCOOLED_US \\
\hline & Fan Coil Units & Fan_CENTRIFUGALAIRFOIL_US \\
\hline & $\begin{array}{l}\text { Air Handling } \\
\text { Units }\end{array}$ & UnitaryEquipment_AIRHANDLER_US \\
\hline & Pumps & (NOT USED in the experimental models) \\
\hline \multirow[t]{10}{*}{ Electrical } & \multirow[t]{3}{*}{ Panels } & ElectricDistributionBoard_DISTRIBUTIONBOARD_DistributionPaneI_US \\
\hline & & ElectricDistributionBoard_SWITCHBOARD_DistributionPaneI_US \\
\hline & & Transformer_VOLTAGE_US \\
\hline & \multirow[t]{2}{*}{ Lighting } & Lamp_FLUORESCENT_Lamp_US \\
\hline & & LightFixture_DIRECTIONSOURCE_LightFixture_US \\
\hline & \multirow[t]{3}{*}{ Outlets } & Outlet_DATAOUTLET_Outlet_US \\
\hline & & Outlet_POWEROUTLET_Outlet_US \\
\hline & & Outlet_TELEPHONEOUTLET_Outlet_US \\
\hline & \multirow[t]{2}{*}{ Switches } & SwitchingDevice_DIMMERSWITCH_US \\
\hline & & SwitchingDevice_TOGGLESWITCH_US \\
\hline \multirow[t]{12}{*}{ Water Systems } & Pipes & PipeSegment_RIGIDSEGMENT_US \\
\hline & Pumps & Pump_CIRCULATOR_US \\
\hline & \multirow[t]{6}{*}{ Fixtures } & SanitaryTerminal_BATH_PlumbingFixtures_US \\
\hline & & SanitaryTerminal_SANITARYFOUNTAIN_PlumbingFixtures_US \\
\hline & & SanitaryTerminal_SHOWER_PlumbingFixtures_US \\
\hline & & SanitaryTerminal_SINK_PlumbingFixtures_US \\
\hline & & SanitaryTerminal_URINAL_PlumbingFixtures_US \\
\hline & & SanitaryTerminal_TOILETPAN_PlumbingFixtures_US \\
\hline & \multirow[t]{4}{*}{ Valves } & Valve_FAUCET_US \\
\hline & & Valve_FLUSHING_US \\
\hline & & Valve_ISOLATING_US \\
\hline & & Valve_STOPCOCK_US \\
\hline
\end{tabular}


Table 5-3. Sample of a property comparison for a window.

\begin{tabular}{|c|c|c|c|c|c|}
\hline SPIE Properties & $\begin{array}{l}\text { GBxml Properties } \\
\text { (Opening element) }\end{array}$ & $\begin{array}{l}\text { GBxml Properties } \\
\text { (Window element) }\end{array}$ & $\begin{array}{l}\text { GBxml Properties } \\
\text { (Glaze element) }\end{array}$ & DOE-2.2 Properties & MFR Performance Properties \\
\hline Infiltration & & & & & Air Infiltration \\
\hline ThermalTransmittance & U-value & U-value & & U-Value & U-Factor \\
\hline VisibleLightReflectance & & & & Visible Reflectance & \\
\hline VisibleLightTransmittance & & & & Visible Transmittance & Visible Light Transmittance \\
\hline \multicolumn{6}{|l|}{ SolarAbsorption } \\
\hline SolarReflectance & Reflectance & Reflectance & Reflectance & Solar Reflectance & \\
\hline SolarTransmittance & Transmittance & Transmittance & Transmittance & Solar Transmittance & \\
\hline SolarHeatGainTransmittance & SolarHeatGainCoeff & SolarHeatGainCoeff & & Solar Heat Gain Coefficient & Solar Heat Gain Coefficient \\
\hline \multirow[t]{7}{*}{ ShadingCoefficient } & ShadingCoeff & ShadingCoeff & & Shading Coefficient & Shading Coefficient \\
\hline & & & & & Relative Heat Gain \\
\hline & & & & & Transmission Ultraviolet Energy (TUV) \\
\hline & & & & & $\begin{array}{l}\text { Transmission Damage Function } \\
\text { (TDW) }\end{array}$ \\
\hline & & & & & Performance Grade \\
\hline & & & & & Glaze Area \\
\hline & & & & & Vent Area \\
\hline \multicolumn{6}{|l|}{ LifeCyclePhase } \\
\hline \multicolumn{6}{|l|}{ ServiceLifeType } \\
\hline \multicolumn{6}{|l|}{ AssemblyPlace } \\
\hline AcquisitionDate & & & & & \\
\hline
\end{tabular}


Table 5-4: Proposed Sustainability Properties.

\begin{tabular}{|c|c|c|c|c|}
\hline Property Name & Property Description & Value & Units & Pset \\
\hline \multicolumn{5}{|l|}{ CommonProperties } \\
\hline PostConsumerRecoveredContent & $\begin{array}{l}\text { Material content from post-consumer recycled or } \\
\text { recovered sources }\end{array}$ & 0 & $\%$ & Pset_Sustainability_US \\
\hline TotalRecoveredContent & $\begin{array}{l}\text { Total material content from recycled content, } \\
\text { including post-consumer content and other } \\
\text { recycled or recovered sources }\end{array}$ & 0 & $\%$ & Pset_Sustainability_US \\
\hline RenewableContent & $\begin{array}{l}\text { Material content from rapidly renewable } \\
\text { resources }\end{array}$ & 0 & $\%$ & Pset_Sustainability_US \\
\hline RenewableMaterial & $\begin{array}{l}\text { Comma delimited list of rapidly renewable } \\
\text { material type(s) }\end{array}$ & $\mathrm{n} / \mathrm{a}, \mathrm{n} / \mathrm{a}$ & Text list & Pset_Sustainability_US \\
\hline BiobasedContent & Material content from biobased resources & 0 & $\%$ & Pset_Sustainability_US \\
\hline BiobasedMaterial & $\begin{array}{l}\text { Comma delimited list of Biobased material } \\
\text { type(s) }\end{array}$ & $\mathrm{n} / \mathrm{a}, \mathrm{n} / \mathrm{a}$ & Text list & Pset_Sustainability_US \\
\hline RawMaterialLocation & $\begin{array}{l}\text { Location at which raw materials are extracted, } \\
\text { harvested, or recovered, Delimited table by (City, } \\
\text { State) }\end{array}$ & $\begin{array}{l}(n / a, n / a),(n / a \\
n / a)\end{array}$ & Text table & Pset_Sustainability_US \\
\hline RegionalMaterialContent & $\begin{array}{l}\text { Comma delimited list of material content from } \\
\text { each raw material location, list \% by weight }\end{array}$ & 0,0 & $\%$ & Pset_Sustainability_US \\
\hline ManufactureLocation & $\begin{array}{l}\text { Location at which materials are manufactured, } \\
\text { Delimited table by (City, State) }\end{array}$ & $\begin{array}{l}(n / a, n / a),(n / a, \\
n / a)\end{array}$ & Text table & Pset_Sustainability_US \\
\hline CertifiedContent & $\begin{array}{l}\text { Material certified through an approved } \\
\text { certification program }\end{array}$ & unknown & logical & Pset_Sustainability_US \\
\hline CertificationType & $\begin{array}{l}\text { Comma delimited list of certification program(s) } \\
\text { that have certified the product }\end{array}$ & $\mathrm{n} / \mathrm{a}, \mathrm{n} / \mathrm{a}$ & $\mathrm{n} / \mathrm{a}$ & Pset_Sustainability_US \\
\hline Emissions & $\begin{array}{l}\text { Measure of pollutants and/or volatile organic } \\
\text { compounds. Delimited table by (Emission Type, } \\
\text { Quantity, Unit of Measure) }\end{array}$ & $\begin{array}{l}(\mathrm{n} / \mathrm{a}, \mathrm{n} / \mathrm{a}),(\mathrm{n} / \mathrm{a} \\
\mathrm{n} / \mathrm{a})\end{array}$ & Text table & Pset_Sustainability_US \\
\hline \multicolumn{5}{|l|}{ Electrical Device Properties } \\
\hline HeatLoad & Heat load of the element & 0 & $\mathrm{Btu} / \mathrm{hr}(\mathrm{W})$ & Pset_ElectricalDevice_Sustainability_US \\
\hline
\end{tabular}




\begin{tabular}{|c|c|c|c|c|}
\hline Property Name & Property Description & Value & Units & Pset \\
\hline EnergyStar & EnergyStar labeled product & unknown & logical & Pset_ElectricalDevice_Sustainability_US \\
\hline \multicolumn{5}{|c|}{ Transformer Properties } \\
\hline EISAEfficiency & $\begin{array}{l}\text { Equipment meets EISA efficiency requirements } \\
\text { (True) or not (False) }\end{array}$ & unknown & logical & Pset_Transformer_Sustainability_US \\
\hline TransformerFillType & $\begin{array}{l}\text { Type of transformer, including Dry Tpe or type of } \\
\text { fill oil for oil filled transformer }\end{array}$ & unset & enumeration & Pset_Transformer_Sustainability_US \\
\hline AcousticRating & $\begin{array}{l}\text { Maximum noise level produced by the } \\
\text { transformer }\end{array}$ & 0 & $\mathrm{dBa}$ & Pset_Transformer_Sustainability_US \\
\hline \multicolumn{5}{|l|}{ Lamp Properties } \\
\hline LampEfficacy & Energy efficacy of the lamp (Lumens per Watt) & 0 & L/W & Pset_Lamp_Sustainability_US \\
\hline MercuryContent & Mercury content of the lamp & 0 & $\mathrm{pg} / \mathrm{L}$ & Pset_Lamp_Sustainability_US \\
\hline \multicolumn{5}{|c|}{ Light Fixture Properties } \\
\hline LuminaireEfficacy & $\begin{array}{l}\text { Energy efficacy of the luminaire (Lumens per } \\
\text { Watt) total for the fixture (all lamps and balast } \\
\text { factors) }\end{array}$ & 0 & L/W & Pset_LightFixture_Sustainability_US \\
\hline LuminaireEfficiency & $\begin{array}{l}\text { Energy efficiency of the luminaire (exiting } \\
\text { lumens/total lumens) }\end{array}$ & 0 & $\%$ & Pset_LightFixture_Sustainability_US \\
\hline BallastType & Ballast type (electronic, dimming, etc.) & unset & enumeration & Pset_LightFixture_Sustainability_US \\
\hline BallastFactor & Ballast factor $(1.1,1.3$, etc.) & $\mathrm{n} / \mathrm{a}$ & Text & Pset_LightFixture_Sustainability_US \\
\hline BallastAcousticRating & Ballast acoustical rating (A, etc.) & $\mathrm{n} / \mathrm{a}$ & Text & Pset_LightFixture_Sustainability_US \\
\hline BacklightUplightGlare & $\begin{array}{l}\text { BUG rating of the fixture (Back Light, Up Light, } \\
\text { and Glare) }\end{array}$ & $\mathrm{n} / \mathrm{a}$ & Text & Pset_LightFixture_Sustainability_US \\
\hline ControlType & $\begin{array}{l}\text { Type of control used on the fixture, including } \\
\text { integral sensors or reference to switching device }\end{array}$ & unset & enumeration & Pset_LightFixture_Sustainability_US \\
\hline \multicolumn{5}{|c|}{ Sanitary Terminal Properties } \\
\hline VolumePerUse & Volume of water consumed per use & 0 & GPU, GPF & Pset_SanitaryTerminal_Sustainability_US \\
\hline WaterSense & EPA WaterSense labeled product & unknown & logical & Pset_SanitaryTerminal_Sustainability_US \\
\hline
\end{tabular}




\begin{tabular}{|c|c|c|c|c|}
\hline Property Name & Property Description & Value & Units & Pset \\
\hline \multicolumn{5}{|l|}{ Material Properties } \\
\hline SNAP & $\begin{array}{l}\text { EPA Significant New Alternatives Policy (SNAP) } \\
\text { Program }\end{array}$ & unknown & logical & Pset_Material_Sustainability_US \\
\hline ThermalResistance & $\begin{array}{l}\text { Thermal resistance of the element, hr-CuFt-F/Btu } \\
\text { (K-Cu m/W) }\end{array}$ & 0 & hr-CuFt-F/Btu & Pset_Material_Sustainability_US \\
\hline \multicolumn{5}{|c|}{ Asphalt Shingle Properties } \\
\hline EnergyStar & EnergyStar labeled product & unknown & logical & Pset_AsphaltShingles_Sustainability_US \\
\hline \multicolumn{5}{|c|}{ Insulation Properties } \\
\hline Carcinogenic & Has the product been found to be carcinogenic? & unknown & logical & Pset_INSULATION_Sustainability_US \\
\hline FormaldehydeFree & Does the product free of formaldehyde? & unknown & logical & Pset_INSULATION_Sustainability_US \\
\hline
\end{tabular}

Table 5-5. Additional OPie Properties.

\begin{tabular}{|c|c|c|c|}
\hline SPie Product Type Name & Recommended OPie Attributes & Existing SPie PSet Attributes & Proposed PSet Attributes \\
\hline \multirow[t]{8}{*}{ Chiller_AIRCOOLED } & RefrigerantType & - & Pset_Chiller_AIRCOOLED_Operations_US \\
\hline & RefrigerantAmount & - & Pset_Chiller_AIRCOOLED_Operations_US \\
\hline & PumpCapacity & - & Pset_Chiller_AIRCOOLED_Operations_US \\
\hline & PumpPower & - & Pset_Chiller_AIRCOOLED_Operations_US \\
\hline & BeltNumber & - & Pset_Chiller_AIRCOOLED_Operations_US \\
\hline & BeltSize & - & Pset_Chiller_AIRCOOLED_Operations_US \\
\hline & BeltType & - & Pset_Chiller_AIRCOOLED_Operations_US \\
\hline & AirFilterType & - & Pset_Chiller_AIRCOOLED_Operations_US \\
\hline \multirow[t]{5}{*}{ Door_DOOR_AluminumDoorsandFrames } & LockType & - & Pset_Door_Operations_US \\
\hline & PositionNormal & - & Pset_Door_Operations_US \\
\hline & PositionEmergency & - & Pset_Door_Operations_US \\
\hline & ClosureType & Pset_DoorCommon_SelfClosing & - \\
\hline & AccessibilityCompliance & $\begin{array}{l}\text { Pset_DoorCommon_HandicapAccessible; } \\
\text { Pset_Specification_AccessibilityPerformance }\end{array}$ & - \\
\hline \multirow[t]{2}{*}{ Door_DOOR_FlushWoodDoors } & LockType & - & Pset_Door_Operations_US \\
\hline & PositionNormal & - & Pset_Door_Operations_US \\
\hline
\end{tabular}




\begin{tabular}{|c|c|c|c|}
\hline SPie Product Type Name & Recommended OPie Attributes & Existing SPie PSet Attributes & Proposed PSet Attributes \\
\hline & PositionEmergency & - & Pset_Door_Operations_US \\
\hline & ClosureType & Pset_DoorCommon_SelfClosing & - \\
\hline & AccessibilityCompliance & $\begin{array}{l}\text { Pset_DoorCommon_HandicapAccessible; } \\
\text { Pset_Specification_AccessibilityPerformance }\end{array}$ & - \\
\hline \multirow[t]{5}{*}{ Door_DOOR_HollowMetalDoorsandFrames } & LockType & - & Pset_Door_Operations_US \\
\hline & PositionNormal & - & Pset_Door_Operations_US \\
\hline & PositionEmergency & - & Pset_Door_Operations_US \\
\hline & ClosureType & Pset_DoorCommon_SelfClosing & - \\
\hline & AccessibilityCompliance & $\begin{array}{l}\text { Pset_DoorCommon_HandicapAccessible; } \\
\text { Pset_Specification_AccessibilityPerformance }\end{array}$ & - \\
\hline \multirow[t]{10}{*}{ Fan_CENTRIFUGALAIRFOIL } & MotorSpeed & - & Pset_FanTypeCommon_Operations_US \\
\hline & MotorPower & - & Pset_FanTypeCommon_Operations_US \\
\hline & FanEfficiency & - & Pset_FanTypeCommon_Operations_US \\
\hline & AirOutput & - & Pset_FanTypeCommon_Operations_US \\
\hline & BeltNumber & - & Pset_FanTypeCommon_Operations_US \\
\hline & BeltSize & - & Pset_FanTypeCommon_Operations_US \\
\hline & BeltType & - & Pset_FanTypeCommon_Operations_US \\
\hline & ContinuousOperation & - & Pset_FanTypeCommon_Operations_US \\
\hline & FanDriveType & Pset_FanTypeCommon_MotorDriveType & - \\
\hline & MotorEnclosure & - & Pset_FanTypeCommon_Operations_US \\
\hline \multirow[t]{6}{*}{ PipeSegment_RIGIDSEGMENT } & InsulationType & - & Pset_PipeSegment_Operations_US \\
\hline & OperatingPressureMaximum & - & Pset_PipeSegment_Operations_US \\
\hline & AllowableTemperatureMaximum & - & Pset_PipeSegment_Operations_US \\
\hline & HangerSpacing & - & Pset_PipeSegment_Operations_US \\
\hline & DurabilityClass & - & Pset_PipeSegment_Operations_US \\
\hline & ChemcialAgentsExposure & - & Pset_PipeSegment_Operations_US \\
\hline \multirow[t]{5}{*}{ Pump_CIRCULAR } & OperatingPressureMaximum & - & Pset_Pump_Operations_US \\
\hline & SetPressure & - & Pset_Pump_Operations_US \\
\hline & AllowableTemperatureMaximum & - & Pset_Pump_Operations_US \\
\hline & PumpCapacity & - & Pset_Pump_Operations_US \\
\hline & PumpPower & - & Pset_Pump_Operations_US \\
\hline
\end{tabular}




\begin{tabular}{|c|c|c|c|}
\hline SPie Product Type Name & Recommended OPie Attributes & Existing SPie PSet Attributes & Proposed PSet Attributes \\
\hline & PressureDrop & - & Pset_Pump_Operations_US \\
\hline & PipeSizelnlet & - & Pset_Pump_Operations_US \\
\hline & PipeSizeOutlet & - & Pset_Pump_Operations_US \\
\hline & FuelFilterNumber & - & Pset_Pump_Operations_US \\
\hline \multirow[t]{5}{*}{ SanitaryTerminal_SINK_PlumbingFixture } & WaterTemperatureMax & - & Pset_SanitaryTerminal_SINK_Operations_US \\
\hline & WaterTemperatureMin & - & Pset_SanitaryTerminal_SINK_Operations_US \\
\hline & OperatingPressureMaximum & - & Pset_SanitaryTerminal_SINK_Operations_US \\
\hline & ValveSize & - & Pset_SanitaryTerminal_SINK_Operations_US \\
\hline & AccessibilityCompliance & Pset_Specification_AccessibilityPerformance & - \\
\hline \multirow[t]{3}{*}{ SanitaryTerminal_TOILETPAN_PlumbingFixture } & OperatingPressureMaximum & - & Pset_SanitaryTerminal_TOILETPAN_US \\
\hline & AccessibilityCompliance & Pset_Specification_AccessibilityPerformance & - \\
\hline & FlushMechanism & - & Pset_SanitaryTerminal_TOILETPAN_US \\
\hline \multirow[t]{3}{*}{ SanitaryTerminal_URINAL_PlumbingFixture } & OperatingPressureMaximum & - & Pset_SanitaryTerminal_URINAL_US \\
\hline & AccessibilityCompliance & Pset_Specification_AccessibilityPerformance & - \\
\hline & FlushMechanism & - & Pset_SanitaryTerminal_URINAL_US \\
\hline \multirow[t]{13}{*}{ UnitaryEquipment_AIRHANDLER } & NominalCoolingCapacity & - & Pset_UnitaryEquipment_AirHandler_Operations_US \\
\hline & CoolingCapacity & - & Pset_UnitaryEquipment_AirHandler_Operations_US \\
\hline & Economizer & - & Pset_UnitaryEquipment_AirHandler_Operations_US \\
\hline & SupplyFanMotorPower & - & Pset_UnitaryEquipment_AirHandler_Operations_US \\
\hline & SupplyFanCapacity & - & Pset_UnitaryEquipment_AirHandler_Operations_US \\
\hline & ReturnFanMotorPower & - & Pset_UnitaryEquipment_AirHandler_Operations_US \\
\hline & ReturnFanCapacity & - & Pset_UnitaryEquipment_AirHandler_Operations_US \\
\hline & AirFilterSize & - & Pset_UnitaryEquipment_AirHandler_Operations_US \\
\hline & BeltNumber & - & Pset_UnitaryEquipment_AirHandler_Operations_US \\
\hline & BeltSize & - & Pset_UnitaryEquipment_AirHandler_Operations_US \\
\hline & BeltType & - & Pset_UnitaryEquipment_AirHandler_Operations_US \\
\hline & VariableFrequencyDrive & - & Pset_UnitaryEquipment_AirHandler_Operations_US \\
\hline & AirFilterType & - & Pset_UnitaryEquipment_AirHandler_Operations_US \\
\hline \multirow[t]{3}{*}{ Valve_FAUCET } & PositionNormal & - & Pset_Valve_Operations_US \\
\hline & PositionEmergency & - & Pset_Valve_Operations_US \\
\hline & OperatingPressureMaximum & Pset_ValveTypeCommon_WorkingPressure & - \\
\hline
\end{tabular}




\begin{tabular}{|c|c|c|c|}
\hline SPie Product Type Name & Recommended OPie Attributes & Existing SPie PSet Attributes & Proposed PSet Attributes \\
\hline & ValveSize & Pset_ValveTypeCommon_Size & - \\
\hline \multirow[t]{4}{*}{ Valve_FLUSHING } & PositionNormal & - & Pset_Valve_Operations_US \\
\hline & PositionEmergency & - & Pset_Valve_Operations_US \\
\hline & OperatingPressureMaximum & Pset_ValveTypeCommon_WorkingPressure & - \\
\hline & ValveSize & Pset_ValveTypeCommon_Size & - \\
\hline \multirow[t]{4}{*}{ Valve_ISOLATING } & PositionNormal & - & Pset_Valve_Operations_US \\
\hline & PositionEmergency & - & Pset_Valve_Operations_US \\
\hline & OperatingPressureMaximum & Pset_ValveTypeCommon_WorkingPressure & - \\
\hline & ValveSize & Pset_ValveTypeCommon_Size & - \\
\hline \multirow[t]{4}{*}{ Valve_STOPCOCK } & PositionNormal & - & Pset_Valve_Operations_US \\
\hline & PositionEmergency & - & Pset_Valve_Operations_US \\
\hline & OperatingPressureMaximum & Pset_ValveTypeCommon_WorkingPressure & - \\
\hline & ValveSize & Pset_ValveTypeCommon_Size & - \\
\hline
\end{tabular}


Table 5-6. Additional SPie and sustainability properties from CSI review.

\begin{tabular}{|c|c|c|c|}
\hline SPie Product Type Name & Recommended OPie Attributes & Existing SPie PSet Attributes & Proposed PSet Attributes \\
\hline \multirow[t]{5}{*}{ Covering_FLOORING_SheetCarpeting } & MaterialsYarn & - & Pset_SheetCarpeting_Specification_US \\
\hline & MaterialsBacking & - & Pset_SheetCarpeting_Specification_US \\
\hline & VaporPermeability & - & Pset_SheetCarpeting_Specification_US \\
\hline & Adhesives & - & Pset_SheetCarpeting_Specification_US \\
\hline & Accessories & - & Pset_SheetCarpeting_Specification_US \\
\hline \multirow[t]{5}{*}{ Covering_FLOORING_TileCarpeting } & MaterialsYarn & - & Pset_TileCarpeting_Specification_US \\
\hline & MaterialsBacking & - & Pset_TileCarpeting_Specification_US \\
\hline & VaporPermeability & - & Pset_TileCarpeting_Specification_US \\
\hline & Adhesives & - & Pset_TileCarpeting_Specification_US \\
\hline & Accessories & - & Pset_TileCarpeting_Specification_US \\
\hline \multirow[t]{2}{*}{ Covering_INSULATION_BlanketInsulation } & Carcinogenic & - & Pset_INSULATION_Sustainability_US \\
\hline & FormaldehydeFree & - & Pset_INSULATION_Sustainability_US \\
\hline \multirow[t]{2}{*}{ Covering_INSULATION_Boardlnsulation } & Carcinogenic & - & Pset_INSULATION_Sustainability_US \\
\hline & FormaldehydeFree & - & Pset_INSULATION_Sustainability_US \\
\hline \multirow{2}{*}{$\begin{array}{l}\text { Covering_INSULATION_ } \\
\text { PolymerBasedExteriorlnsulationandFinishSystem }\end{array}$} & Carcinogenic & - & Pset_INSULATION_Sustainability_US \\
\hline & FormaldehydeFree & - & Pset_INSULATION_Sustainability_US \\
\hline \multirow[t]{3}{*}{ Covering_ROOFING_AsphaltShingle } & Exposure & - & Pset_AsphaltShingles_Specification_US \\
\hline & EnergyStar & - & Pset_AsphaltShingles_Sustainability_US \\
\hline & SolarReflectanceFront & Pset_MaterialOptical & - \\
\hline \multirow[t]{2}{*}{ Covering_ROOFING_SheetMetalRoofing } & WindLoad & - & Pset_SheetMetalRoofing_Specification_US \\
\hline & SnowLoad & - & Pset_SheetMetalRoofing_Specification_US \\
\hline \multirow[t]{9}{*}{ Door_DOOR_FlushWoodDoors } & Cut & - & Pset_FlushWoodDoors_Specification_US \\
\hline & EdgeMaterialSide & - & Pset_FlushWoodDoors_Specification_US \\
\hline & EdgeMaterialTopBottom & - & Pset_FlushWoodDoors_Specification_US \\
\hline & DoorEdgeShape & - & Pset_FlushWoodDoors_Specification_US \\
\hline & CoreConstruction & - & Pset_FlushWoodDoors_Specification_US \\
\hline & Blocking & - & Pset_FlushWoodDoors_Specification_US \\
\hline & Adhesive & - & Pset_FlushWoodDoors_Specification_US \\
\hline & PreWired & - & Pset_FlushWoodDoors_Specification_US \\
\hline & Astragal & - & Pset_FlushWoodDoors_Specification_US \\
\hline
\end{tabular}




\begin{tabular}{|c|c|c|c|}
\hline SPie Product Type Name & Recommended OPie Attributes & Existing SPie PSet Attributes & Proposed PSet Attributes \\
\hline \multirow[t]{13}{*}{ Door_DOOR_HollowMetalDoorsandFrames } & DoorMaterialsExterior & - & Pset_HollowMetalDoorsandFrames_Specification_US \\
\hline & FrameMaterialsExterior & - & Pset_HollowMetalDoorsandFrames_Specification_US \\
\hline & FrameConstruction & - & Pset_HollowMetalDoorsandFrames_Specification_US \\
\hline & CoreMaterial & - & Pset_HollowMetalDoorsandFrames_Specification_US \\
\hline & CoreConstruction & - & Pset_HollowMetalDoorsandFrames_Specification_US \\
\hline & EdgeConstruction & - & Pset_HollowMetalDoorsandFrames_Specification_US \\
\hline & Louvers & - & Pset_HollowMetalDoorsandFrames_Specification_US \\
\hline & LouverFireRating & - & Pset_HollowMetalDoorsandFrames_Specification_US \\
\hline & SmokeRating & - & Pset_HollowMetalDoorsandFrames_Specification_US \\
\hline & PreWired & - & Pset_HollowMetalDoorsandFrames_Specification_US \\
\hline & LabelClassification & - & Pset_HollowMetalDoorsandFrames_Specification_US \\
\hline & TemperatureRise & - & Pset_HollowMetalDoorsandFrames_Specification_US \\
\hline & FrameAnchorage & - & Pset_HollowMetalDoorsandFrames_Specification_US \\
\hline Footing_STRIP_FOOTING & Projection & & Pset_Footing_Specification_US \\
\hline Outlet_DATAOUTLET_Outlet & MountingType & - & Pset_Outlet_Specification_US \\
\hline Outlet_POWEROUTLET_Outlet & MountingType & - & Pset_Outlet_Specification_US \\
\hline Outlet_TELEPHONEOUTLET_Outlet & MountingType & - & Pset_Outlet_Specification_US \\
\hline SwitchingDevice_DIMMERSWITCH & MountingType & - & Pset_SwitchingDevice_Specification_US \\
\hline SwitchingDevice_TOGGLESWITCH & MountingType & - & Pset_SwitchingDevice_Specification_US \\
\hline \multirow[b]{3}{*}{ Wall_USERDEFINED_BrickMasonry } & MortarType & - & Pset_BrickMasonry_Specification_US \\
\hline & MortarColor & - & Pset_BrickMasonry_Specification_US \\
\hline & Reinforcement & - & Pset_BrickMasonry_Specification_US \\
\hline Wall_USERDEFINED_ConcreteUnitMasonry & BondBeams & - & Pset_ConcreteUnitMasonry_Specification_US \\
\hline \multirow[b]{2}{*}{ Window_SKYLIGHT_UnitSkylights } & GlassColorInterior & - & Pset_DoorWindowGlazingType_Specifiations_US \\
\hline & GlassColorExterior & - & Pset_DoorWindowGlazingType_Specifiations_US \\
\hline \multirow[b]{4}{*}{ Window_WINDOW_AluminumWindows } & FrameMaterialConfiguration & - & Pset_AluminumWindows_Specification_US \\
\hline & FrameFinish & - & Pset_AluminumWindows_Specification_US \\
\hline & WaterInfiltration & - & Pset_AluminumWindows_Specification_US \\
\hline & UVTransmittance & - & Pset_AluminumWindows_Specification_US \\
\hline \multirow[b]{2}{*}{ Window_WINDOW_VinylWindows } & WaterInfiltration & - & Pset_VinylWindows_Specification_US \\
\hline & UVTransmittance & - & Pset_VinylWindows_Specification_US \\
\hline
\end{tabular}




\begin{tabular}{|l|l|l|l|}
\hline SPie Product Type Name & Recommended OPie Attributes & Existing SPie PSet Attributes & Proposed PSet Attributes \\
\hline \multirow{5}{*}{ Window_WINDOW_WoodWindows } & ExteriorWoodFinish & - & Pset_WoodWindows_Specification_US \\
\cline { 2 - 4 } & ExteriorCladding & - & Pset_WoodWindows_Specification_US \\
\cline { 2 - 4 } & WaterInfiltration & - & Pset_WoodWindows_Specification_US \\
\cline { 2 - 4 } & UVTransmittance & - & Pset_WoodWindows_Specification_US \\
\hline
\end{tabular}


Table 5-7. Property-product matrix.

Part 1

\begin{tabular}{|c|c|c|c|c|c|c|c|c|c|c|c|c|c|c|}
\hline Product & 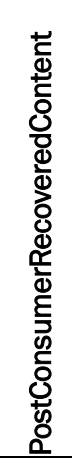 & 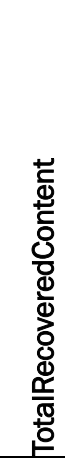 & 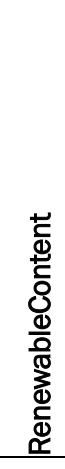 & 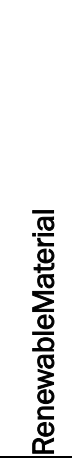 & 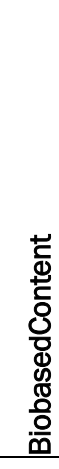 & 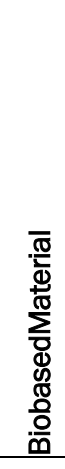 & 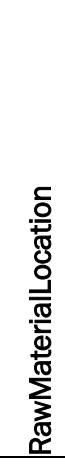 & 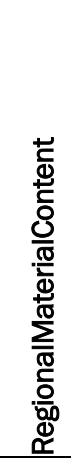 & 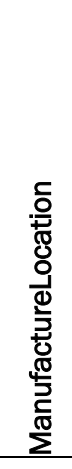 & 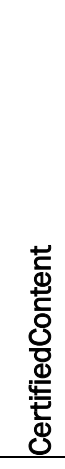 & 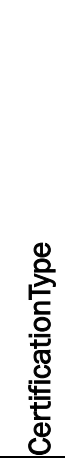 & 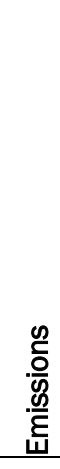 & 号 & 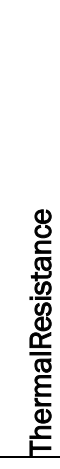 \\
\hline Chiller_AIRCOOLED_US & $x$ & $x$ & $x$ & $x$ & $x$ & $x$ & $x$ & $x$ & $x$ & $x$ & $x$ & $x$ & $x$ & $x$ \\
\hline Covering_CEILING_AcousticalPanelCeilings_US & $x$ & $x$ & $x$ & $x$ & $x$ & $x$ & $x$ & $x$ & $x$ & $x$ & $x$ & $x$ & $x$ & $x$ \\
\hline Covering_CLADDING_AluminumSiding_US & $x$ & $x$ & $x$ & $x$ & $x$ & $x$ & $x$ & $x$ & $x$ & $x$ & $x$ & $\mathrm{x}$ & $x$ & $x$ \\
\hline Covering_CLADDING_GypsumBoardAssemblies_US & $x$ & $x$ & $x$ & $x$ & $x$ & $x$ & $x$ & $x$ & $x$ & $x$ & $x$ & $x$ & $x$ & $x$ \\
\hline Covering_CLADDING_Sheathing_US & $x$ & $x$ & $x$ & $x$ & $x$ & $x$ & $x$ & $x$ & $x$ & $x$ & $x$ & $x$ & $x$ & $x$ \\
\hline Covering_FLOORING_CeramicTiling_US & $x$ & $x$ & $x$ & $x$ & $x$ & $x$ & $x$ & $x$ & $x$ & $x$ & $x$ & $x$ & $x$ & $x$ \\
\hline Covering_FLOORING_ResilientTileFlooring_US & $x$ & $x$ & $x$ & $x$ & $x$ & $x$ & $x$ & $x$ & $x$ & $x$ & $x$ & $x$ & $x$ & $x$ \\
\hline Covering_FLOORING_SheetCarpeting_US & $x$ & $x$ & $x$ & $x$ & $x$ & $x$ & $x$ & $x$ & $x$ & $x$ & $x$ & $x$ & $x$ & $x$ \\
\hline Covering_FLOORING_TileCarpeting_US & $x$ & $x$ & $x$ & $x$ & $x$ & $x$ & $x$ & $x$ & $x$ & $x$ & $x$ & $x$ & $x$ & $x$ \\
\hline Covering_FLOORING_WoodStripandPlankFlooring_US & $x$ & $x$ & $x$ & $x$ & $x$ & $x$ & $x$ & $x$ & $x$ & $x$ & $x$ & $\mathrm{x}$ & $x$ & $x$ \\
\hline Covering_INSULATION_BlanketInsulation_US & $x$ & $x$ & $x$ & $x$ & $x$ & $x$ & $x$ & $x$ & $x$ & $x$ & $x$ & $x$ & $x$ & $x$ \\
\hline Covering_INSULATION_BoardInsulation_US & $x$ & $x$ & $x$ & $x$ & $x$ & $x$ & $x$ & $x$ & $x$ & $x$ & $x$ & $x$ & $x$ & $x$ \\
\hline Covering_INSULATION_PolymerBasedExteriorInsulationandFinishSystem_US & $x$ & $x$ & $\mathrm{x}$ & $x$ & $x$ & $\mathrm{x}$ & $x$ & $x$ & $x$ & $x$ & $\mathrm{x}$ & $\mathrm{x}$ & $x$ & $x$ \\
\hline Covering_MEMBRANE_AirBarriers_US & $x$ & $\mathrm{x}$ & $\mathrm{x}$ & $\mathrm{x}$ & $x$ & $\mathrm{x}$ & $x$ & $\mathrm{x}$ & $x$ & $x$ & $\mathrm{x}$ & $x$ & $x$ & $x$ \\
\hline Covering_MEMBRANE_EthylenePropyleneDieneMonomerRoofing_US & $x$ & $x$ & $x$ & $x$ & $x$ & $x$ & $x$ & $x$ & $x$ & $x$ & $x$ & $x$ & $x$ & $x$ \\
\hline Covering_MEMBRANE_Painting_US & $x$ & $x$ & $x$ & $x$ & $x$ & $x$ & $x$ & $x$ & $x$ & $x$ & $x$ & $\mathrm{x}$ & $x$ & $x$ \\
\hline Covering_ROOFING_AsphaltShingles_US & $x$ & $x$ & $x$ & $x$ & $x$ & $x$ & $x$ & $x$ & $x$ & $x$ & $x$ & $x$ & $x$ & $x$ \\
\hline Covering_ROOFING_SheetMetalRoofing_US & $x$ & $x$ & $x$ & $x$ & $x$ & $x$ & $x$ & $x$ & $x$ & $x$ & $\mathrm{x}$ & $x$ & $x$ & $x$ \\
\hline Covering_ROOFING_VegetatedProtectedMembraneRoofing_US & $x$ & $x$ & $x$ & $\mathrm{X}$ & $x$ & $x$ & $x$ & $X$ & $x$ & $x$ & $x$ & $\mathrm{x}$ & $x$ & $x$ \\
\hline CurtainWall_USERDEFINED_AluminumFramedEntrancesandStorefronts_US & $x$ & $x$ & $\mathrm{x}$ & $\mathrm{X}$ & $x$ & $\mathrm{x}$ & $x$ & $x$ & $x$ & $x$ & $\mathrm{x}$ & $\mathrm{x}$ & $x$ & $x$ \\
\hline
\end{tabular}




\begin{tabular}{|c|c|c|c|c|c|c|c|c|c|c|c|c|c|c|}
\hline Product & 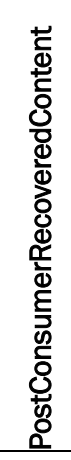 & 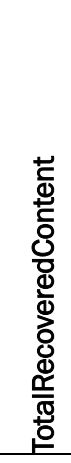 & 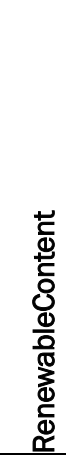 & 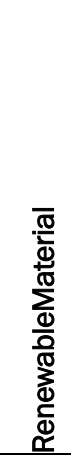 & 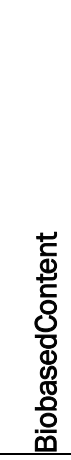 & 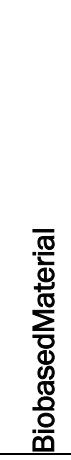 & 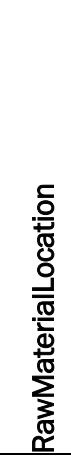 & 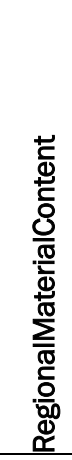 & 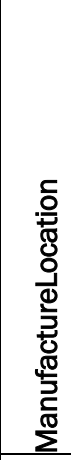 & 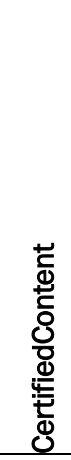 & 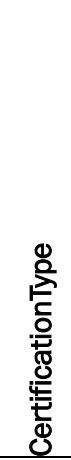 & 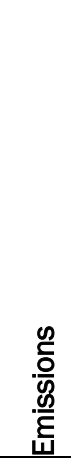 & 足 & 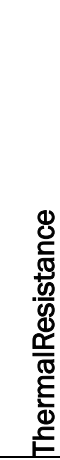 \\
\hline CurtainWall_USERDEFINED_GlazedAluminumCurtainWalls_US & $x$ & $x$ & $x$ & $x$ & $x$ & $x$ & $x$ & $x$ & $x$ & $x$ & $x$ & $\mathrm{x}$ & $x$ & $x$ \\
\hline Door_DOOR_AluminumDoorsandFrames_US & $\mathrm{x}$ & $\mathrm{x}$ & $\mathrm{x}$ & $\mathrm{x}$ & $x$ & $\mathrm{x}$ & $\mathrm{x}$ & $\mathrm{x}$ & $x$ & $\mathrm{x}$ & $\mathrm{x}$ & $x$ & $x$ & $\mathrm{x}$ \\
\hline Door_DOOR_FlushWoodDoors_US & $x$ & $x$ & $x$ & $x$ & $x$ & $x$ & $x$ & $x$ & $x$ & $x$ & $x$ & $x$ & $x$ & $x$ \\
\hline Door_DOOR_HollowMetalDoorsandFrames_US & $x$ & $x$ & $x$ & $\mathrm{x}$ & $x$ & $x$ & $x$ & $x$ & $x$ & $x$ & $x$ & $x$ & $x$ & $x$ \\
\hline ElectricDistributionBoard_DISTRIBUTIONBOARD_DistributionPanel_US & $x$ & $x$ & $x$ & $x$ & $\mathrm{x}$ & $x$ & $x$ & $x$ & $x$ & $x$ & $x$ & $x$ & $x$ & $x$ \\
\hline ElectricDistributionBoard_SWITCHBOARD_DistributionPaneI_US & $x$ & $x$ & $x$ & $x$ & $x$ & $x$ & $x$ & $x$ & $x$ & $x$ & $x$ & $x$ & $x$ & $x$ \\
\hline Fan_CENTRIFUGALAIRFOIL_US & $x$ & $x$ & $x$ & $\mathrm{x}$ & $x$ & $x$ & $\mathrm{x}$ & $x$ & $x$ & $\mathrm{x}$ & $x$ & $x$ & $x$ & $x$ \\
\hline Footing_PAD_FOOTING_US & $x$ & $x$ & $x$ & $x$ & $x$ & $x$ & $x$ & $x$ & $x$ & $x$ & $x$ & $x$ & $x$ & $x$ \\
\hline Footing_STRIP_FOOTING_US & $x$ & $x$ & $x$ & $x$ & $x$ & $x$ & $x$ & $x$ & $x$ & $x$ & $x$ & $x$ & $x$ & $x$ \\
\hline Lamp_FLUORESCENT_Lamp_US & $x$ & $x$ & $x$ & $x$ & $x$ & $x$ & $x$ & $x$ & $x$ & $x$ & $x$ & $x$ & $x$ & $x$ \\
\hline LightFixture_DIRECTIONSOURCE_LightFixture_US & $x$ & $x$ & $x$ & $x$ & $x$ & $x$ & $x$ & $x$ & $x$ & $x$ & $x$ & $x$ & $x$ & $x$ \\
\hline Outlet_DATAOUTLET_Outlet_US & $x$ & $x$ & $x$ & $x$ & $x$ & $x$ & $x$ & $x$ & $x$ & $x$ & $x$ & $x$ & $x$ & $x$ \\
\hline Outlet_POWEROUTLET_Outlet_US & $x$ & $x$ & $x$ & $x$ & $x$ & $x$ & $x$ & $x$ & $x$ & $x$ & $x$ & $x$ & $x$ & $x$ \\
\hline Outlet_TELEPHONEOUTLET_Outlet_US & $x$ & $x$ & $x$ & $x$ & $x$ & $x$ & $x$ & $x$ & $x$ & $x$ & $x$ & $x$ & $x$ & $x$ \\
\hline PipeSegment_RIGIDSEGMENT_US & $x$ & $x$ & $x$ & $x$ & $x$ & $x$ & $x$ & $x$ & $x$ & $x$ & $x$ & $x$ & $x$ & $x$ \\
\hline Pump_CIRCULATOR_US & $x$ & $\mathrm{x}$ & $x$ & $\mathrm{x}$ & $x$ & $x$ & $\mathrm{x}$ & $\mathrm{x}$ & $x$ & $\mathrm{x}$ & $x$ & $x$ & $x$ & $x$ \\
\hline SanitaryTerminal_BATH_PlumbingFixtures_US & $x$ & $x$ & $x$ & $x$ & $x$ & $x$ & $x$ & $\mathrm{x}$ & $x$ & $x$ & $x$ & $x$ & $x$ & $x$ \\
\hline SanitaryTerminal_SANITARYFOUNTAIN_PlumbingFixtures_US & $x$ & $x$ & $x$ & $x$ & $x$ & $x$ & $x$ & $x$ & $x$ & $x$ & $x$ & $x$ & $x$ & $x$ \\
\hline SanitaryTerminal_SHOWER_PlumbingFixtures_US & $x$ & $x$ & $\mathrm{x}$ & $x$ & $x$ & $x$ & $x$ & $x$ & $x$ & $x$ & $x$ & $x$ & $x$ & $x$ \\
\hline SanitaryTerminal_SINK_PlumbingFixtures_US & $x$ & $x$ & $x$ & $x$ & $x$ & $x$ & $x$ & $x$ & $x$ & $x$ & $x$ & $x$ & $x$ & $x$ \\
\hline SanitaryTerminal_TOILETPAN_PlumbingFixtures_US & $x$ & $x$ & $x$ & $x$ & $x$ & $x$ & $x$ & $x$ & $x$ & $x$ & $x$ & $x$ & $x$ & $x$ \\
\hline SanitaryTerminal_URINAL_PlumbingFixtures_US & $x$ & $x$ & $x$ & $x$ & $x$ & $x$ & $x$ & $x$ & $x$ & $x$ & $x$ & $x$ & $x$ & $x$ \\
\hline
\end{tabular}




\begin{tabular}{|c|c|c|c|c|c|c|c|c|c|c|c|c|c|c|}
\hline Product & 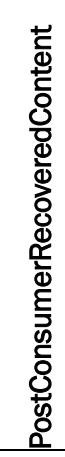 & 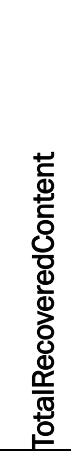 & 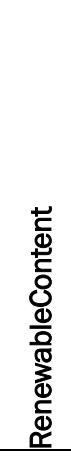 & 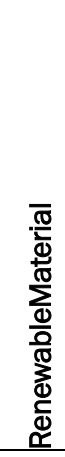 & 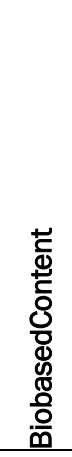 & 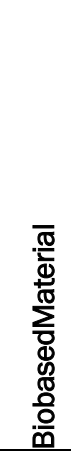 & 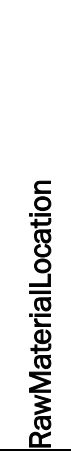 & 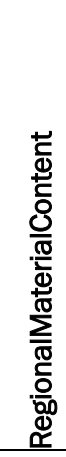 & 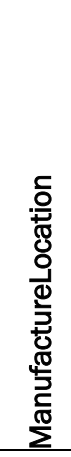 & 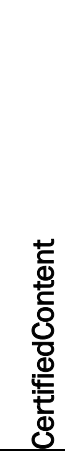 & 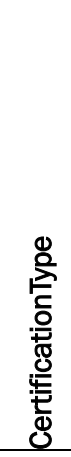 & 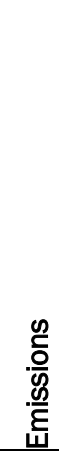 & 足 & 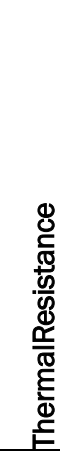 \\
\hline SwitchingDevice_DIMMERSWITCH_US & $x$ & $x$ & $x$ & $x$ & $x$ & $x$ & $x$ & $x$ & $x$ & $x$ & $x$ & $x$ & $x$ & $x$ \\
\hline SwitchingDevice_TOGGLESWITCH_US & $x$ & $x$ & $x$ & $x$ & $x$ & $x$ & $x$ & $x$ & $x$ & $x$ & $x$ & $x$ & $x$ & $x$ \\
\hline Transformer_VOLTAGE_US & $x$ & $x$ & $x$ & $x$ & $x$ & $x$ & $x$ & $x$ & $x$ & $x$ & $x$ & $x$ & & \\
\hline UnitaryEquipment_AIRHANDLER_US & $x$ & $x$ & $x$ & $x$ & $x$ & $x$ & $x$ & $x$ & $x$ & $x$ & $x$ & $x$ & $x$ & $x$ \\
\hline Valve_FAUCET_US & $x$ & $x$ & $x$ & $x$ & $x$ & $x$ & $x$ & $x$ & $x$ & $x$ & $x$ & $x$ & $x$ & $x$ \\
\hline Valve_FLUSHING_US & $x$ & $x$ & $x$ & $x$ & $x$ & $x$ & $x$ & $x$ & $x$ & $x$ & $x$ & $x$ & $x$ & $x$ \\
\hline Valve_ISOLATING_US & $x$ & $x$ & $x$ & $x$ & $x$ & $x$ & $x$ & $x$ & $x$ & $x$ & $x$ & $x$ & $x$ & $x$ \\
\hline Valve_STOPCOCK_US & $x$ & $x$ & $x$ & $x$ & $x$ & $x$ & $x$ & $x$ & $x$ & $x$ & $x$ & $x$ & $x$ & $x$ \\
\hline Wall_USERDEFINED_BrickMasonry_US & $x$ & $x$ & $x$ & $x$ & $x$ & $x$ & $x$ & $x$ & $x$ & $x$ & $x$ & $x$ & $x$ & $x$ \\
\hline Wall_USERDEFINED_ConcreteUnitMasonry_US & $x$ & $x$ & $x$ & $x$ & $x$ & $x$ & $x$ & $x$ & $x$ & $x$ & $x$ & $x$ & $x$ & $x$ \\
\hline Window_SKYLIGHT_UnitSkylights_US & $x$ & $x$ & $x$ & $x$ & $x$ & $x$ & $x$ & $x$ & $x$ & $x$ & $x$ & $x$ & $x$ & $x$ \\
\hline Window_WINDOW_AluminumWindows_US & $x$ & $x$ & $x$ & $x$ & $x$ & $x$ & $x$ & $x$ & $x$ & $x$ & $x$ & $x$ & $x$ & $x$ \\
\hline Window_WINDOW_VinylWindows_US & $x$ & $x$ & $x$ & $x$ & $x$ & $x$ & $x$ & $x$ & $x$ & $x$ & $x$ & $x$ & $x$ & $x$ \\
\hline Window_WINDOW_WoodWindows_US & $x$ & $x$ & $x$ & $x$ & $x$ & $x$ & $x$ & $x$ & $x$ & $x$ & $x$ & $x$ & $x$ & $x$ \\
\hline
\end{tabular}


Table 5-7. Property-Product Matrix (continued).

Part 2

\begin{tabular}{|c|c|c|c|c|c|c|c|c|c|c|c|c|c|c|c|c|c|c|c|}
\hline Product & 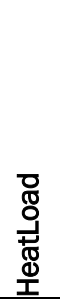 & 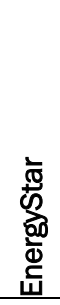 & 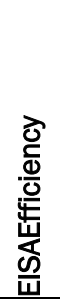 & 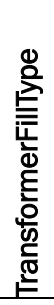 & 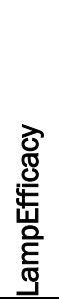 & 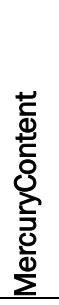 & 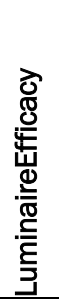 & 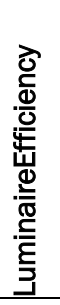 & 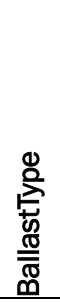 & 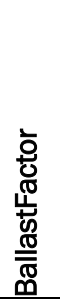 & 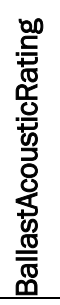 & 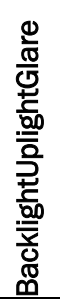 & 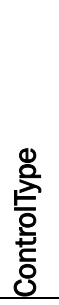 & 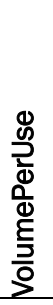 & 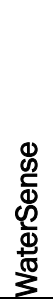 & 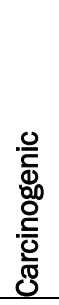 & 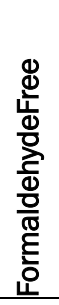 & 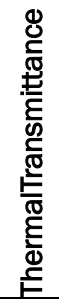 & 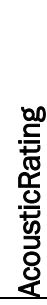 \\
\hline Chiller_AIRCOOLED_US & $\mathrm{x}$ & $x$ & & & & & & & & & & & & & & & & & \\
\hline Covering_CEILING_AcousticalPanelCeilings_US & & & & & & & & & & & & & & & & & & $x$ & $x$ \\
\hline Covering_CLADDING_AluminumSiding_US & & & & & & & & & & & & & & & & & & $x$ & $x$ \\
\hline Covering_CLADDING_GypsumBoardAssemblies_US & & & & & & & & & & & & & & & & & & $x$ & $x$ \\
\hline Covering_CLADDING_Sheathing_US & & & & & & & & & & & & & & & & & & $x$ & $x$ \\
\hline Covering_FLOORING_CeramicTiling_US & & & & & & & & & & & & & & & & & & $x$ & $x$ \\
\hline Covering_FLOORING_ResilientTileFlooring_US & & & & & & & & & & & & & & & & & & $x$ & $x$ \\
\hline Covering_FLOORING_SheetCarpeting_US & & & & & & & & & & & & & & & & & & $x$ & $x$ \\
\hline Covering_FLOORING_TileCarpeting_US & & & & & & & & & & & & & & & & & & $x$ & $x$ \\
\hline Covering_FLOORING_WoodStripandPlankFlooring_US & & & & & & & & & & & & & & & & & & $x$ & $x$ \\
\hline Covering_INSULATION_BlanketInsulation_US & & & & & & & & & & & & & & & & $x$ & $x$ & $x$ & $x$ \\
\hline Covering_INSULATION_BoardInsulation_US & & & & & & & & & & & & & & & & $x$ & $x$ & $x$ & $x$ \\
\hline $\begin{array}{l}\text { Covering_INSULATION_PolymerBasedExteriorlnsulationandFinish } \\
\text { System_US }\end{array}$ & & & & & & & & & & & & & & & & $\mathrm{x}$ & $\mathrm{x}$ & $x$ & $x$ \\
\hline Covering_MEMBRANE_AirBarriers_US & & & & & & & & & & & & & & & & & & $x$ & $x$ \\
\hline $\begin{array}{l}\text { Covering_MEMBRANE_EthylenePropyleneDieneMonomerRoofing } \\
\text { _US }\end{array}$ & & & & & & & & & & & & & & & & & & $x$ & $x$ \\
\hline Covering_MEMBRANE_Painting_US & & & & & & & & & & & & & & & & & & $x$ & $x$ \\
\hline Covering_ROOFING_AsphaltShingles_US & & $x$ & & & & & & & & & & & & & & & & $x$ & $x$ \\
\hline Covering_ROOFING_SheetMetalRoofing_US & & & & & & & & & & & & & & & & & & $\mathrm{x}$ & $x$ \\
\hline Covering_ROOFING_VegetatedProtectedMembraneRoofing_US & & & & & & & & & & & & & & & & & & $x$ & $x$ \\
\hline $\begin{array}{l}\text { CurtainWall_USERDEFINED_AluminumFramedEntrancesandStore } \\
\text { fronts_US }\end{array}$ & & & & & & & & & & & & & & & & & & $x$ & $x$ \\
\hline CurtainWall_USERDEFINED_GlazedAluminumCurtainWalls_US & & & & & & & & & & & & & & & & & & $x$ & $x$ \\
\hline
\end{tabular}




\begin{tabular}{|c|c|c|c|c|c|c|c|c|c|c|c|c|c|c|c|c|c|c|c|}
\hline Product & 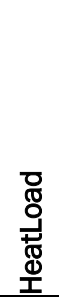 & 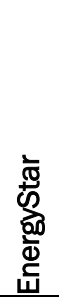 & 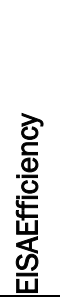 & 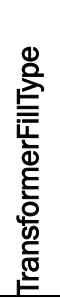 & 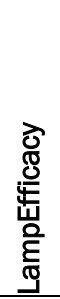 & 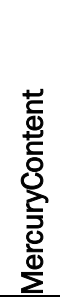 & 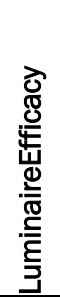 & 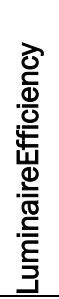 & 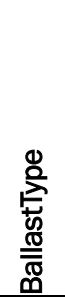 & 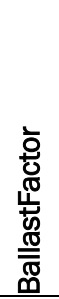 & 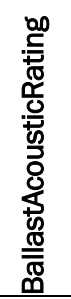 & 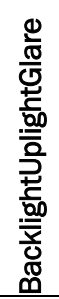 & 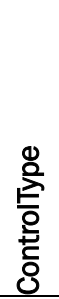 & 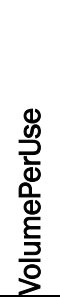 & 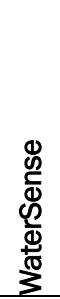 & 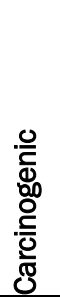 & 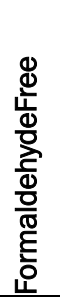 & 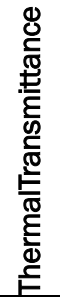 & 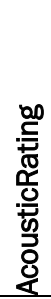 \\
\hline Door_DOOR_AluminumDoorsandFrames_US & & & & & & & & & & & & & & & & & & $\mathrm{x}$ & $\mathrm{x}$ \\
\hline Door_DOOR_FlushWoodDoors_US & & & & & & & & & & & & & & & & & & $x$ & $x$ \\
\hline Door_DOOR_HollowMetalDoorsandFrames_US & & & & & & & & & & & & & & & & & & $x$ & $\mathrm{x}$ \\
\hline $\begin{array}{l}\text { ElectricDistributionBoard_DISTRIBUTIONBOARD_DistributionPanel } \\
\text { _US }\end{array}$ & $\mathrm{x}$ & $\mathrm{x}$ & & & & & & & & & & & & & & & & & \\
\hline ElectricDistributionBoard_SWITCHBOARD_DistributionPaneI_US & $x$ & $x$ & & & & & & & & & & & & & & & & & \\
\hline Fan_CENTRIFUGALAIRFOIL_US & $x$ & $x$ & & & & & & & & & & & & & & & & & \\
\hline \multicolumn{20}{|l|}{ Footing_PAD_FOOTING_US } \\
\hline \multicolumn{20}{|l|}{ Footing_STRIP_FOOTING_US } \\
\hline Lamp_FLUORESCENT_Lamp_US & $x$ & $x$ & & & $x$ & $x$ & & & $x$ & & & & & & & & & & \\
\hline LightFixture_DIRECTIONSOURCE_LightFixture_US & $x$ & $\mathrm{x}$ & & & & & $x$ & $x$ & $x$ & $\mathrm{x}$ & $x$ & $\mathrm{x}$ & $\mathrm{x}$ & & & & & & \\
\hline \multicolumn{20}{|l|}{ Outlet_DATAOUTLET_Outlet_US } \\
\hline \multicolumn{20}{|l|}{ Outlet_POWEROUTLET_Outlet_US } \\
\hline \multicolumn{20}{|l|}{ Outlet_TELEPHONEOUTLET_Outlet_US } \\
\hline \multicolumn{20}{|l|}{ PipeSegment_RIGIDSEGMENT_US } \\
\hline Pump_CIRCULATOR_US & $x$ & $x$ & & & & & & & & & & & & & & & & & \\
\hline SanitaryTerminal_BATH_PlumbingFixtures_US & & & & & & & & & & & & & & $x$ & $x$ & & & & \\
\hline SanitaryTerminal_SANITARYFOUNTAIN_PlumbingFixtures_US & & & & & & & & & & & & & & $x$ & $x$ & & & & \\
\hline SanitaryTerminal_SHOWER_PlumbingFixtures_US & & & & & & & & & & & & & & $x$ & $x$ & & & & \\
\hline SanitaryTerminal_SINK_PlumbingFixtures_US & & & & & & & & & & & & & & $x$ & $x$ & & & & \\
\hline SanitaryTerminal_TOILETPAN_PlumbingFixtures_US & & & & & & & & & & & & & & $x$ & $x$ & & & & \\
\hline SanitaryTerminal_URINAL_PlumbingFixtures_US & & & & & & & & & & & & & & $\mathrm{x}$ & $\mathrm{x}$ & & & & \\
\hline SwitchingDevice_DIMMERSWITCH_US & $x$ & $x$ & & & & & & & & & & & & & & & & & \\
\hline SwitchingDevice_TOGGLESWITCH_US & $x$ & $x$ & & & & & & & & & & & & & & & & & \\
\hline Transformer_VOLTAGE_US & $x$ & $x$ & & $x$ & & & & & & & & & & & & & & & $\mathrm{x}$ \\
\hline UnitaryEquipment_AIRHANDLER_US & $x$ & $x$ & & & & & & & & & & & & & & & & & \\
\hline
\end{tabular}




\begin{tabular}{|c|c|c|c|c|c|c|c|c|c|c|c|c|c|c|c|c|c|c|c|}
\hline Product & 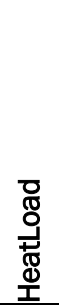 & 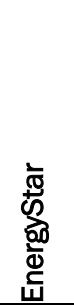 & 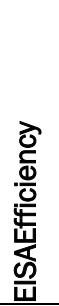 & 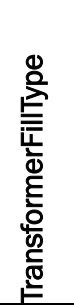 & 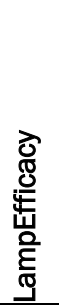 & 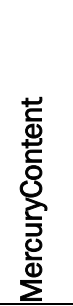 & 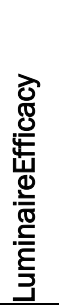 & 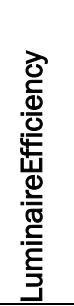 & 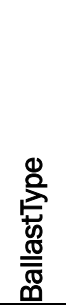 & 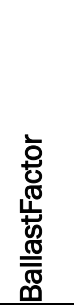 & 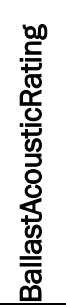 & 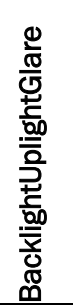 & 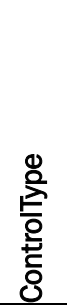 & 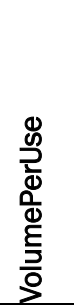 & 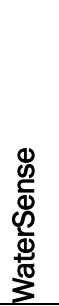 & 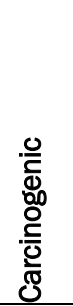 & 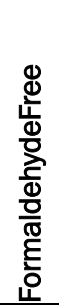 & 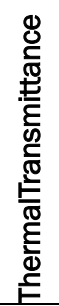 & 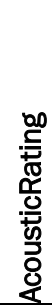 \\
\hline \multicolumn{20}{|l|}{ Valve_FAUCET_US } \\
\hline \multicolumn{20}{|l|}{ Valve_FLUSHING_US } \\
\hline \multicolumn{20}{|l|}{ Valve_ISOLATING_US } \\
\hline \multicolumn{20}{|l|}{ Valve_STOPCOCK_US } \\
\hline Wall_USERDEFINED_BrickMasonry_US & & & & & & & & & & & & & & & & & & $\mathrm{x}$ & $x$ \\
\hline Wall_USERDEFINED_ConcreteUnitMasonry_US & & & & & & & & & & & & & & & & & & $\mathrm{x}$ & $\mathrm{x}$ \\
\hline Window_SKYLIGHT_UnitSkylights_US & & & & & & & & & & & & & & & & & & $\mathrm{x}$ & $\mathrm{x}$ \\
\hline Window_WINDOW_AluminumWindows_US & & & & & & & & & & & & & & & & & & $x$ & $\mathrm{x}$ \\
\hline Window_WINDOW_VinyIWindows_US & & & & & & & & & & & & & & & & & & $\mathrm{x}$ & $\mathrm{x}$ \\
\hline Window_WINDOW_WoodWindows_US & & & & & & & & & & & & & & & & & & $\mathrm{x}$ & $x$ \\
\hline
\end{tabular}




\section{Sustainability Analysis Scenarios}

\subsection{Overview}

Architectural design projects typically require teams to develop multiple scenarios in an effort to provide the best solution to the design challenge. When deciding on what is included in each scenario, the building envelope and building systems often play a major role in developing these options. In order to help streamline the process of exploring energy-efficient options within the BIM, it is necessary to research and embed pertinent information on various building products within the model.

Information on architectural, mechanical, electrical, and plumbing products typically found in traditional Army facilities was first gathered and then entered into Microsoft Excel spreadsheets as a starting point for collecting data. Utilizing the duplex apartment BIM previously modeled using Revit Architecture 2011 and Revit MEP 2011, the product data gathered were added to several of the families in the existing project to further expand on the experimental model.

The energy efficiency, product criteria and/ or usage information added to building components provide examples of how this information can be used in exploring various energy saving scenarios.

This chapter documents the process for gathering sustainable property information, outline how the information was applied to BIM families and objects, and to demonstrate how the information can be used to make informed design decisions regarding the building systems and envelope elements. This information will provide the overall concepts that can be applied to any object in the BIM to help analyze various design scenarios.

\subsection{Standards}

In determining what sustainability properties should be applied to BIM objects, the information contained in the spreadsheets based on SPie requirements and the US sustainability property sets was used to establish the criteria typically required when analyzing the efficiency of building envelopes and systems. This information was embedded in the various model families as both standard parameters and shared parameters. 


\subsubsection{Family parameters}

In order to use additional parameters associated with a family object effectively, the intended use of the parameter data must be known so that the Type of Parameter option can be set accordingly (Figure 6-1). Establishing this early in the process will remove the need of having to recreate parameters that do not represent the correct type.

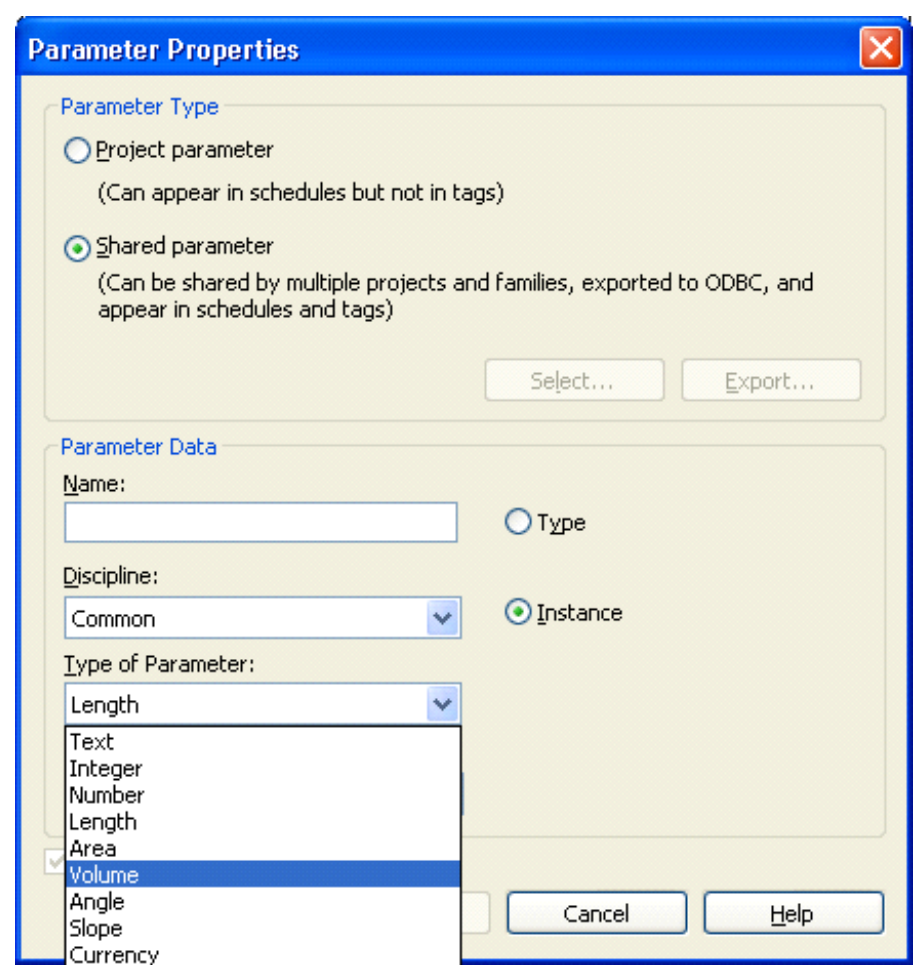

Figure 6-1. Parameter properties dialog.

\subsubsection{Shared parameters}

To ensure that custom parameters could be shared among projects and families, the approach taken was to develop the additional sustainability properties criteria as shared parameters. Shared parameters were edited and/ or created within Revit MEP 2011.

\subsubsection{Sustainability requirements}

Energy efficiency and/ or usage information was added to plumbing fixtures and the roofing components to provide an example of how the information could be used to explore various energy saving scenarios, based on the sustainability properties templates. The next sources of requirements needed for extracting useful data from the BIM were found in the 
latest version of the LEED reference guide for Green Building Design and Construction (US Green Building Council. LEED Reference Guide for Green Building Design and Construction, 2009 Edition). This allowed for a direct comparison within the BIM of baseline requirements against more energy efficient options.

\subsection{Scenario 1: LEED Water Efficiency Credit 3-Water Use Reduction}

In addition to the common sustainability properties, sanitary terminals have two additional properties: VolumePerUse and WaterSense. In this scenario, we will use these properties to make a comparison between two different specification sets in order to determine the potential reduction in water use and whether the more efficient fixtures result in a LEED credit for the design. A different set of specifications is applied to each of the two apartments in the Duplex model.

The illustration below (Figure 6-2) shows the baseline volume per use figures related to plumbing fixtures in a residential setting. The arrows highlight the three fixtures used in this scenario.

\begin{tabular}{|c|c|}
\hline Residential Fixtures, Fittings, and Appliances & Current Baseline \\
\hline Residential toilets & $1.6(\mathrm{gpf})^{\star \star \star}$ \\
\hline Residential lavatory (bathroom) faucets $\leftarrow$ & \multirow{2}{*}{$2.2(\mathrm{gpm})$ at $60 \mathrm{psi}$} \\
\hline Residential kitchen faucet & \\
\hline Residential showerheads & $2.5(\mathrm{gpm})$ at 80 (psi) per shower stall ${ }^{\star \star \star \star}$ \\
\hline
\end{tabular}

Figure 6-2. Reproduction of table from 2009 edition of LEED Reference Guide for Green Building Design and Construction.

In addition to volume usage baseline requirements, the LEED reference guide also outlined information needed to calculate total usage. The other factors necessary to determine total usage were:

- Number of Users

- Number of Uses per Day

- Minutes in Use

The LEED water use reduction credit requires a 30\% minimum decrease in water usage from the baseline standards. 
In this scenario, Duplex A plumbing fixtures were replaced with baseline level fixtures and Duplex B plumbing fixtures were updated with resourcesaving options. All properties used represent fixtures which are currently readily available for purchase. Once the BIM was fully updated, the information contained in it regarding water usage could be reviewed through the use of schedules. In order to determine total volume of water usage per day the following formula was set up in Revit as a calculated value:

$$
\begin{gathered}
\text { NumberOfUsers } * \text { NumberOfUsesPerDay * MinutesInUse } * \text { VolumePerUse }= \\
\text { Volume per Day }
\end{gathered}
$$

This allowed the total annual volume to be calculated by multiplying the volume per day by the number of days in use, 365 days in this example.

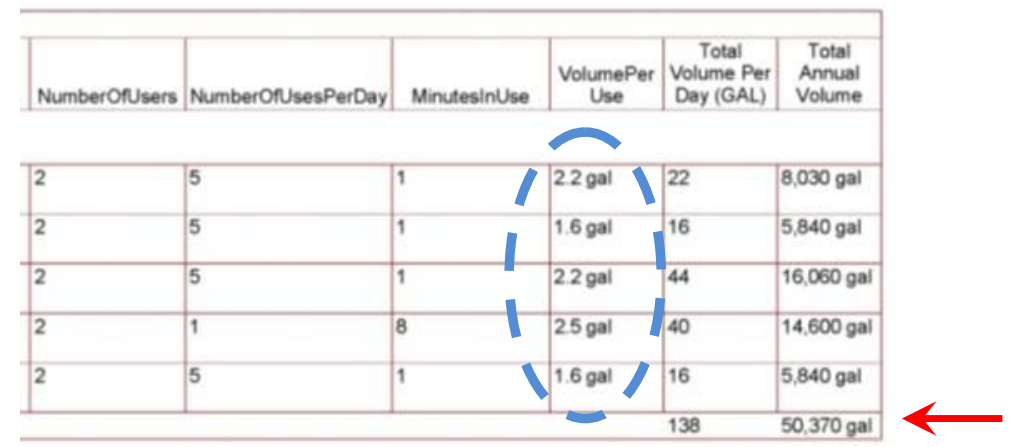

Figure 6-3. Duplex A, total annual water usage schedule.
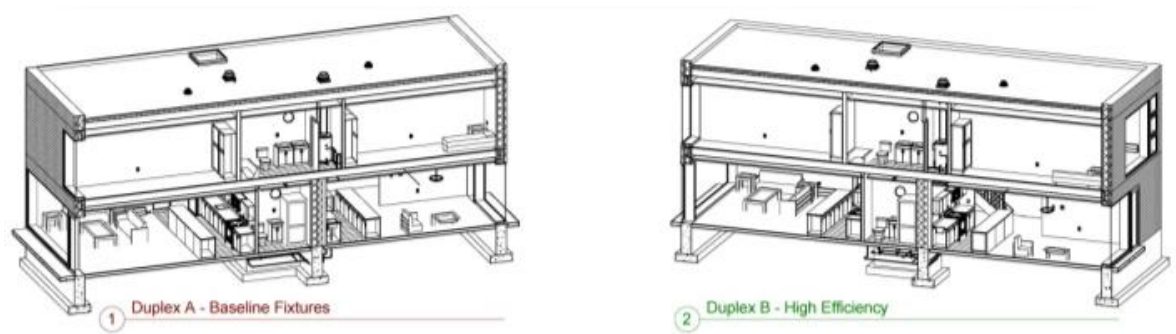

Figure 6-4. Duplexes A and B, plumbing fixtures.

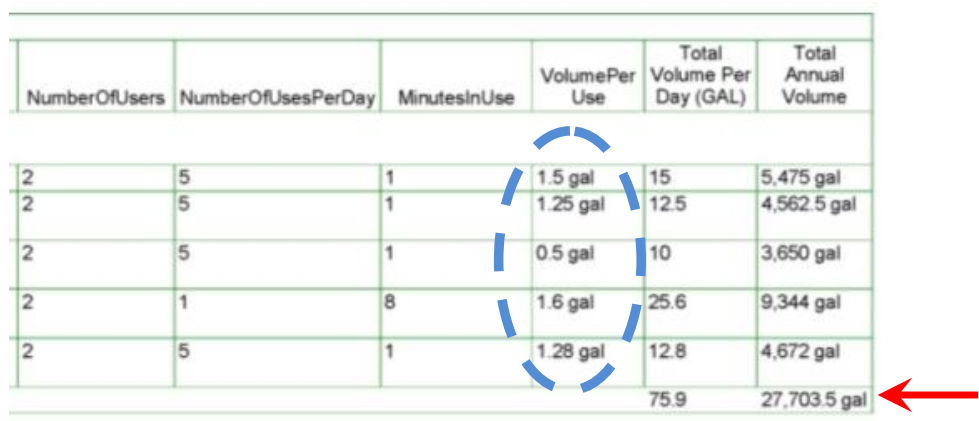

Figure 6-5. Duplex B, total annual water usage schedule. 
Utilizing the filtering options available in Revit schedules, the plumbing fixtures were separated by unit and the schedules above document the total annual volume of water usage. Since the grand total figure generated in the Revit schedule can't be used in another calculated value in this version of Revit, the percentage of water use reduction can be figured manually by performing the following calculation:

$$
\begin{gathered}
(100 \%)-(27,703.5 \mathrm{gal} / 50,370 \mathrm{gal})= \\
45 \% \text { Reduction in Water Usage from baseline fixtures }
\end{gathered}
$$

A water use reduction of $45 \%$ over the baseline unit was achieved through the use of high efficiency plumbing fixtures. This qualifies for four points under Water Efficiency (WE) Credit 3.

\subsection{Scenario 2: LEED Sustainable Sites Credit 7.2-Heat Island Effect - Roof}

For a second scenario, three different roof types were created and updated with the necessary information required to determine whether or not the roof would qualify for Sustainable Sites Credit 7.2 Heat Island Effect. This required that a parameter for the Solar Reflectance Index (SRI) be added to the shared parameters file in order for it to be added to each roof element. To receive one point in the LEED rating system for this credit, it requires that the SRI value of the roofing material be equal to or greater than the baseline SRI value indicated in the LEED reference guide (Figure 6-6).

\begin{tabular}{|l|c|c|}
\hline Roof Type & Slope & SRI \\
\hline Low-sloped roof & $\leq 2: 12$ & 78 \\
\hline Steep-sloped roof & $>2: 12$ & 29 \\
\hline
\end{tabular}

Figure 6-6. Baseline SRI requirements-Table from 2009 LEED reference guide.

Since the duplex model used in this experiment contains a low-slope roof, the SRI value of 78 was used as the baseline figure for comparing the two membrane roofing options. If a project contains a vegetated roof consisting of a value equal to or greater than $50 \%$ of the roof area, it meets the requirements of this credit.

To compare two different scenarios, the Revit design options feature was used to create both the EPDM and TPO roof options (Figure 6-7 and Figure 6-8). 


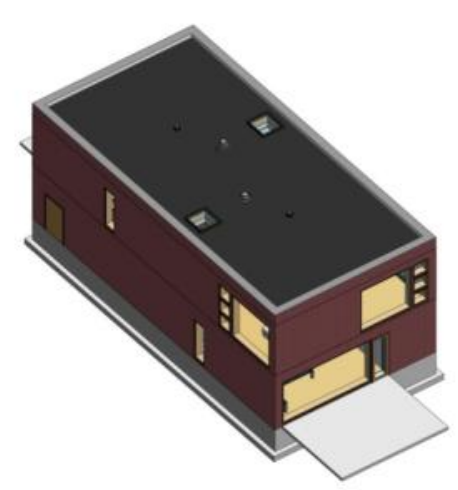

Figure 6-7: Option 1: EPDM Roof- SRI of 7.

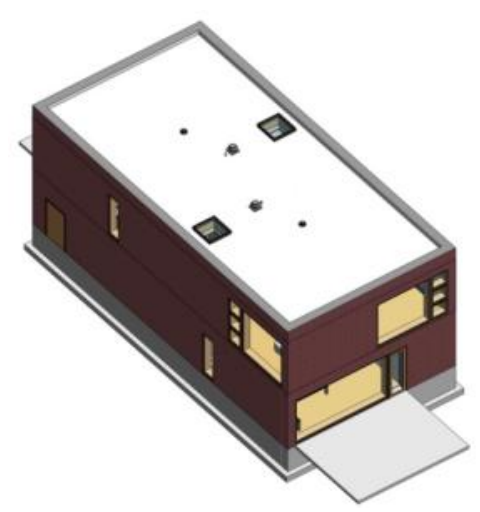

Figure 6-8: Option 2: TPO Roof-SRI of 111.

Having the SRI information associated with the roof elements allowed for a quick determination as to whether or not the roofing material used would meet the criteria indicated in the LEED reference guide. The schedule images below (Figure 6-9 and Figure 6-10) illustrate how the information is viewed within Revit 2011.

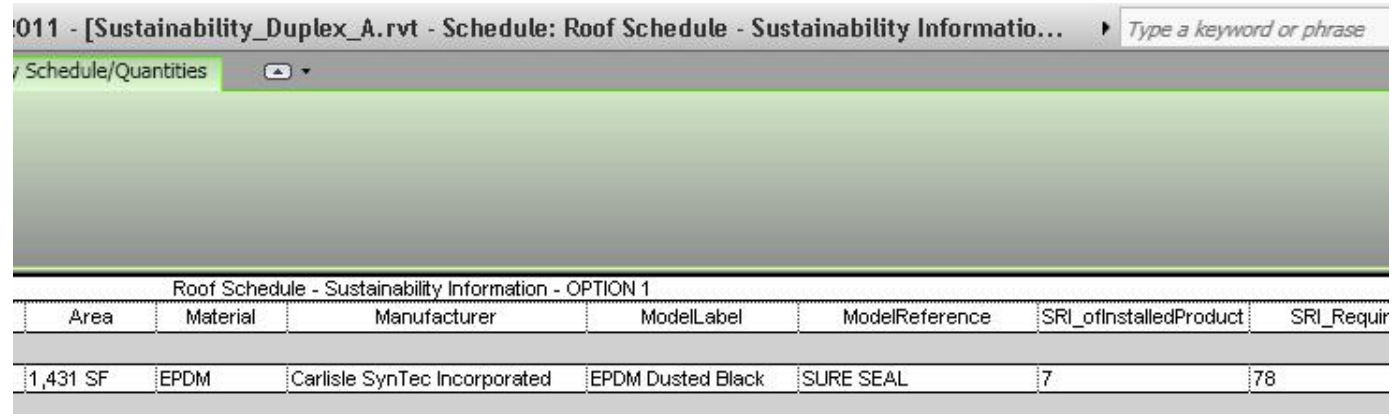

Figure 6-9. Option 1-EPDM roofing schedule

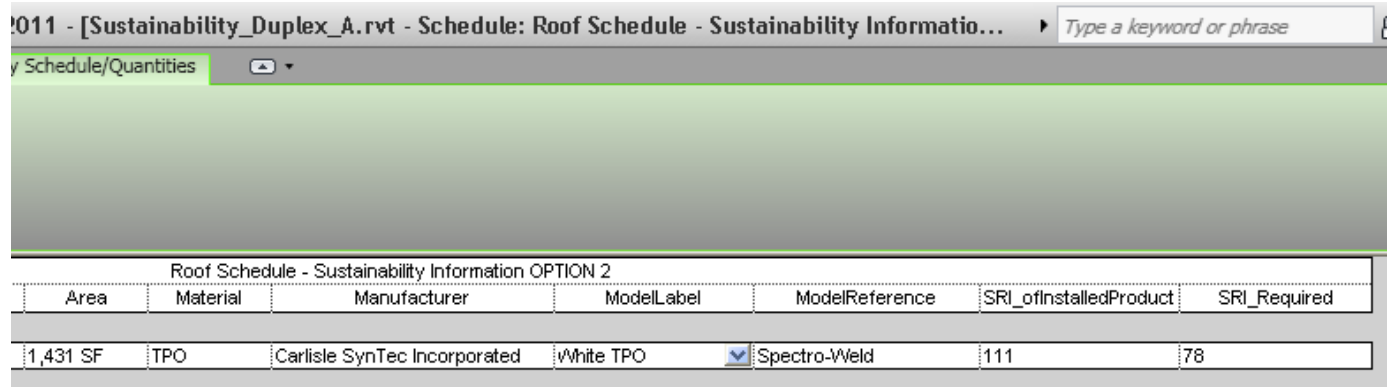

Figure 6-10. Option 2-TPO roofing schedule.

A quick review of the information determined that Option 1 - EPDM roofing would not qualify for the LEED credit since the SRI for that particular EPDM product is below the minimum 78. Option 2 - TPO roofing has a 
SRI value of 111 and covers over $75 \%$ of the roof surface, qualifying it to receive the one available point under this credit.

\subsection{Summary}

The two scenarios illustrated in this chapter provided a brief overview of the capabilities of the software to calculate and/ or display sustainability information when the appropriate sustainability property data is applied to building components in a BIM.

In addition to illustrating the utility of defining standardized sustainability properties, these scenarios also show that it is sometimes necessary to add additional properties in order to accommodate specific analyses.

By defining a minimum set of sustainability properties, we anticipate that product vendors will provide more specific property information about their products and that software vendors will develop automated checking and analysis programs that use these properties. 


\section{Adding Sustainability Properties to IFC Model Through COBie Spreadsheet}

\subsection{Overview}

A building design is often analyzed for numerous reasons, one of those being for its potential sustainability characteristics. Sometimes the design team may not be responsible for energy modeling or sustainability analysis, and if so, the analysis team may not have access to the BIM authoring software used to develop the model. The analysis team then needs some other means to add sustainability properties to the design model.

In order to provide a method for third-party analysis outside the BIM authoring software environment, the duplex apartment building experimental BIM was exported as an IFC file from Revit MEP 2011. To add more information to the IFC file, the AEC3 BIMServices Transform1 utility was used to generate a COBie spreadsheet that could be updated with sustainability information, then be converted back to an IFC file for analysis in a model checking program.

This chapter documents the process for applying sustainable property information to elements in project without BIM authoring software.

\subsection{Procedure}

The MEP model for the duplex apartment building experimental BIM was exported from Revit MEP 2011 to an IFC file. AEC3's BIMServices version 2010.12.28 was utilized to perform the IFC to COBie conversion. Microsoft Excel 2007 was used to update property attribute information in the spreadsheet, and Solibri Model Checker version 7.0.0.197 was used to simulate a potential sustainability analysis scenario.

The sustainability properties product data for high-efficiency toilet fixtures, previously used in the sustainability duplex experimental BIM project, was referenced for updating the COBie spreadsheet. 


\subsection{Demonstration}

If a LEED consultant or energy analyst receives an IFC format file with no sustainability data associated with the building components, they would need to add that information in order to perform an analysis on fixture efficiency. This scenario explores a way for them to do this without need for the BIM authoring software, in this case Autodesk Revit MEP.

In the first step of the demonstration, the BIM files were exported from Revit 2011 as IFC format files. Once the IFC file was exported, it was opened in Solibri model checker to confirm that the COBie properties associated with the fixture in the original Revit model were present.

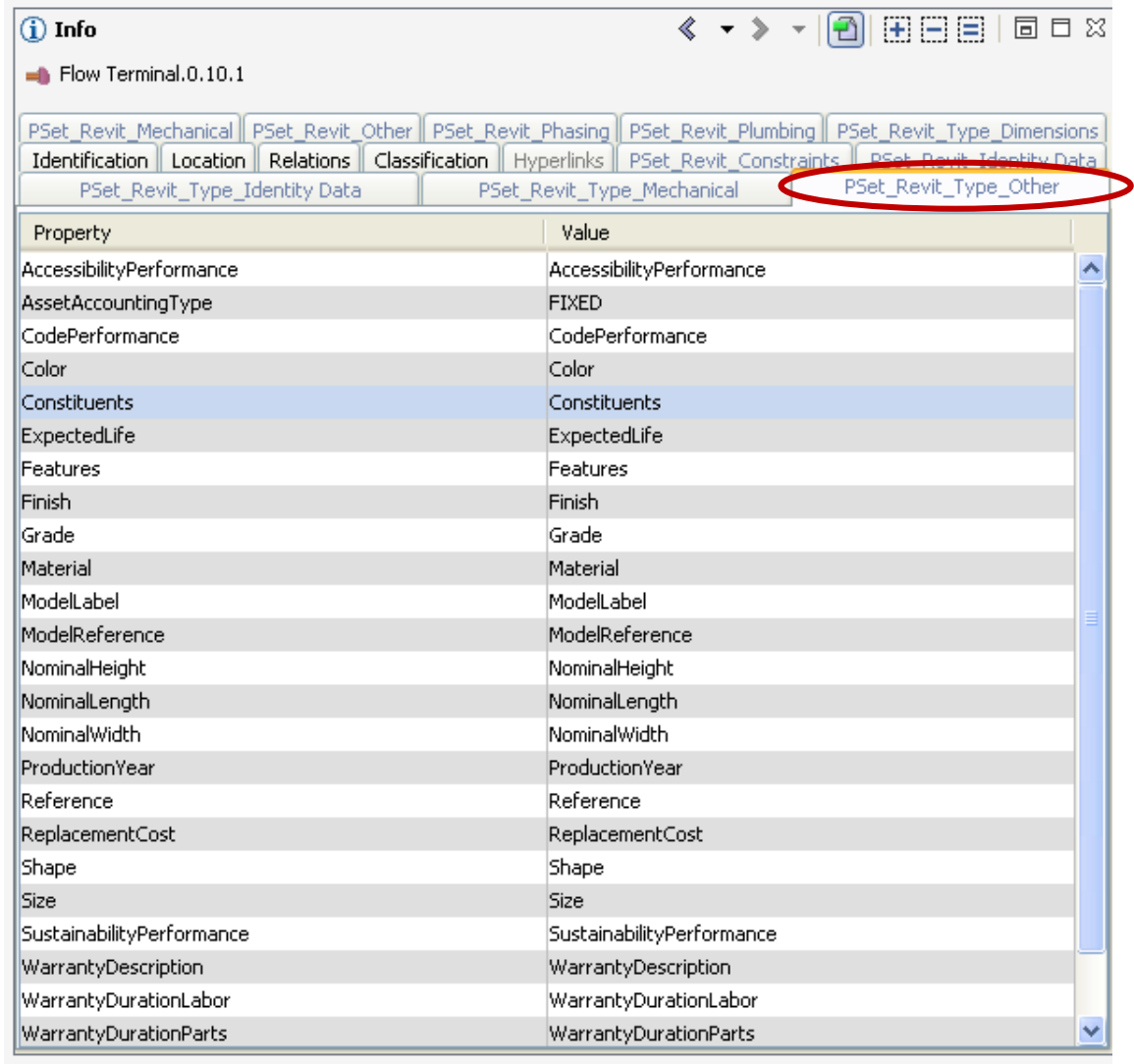

Figure 7-1. COBie Properties of fixture in Solibri.

Although COBie information was present, no sustainability information had been included in the Revit model for the plumbing fixture. Note that in the IFC file exported from Revit, all of the COBie information is located on the PSet_Revit_Type_Other tab. 
In order to analyze the efficiency of the plumbing fixture by adding additional properties to the element, the IFC file needs to be converted to a COBie spreadsheet. The Duplex IFC file (MEP) was transformed to COBie format utilizing the BIMServices Transform1 utility. This process was previously documented in the Experimental Building Information Models report (September 2011). The main file created during the conversion for use in this example was Duplex MEP_as_COBIE2.xls. Additional files were also created (.IFCXML, .XML and .CSV), but the .XLS file was the only one required for this workflow scenario.

The COBie spreadsheet generated from the BIM Services Transform1 utility contained 21 total worksheets within the workbook, but the only one necessary to review for this project was the Attributes tab. The Attributes tab's importance is related to the BIM Services Transform1 FromCobie utility since this is where the utility looks for property set information pertaining to an object when converting a COBie spreadsheet to IFC format.

\begin{tabular}{|c|c|}
\hline M_Water Closet - Flush Tank:Private - 6.1 Lpf:Private - 6.1 Lpf:582918 & 4.921259843E-2 \\
\hline M_Water Closet - Flush Tank:Private - 6.1 Lpf:Private - 6.1 Lpf:582918 & \\
\hline M_Water Closet - Flush Tank:Private - 6.1 Lpf:Private - 6.1 Lpf:582918 & \\
\hline M_Water Closet - Flush Tank:Private - 6.1 Lpf:Private - 6.1 Lpf:582918 & \\
\hline 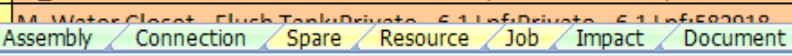 & Actribute Cooronate / I I \\
\hline
\end{tabular}

Figure 7-2. COBie spreadsheet Attributes tab.

The COBie spreadsheet was manually edited to include the sustainability properties required for analysis. In this example, the water closet attributes were updated to include information regarding water usage criteria used to determine water use efficiency of the fixture. Those properties included:

1. Number of Users Per Day

2. Volume Per Use

3. Number of Uses Per Day

Once the necessary attributes were added, the file was renamed and saved.

The BIMServices Transform1 utility was then used to convert the spreadsheet back to IFC format. After opening the converted COBie to IFC file in Solibri Model Checker, the sustainable information properties associated with the toilet fixture were visible by selecting the "Private 1.6 LPF" folder in the modeling tree and selecting one of the flow terminal elements. The 
sustainability information about each object is displayed in the Pset_Component_COBie2 information window.

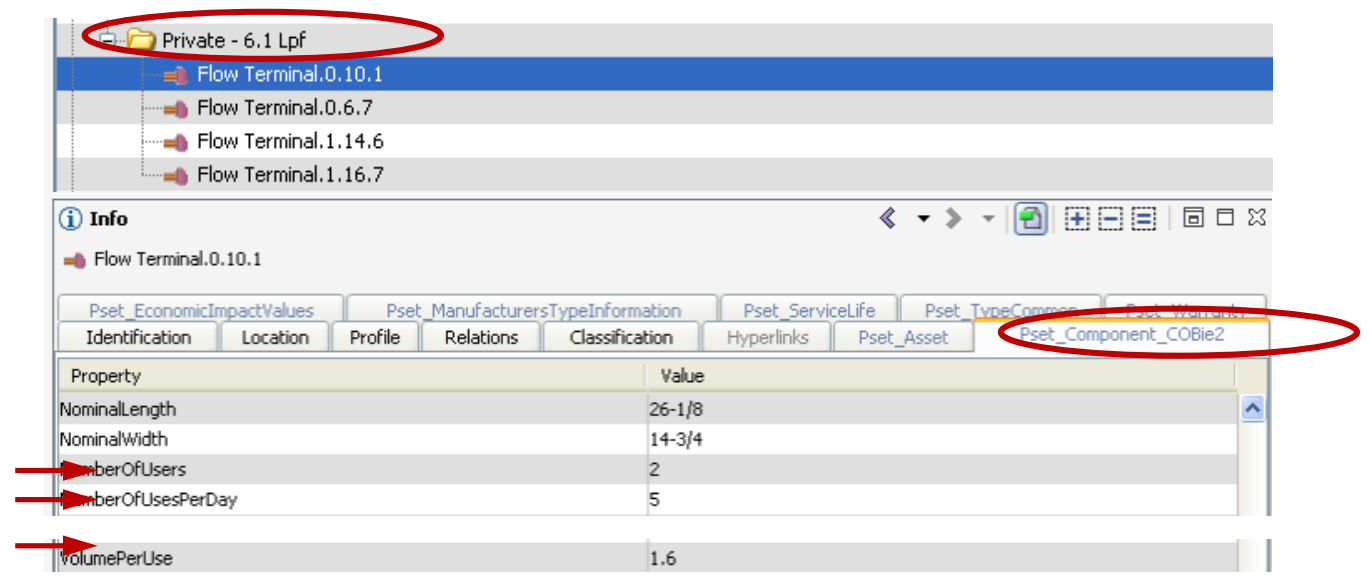

Figure 7-3. Sustainability properties information.

Note that COBie and sustainability property information are located on the same tab in this translated file.

Since the standard Solibri pre-energy analysis rule template does not review sustainability properties of models, a custom rule was created to check models elements for these properties. The rule could also be set to check for all COBie information as well if necessary. The Solibri rule set modified to perform this check was the Required Property Sets file.

\subsection{Conversion issues}

\subsubsection{Loss of model geometry}

Although the original IFC file could be converted to a COBie spreadsheet (XLS format) and then converted back to an IFC file, it should be noted that the actual geometry of the building is lost in the process. The following screenshots provide an example of how the geometry is affected by the conversion. The first image shows that the MEP systems geometry is fully recognizable when the IFC file is opened directly after exporting from Revit. However, once the IFC file is converted to a COBie spreadsheet and back to an IFC format model file, the geometry is no longer recognizable as building systems and elements. This result is expectable, however, as the COBie spreadsheet is not designed to record geometry. 


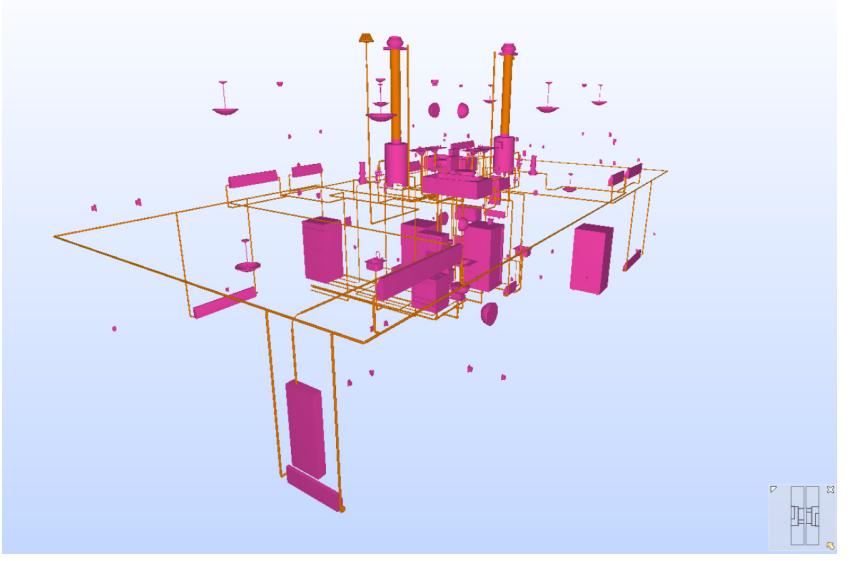

Figure 7-4. IFC MEP model in Solibri after export from Revit.

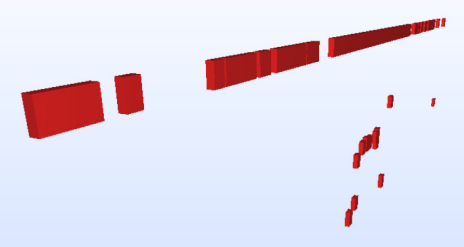

Figure 7-5. IFC MEP model after BIM Services conversion from COBIE to IFC.

The model data is maintained, but not the physical characteristics of the system components. As a result, the data contained in the file can be checked, but no visual analysis is currently possible utilizing this workflow.

\subsubsection{BIM Services}

During the conversion of the updated COBie spreadsheet, the BIM Services tool did not create an IFC model file on the first attempt when tested. Only after shutting down BIM Services and restarting ( $2-3$ times typical) did it create an IFC file.

\subsection{Conclusion}

Updating IFC files to include sustainable property information for further analysis can be accomplished through this conversion process. This pro- 
cess allows other project team members without BIM authoring software to use and supplement the information contained in the original model for analysis in other programs. It should be noted that the final converted IFC model geometry is longer recognizable in the analysis software or in Revit 2011, the originating software. 


\section{Appendix A: Proceedings of the ERDC-CERL Sustainability Product Properties Workshop}

\section{Workshop Purpose and Objectives}

A meeting of US and international sustainability experts was convened on July 13, 2011, to present Army sustainability policy goals and identify how existing national and international technical standards could be organized to support the delivery of required specification and performance information through the use of Building Information Model (BIM) information exchanges. Fifteen people attended the meeting in-person and 13 attended using Internet access. Then agenda of the meeting is reproduced below.

\section{:Primera}

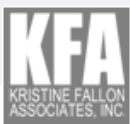

ERDC-CERL Sustainability Product Properties Workshop

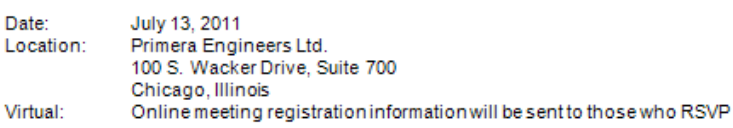

\begin{tabular}{|c|c|}
\hline 9:15 AM-10:00AM & Continental breskfast and check-in \\
\hline 10:00 AM-10:15 AM & $\begin{array}{l}\text { Kristine Fallon - Welcome. Introduction of CERL, KFA and Primers } \\
\text { participants. Agends review. }\end{array}$ \\
\hline 10:15 AM-10:30 AM & Otherparticipsnts introduce selves and organizations \\
\hline 10:30 AM-11:00 AM & Bill Esst-Background on LCM and SPie \\
\hline 11:00 AM-11:15 AM & $\begin{array}{l}\text { Mark Kalin-Vision of specifying vis the model: how that works for the } \\
\text { design team (including specifier) and how that works fordownstream } \\
\text { users of the dats. }\end{array}$ \\
\hline 11:15 AM-11:45 AM & $\begin{array}{l}\text { Lourdes Gonzalez, Primerg- Ovenview of Army Sustain a bility Policy. } \\
\text { Discussion on similgrities with other agencies. }\end{array}$ \\
\hline 11:45 AM-12:15 PM & Holly Genc, Primerg- Gap Anslysis \\
\hline 12:15 PM-12:30 PM & $\begin{array}{l}\text { Vladimir Bazjansc-Implementation of building performance anglysis } \\
\text { simulation }\end{array}$ \\
\hline 12:30 PM-1:15 PM & Box lunches and conversation \\
\hline 1:15 PM- 1:30 PM & Paul Bertram-EPDs \\
\hline 1:30 PM- 1:45 PM & John Kennedy-gbXML coversge \\
\hline 1:45 PM-2:30 PM & $\begin{array}{l}\text { Kristine Fallon \& Robert Feldman- Sustsins bility Product Properties } \\
\text { Project Discussion }\end{array}$ \\
\hline $2: 30 \mathrm{PM}-2: 45 \mathrm{PM}$ & Break \\
\hline 2:45 PM-3:00 PM & Arol Wolford-Why manufacturers should get involved \\
\hline 3:00 PM-3:30 PM & Formation of working groups \\
\hline 3:30 PM- 4:00 PM & Next steps and adjoumment \\
\hline
\end{tabular}

Presentations and summary discussions from this workshop will be published as a chapter in an ERDC-CERL Technical Report. 
The objective of this meeting was to establish a national panel of coordinating experts for the definition of open source building information exchange standards. The desired workshop outcomes were to (1) demonstrate need for computable product properties for sustainability analyses, (2) identify prior/ current work to build upon and (3) form working groups to define open source sustainability product properties specifications for architectural, mechanical, electrical and water systems.

\section{Opening Remarks and Introductions}

Ms. Fallon welcomed the in-person and virtual attendees to the workshop. She then stated the project objective:

The objective of this project is to develop, document and create examples of a proposed model for the specification, delivery and measurement of sustainability information on US Army building projects. Three project types will be evaluated: officer apartment housing, headquarters offices and clinics.

This workshop was the first of two scheduled meetings. The desired outcomes of day were to:

- Demonstrate need for computable product properties for sustainability analyses

- Identify prior/ current work to build upon

- Form working groups to define open source sustainability product properties specifications for architectural, mechanical, electrical, and water systems.

Fallon then introduced the project team members, all of whom attended in-person. The team consisted of members from ERDC-CERL, Primera Engineers, and Kristine Fallon Associates. In addition to the professional background information provided next, a complete list of participants and affiliations is reproduced below. 
Alphabetical list of workshop participants.

\begin{tabular}{|c|c|c|c|}
\hline Last Name & First & Organization & Attendance \\
\hline Akinci & Burcu & Carnegie Mellon University & virtual \\
\hline Bazjanac & Vladimir & Lawrence Berkeley National Laboratory & in person \\
\hline Bertram & Paul & $\begin{array}{l}\text { Director for Environment and Sustainability for Kingspan } \\
\text { Insulated Panels, CSI Pres-Elect, LEED M and R TAG } \\
\text { member }\end{array}$ & in person \\
\hline Brett & Marty & Wheatland Tube Company, NEMA & virtual \\
\hline Brodt & Bill & NASA & virtual \\
\hline Brown & Christopher & NIST & virtual \\
\hline Budrose & Wesley & Sphere E, Director of Information Technology & in person \\
\hline East & Bill & ERDC-CERL & in person \\
\hline Fallon & Kristine & Kristine Fallon Associates, Inc. & in person \\
\hline Feldman & Robert & Kristine Fallon Associates, Inc. & in person \\
\hline Genc & Holly & Primera Engineers, Ltd. & in person \\
\hline Gonzalez & Lourdes & Primera Engineers, Ltd. & in person \\
\hline Greenberger & Julia & Kristine Fallon Associates, Inc. & in person \\
\hline Greenfield & Josh & Primera Engineers, Ltd. & in person \\
\hline Hitchcock & Rob & Hitchcock Consulting, ASHRAE & virtual \\
\hline Johnson & Mark & Kristine Fallon Associates, Inc. & in person \\
\hline Kalin & Mark & Kalin Associates Inc., AIA, CSI & virtual \\
\hline Kennedy & John & Autodesk, Green Building Studio & virtual \\
\hline Kershaw & Dean & L-3 Stratis & virtual \\
\hline Kiff & Liana & Honeywell & virtual \\
\hline McKay & David & ERDC-CERL & in person \\
\hline Napier & Thomas & ERDC-CERL & in person \\
\hline Nisbet & Nick & AEC3 Itd. & virtual \\
\hline Palmer & Mark & NIST & virtual \\
\hline Skender & Chris & Kristine Fallon Associates, Inc. & in person \\
\hline Smith & Deke & DKS Information Consulting, LLC & virtual \\
\hline Stumpf & Annette & ERDC-CERL & virtual \\
\hline Wolford & Arol & Smart BIM & in person \\
\hline
\end{tabular}

\section{ERDC-CERL Particpants}

Team members from ERDC-CERL included Dr. Bill East and Mr. David T. McKay.

Dr. East is a Senior Research Civil Engineer at the US Army Corps of Engineers, Engineer Research and Development Center, Champaign, Illinois. Dr. East has been instrumental in the creation, development, and deployment of secure government-to-business process collaboration tools in the United States public-sector capital facilities industry. Having standardized 
essential government-to-business process, Dr. East's current efforts are aimed at transforming the content of those processes from paper and $e$ paper documents to useful building information. To support this effort Dr. East is also the buildingSMART Alliance project coordinator, where his COBie (Construction-Operations Building Information Exchange) project provides open Building Information Modeling data in lieu of the wasteful paper construction handover documents that are currently required by contract. The SPie (Specifiers' Properties information exchange) project is creating open building information from building product manufacturers to streamline the design, procurement, installation, and operations of building products and equipment. In recognition of these efforts Dr. East has received awards from the National Institute of Building Sciences and the Construction Specifications Institute.

Dr. East is an active member of American Society of Civil Engineers and the International Council for Research and Innovation in Building and Construction, also known as CIB. Through CIB, Dr. East and his colleagues are leading efforts to accelerate research based on open building information through the development of common test beds and repeatable verification and validation protocols. Dr. East is Fellow, American Society of Civil Engineers.

Mr. McKay is the Contracting Officer Technical Representative for Dr. East's projects.

\section{Primera Engineers, Ltd., Participants}

Ms. Lourdes Gonzalez, Ms. Holly Genc, and Mr. J osh Greenfield represented Primera at the workshop.

Ms. Gonzalez, AIA, LEED AP, is Senior Vice President at Primera Engineers. With over 25 years' experience in the building industry, Ms. Gonzalez is a Licensed Architect and, as the firm's Director of Sustainability, she managed the firm's Sustainability, Architecture and Construction Management Group for the last ten years.

Ms. Gonzalez has played an instrumental role in Primera's growth over the past decade. She leads the firm's sustainability efforts and helped position Primera as an innovator in the green building movement. Her entrepreneurial spirit is also helping Primera gain an international presence, as the Project Manager for two high-profile high rise projects in Mexico City. She 
has a Bachelor of Science in Architectural Studies and a Master of Architecture, with a Historic Preservation specialty, from the University of Illinois at Urbana-Champaign. Ms. Gonzalez is also a graduate of the 2010 Hispanic Alliance for Career Enhancement (HACE) Mujeres de HACE program which empowers high-potential Latinas to succeed professionally and thrive personally by providing insight, access and professional development.

Ms. Genc, AIA, LEED AP, is a Senior Associate at Primera Engineers. With over 14 years of experience in design, production of construction documents and construction administration, she is a project manager, managing communications with clients, consultants and contractors. Her projects include a wide variety of types including institutional, commercial, higher education, exterior façade renovation and residential. Ms. Genc has experience with projects in both the public and private sectors. She is one of the lead reviewers for the City of Chicago's Green Permit Program.

Mr. Greenfield is a professional Mechanical Engineer, LEED Accredited Professional and ASHRAE Certified Building Energy Modeling Professional with 10 years of experience highlighted by extensive energy consulting and design experience both as the project LEED consultant and Energy Modeler, as well as serving as the mechanical engineer on several LEED design projects. He is involved on multiple sustainable consulting projects in various markets from the private and public sectors following all current LEED Green Building Rating Systems including the LEED-2009 Rating Systems. His expertise and knowledge of the LEED principles and rating system have also been utilized by General Contractors who require LEED consulting services throughout the construction phase of projects. Mr. Greenfield specializes in Energy Model creation following ASHRAE 90.1 Guidelines as well as Integrated Design Phase Energy Modeling to aide in the selection of architectural envelope properties and mechanical system efficiencies. His knowledge of Energy Modeling is also utilized as a reviewer of City of Chicago Department of Buildings Green Permit Program project Energy Models.

\section{Kristine Fallon Associates, Inc. (KFA), Participants}

Ms. Kristine Fallon, Ms. J ulia Greenberger, Dr. Robert Feldman, Mr. Mark J ohnson and Mr. Christopher Skender represented KFA. 
Ms. Kristine Fallon has worked on open data standards initiatives in the AEC industry since the 1980's. She first worked with Dr. East when he served on the Advisory panel for a NIST project: the General Buildings Information Handover Guide: Principles, Methodology and Case Studies.

Fallon completed a 5-year term on the AIA's national Technology in Architectural Practice Advisory Group in 2008. She is currently serving on the buildingSMART Alliance Board and working on the National BIM Standard. She has advised major owners, including GSA and the National Institutes of Health on BIM strategy and implementation.

Ms. J ulia Greenberger is the KFA intern for this project. She will be a senior this fall at Washington University in St. Louis, studying systems engineering and mathematics.

Dr. Robert Feldman, Ph.D., is KFA's developer and open source expert. He assisted the Art Institute of Chicago in developing an open source repository for digital design data. He has worked on IFC, ifcXML and COBie projects, including another project for Dr. East. He has written API extensions for Autodesk products such as Revit and NavisWorks. He will be working on the sustainability properties templates.

Mr. MarkJ ohnson and Mr. Chris Skender are KFA's BIM experts. They are currently working on another project for Dr. East- Experimental BIMs - and will be working with Dr. Feldman on the technical implementation of the sustainability templates.

\section{Other Participants}

Dr. Vladimir Bazjanac is the building software interoperability team leader in the Building Technologies Department, Lawrence Berkeley National Laboratory at the University of California. He is also a consulting professor in environmental engineering at Stanford University and leader of the buildingSMART International Technical Advisory Group. He has experience in architectural design, building construction, computer science, and computer simulation.

Mr. Paul Bertram is Director of Environment and Sustainability for Kingspan Insulated Panels and President of the Construction Specifications Institute (CSI). He has been involved with the buildingSMART IFD library, ASHRAE 90.1, and LEED. 
Mr. Martin Brett works at Wheatland Tube Company and is a member of the National Electrical Manufacturers Association (NEMA).

Mr. Bill Brodt works with NASA. He was a co-sponsor of COBie and currently sits in on a work group led by GSA and EPA to develop sustainability standards for products procured by federal agencies. They have identified 600 existing sustainability labels and intend to cover building industry products in that effort.

Mr. Chris Brown represents National Institute of Standards and Technology (NIST).

Mr. Wesley Budrose is the Director of Information Technology at Sphere E LLC, a company partnering with Onuma Inc to integrate product performance data into BIM software.

Mr. Rob Hitchcock is an independent consultant with a background in Building Information Modeling and energy daylighting simulation. He is currently leading an HVAC modeling project under Bill East's LCM umbrella.

Mr. Mark Kalin is the president of Kalin Associates. He has worked on SPie property sets with Dr. East and is currently national chair of CSI Sustainable Facilities Practice Group. His firm prepares specifications for many designers and has worked on 180 LEED products. He is involved with AIA and building product manufacturers' reactions to various certification systems.

Mr. J ohn Kennedy is a Senior Manager of the Building Performance Analysis products at Autodesk. He is also on the gbXML advisory board.

Mr. Dean Kershaw is from L-3 Communications, STRATIS division. His organization is a defense contractor and works in IT, but has legacy architect engineer services. His team built PACES (Parametric Automated Cost Engineering Software) and today works with the BIM community.

Ms. Liana Kiff is a research scientist at Automation and Control Solutions (ACS) Labs at Honeywell. 
Mr. Thomas Napier works at ERDC-CERL with Dr. East, Mr. McKay, and Ms. Stumpf.

Mr. Nick Nisbet is with AEC3 UK, an international consulting firm based in the United Kingdom, has worked with Dr. East on implementations of BIM and COBie and has done work in the UK on sustainability, including BREEAM and Ecopoints.

Mr. Mark Palmer represents the National Institute of Standards and Technology (NIST).

Ms. Annette Stumpf works at ERDC-CERL with Dr. East, Mr. McKay, and Mr. Napier. She is an expert on sustainable design.

Mr. Arol Wolford is President and CEO of SmartBIM and is a pioneer and passionate advocate of building intelligence. He has devoted his career to the proposition that sharing information among owners, architects, contractors, and manufacturers is the key to creating better and more efficient buildings.

\section{Overview of Life-Cycle Model Project (LCM) and SPie - Bill East}

The following is a lightly edited transcript of Dr. East's presentation.

There are two topics for me to talk about today. The first is the Life Cycle Model for Mission Ready, Sustainable Facilities. That's the long name of this Army R and D project. To unpack that a little bit, Nick [Nisbet] and I and other colleagues have been working on a life cycle model for mission readiness for some time. That has been published in the LCie project that's part of the buildingSMART alliance. It indentifies the requirements for data exchange in the building, starting at the beginning of the project and going through all the way to the end. In the US we would consider that the recycling stage. In the UK they would consider recycling to be stage 1 . Depending on where your circle starts, it's a circle.

Today we're focused on the sustainability end of it. I think I'd like to take a side bar for a minute and talk about the long view. In my career with the Army Corps there have been three movements that have forced a major change in thinking in the way buildings have been done-Americans with Disabilities Act, Forest Protection, and now people are engaged in sustainability. Each one of these requirements brought new emphasis that people 
had to chase down to solve. In looking at sustainability and thinking about do we want to have yet another set of data requirements? Isn't there a fundamental approach to building control? That led me to thinking about control cycles. The basic idea of the Life Cycle Model project is to understand what the requirements are and capture information as we go though the building process. By capturing that we identify the specific properties necessary for components, assemblies and connections. Then we can use sensor systems we have in place to give us feedback about the actual performance and validate the information that we needed back at the beginning.

In the Mission area, just to give you an example, the thing we're focused on quite a bit is requirements for things like standard room data sheets. Everybody knows big owners have these criteria documents and then during the architectural programming phase these room data sheets are expressed and then subsequently lost forever. The idea is we want to have information available to us so when we have to take our hospital that has been running for 50 years and transform doctors' offices back into labs, we know that these offices were actually labs and the piping is still behind the walls. So that's one of the ideas.

The area of resource utilization is where I think about sustainability. If you take a building, like an Air Force radar station up in Alaska, and say it uses more power than any other building in the Department of Defense, it doesn't really matter because if you shut off the power, you no longer have a radar station. Right now people can find out who uses the most power and cut them, but not identify what the actual requirements are and then evaluate the actual performance. At that point you can identify the delta between what you need to run your building and what is wasteful or could be reduced. This idea of a control cycle is pretty important.

Coming back now to sustainability, there are lots of different approaches. It's interesting the approaches I didn't know going into this, and I think Tom [Napier] and Annette [Stumpf] knew that there were 7 different rating schemes, at least. Think about it: which should the Army use? It seemed to me the first thing to do was actually find out which of these has meaningful information that can be put in a control cycle because simply counting bike racks is not the right approach, although there's always a dynamic tension between the soup du jour and the actual meal you want to eat. 
If we're able to define the criteria then we can certainly enforce the delivery. In terms of the enforcement of the delivery of information, we're talking about product properties. This is something manufacturers need to provide - architects should not have to type them in. It's not something contractors or commissioning agents should have to type. The manufacturers create the products and they're responsible for that information. I think the life cycle model that's already been created has the capability of adding these properties if everyone can decide what they are. There's going to be different properties for different kinds of products, which is what led Mark [Palmer], Nick, and I to talk about the sustainability project to begin with. When we're selecting equipment, we need to know the criteria to be used. The outcome of identification of product type templates can end up being a national standard through the buildingSMART alliance and the National BIM Standard.

Let me tell you a little bit about SPie. Part of delivery of a set of assets in the building is information about equipment. When I first started thinking about this building information modeling area, people said, 'It's never going to work until manufacturers start providing their data.' I heard that loud and clear and Mark and I had a conversation 4 - 5 years ago that led to the Specifiers Properties information exchange. There are lots of different properties people might be interested in: specifiers have different properties, operators have certain properties. Fan hole placements are very important for facility operators, not so much for designers. Different properties need different specifications. Specifiers' properties are related to those that allow the product to be purchased. There's motivation there for manufacturers to participate because it helps them sell the products. It also helps them sell back into the building as opposed to what happens now, which is the building is bought by the contractor and forever after those same manufacturers' products have to be purchased. This is particularly the case with control systems, so I'm glad to see Liana [Kiff] here from Honeywell.

The goal of the SPie project and projects related to it, one of which might become the sustainability properties information exchange, is to produce templates to provide a set of specification requirements. After that manufacturers can provide any differentiating properties they wish. A minimum agreed set plus a differentiating set of properties. These will be expressed through Industry Foundation Class model, so we can ensure open access 
to this information regardless of what computers we're using 20 years from now.

IFC is the basis, but then there's also an easier-for-humans-to-read version of that, which is COBie. It looks like a spreadsheet. It's about the information content that's inside the spreadsheet. The spreadsheet is just one artifact that can be used to express this. It's a particularly handy format for humans to digest.

The idea is to create the templates. Where do the templates come from? The first set of templates, which are released in the Whole Building Design Guide, were created by Mark Kalin. The next version of these were developed by Nick Nisbet. He extracted all of the properties that came out of IFC for each of the different types of product and also added properties Mark had in the cases where they were different. Now we're taking Nick's templates as much more robust templates for a much wider range of products. We're taking them to manufacturers like General Electric and Leviton on the electrical side. We're taking them to HVAC software companiesEast Coast, TSI. And we're also taking them to other manufacturers. Nick Nisbet is under contract to the National Institute of Building Sciences to help facilitate that communication and those templates.

This product guide is going to have its next release following an August project meeting. By November, we'll have Product Guide Version 2 available and that will have IFC Step files, ifcXML files, and several manufacturers' examples. That's going to lead to demonstrations in December at Ecobuild, then at the NIBS annual convention in J anuary. We're going to be demonstrating the use of this on the electrical side, as well as the HVAC side.

I think that gives a summary of the overall Army R and D project as well as the specific SPie project.

\section{Workshop presentations}

The workshop continued with presentations summarized below. Workshop participants Mark Kalin, Vladimir Bazjanac, Paul Bertram, J ohn Kennedy, and Arol Wolford spoke about sustainability properties from their points of view. Lourdes Gonzalez, Holly Genc, and J osh Greenfield, all from Primera, summarized their research documented in Chapters 1 
and 2 of this Technical Report. PowerPoint slides from the presentations are included in Annex A.

\section{BIM, Specs and Sustainability - Mark Kalin}

As the president of Kalin Associates Inc., an architectural specification consulting firm, Mr. Kalin gave a specifier's view on the importance of incorporating sustainability properties into building information modeling. Fortunately, many firms are transitioning to the use of BIM software, which allows all contributors to a building's design and construction to access information downstream. The ability to access specifier's property sets downstream using BIM is very valuable.

One of the difficulties with property sets is that each user is often interested only in certain properties. Mr. Kalin gave an example of this problem using the Air Barrier Association of America (ABAA) process of evaluating membrane performance. The ABAA cares about ozone resistance and elongation as key property sets that determine if that membrane will perform. They are not concerned with regional materials or recycled content. National CAD Standard, MasterFormat, UniFormat, GreenFormat, and others all define property sets.

Specifiers roles are changing from writing text to creating BIM models and becoming more involved in the design phase. In the future, BIM and specifications will become more integrated. Software is being developed for BIM-generated specifications, allowing users to link drawings and specs. The problem with BIM-generated specifications is that specifiers, like Mr. Kalin, do full specifications in the design development phase, but the drawings are far from complete at that point in the process. According to Mr. Kalin, spec-constrained BIM models are a great opportunity for the future.

Mr. Kalin compared a CSI-format spec and a BIMspec, showing the BIMspec contains more detailed and valuable information, including LEED credit contributions.

In the discussion following Mr. Kalin's presentation, Mr. Napier mentioned the book Construction Materials Evaluation and Selection: A Systematic Approach by Harold J . Rosen and Philip M. Bennett. Although the book was written over 25 years ago, the premise of the book is that, as opposed to taking manufacturer literature supplied by manufacturing repre- 
sentatives (which is written to inform designers about what the manufacturers want them to know), the specifiers reverse that process and establish what they need to know about a product in order to use it with confidence and then require that information be provided by the vendors or manufacturers. The group agreed that this was precisely the goal of property sets.

Some participants expressed concern that manufacturers would not make their product information readily available, but Mr. Wolford and Mr. Kalin were confident that manufacturers would not refuse to provide that information. By creating sustainability product property templates, manufacturers could provide information (now in databases) in a computable form to architects and specifiers.

\section{Overview of Army Sustainability Policy - Lourdes Gonzalez, Primera}

Lourdes Gonzalez gave an overview of Army sustainability policy including policy history and current mandates. This research is documented in Chapter 1 of this Technical Report.

\section{Gap Analysis - Holly Genc and Josh Greenfield, Primera}

Holly Genc and J osh Greenfield shared their results of a gap analysis of green rating systems and compliance tools. This analysis is documented in Chapter 3 of this Technical Report.

\section{Using Building Energy Performance (BEP) Simulation in AECOO Industry - Vladimir Bazjanac}

Dr. Bazjanac's first point was that good simulation software does not necessarily create accurate models. The simulation must have the correct, valid data as input. After the simulation has run, the user must have the knowledge and experience to make justified design decisions based on the simulation results. Even with valid data and an experienced user, simulation software can not yet model the performance of innovative building systems. His team at LBNL is trying to remedy this problem by developing software that is able to model innovative systems.

The information and BIM models provided by the architects and mechanical engineers contain information that is too complex for Building Energy Performance (BEP) simulation. The data must be simplified to be used as 
an input in EnergyPlus and other BEP software. There is currently software that simplifies the building geometry from the architect as needed by EnergyPlus using rules given by the software designer. Dr. Bazjanac's team is working on Project Mojito, which will transform data from the HVAC design into a simplified format for use in EnergyPlus.

Dr. Bazjanac showed the rules embedded in the GST/IDF generator to transform and simplify the building geometry. The transformation uses sets of rules in an attempt to automate as much of the information exchange between the BIM model and the analysis program as possible. These rules include actions such as skipping of internal wall objects when those walls are entirely contained within the same thermal zone, recognition of exterior building shade types, identification of floor and ceiling surfaces of a slab and adjustment of window area to effective glass area.

The Mojito platform, SimModel, allows the use of data that comes from different data models such as IFC, gbXML, IDD, and OpenStudio. Project Mojito's interoperability makes it an important tool for the future of BEP simulation.

\section{Life-cycle Assessment (LCA), Product Category Rules (PCRs), Environmental Product Declarations (EPDs) - Paul Bertram}

Mr. Bertram is the Director of Environment and Sustainability for Kingspan Insulated Panels and president of the Construction Specifications Institute (CSI) and he has been involved with the buildingSMART IFD library, ASHRAE 90.1, and LEED. Mr. Bertram began by stating lifecycle assessment (LCA), product category rules (PCR), and environmental product declarations (EPD) are all inter-related and must be used together. The PCR specify common goals and relevant rules for the product category LCA. They also contain requirements for reporting and producing the data required for the EPD. The EPD is how the LCA information is reported.

Mr. Bertram then explained the methodology and impact categories of lifecycle impact assessment. LCA includes impact categories from the Tool for the Reduction and Assessment of Chemical and Other Environmental Impacts (TRACI), such as global warming, acidification, ozone depletion, and smog creation. Other impact categories, including energy demand of fossil energy resources and resources consumption, are derived from the Intergovernmental Panel on Climate Change (IPCC). 
A client must collaborate with a program operator (e.g., UL Environment) to develop an EPD. The client receives an EPD template based on PCR from the program operator. Once the EPD template is completed with LCA information, the program operator designs a final EPD and certifies the client has an approved EPD. The program operator is responsible for the administration of the EPD. There are very few PCRs and EPDs registered in the US currently. Ultimately, just because a product has an EPD does not necessarily make that product more green.

\section{Green Building XML (gbXML): The Open XML Schema for Sustainable Design - John Kennedy}

Mr. Kennedy is Senior Manager of the Building Performance Analysis Products at Autodesk and serves on the gbXML advisory board. He explained that gbXML was designed to support data exchange between 3D$\mathrm{CAD}$ and green analysis applications and is a non-proprietary open data standard maintained by an advisory board of industry members, comprised of mostly software companies. The goal of gbXML is to assist in sustainable building analyses by minimizing the need for human interpretation of data. gbXML is used in a variety of sustainable building analyses including whole building energy use and costs, carbon emissions, and water use. gbXML has more data capabilities than any other open format because it is designed for data flows among 3D-CAM, BIM, and building performance analysis tools. It is the most widely adopted interoperability format for building energy performance analysis. The next update of gbXML will include a tighter mapping to COMNET (Commercial Energy Services Network) descriptors.

Mr. Kennedy continued with some examples of that data can be encapsulated in the gbXML schema. For example, gbXML can store energy and photometry data for lighting fixtures. Performance data for HVAC includes energy, design temps, capacity information, and part-load data.

\section{Manufacturer Involvement - Arol Wolford}

The following is a lightly edited transcript of Arol Wolford's presentation.

I'm so excited about what this group is doing. I think it's really relevant to the building product manufacturers. I've had the opportunity to work for and serve building product manufacturers for the last 30 years. My wife and I got out of college in the late "70s and set up this quantity survey 
company for building product manufacturers that my Dad had started in 1957. I'm focused on this concept of quantity survey.

We were working with building product manufacturers and their representatives. One of the things one has to understand with the building product manufacturers -- why it's hard for you to connect with them--is because often times they are in these subgroups and they actually see themselves more as a general manufacturer, rather than a lighting manufacturer. The making is very important to them. To further separate them from the industry, $80 \%$ of them work through independent manufacturer representatives. You'll have 40 major metropolitan areas and the manufacturers work through these independent representatives. Those folks have the architecture degrees, the engineering degrees, and they represent the manufacturers. There are about 10,000 building product manufacturers in the US, with 3,000 active manufacturers. If one looked at BIM, at Revit, how many of those building product manufacturers have stepped up and made objects and Revit families? One would see that there are about 400 of them that have stepped up, but of these, only 100 - 125 have made a substantial investment in creating the objects. Most of the manufacturers may have a product line of 100 families, but they have only made 3 or 4 Revit families, not a big commitment yet. . They're dipping their toes in the water. There are about 125 - 150 manufacturers who have made the commitment to do 25 - 30\% of their product line. They know about building information modeling now, but they have not made the investment. They're sitting on the sideline.

This group has an opportunity with the definitions they've created and a backing from a large owner like the Army to have a really strong impact. For all of us, we realize how important sustainability is to our world. I found out $5-6$ years ago that $48 \%$ of energy was being used by buildings and $42 \%$ of the $\mathrm{CO}_{2}$ emissions were coming from buildings. At that time I had the opportunity to be on this AIA 150 group. We did a survey of the architects and asked them, Who is the culprit? Are buildings a culprit in $\mathrm{CO}_{2}$ emissions?' Only $7 \%$ of them got it right and said, 'Yes, we are.' $40 \%$ said cars, $18 \%$ said natural causes. This was 6 years ago. The good news is the young folks coming in want to become architects to do something about sustainability and want to create smart buildings that not only have beauty and performance, but also sustainability. We're unified in that. The building product manufacturers know that's important but they don't know how to implement it. They are getting hit from so many sides that 
they don't know how to connect and share their information. I think they're willing to share their information. There are some secret sauces and things they may not share, but on the whole, $90 \%$ of what we need to get filled out from the building product manufacturers, they would readily share if they knew how to do it and why it needs to be done. I believe this group can have a strong impact.

I had this company in the '80s called Construction Market Data that reported on construction all over the US, then went to Europe and Asia, and grew and had 1,500 people working with us. As we set up these 85 plan rooms, as we queried the different projects, we were shocked how much money is being spent counting and measuring things. If you took designbid-build in the US, about $\$ 300$ billion right now, $\$ 30$ billion is being spent counting and measuring things. $\$ 20$ billion is being paid to all the architects, mechanical engineers, and structural engineers for doing design; they have $\$ 30$ billion counting and measuring things.

I was giving a little speech at Harvard to architectural students and a guy came up to me and he said, 'Hi, my name is Leonid. I have some software that's going to fix that problem. Would you be willing to invest in my company? We've got a lot of software people, but we need some practical people and I like that quantity survey idea.' Leonid had started this company Revit. I was enamored. I had worked with Autodesk throughout the '90s and we were contacting building product manufacturers to do CAD details. And I actually started this company called Buzzsaw with Autodesk. They owned $40 \%$ and we owned $40 \%$ and this was in the 2000s. I thought we were going to do the quantity surveys, but we got diverted and weren't able to do that. Then I met Leonid from Revit and he said, 'Arol, it's critical that the building product manufacturers cooperate or we are not going to be able to actualize the power of BIM.' Autodesk came in and then bought the company from us and I think have done a wonderful job. There was some criticism at first because this was a company doing less than $\$ 1$ million revenue, yet it got $\$ 133$ million paid for it. That tells me that was powerful software that Leonid created with his team. Autodesk invested heavily and have this great product Revit. It's not the end-all and there are flaws. It's a powerful building information modeling system. Even with that, when they bought Revit, Carl Bass said, 'Arol, we need building product manufacturers filling this out. Unless building product manufacturers share the data, use that for the families, this BIM isn't going to work up to its full capability.' 
There are about 10,000 building product manufacturers, with 3,000 strong players, and only 150 of those building product manufacturers have put their product line up on our site, SmartBIM or the Autodesk Seek site. I think you can get some of the software people, like Google SketchUp, like Revit, to back what you're doing as well because we all need the building product manufacturers to step up. If they do, we'll get quantity survey. Construction is a big industry, $\$ 3.5$ billion, about $10 \%$ of the worlds GDP. Usually within these projects, $35 \%$ of that is going to the building product manufacturers. They have pretty deep pockets-not the architects and design folks. Manufacturers would save a lot of money if they had their objects up and things were being automatically counted for them. If you have the objects with the appropriate properties being built in, I think a lot of the properties you want we're already gathering to make the Revit families. More manufacturers need to share data that we all need here.

There's the noble side to this too. If you have a quantity survey connected to a costing company, what is the green impact? We have free software called ecoSorecard. Architects and engineers use it to calculate for the materials of the five leading groups. Again, we have to go to building product manufacturers and to find out the green properties. What you're doing is very consistent with what needs to be done for BIM and for green BIM. We need the green properties in the families. We need the properties themselves from more building product manufacturers. 150 building product manufacturers probably doesn't sound like very much, but I know we have done over 100 ourselves. If you have a cross section of building product manufacturers, you actually get a good insight into the data. If it were air conditioning, you don't need all 4 manufacturers to have properties. They all have crossover sheets between one another. You just have to get one manufacturer per main category. It's good to have all of them, but if you get representation in all of the categories, you get valuable information. Once one has signed up, you probably have good leverage with the others as well. There can be a strong systematic approach to getting information from the building product manufacturers where they win, green wins, you all win too.

In the question and answer session after Mr. Wolford's presentation, Mark Kalin agreed that if there's an industry leader in each manufacturing category, those sustainability product property rules will become self apparent. He suggested a book by Robert Weygant called BIM Development as a 
source of more information on this topic. GSA gave the book a good review.

Dr. East proposed that Wolford join his team, along with buildingSMART and CSI, to broaden their SPie project to get manufacturers involved. Wolford was very willing to contribute to SPie.

\section{Sustainability Product Properties Discussion}

Kristine Fallon led two discussion sessions during the afternoon portion of the workshop. The group first discussed the validity of project assumptions. Robert Feldman then spoke about other efforts to define sustainability properties, specifically gbXML and an IFC Energy Analysis MVD. Participants asked questions and gave their opinions on the two models.

The goal in the second group discussion was to form working groups for architectural finish elements, mechanical equipment, electrical equipment, and water systems.

\section{General Project Discussion}

Fallon began the discussion by encouraging the participants to talk about the future of the project and its ultimate goals. She used the list of desired outcomes of the workshop to guide the discussion. The group generally agreed that there was a demonstrated need for computable product properties for sustainable analyses. Fallon continued that at the end of the workshop participants would form working groups to define open source sustainability product properties specifications for architectural, mechanical, electrical and water systems.

Before continuing the discussion, Fallon looked to the group to gather consensus on the validity of the project assumptions. The first project assumption was that indentifying the sustainability properties necessary to select and analyze various building products and materials would be useful to the industry. Tom Napier added that in order to focus the project, we need to define the user of these properties in order to determine the specific properties needed for analysis. Ms. Fallon and Dr. East suggested a backwards approach to this project where you first define the Army sustainability goals, then determine how to assess these goals, what data you need to assess the goals, and how to get this data. The group also agreed that the goal of the project is to make sustainability assessment and analy- 
sis directly computable from a building model and that there have been efforts to define necessary/ desired sustainability properties, but for the most part, these have not been in a computable form.

Fallon then stressed the importance of a common conceptual framework, using the IFC model (buildingSMART model) as an information model and SPie as a model for standard attribute templates. The SPie template starts with the IFC model to understand objects, properties, subtypes, and so forth. Standard nomenclature and classification in SPie are very important and are derived from MasterFormat, UniFormat, and OmniClass. SPie data comes from manufacturers, manufacturers associations, and practice.

Dr. Feldman continued with a presentation on gbXML and IFC Energy Analysis Model View (MVD), which have demonstrated computable sustainability properties efforts. gbXML was designed for interoperability between building design models and a variety of engineering analysis tools and is now widely used in design and analysis programs. gbXML contains extensive properties (e.g., recycled content, cost, indoor air quality) for many systems and materials, but only the major MEP equipment elements have age and life attributes needed for life-cycle analysis. These attributes need to be extended to all materials in order to do thorough sustainability analyses using gbXML.

Dr. Feldman also described the BSA-002 Concept Design to Building Performance Energy Analysis Concept Model. It is one of the few models that included mechanical, electrical, and plumbing systems, as well as the basic building geometry and architectural systems. Unfortunately more information about this MVD was not readily available, but Dr. Bazjanac was able to give more insight into MVDs.

According to Bazjanac, the idea behind MVDs is they identify a particular discipline, practice, organization, or individual view of something in the building industry that is defined in the IFC general model. The IFC model is so large that no one single application can possibly implement every single entity defined in the IFC data model. You must create subsets of the IFC data model to be implemented. With MVDs, anyone who wants to be compliant with a particular view of the IFC data model would have to implement the entire subset to be certified. The end result is to be certified that they comply with that MVD. 
Fallon added that the MVD defines a domain of discourse and defines specific mappings to the IFC data elements, which is very important for computability.

J ohn Kennedy asked the group why IFCs were the primary format for the project, rather than gbXML. He noted that while gbXML may lack some age and life characteristics on some elements, it is widely used in the commercial market today. Dr. East responded that the project's purpose is to focus on information requirements, not the format. The project's format is IFC because that is the format of building information models; transferring IFC data to a COBie spreadsheet or a gbXML file is fairly trivial once you have the information. The group first must specify the information required for sustainability product property templates, but must also ensure the templates are available to all people that need them, not just energy modeling tools.

Mark Kalin suggested the project team add 'exterior enclosures' to the list of product categories. He proposed roofing, cladding, windows/ doors, and foundations as possible subcategories. Kennedy added shading elements to the list of subcategories. Dr. East and Fallon liked the suggestions and announced they would take them consideration as the project progresses.

\section{Formation of Working Groups}

Ms. Fallon began the session by outlining the process and goals of forming working groups for each category of products. The plan was to establish small groups of select participants and interested parties for architectural, mechanical, electrical, and plumbing systems. The group will facilitate 2 3 teleconferences and then identify at least three product types in each subcategory (e.g., for architectural elements, three types of doors, three types of windows, and so forth). For each product type, the group will propose a minimum set of sustainability properties.

Ms. Fallon continued by proposing the working group for the architectural finish elements category. Wesley Budrose (Sphere-E) expressed an interest in participating in that working group.

The group discussed the possibility of recruiting more participants from CSI and buildingSMART. According to Dr. East, at the CSI and buildingSMART meeting the week of J uly 17, 2011, the project team could recruit more people to join the working groups. Mr. Kalin said this project 
was on the agenda of the CSI National Technical Meeting the weekend of J uly 16-17. Mr. Brodt offered to get contacts from the EPA and GSA from the Interagency Council on Environmental Quality. Wolford was excited to participate in the working group and wanted to get more industry members involved as well. Dr. Bazjanac contributed as well, saying he could organize participation of manufacturers in Project Mojito. Participants were eager to join working groups and recruit other interested parties.

Dr. East then addressed the workshop and stated that he though forming working groups was premature at this stage of the project. The framework for the project must be developed before volunteers can join working groups. Once the idea for the project is more concrete, different teams with volunteers from CSI, GSA, and other organizations would be formed with the help of Mr. Kalin. He stressed the goal of the project was to create templates that would be free to use. Manufacturers would have the ability to add differentiating properties to the templates, but the common properties would be fixed and required for the whole class of a product. He concluded that although one goal of the workshop was to form working groups, the working groups should instead be formed through CSI to involved more people than just the attendees of the workshop.

\section{Summary}

There was consensus among the meeting's participants that the major project assumptions, that (1) identifying the sustainability properties necessary to selection and analysis of various building products and materials will be useful to the industry and (2) the goal of making sustainability assessment and analysis directly computable from a building model (BIM), are important and valid.

There was also general agreement that the information requirements are more important than the specific format in which the information is exported from a building model.

It was also agreed that an additional class of building elements, Building Enclosure elements, be added to the four classes of elements in the original task.

At the end of the workshop, Dr. East and Ms. Fallon informed participants of the project's next steps. By J uly 22, 2011 (the week after the workshop), buildingSMART and CSI will have discussed the framework of the project 
and will distribute the information to a variety of different mailing lists, including the participants of the workshop. The next goal is to have an updated set of templates, which would include specifiers' properties as well as the sustainability properties, available for distribution through the Product Guide in the Whole Building Design Guide, and simultaneously through some CSI vehicles, in December 2011 at Ecobuild.

Dr. East told participants the documentation of presentations and discussions would be available from the SPie page on buildingSMART. The documentation would include a participant list, presentations slides, and a brief synopsis of the purpose and goals of the workshop. 


\section{Annex A: Presentation Slides}

Welcome and Introduction - Kristine Fallon
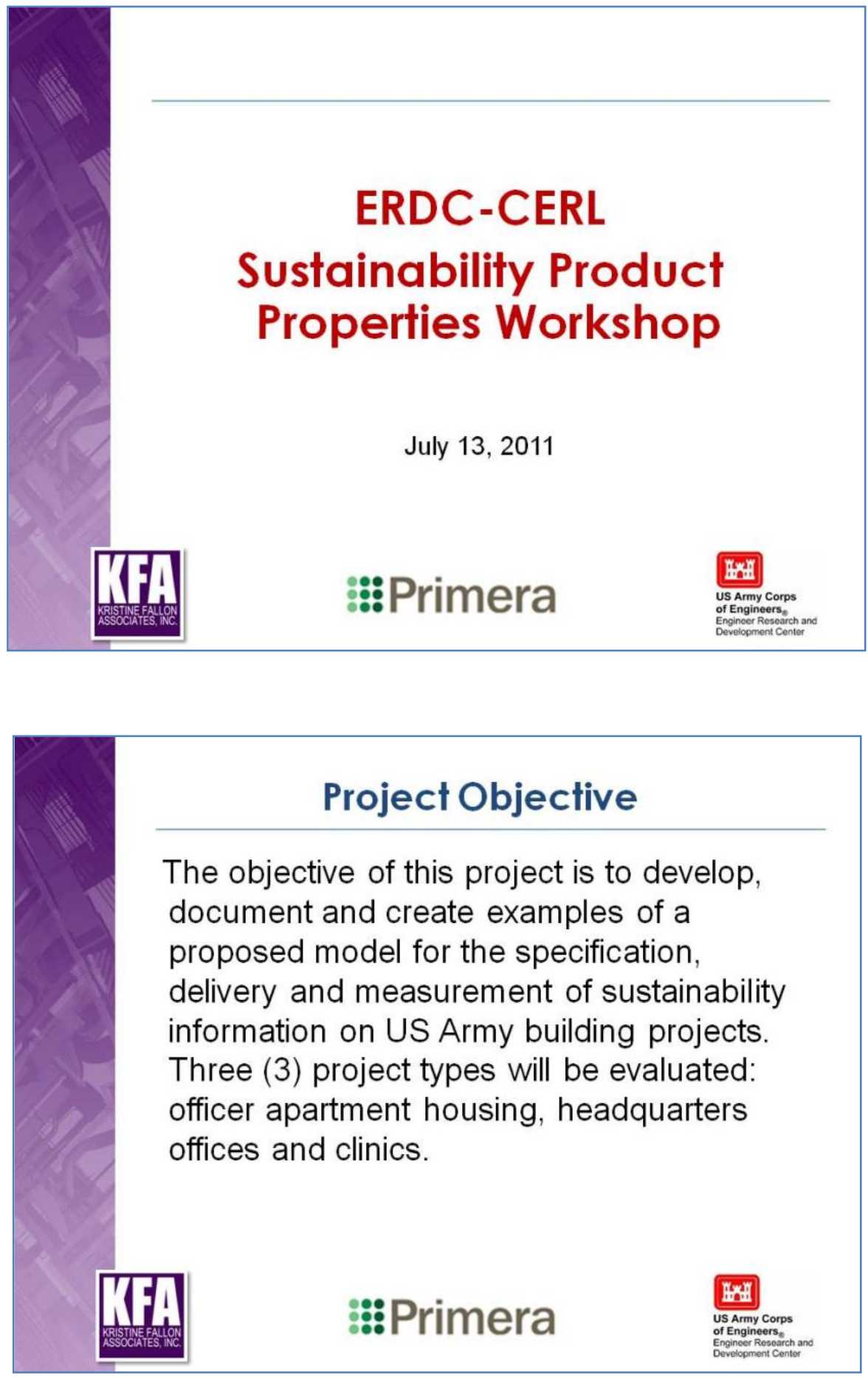


\section{Desired Workshop Outcomes}

- Demonstrate need for computable product properties for sustainability analyses

- Identify prior/current work to build upon

- Form working groups to define open source sustainability product properties specifications for architectural, mechanical, electrical and water systems

\section{Project Team}

- ERDC-CERL

- E. William (Bill) East, PhD, PE, F.ASCE

- David T. McKay

- Primera

- Lourdes Gonzalez, AIA, LEED AP

- Holly Genc, AIA, LEED AP

- Josh Greenfield, PE, LEED AP

- KFA

- Kristine K. Fallon, FAIA

- Julia Greenberger

- Robert Feldman, Ph.D.

- Mark Johnson

- Chris Skender 


\begin{tabular}{|l|l|}
\hline \multicolumn{2}{|c|}{ A genda } \\
\hline 9:15 AM - 10:00 AM & Continental breakfast and check-in \\
\hline 10:00 AM - 10:15 AM & $\begin{array}{l}\text { Kristine Fallon - Welcome. Introduction of CERL, KFA and Primera } \\
\text { participants. Agenda review. }\end{array}$ \\
\hline 10:15 AM - 10:30 AM & Other participants introduce selves and organizations \\
\hline 10:30 AM - 11:00 AM & Bill East- Background on LCM and SPie \\
\hline 11:00 AM - 11:15 AM & $\begin{array}{l}\text { Mark Kalin- Vision of specifying via the model: how that works for the } \\
\text { design team (including specifier) and how that works for downstream } \\
\text { users of the data. }\end{array}$ \\
\hline 11:15 AM - 11:45 AM & $\begin{array}{l}\text { Lourdes Gonzalez, Primera- Overview of Army Sustainability Policy. } \\
\text { Discussion on similarities with other agencies. }\end{array}$ \\
\hline 11:45 AM - 12:15 PM & Holly Genc, Primera- Gap Analysis \\
\hline 12:15 PM - 12:30 PM & $\begin{array}{l}\text { Vladimir Bazjanac- Implementation of building performance analysis } \\
\text { simulation }\end{array}$ \\
\hline 12:30 PM - 1:15 PM & Box lunches and conversation \\
\hline 1:15 PM - 1:30 PM & Paul Bertram- EPDs \\
\hline 1:30 PM - 1:45 PM & John Kennedy- gbXML coverage \\
\hline 1:45 PM - 2:30 PM & $\begin{array}{l}\text { Kristine Fallon \& Robert Feldman- Sustainability Product Properties } \\
\text { Project Discussion } \\
\text { Break }\end{array}$ \\
\hline 2:30 PM - 2:45 PM & Arol Wolford- Why manufacturers should get involved \\
\hline 2:45 PM - 3:00 PM & Formation of working groups \\
\hline 3:00 PM - 3:30 PM & Next steps and adjournment \\
\hline 3:30 PM - 4:00 PM &
\end{tabular}

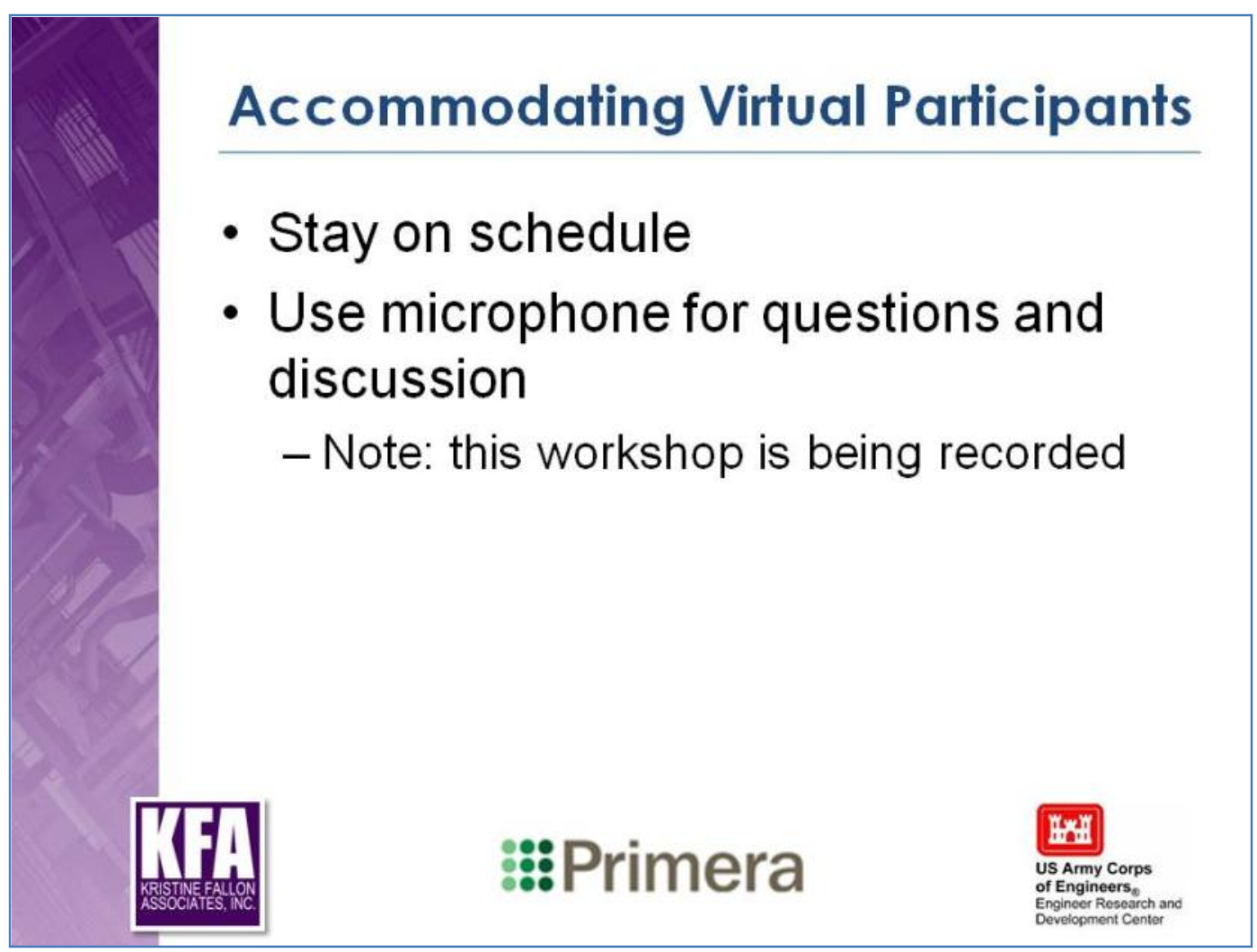




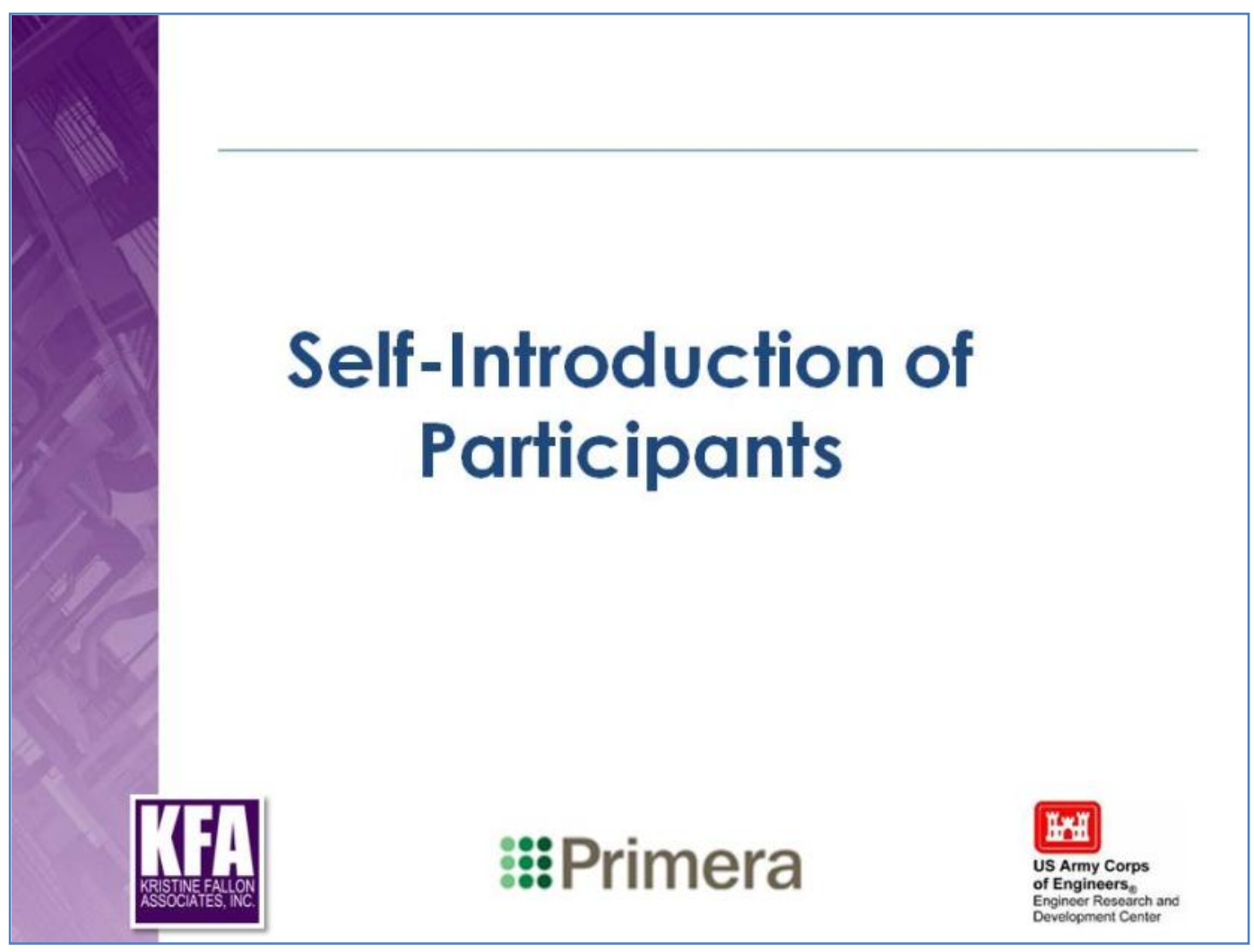


BIM, Specs and Sustainability - Mark Kalin

\section{BIM, Specs and Sustainability}

ERDC-CERL Sustainability Product Properties Workshop Mark Kalin FAIA FCSI LEED

Kalin Associates Specifications

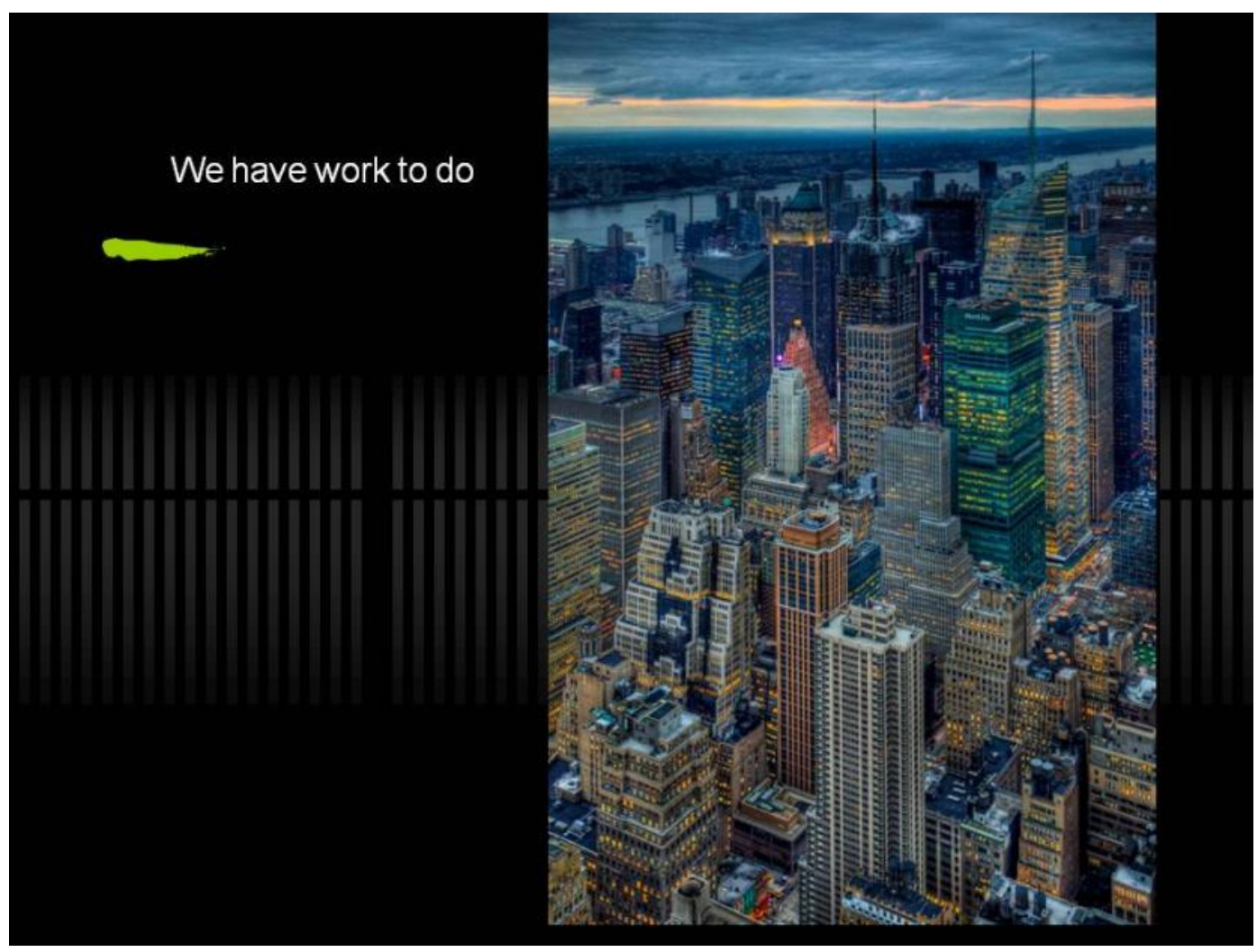


We have to get it right during design

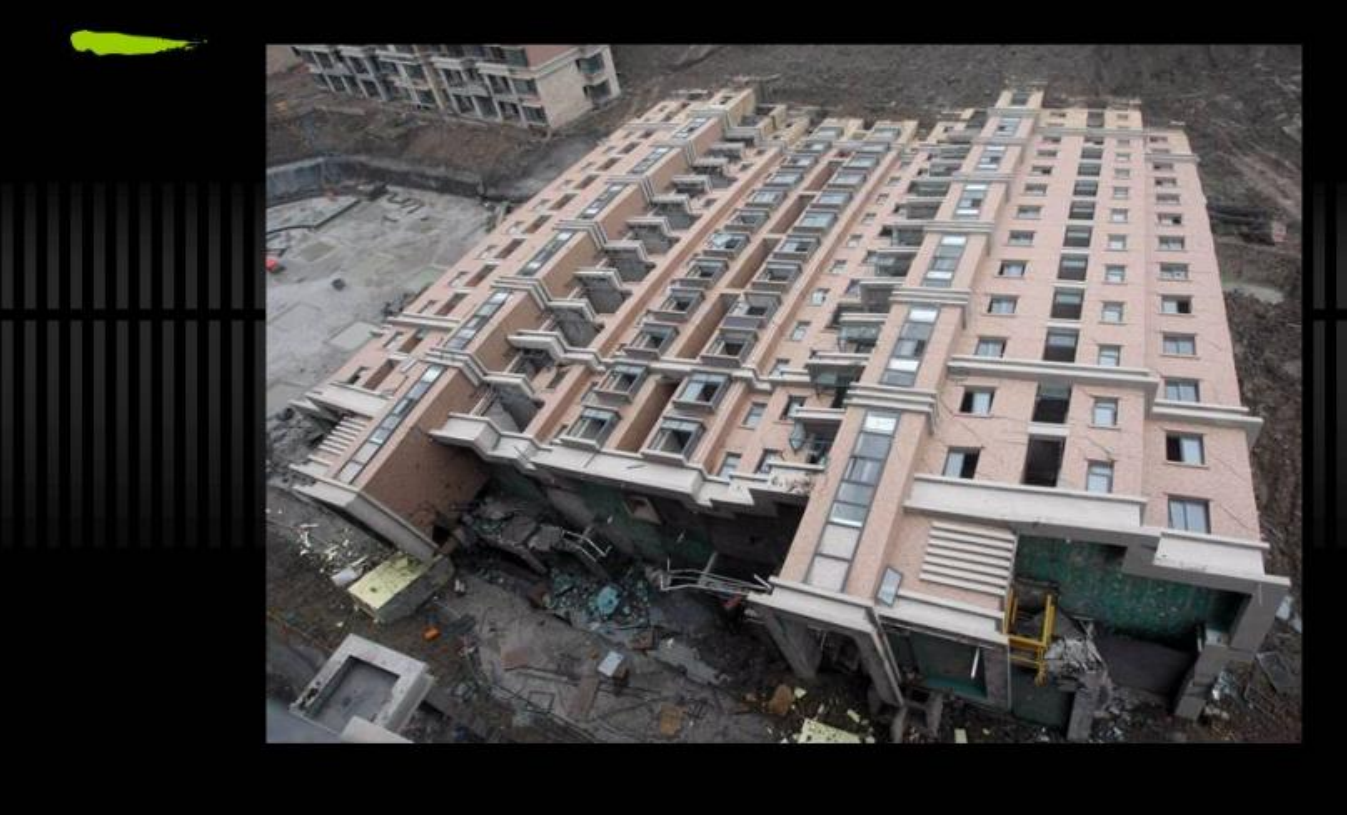

Even sustainability is a point of view

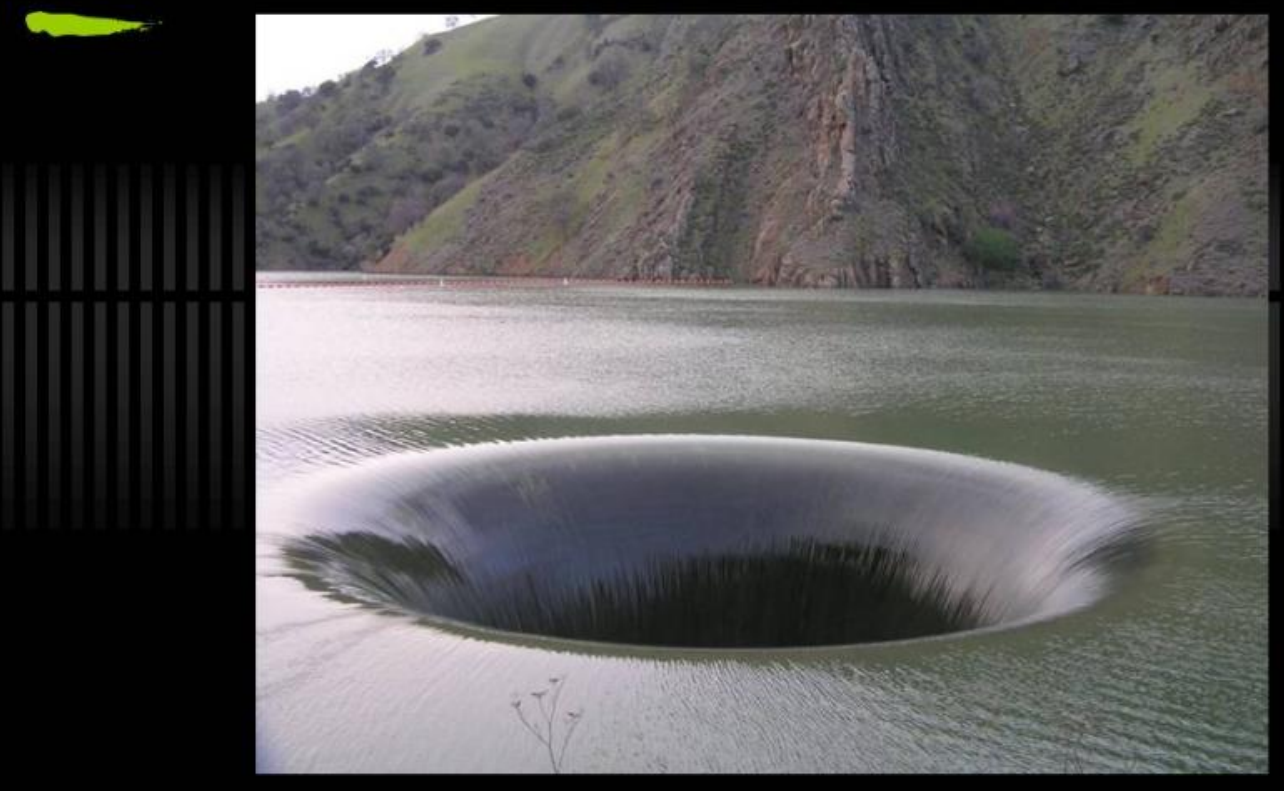


Nature's realm - with 2 billion years of experience

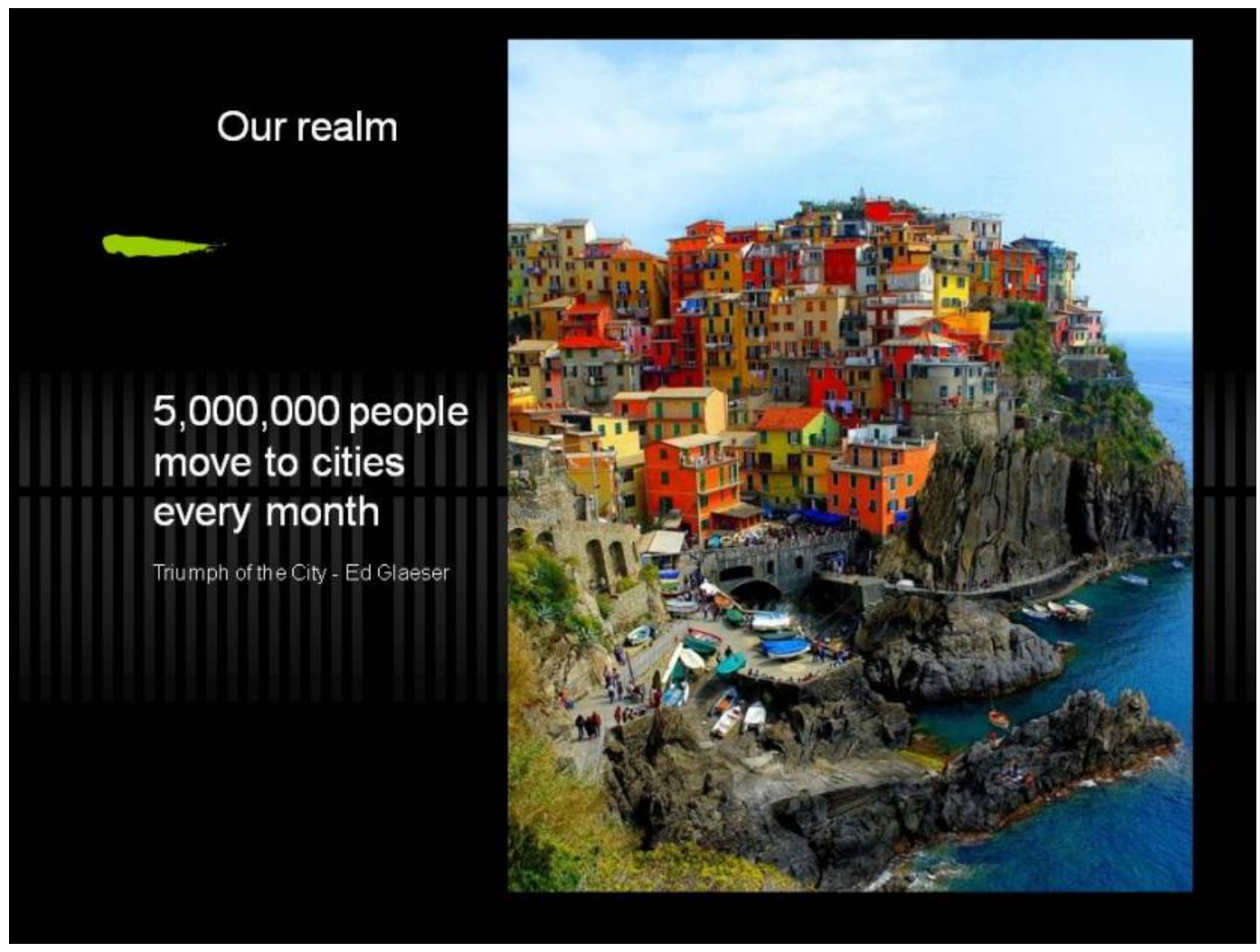




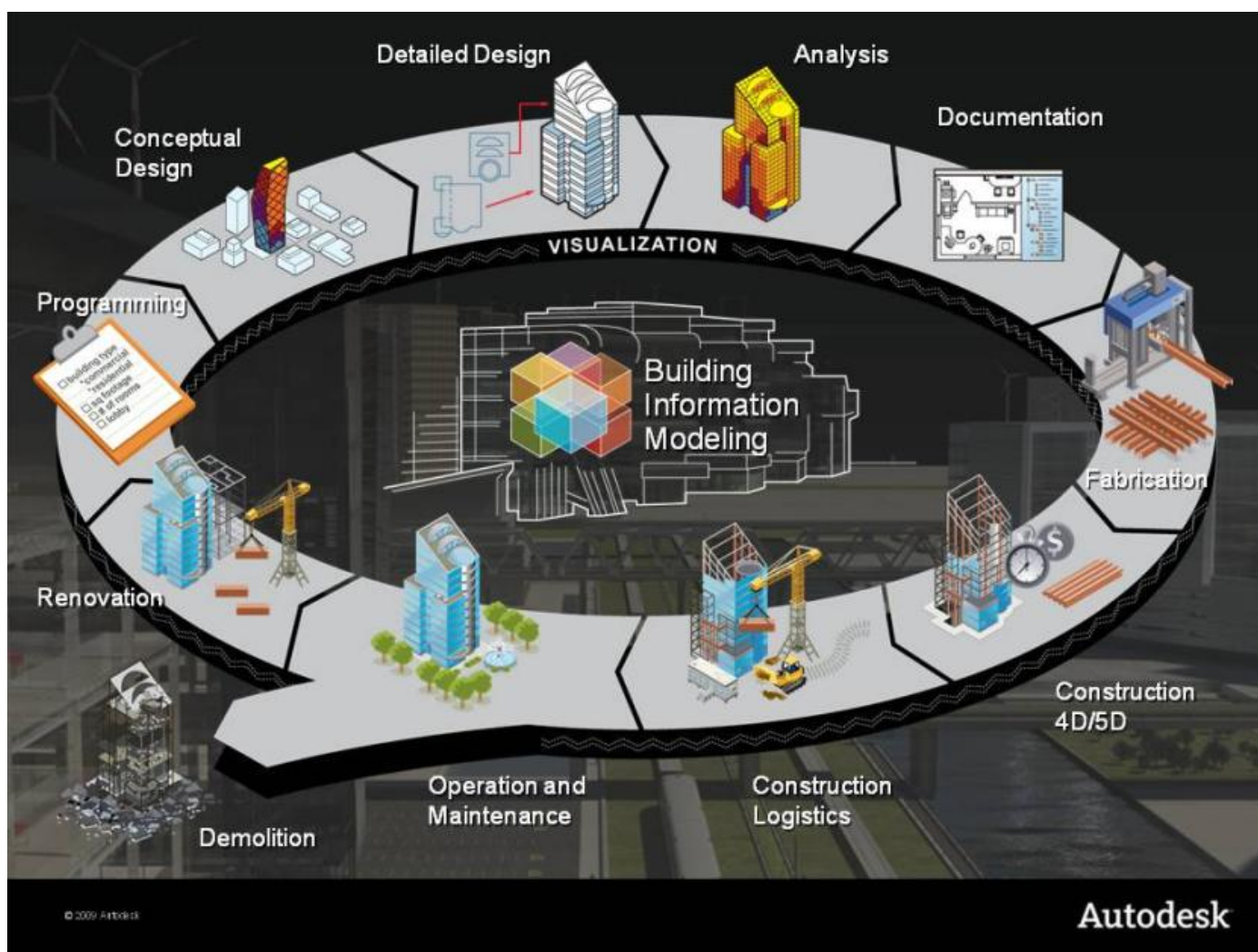

Project Information is distributed in multiple formats, and changes over time

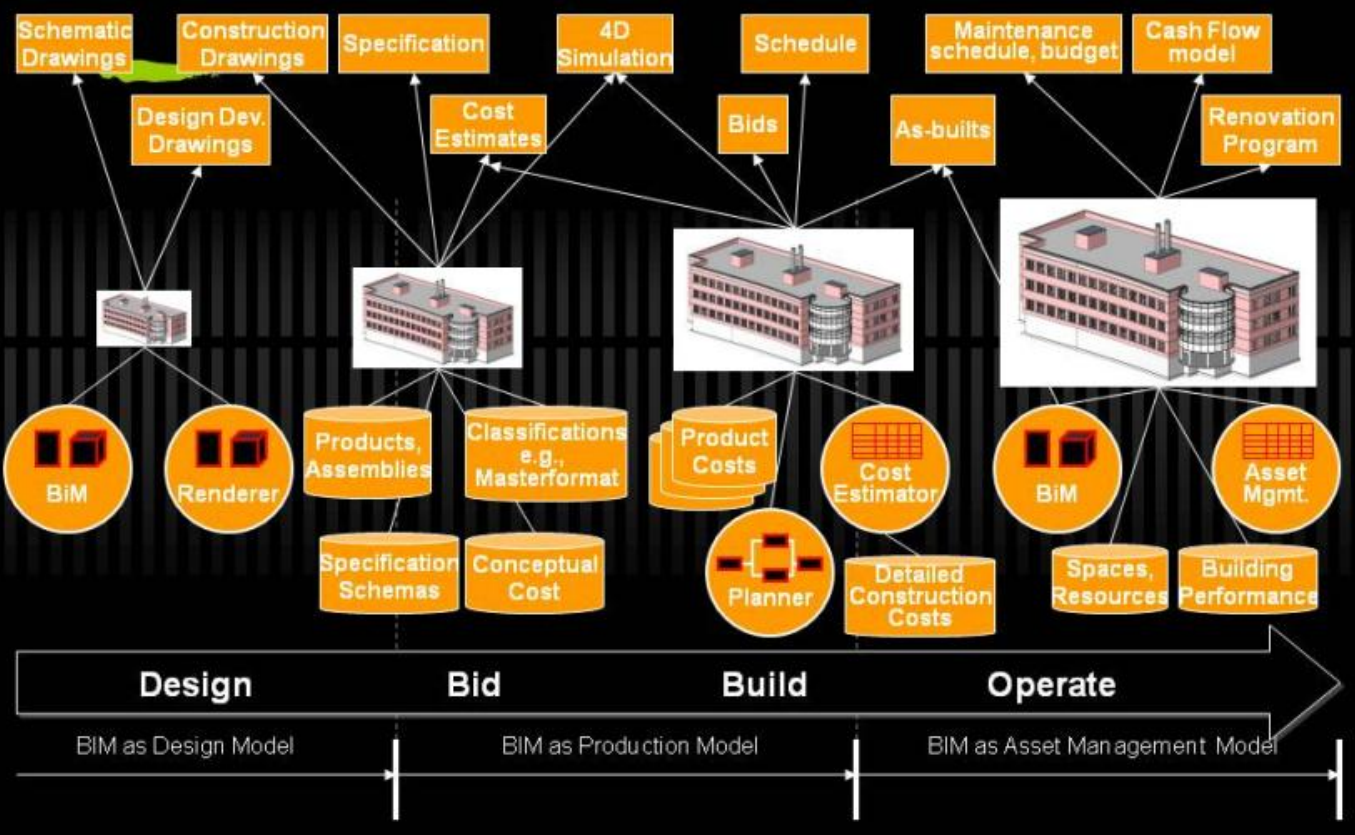



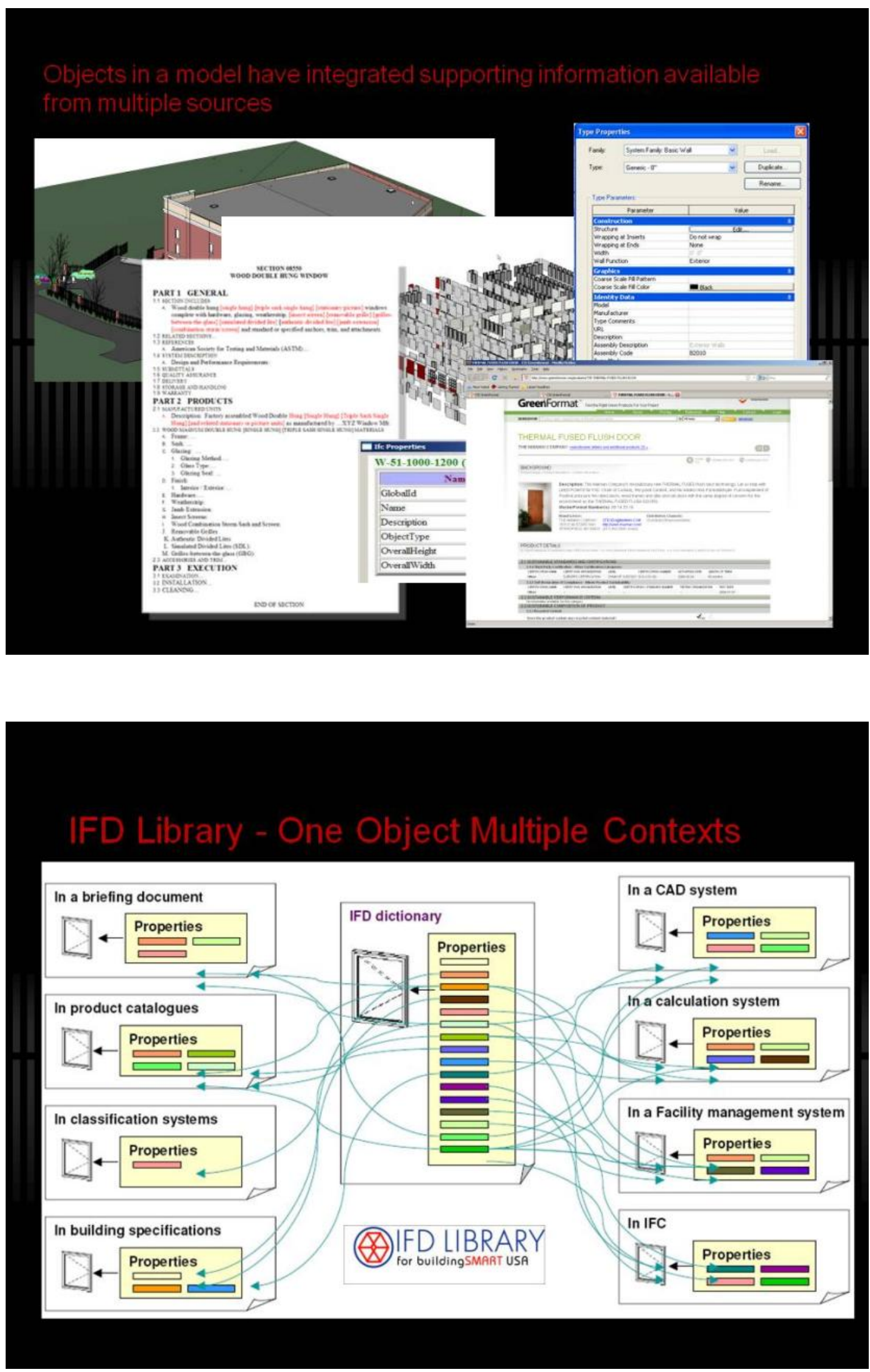


\section{Specifiers' Property Sets Workflow}

\section{BIMspec Platform}

Project, Object, Material, Attributes

\section{Data Formats}

Masterformat, UniFormat, OmniClass, GreenFormat, NCS

\section{Documentation Output}

CAD Objects, BIM Objects, Reports, Specifications, Estimates

\section{MasterFormat Property Sets}

\section{Specifiers' Properties Information Exchange (Spie)

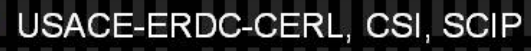




\section{CSI Tools for Delivering Climate Neutral Construction}

Upfront costing \& Environmental LCA

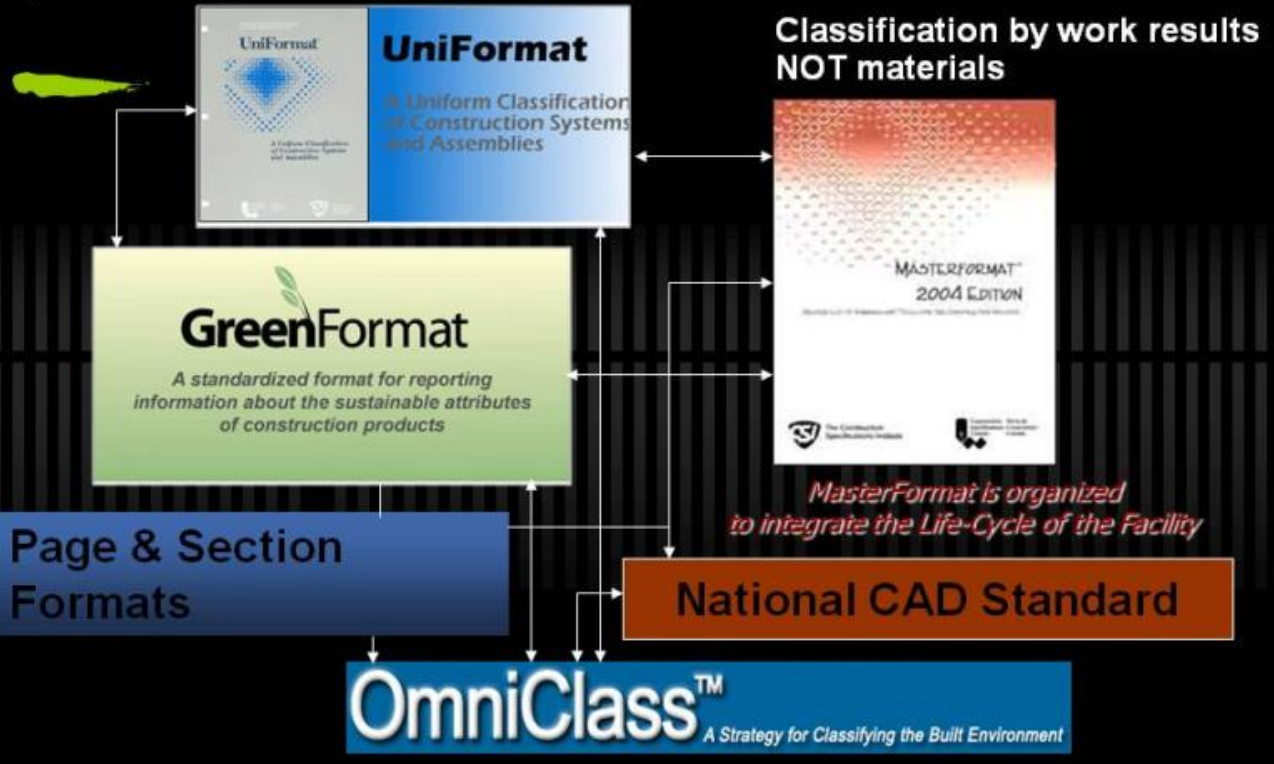

Information Formats and Standards

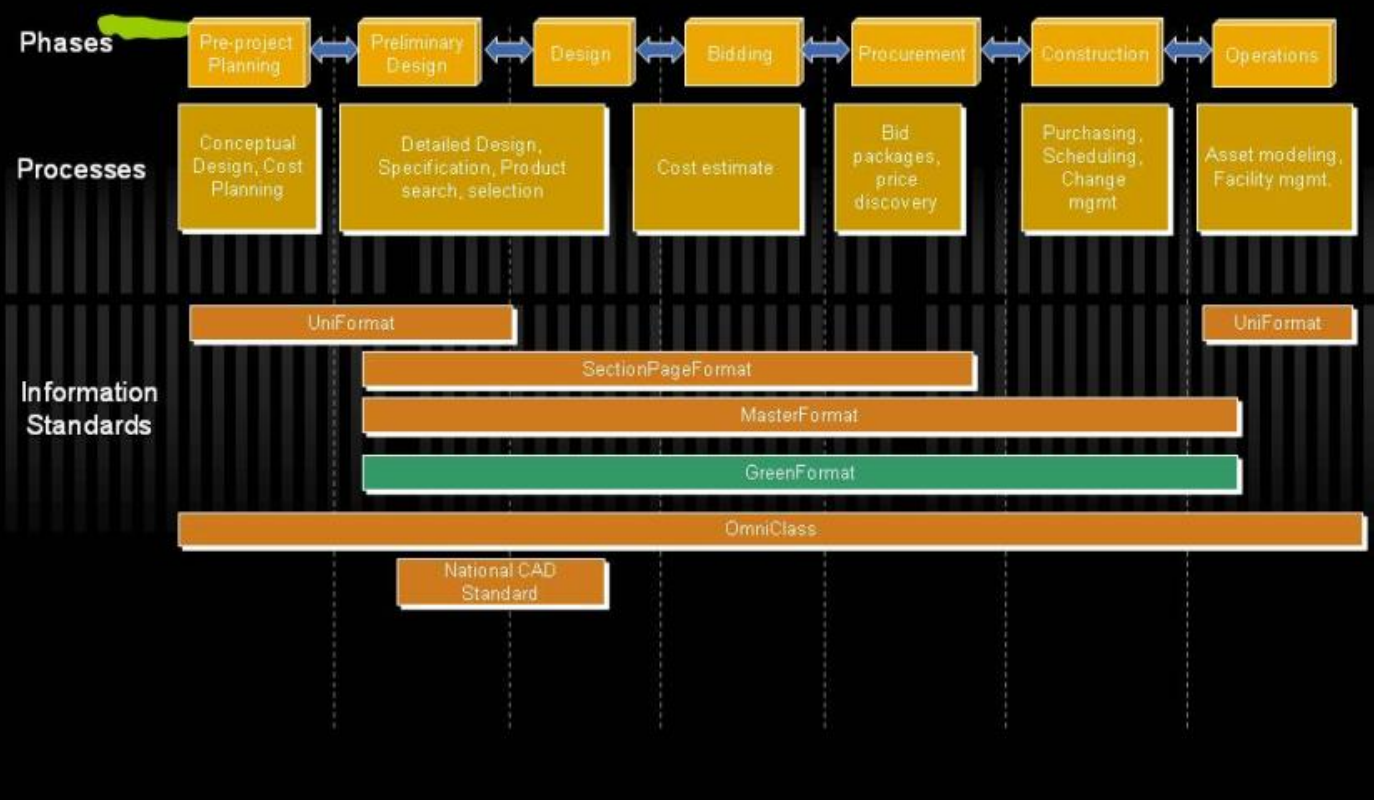




\section{Specifier's Changing Role}

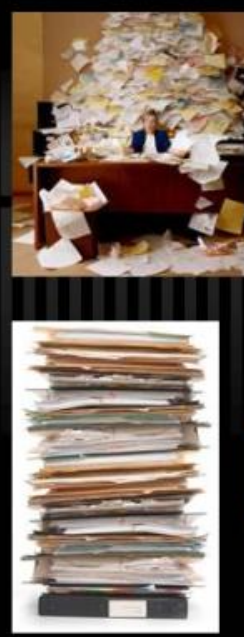

Static

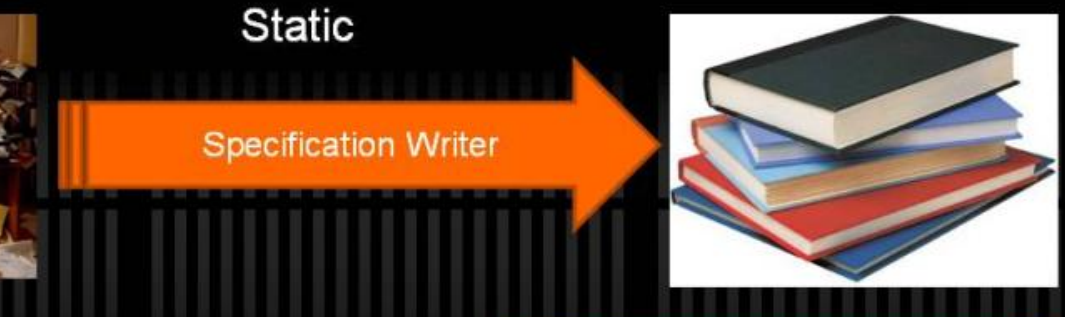

Dynamic

Knowledge Manager

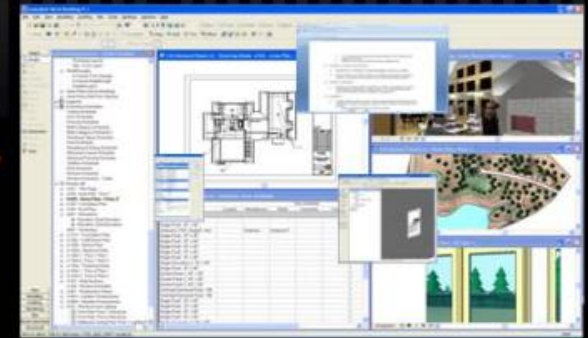

\section{BIM-generated specifications}

Spec-constrained BIM models

From Ifits.

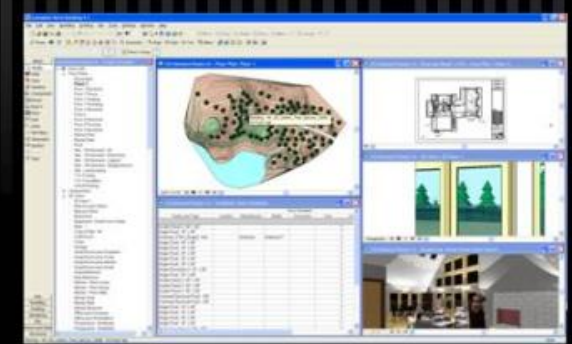

$\mathscr{T}$ This

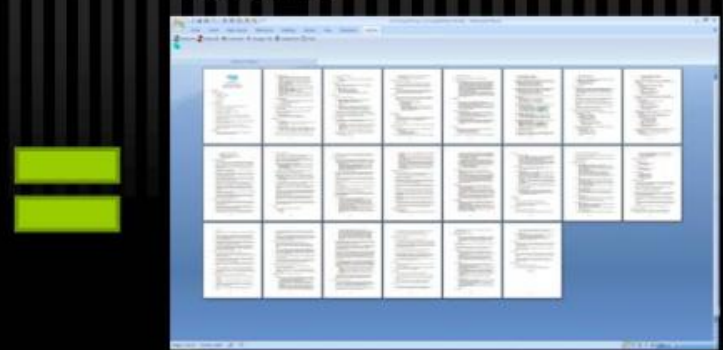



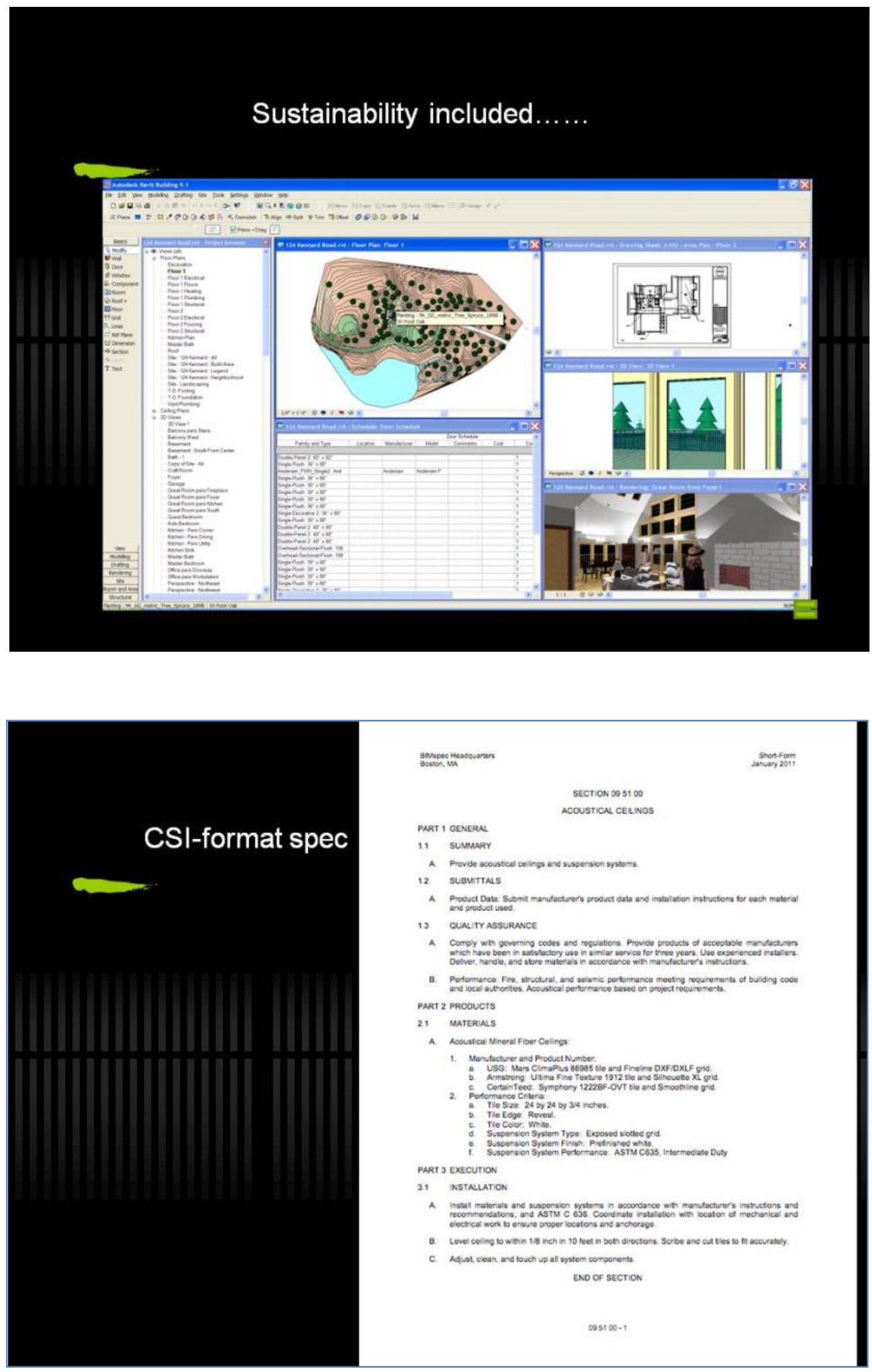

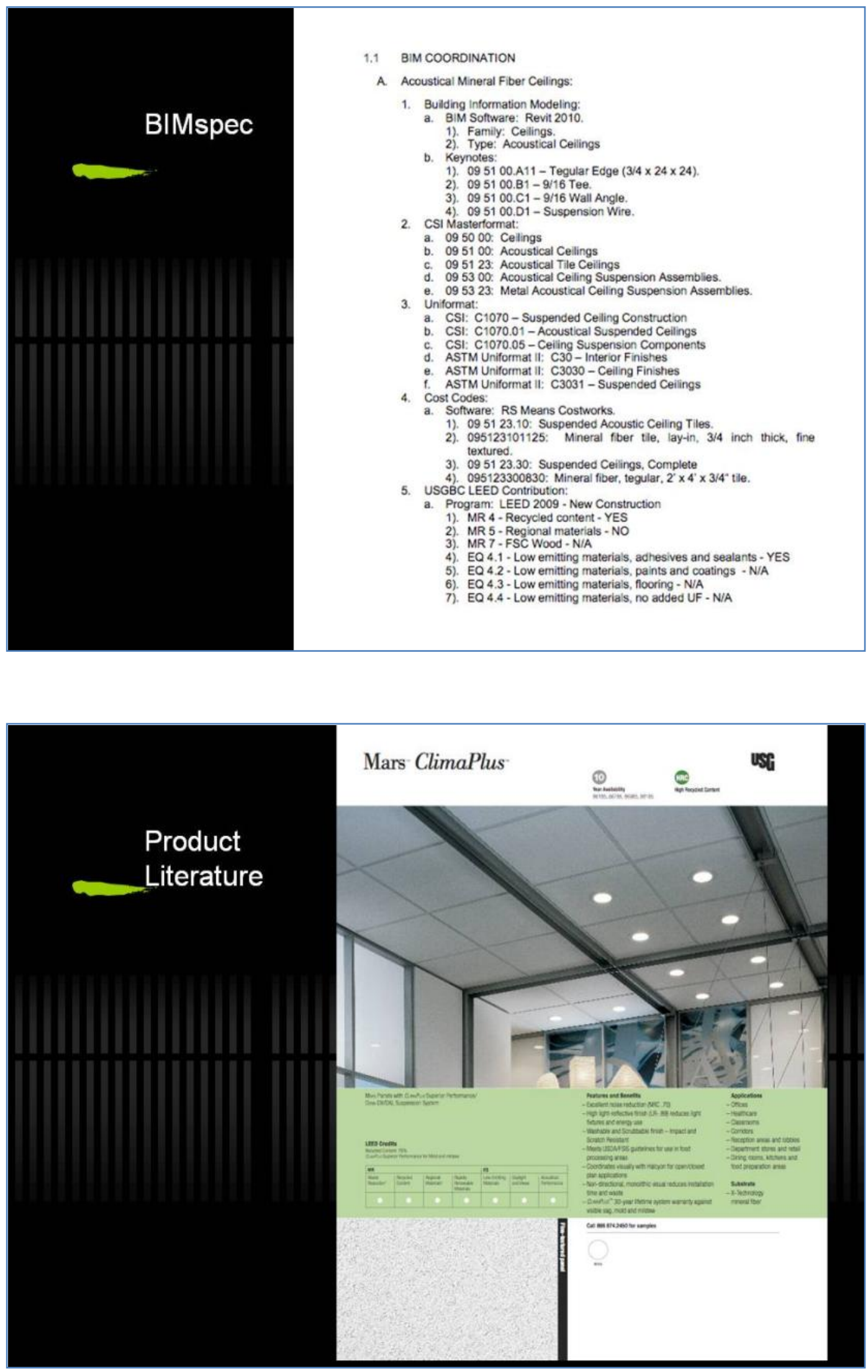

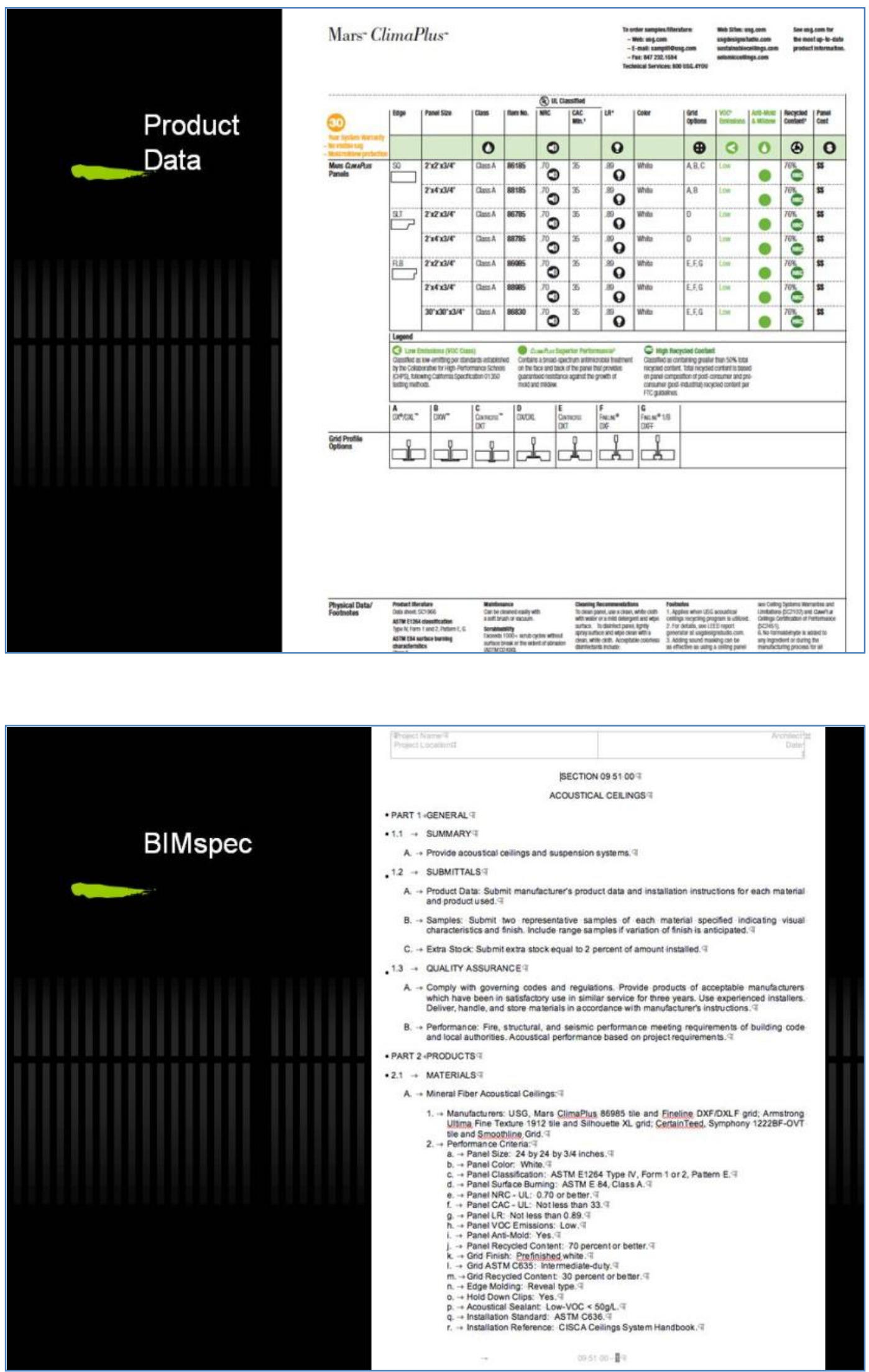


\begin{tabular}{|c|c|c|c|c|}
\hline \multirow{29}{*}{ BlMformat } & \multicolumn{4}{|l|}{ Type Properties } \\
\hline & Type & \multicolumn{3}{|l|}{ Acoustical Ceilings } \\
\hline & Uniformat Number & \multicolumn{3}{|l|}{ C1070 } \\
\hline & Masterformat Number & \multicolumn{3}{|l|}{0951004} \\
\hline & \multicolumn{4}{|l|}{$\begin{array}{l}\text { TI } \\
\text { Type Parameters } 4\end{array}$} \\
\hline & Parameter & Value & म & म \\
\hline & Keynoteliz & ACT-1म & 口 & म \\
\hline & Manufacturer & USG Corporation & Armstrong & CertainTeed \\
\hline & Product NameII & Mars ClimaPlus & Ultima Fine Texture & Symphony \\
\hline & Product Number' & 86985 & 1912 & 1222BF-OVTH \\
\hline & Grid Profilet] & \begin{tabular}{|l|l} 
Fineline DXF/DXLFI \\
\end{tabular} & Silhouette XL" & Smoothline \\
\hline & Panel Sizell & 24 by 24 by $3 / 4$ inches & ㅁ & म \\
\hline & Panel Color' & White & 口 & म \\
\hline & Panel Classification & $\begin{array}{l}\text { ASTM E1264 Type IV, } \\
\text { Form } 1 \text { or 2, Pattern E }\end{array}$ & म & 마 \\
\hline & Panel Surface Burning & ASTM E 84, Class A & म & म \\
\hline & Panel NRC - ULI & 0.70 or better & 무 & 무 \\
\hline & Panel CAC - UL & Not less than 33 & म & 무 \\
\hline & Panel LR & Not less than 0.89 & म & मㅈ \\
\hline & Panel VOC Emissions & Low & ㅁ & 무 \\
\hline & Panel Anti-Mold & Yes & म & प \\
\hline & Panel Recycled Content: & 70 percent or better 1 & 무 & 무 \\
\hline & Grid Finish & Prefinished white & म & 무 \\
\hline & Grid ASTM C635 & Intermediate-duty & म & 마 \\
\hline & Grid Recycled Contentt & 30 percent or better & 마 & 무 \\
\hline & Edge Molding & Reveal type & म & म \\
\hline & Hold Down Clips I & Yes म्र & म & म \\
\hline & Acoustical Sealantr & Low-VOC $<50 \mathrm{~g} /$ म & म & ㅁ \\
\hline & Installation Standard & ASTM C636: & 무 & 마 \\
\hline & Installation Reference & $\begin{array}{l}\text { CISCA Ceilings System } \\
\text { Handbook }\end{array}$ & म & म \\
\hline
\end{tabular}

\section{Create a schedule}

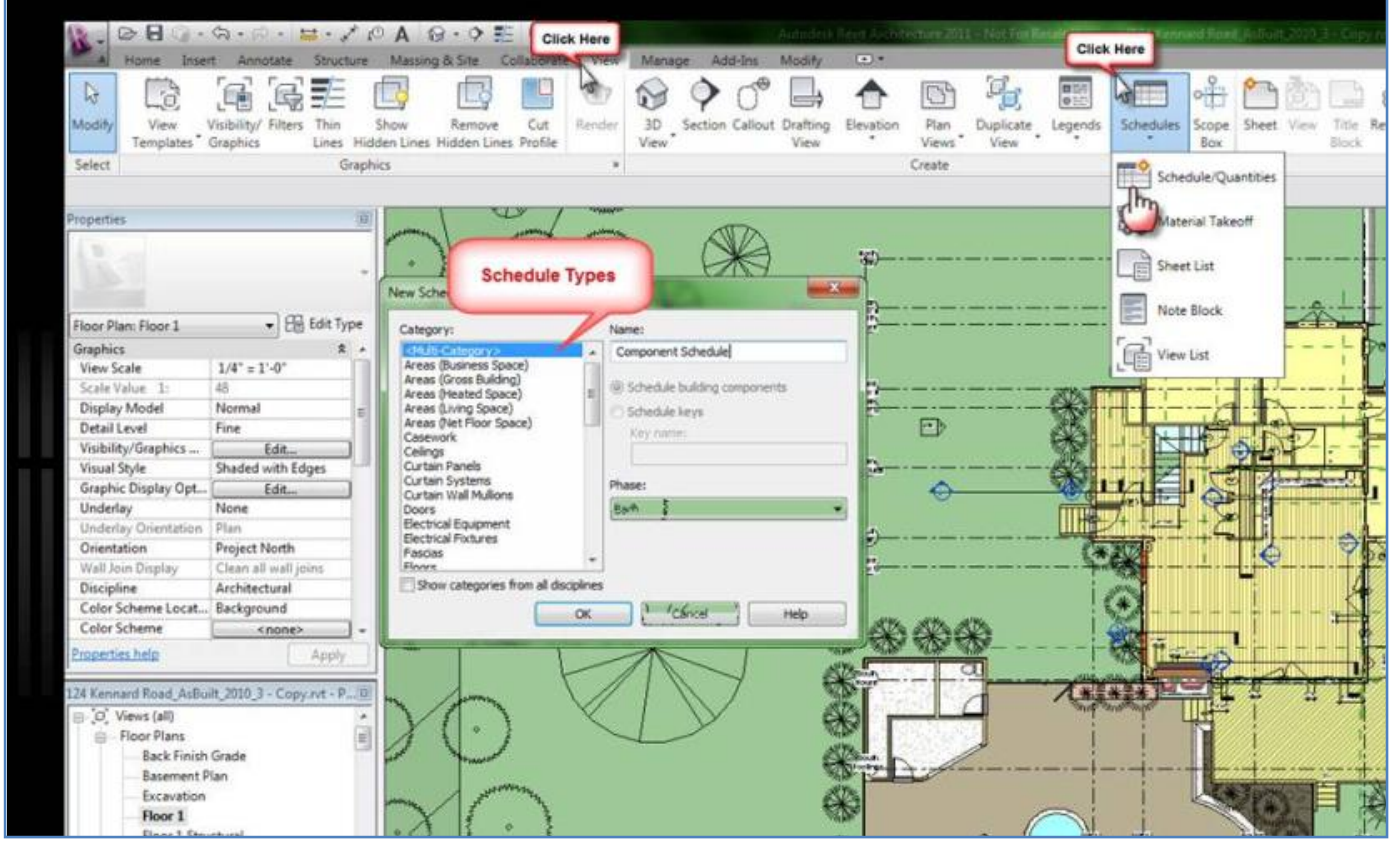




\section{Output a schedule}

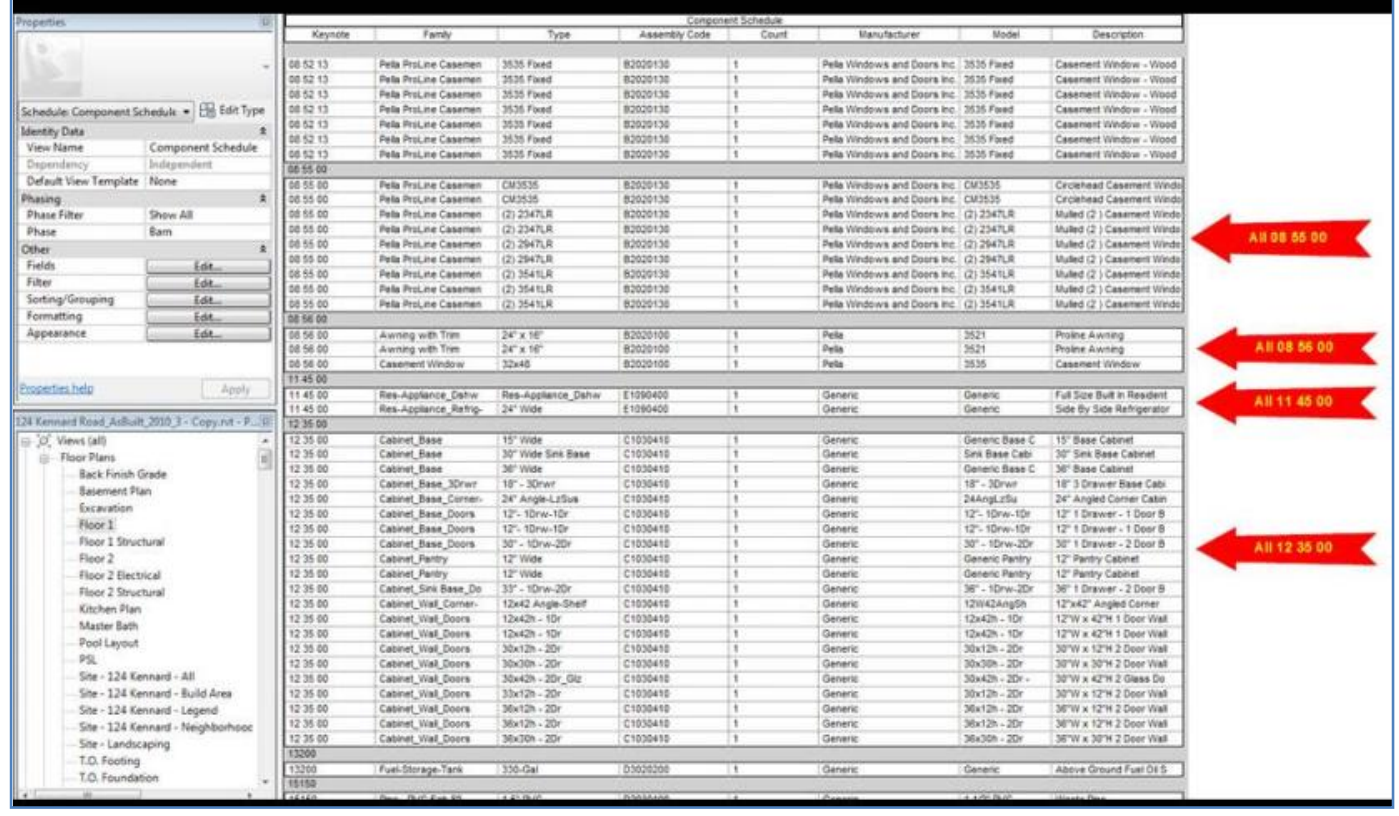

Finish Schedule from a BIM model

\begin{tabular}{|c|c|c|c|c|c|c|c|c|}
\hline \multirow{25}{*}{ r. } & $\cos =$ & 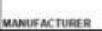 & Proovect mune & PROOUCT MINUERR & & sefe & sment & LOCATON KOIIS \\
\hline & a.s. & 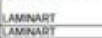 & & 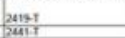 & 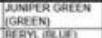 & & & \\
\hline & ans & powite & & maner & New wherte & & verour inser & 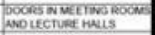 \\
\hline & 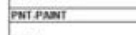 & & & & & & & 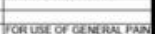 \\
\hline & artis & 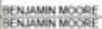 & 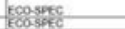 & $\frac{10 x}{106}$ & $\begin{array}{l}\text { Whare bove } \\
\text { White }\end{array}$ & & 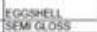 & conos \\
\hline & 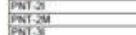 & 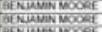 & 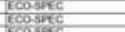 & 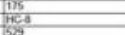 & 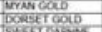 & & 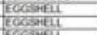 & 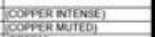 \\
\hline & 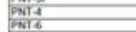 & 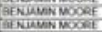 & 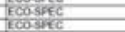 & $\frac{17}{1000}$ & 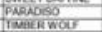 & & 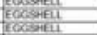 & 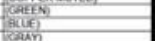 \\
\hline & anta & anvuren wodoef & kcospec & Herts & 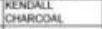 & & Eoostell & 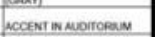 \\
\hline & 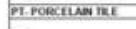 & & मिक्षवत्मिड & & & क्wox & & \\
\hline & p1.1. & Strowe solve & 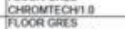 & 715615 & $\log _{10} 10$ & 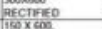 & WuTte finss & \\
\hline & 012 & STone sounct & 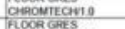 & & $\cos 10$ & 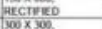 & murtersosis & \\
\hline & pis & stome sovere & 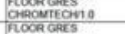 & nosen & $\cos 10$ & 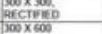 & wirrefoes & \\
\hline & & stone sonace & 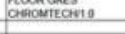 & nssin & $\cos 33^{3}$ & 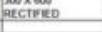 & mortrumsin & \\
\hline & 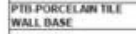 & & & & & & & \\
\hline & 2781 & sroser sover & 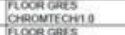 & nows & $\cos \times 10$ & ropersm & mutre fiser & conp wauns: \\
\hline & pais & Strone sounce & 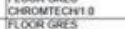 & nows & $\cos x 10$ & 150000m & warte fives & 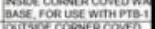 \\
\hline & pasis & srowe solec of & 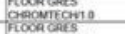 & nowa & $\cos x 10$ & moneen & marte fiveses & 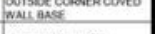 \\
\hline & P1B2 & stone sounce. & 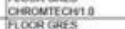 & nowe & $\cos x 30$ & 1000m & warte rises & coved wainese \\
\hline & p182a & STOWE SOURCE & 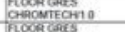 & nowas & $000 \times 30$ & 150 несет & mane finsos & 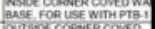 \\
\hline & p18 28 & stone sonice & 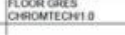 & nowes & $\cos 33^{\circ}$ & nos rean & watre rises & 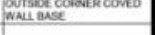 \\
\hline & 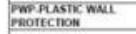 & & & & & & & \\
\hline & PaA-1 & csancrouns & Hereswepact raveo & & serwate & hifichts & sneme & 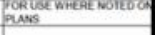 \\
\hline & 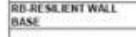 & & & & & & & \\
\hline & ant 1 & poper & Pubers ous & nex is & mosowe & Henumaren on & & Plok \\
\hline & & cansovite & TReancens & $\mathrm{H}^{-1}$ & sterasas svver & & & \\
\hline
\end{tabular}




\section{Specifier Comments for Finish Legend}

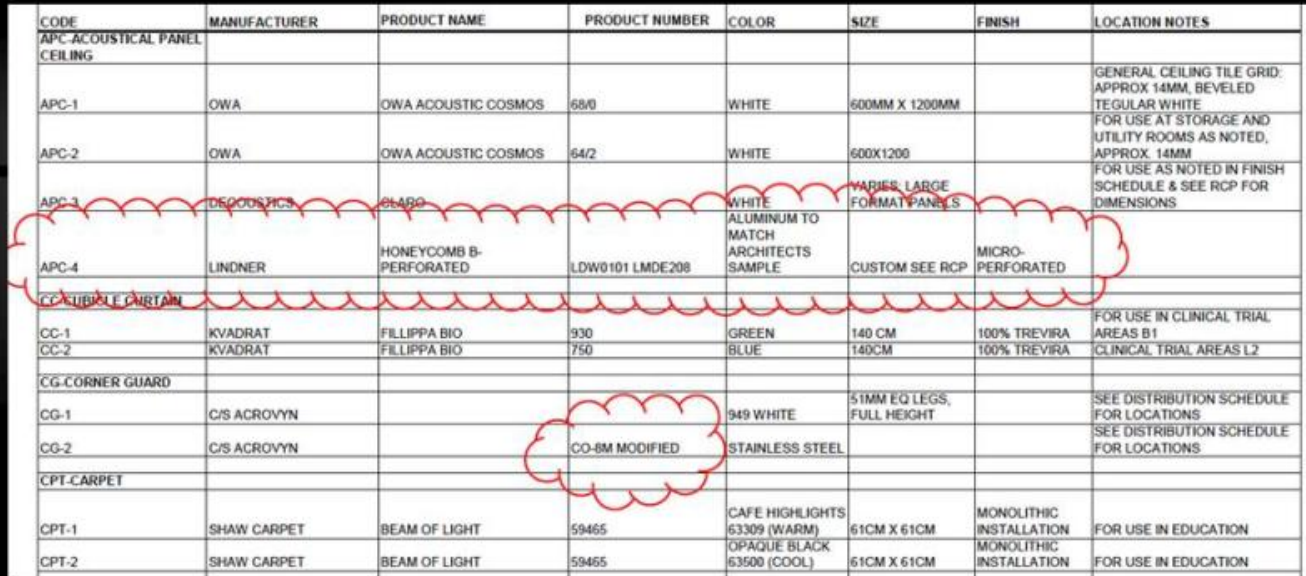

Mike's Story - Small Firm

BIMspec

Chuck's Story - Medium Firm

Connie's Story - Large Firm

Omar's Story - Owner

Bob's Story - Contractor

John's Story - Subcontractor

Ric's Story - Manufacturer

Bill's Story - Catalog Provider

Gil's Story - Automator

Erol's Story - Integrator

Meredith's Story - Sustainability

Mark's Story - Spec Writer

Stefan's Story - Into the Future 


\section{Green Labeled Products}
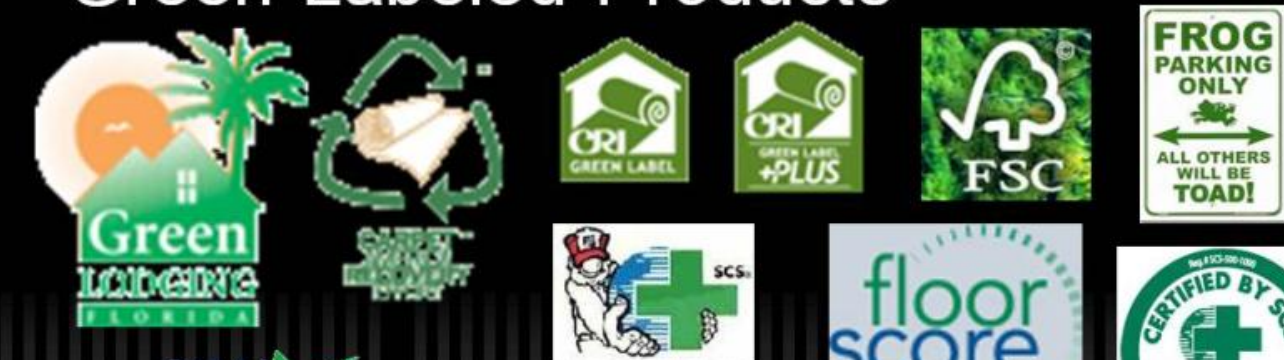

MaMr W

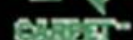

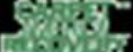
isigh
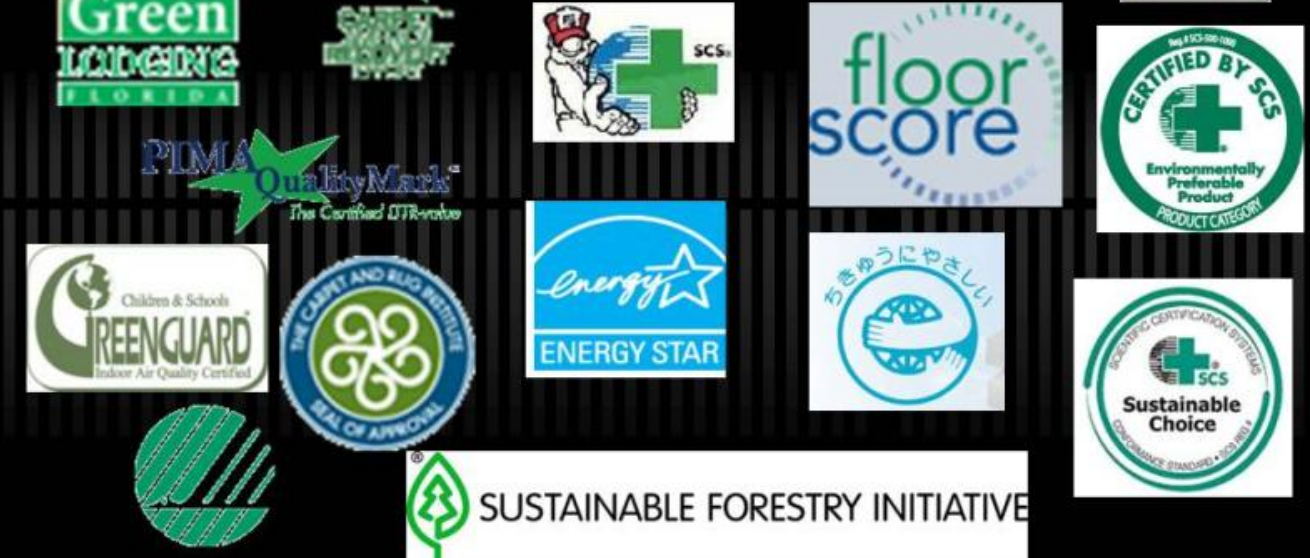

(2)

SUSTAINABLE FORESTRY INITIATIVE

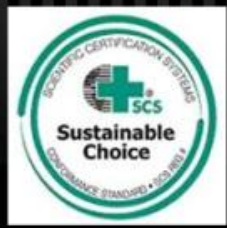

\section{Green Rating Systems \& Programs}

\section{H. ASHRAE COMMITTEE 189 (SPC 189) \\ 4.4 standard for the Design of High Portormance,}

42 .

(B) commercial buildings initiative

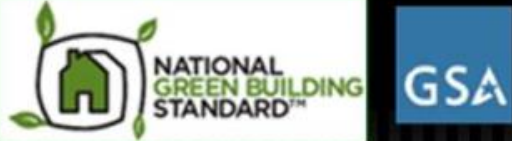

\section{BOMA}

A avarnerd

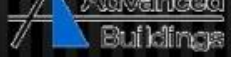

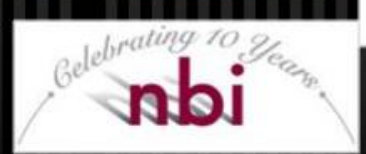

SUSTAINABLE BUILDINGS INDUSTRY COUNCIL. Advancing a
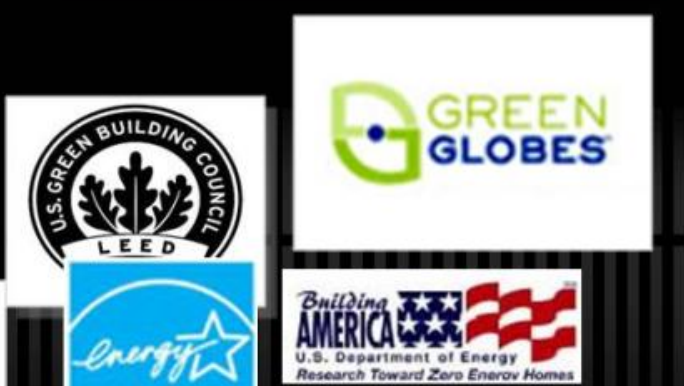

Research Toward Zero Enerov Homes

inergystar.gov

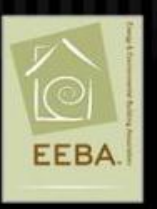


This may be risky business

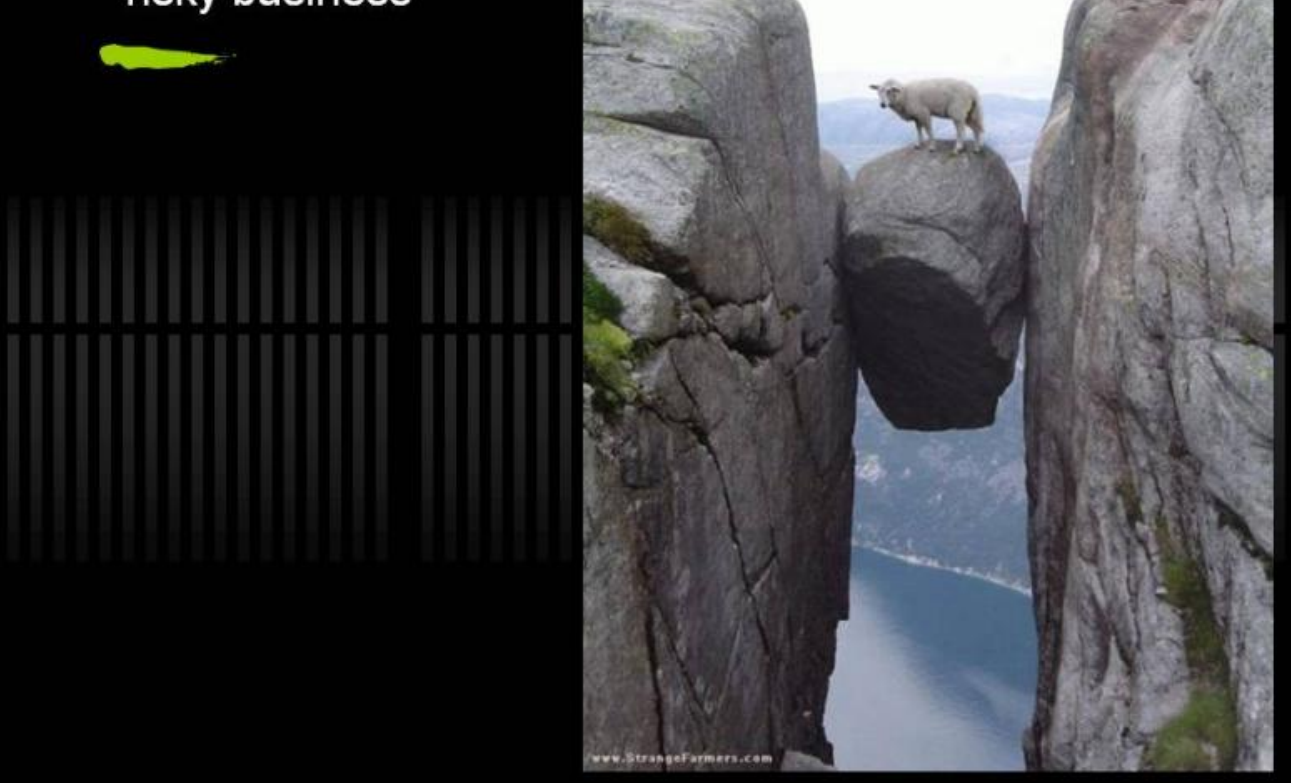

But we can do anything we put our mind to
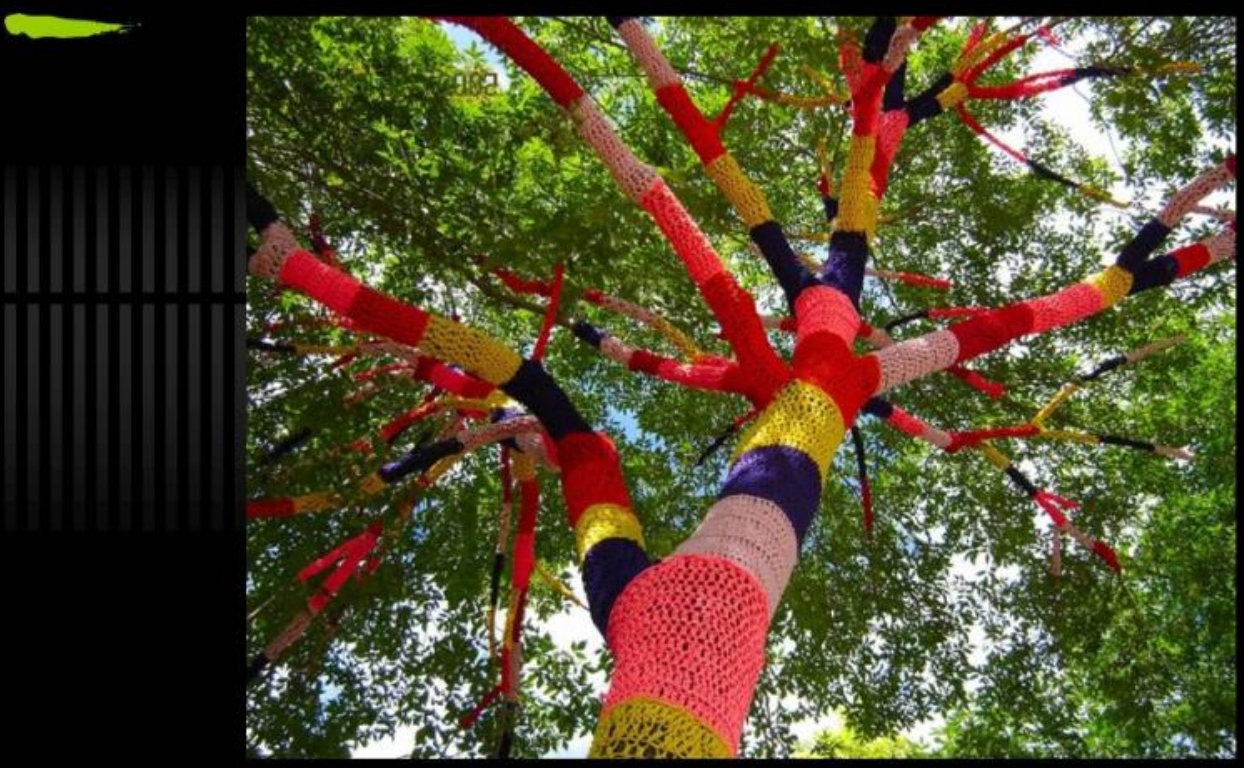


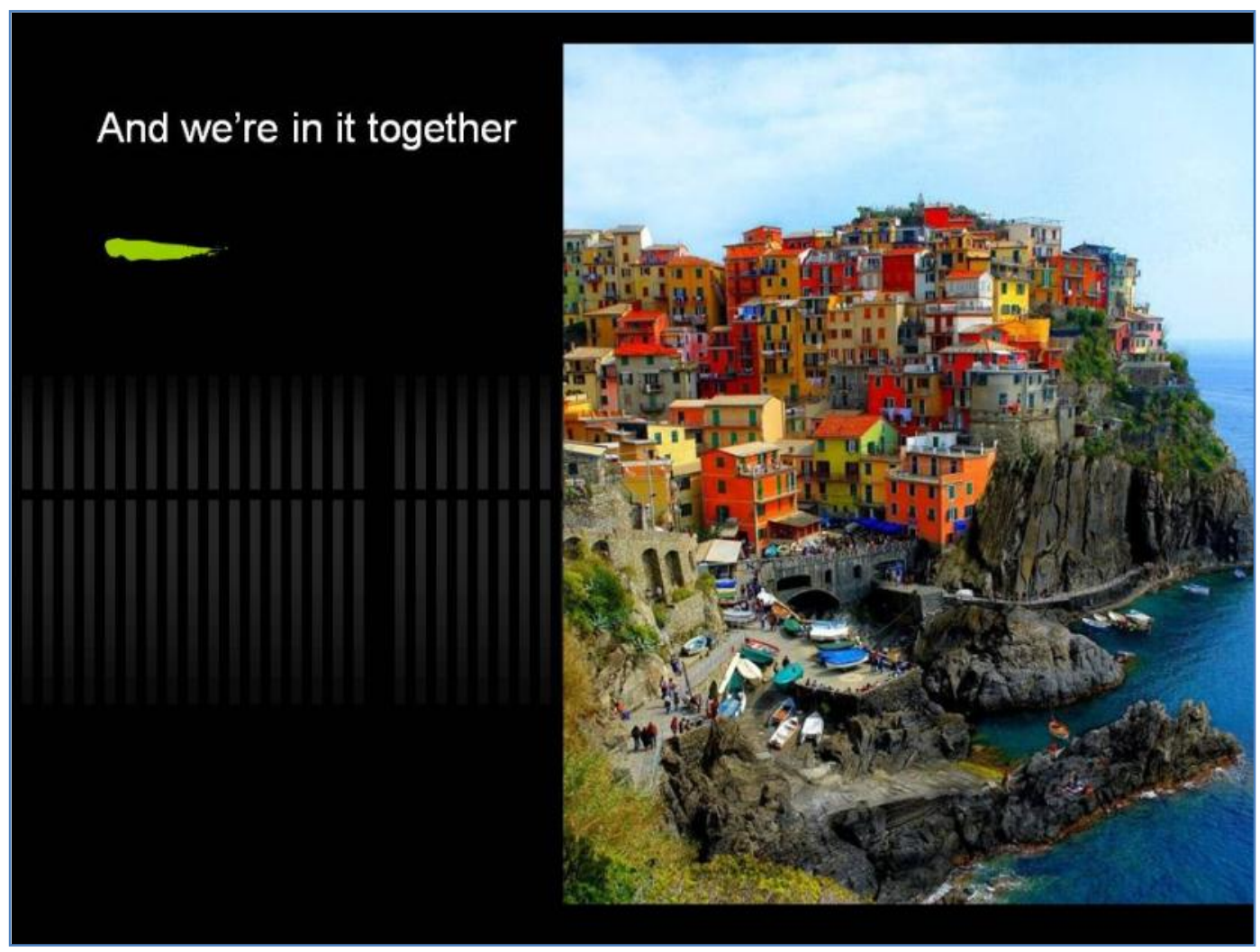

\section{BIM, Specs and Sustainability}

\section{Presented by Mark Kalin FAIA FCSI LEED}

mkalin@kalinassociates.com

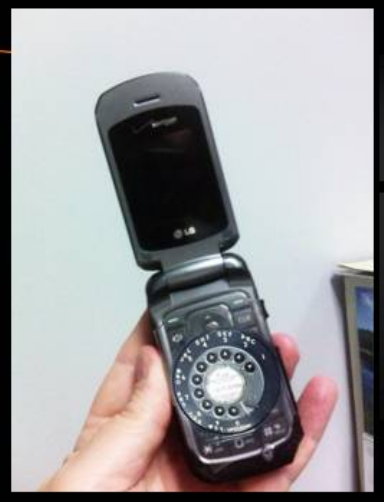


Overview of Army Sustainability Policy - Lourdes Gonzalez, Primera

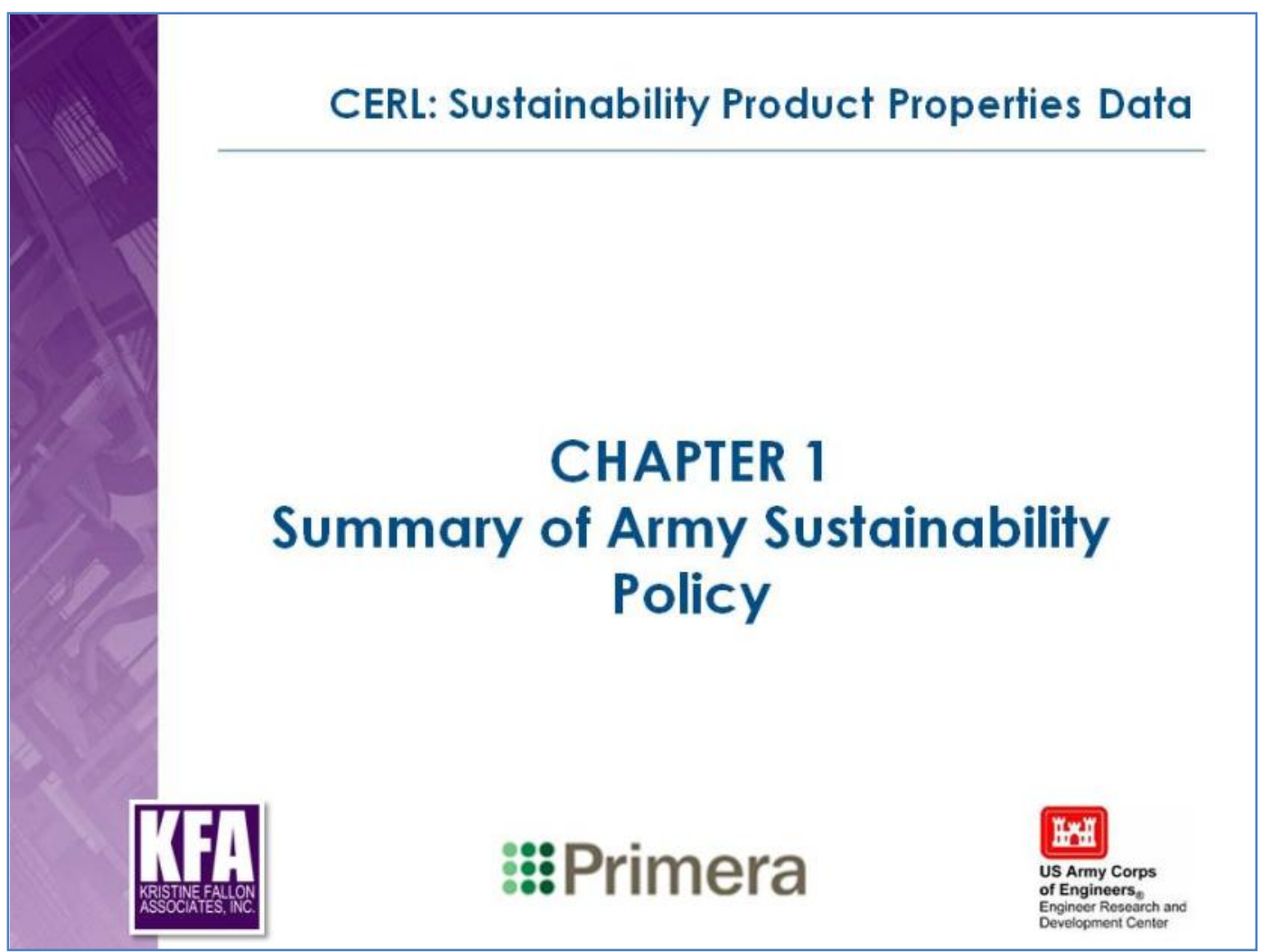

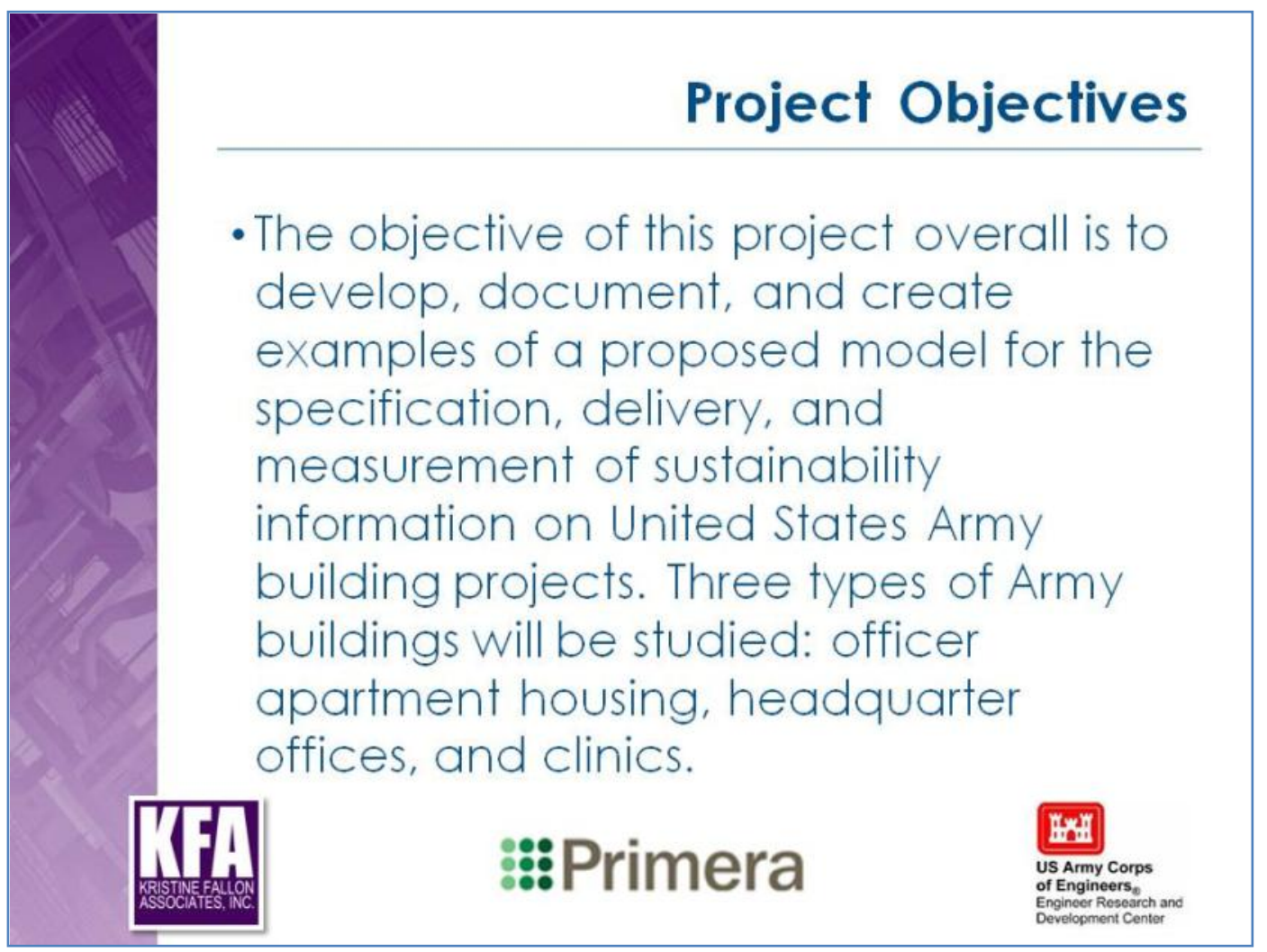



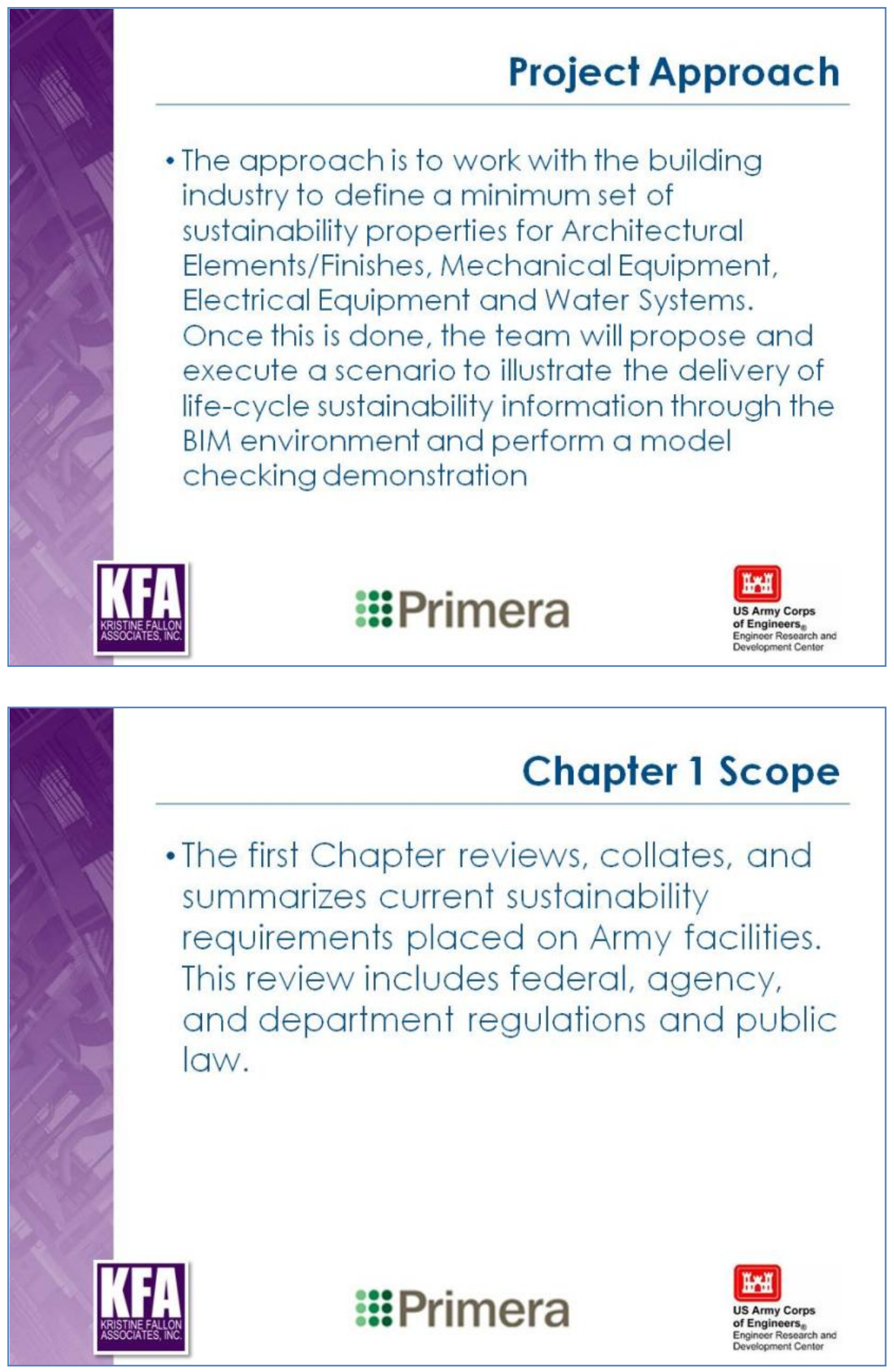


\section{Future Chapters}

- Subsequent Chapters will cover the following elements

-Evaluate Current Sustainability Tools

-Review of National Sustainability Agenda

-Architectural Element or Finish Sustainability

Properties

-Mechanical Equipment Sustainability Properties

-Electrical Equipment Sustainability Properties

-Water System Sustainability Properties

-Example Sustainability Product Models

-Example Sustainability Models Checking Demonstration

-Draft Technical Report and Presentation 


\section{The Army and Guiding Principles}

- Memorandum of Understanding (MOU) that establishes the Guiding Principles stated that the Federal government is committed to designing, constructing, and operating its facilities in an energyefficient and environmentally sustainable manner, consistent with Federal agency missions. 


\section{Guiding Principles Goals}

- The Guiding Principles translates these goals into five sustainable practices including: employ integrated design principles, optimize energy performance, protect and conserve water, enhance indoor environmental quality and reduce environmental impact of materials. 

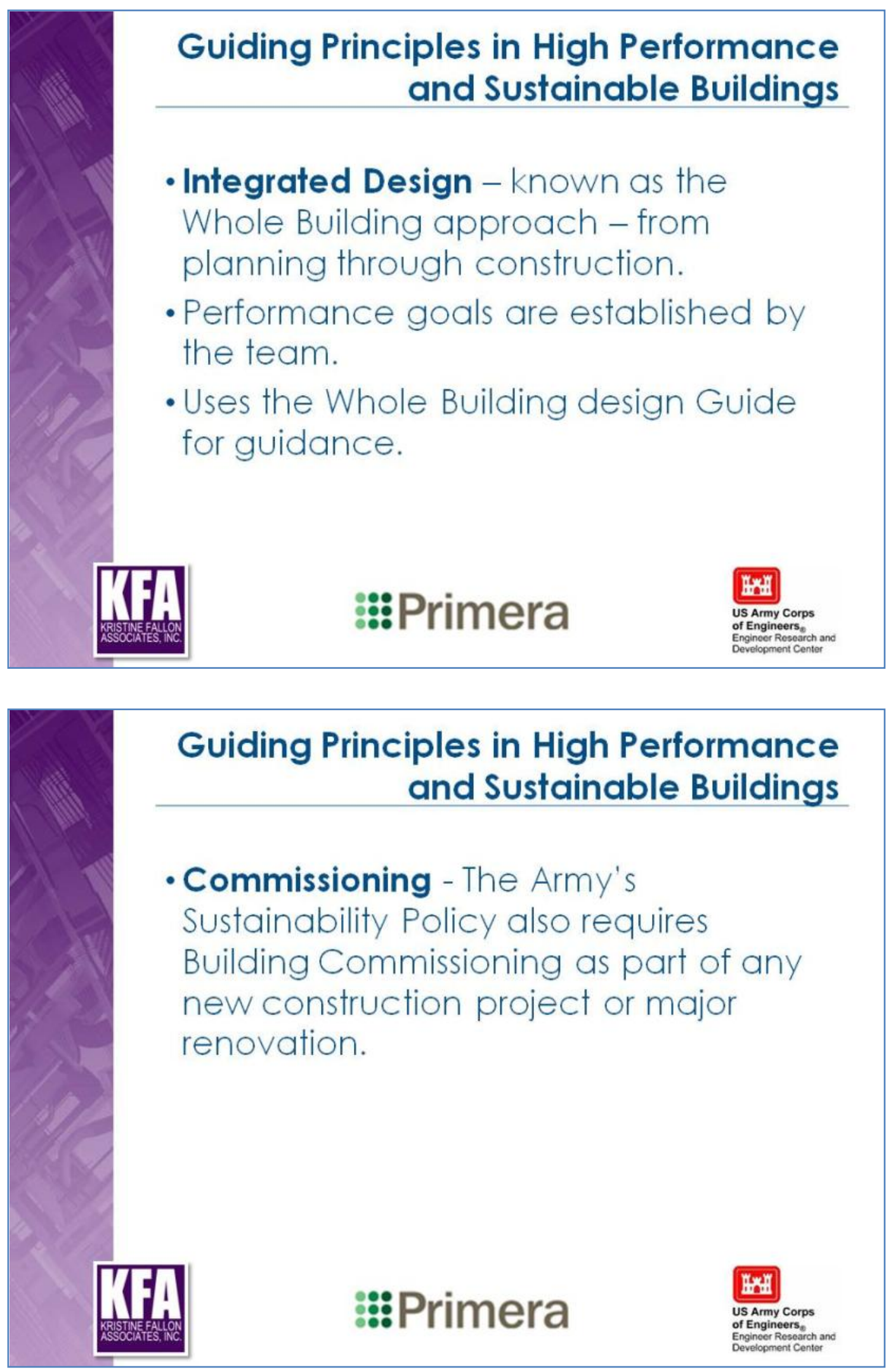

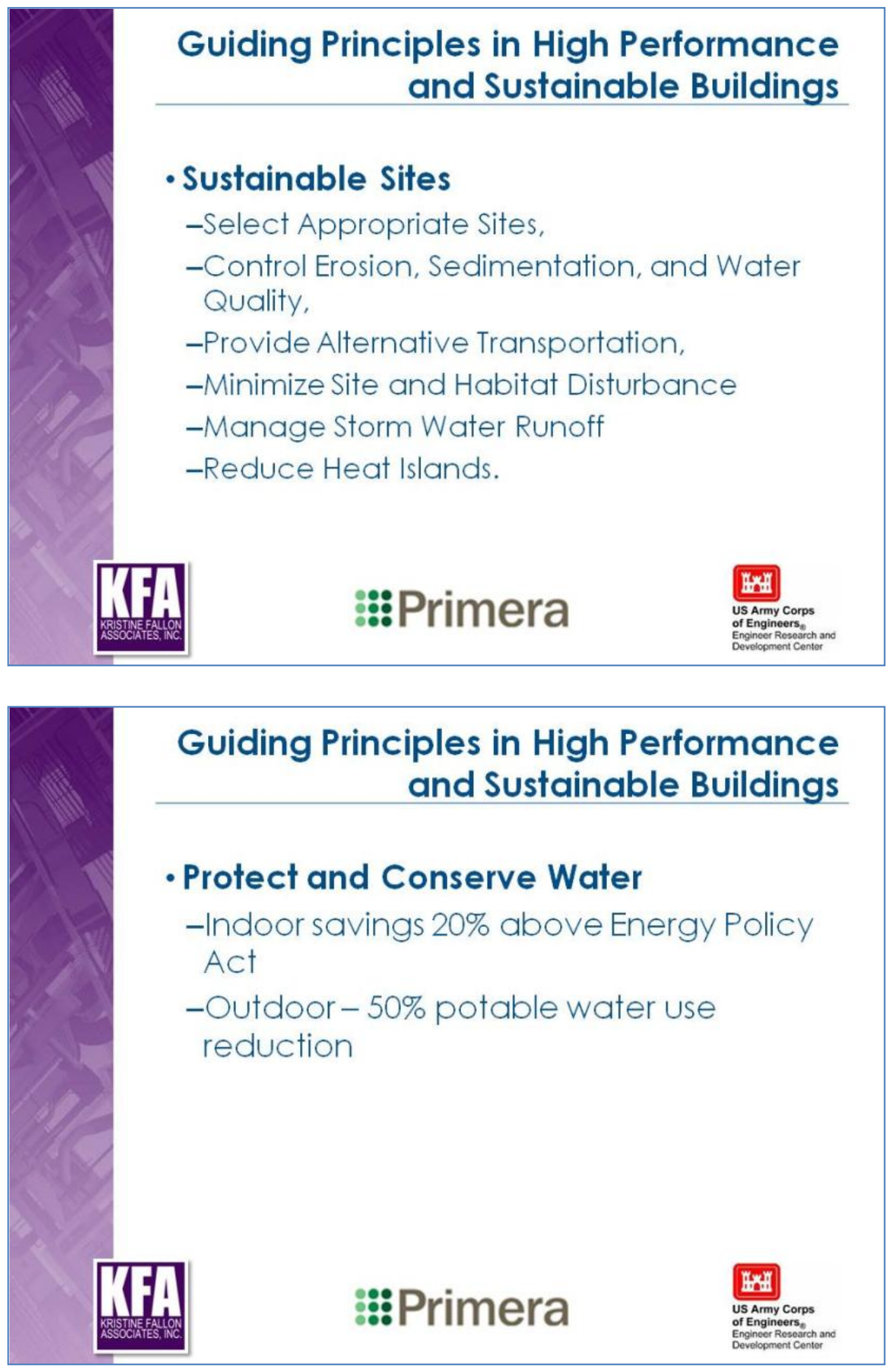

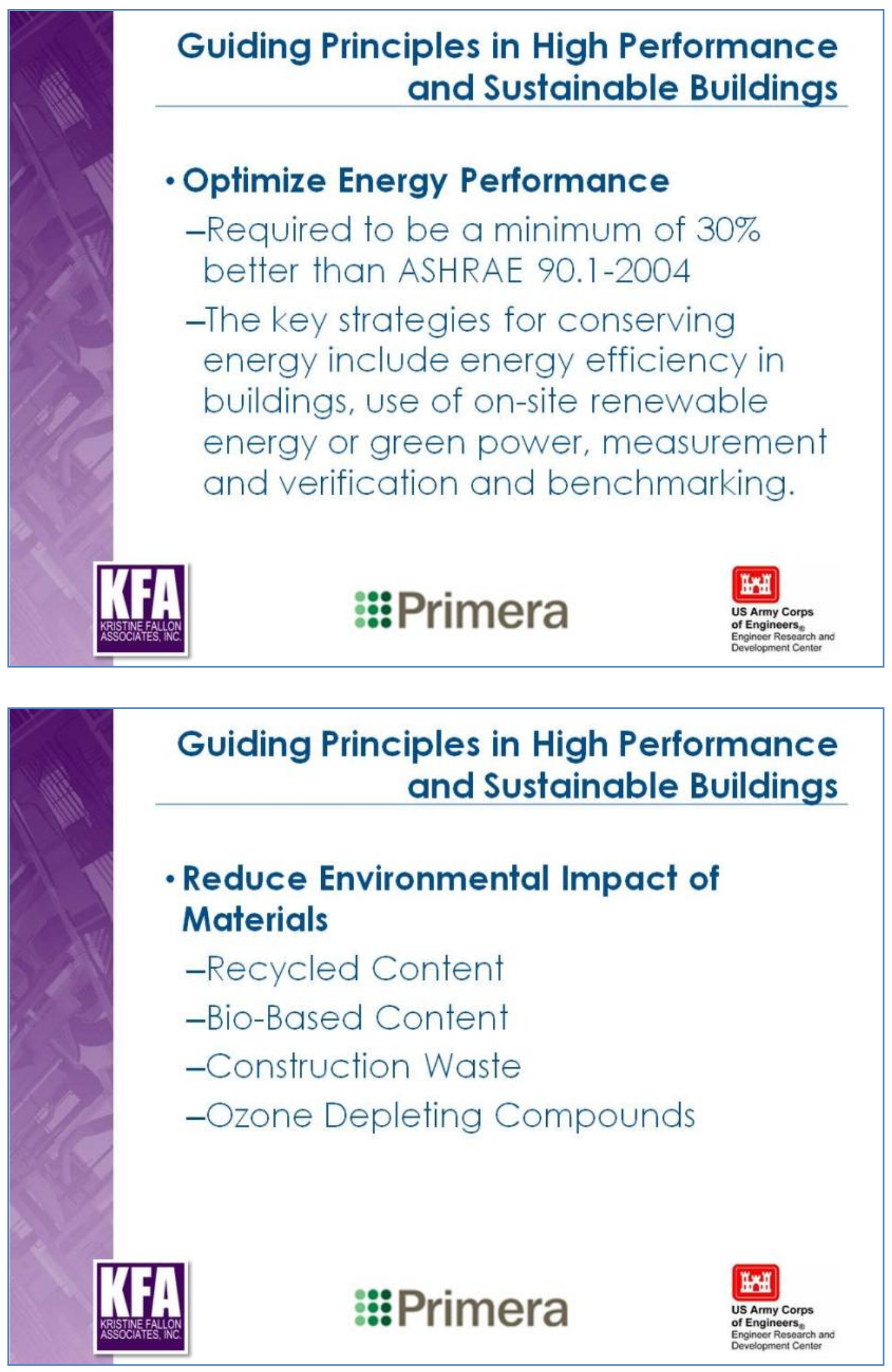


\section{Guiding Principles in High Performance and Sustainable Buildings}

- Enhance Indoor Environmental Quality

-Ventilation and Thermal Comfort

-Moisture Control

-Daylighting

-Low-Emitting Materials

-Protect Indoor Air Quality during

Construction

-Smoke Free

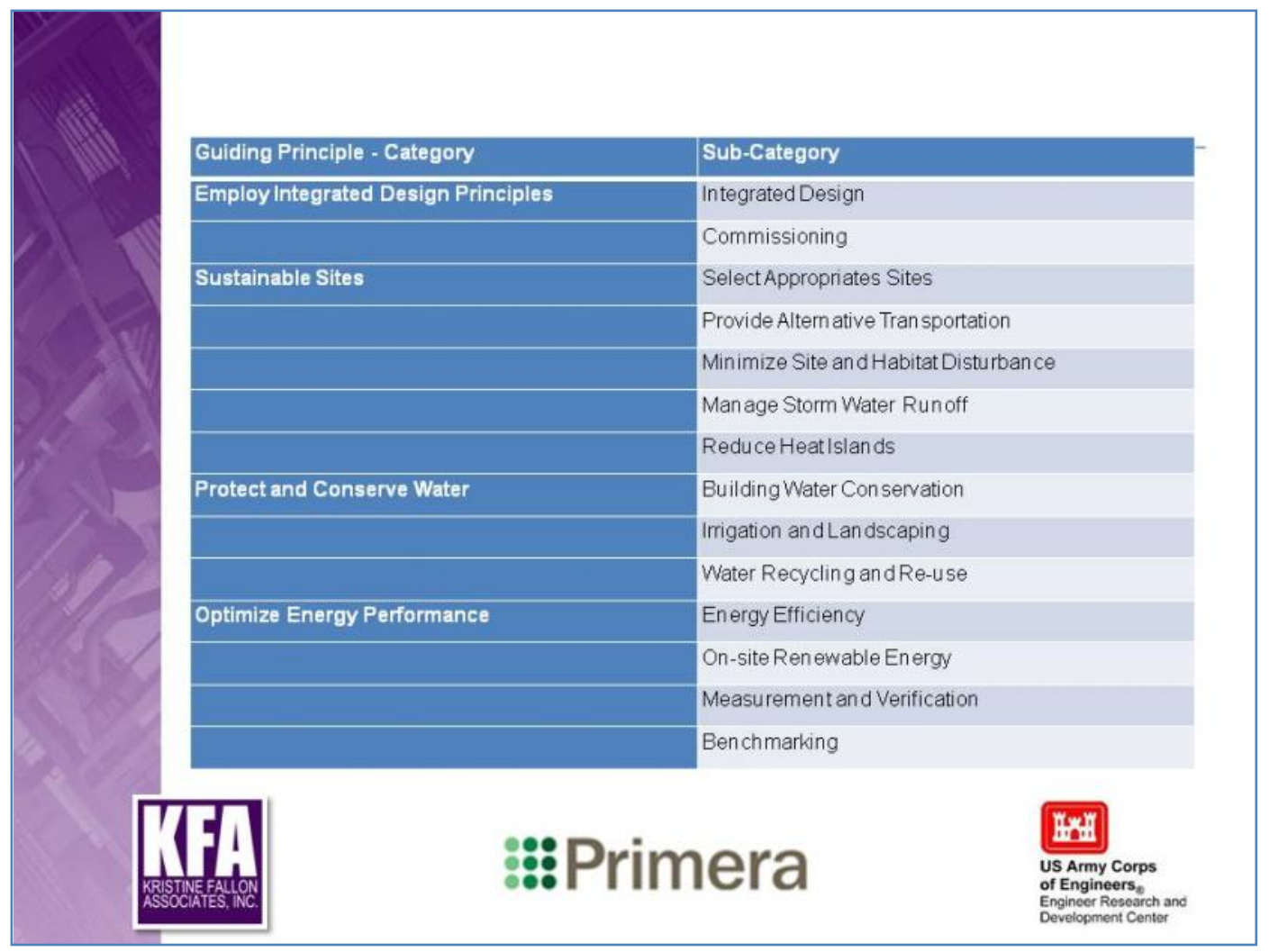




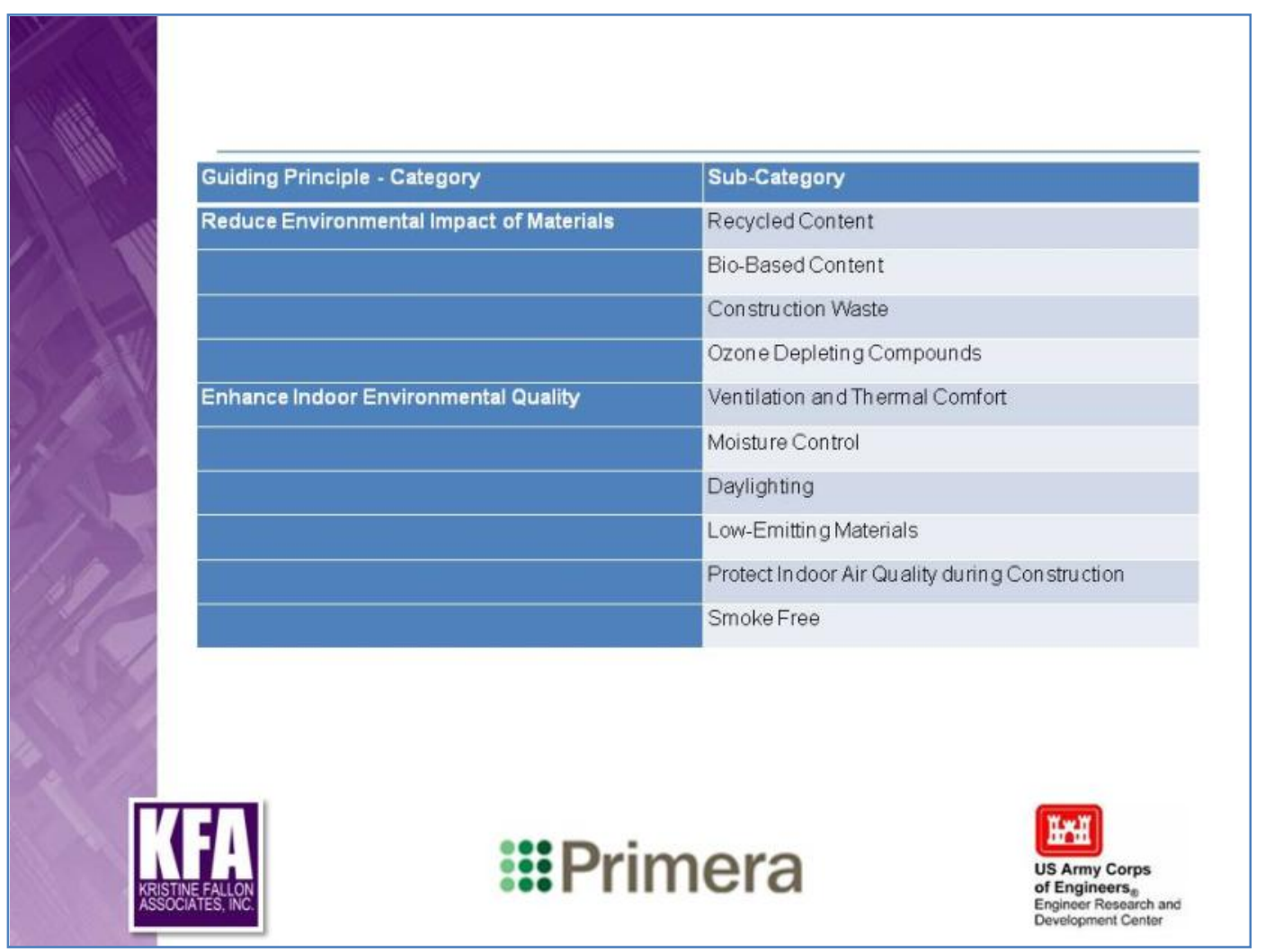




\section{Gap Analysis - Holly Genc and Josh Greenfield, Primera}
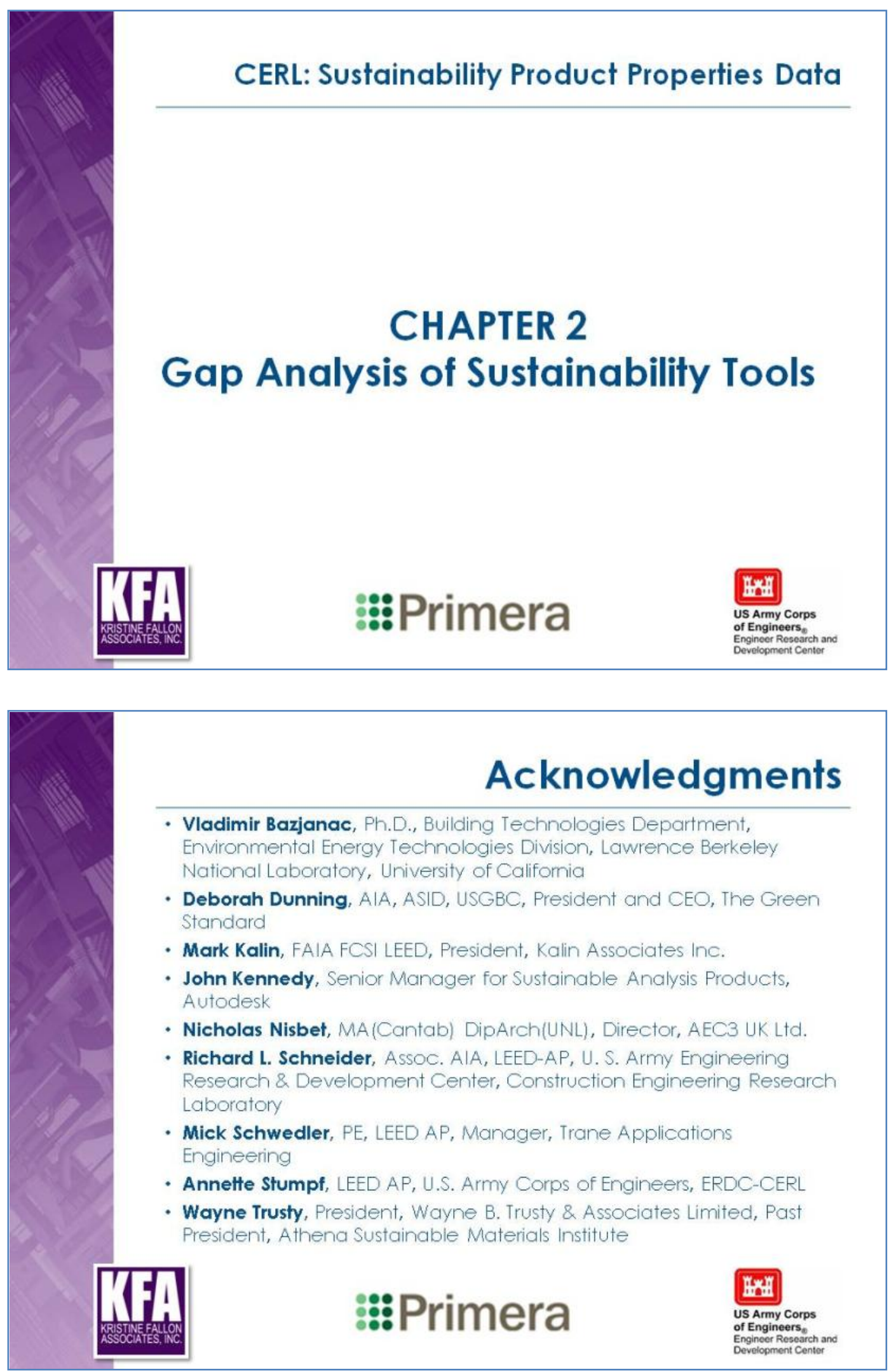

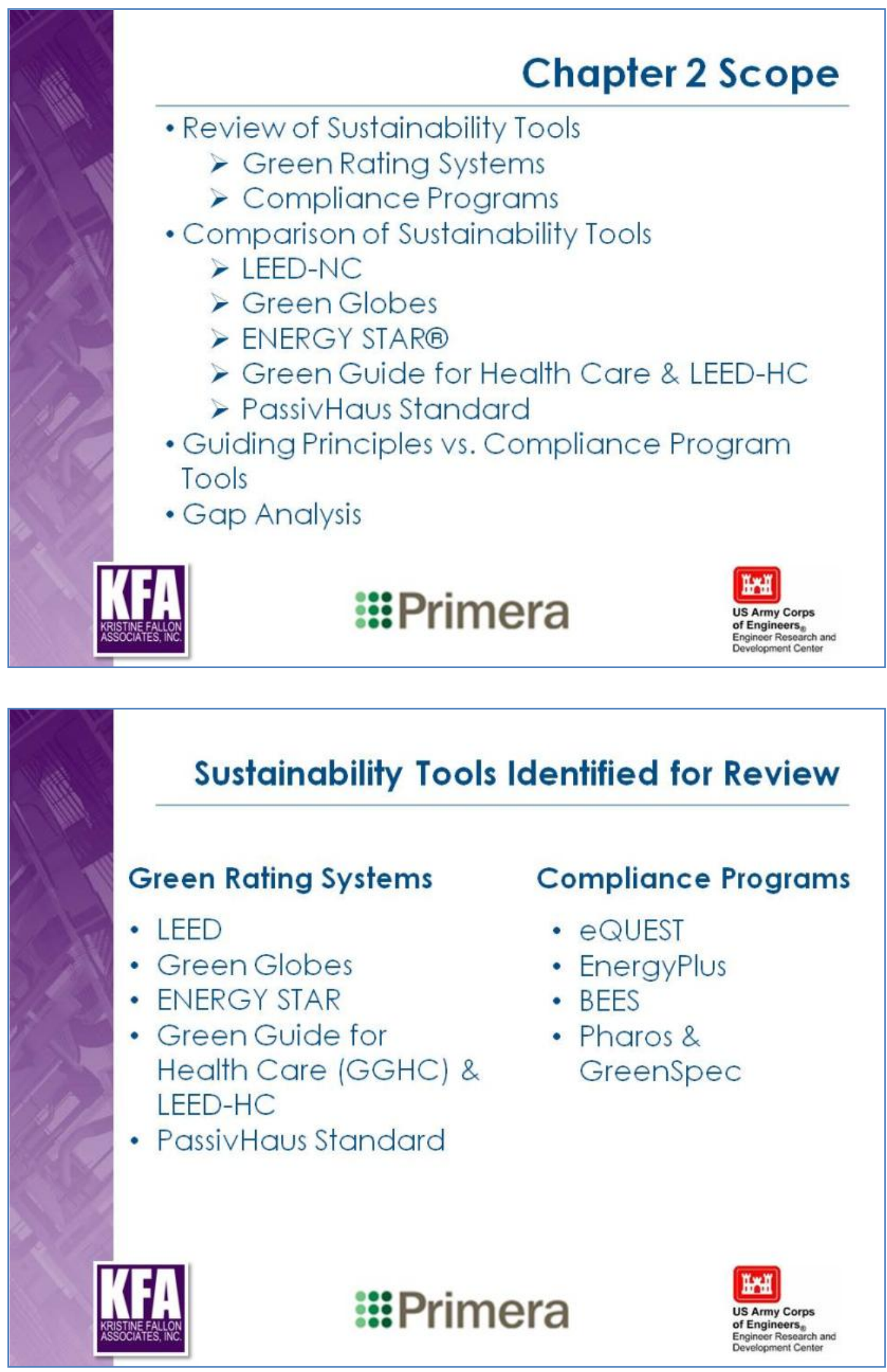

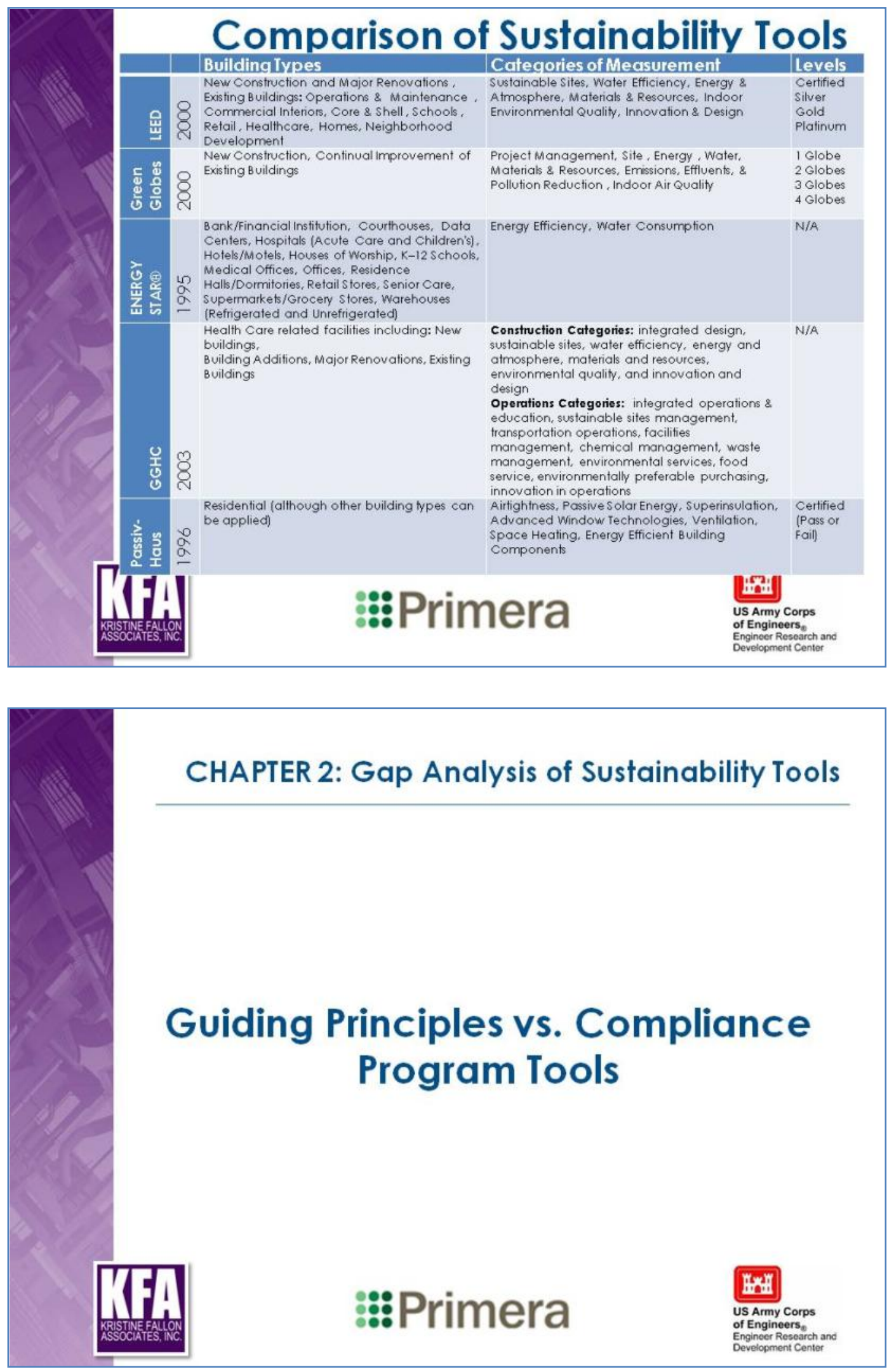

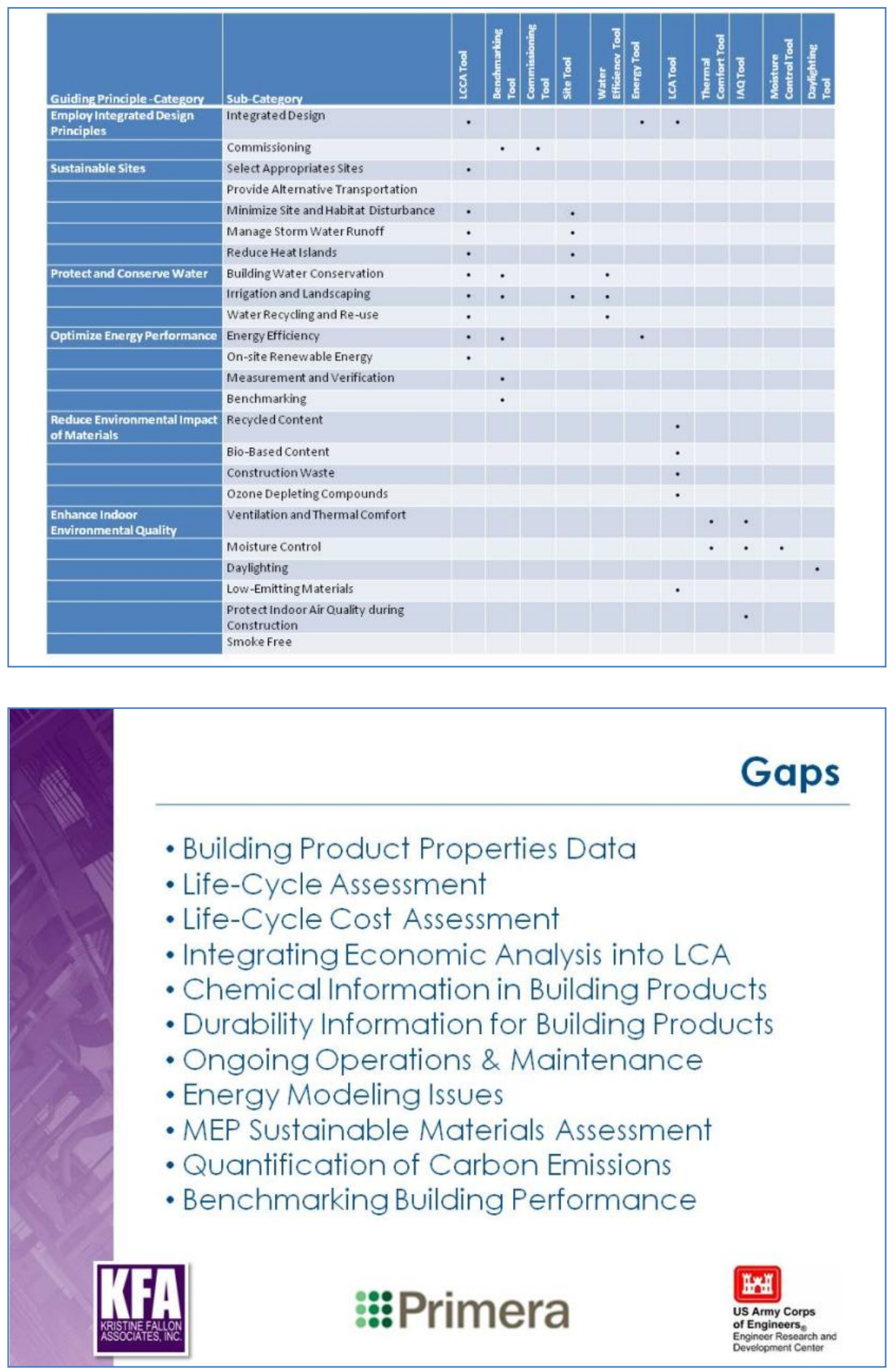


\section{Building Product Properties Data}

- Ideally, a standardized template provided by the manufacturer would list any information required as inputs to the COMPLIANCE PROGRAMS used to meet the RATING SYSTEM criteria

- Need to know what standards a building product should follow

-What set of properties should be required information

- How is this information validated

- These questions lead us to look at LCA-based Environmental Product Declarations (EPD) 


\section{Life-Cycle Cost Analysis}

- Life-Cycle Costing focuses on the dollar costs of building and maintaining a structure over its life cycle

- Required to substantiate decisions made

- Lack of good cost data available

Chemical Information in Building Products
- Green Rating Systems do reward
inclusion of Low-Emitting Materials
- Do NOT require elimination of
building products that contain
toxins
- Problem: chemical information is
not readily available


Building Product Durability Information

- Army Facilities are built to last 50+ years

- Need information of building products'

$>$ Long term reuse

$>$ Recycling

> Disposal implications

Ongoing Operations \& Maintenance
- Important tenet of sustainability
- Offsets potential higher first costs of
higher efficiency systems and metering
- Additionally, training and education of
maintenance staff and occupants is
important
- Although not addressed in most of the
Green Rating Systems discussed, it can
be borrowed from LEE-EBOM and is
provided in Green Guide for Health
Care




\section{Energy Modeling Issues}

- Energy Modelers that are not qualified are creating inaccurate models (GIGO)

- Building Design is dynamic, Modeling Tools are static

- Process for updating the software does not keep pace with the latest technologies

MEP Sustainable Materials Assessment
- Mechanical/Electrical/Plumbing
Equipment and Fixtures are very
complex
- Made up of several components
that require individual life-cycle
analysis
- Green Rating Systems do not
address M/E/P sustainable
materials
a.Primera




\section{Quantification of Carbon Emissions}

- Most Green Rating Systems reduce carbon emissions in an indirect way

- They do not do so in a manner that is easily quantifiable or open to accountability 

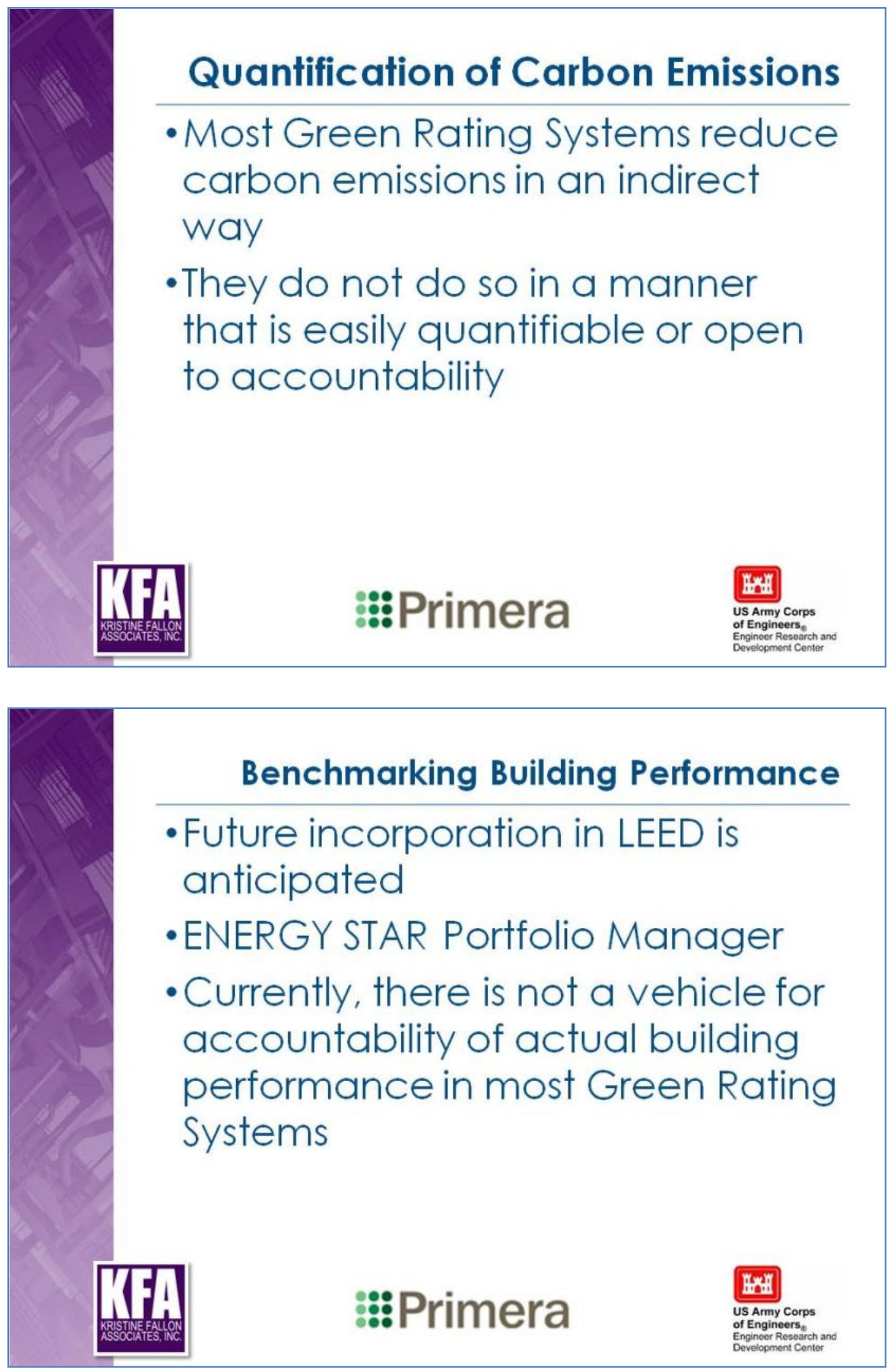
Using Building Energy Performance (BEP) Simulation in AECOO Industry Vladimir Bazjanac

Dr. Bazjanac's slides were unavailable for publication.

Life-cycle Assessment (LCA), Product Category Rules (PCRs), Environmental Product Declarations (EPDs) - Paul Bertram

\section{ERDC-CERL Sustainability Product Properties Workshop}

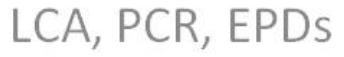

Paul Bertram, FCSI, CDT, LEED AP

Director, Environment \& Sustainability

Kingspan Insulated Panels, North America 


\section{ISO Standards}

- ISO 14021:1999, Environmental labels and declarations - Self-declared environmental claims (Type II environmental labeling)

- ISO 14024:1999, Environmental labels and declarations - Type I environmental $3^{\text {rd }}$ party labeling

- ISO 14040:20061, Life cycle assessment

- ISO -21930, Sustainability in building construction

- Environmental declaration of building products

- ISO 14025 for the EPD of building products

- PCR - Product Category Rules

- set of specific rules, requirements and guidelines for developing Type III environmental declarations

\section{Preparation of a PCR document.}

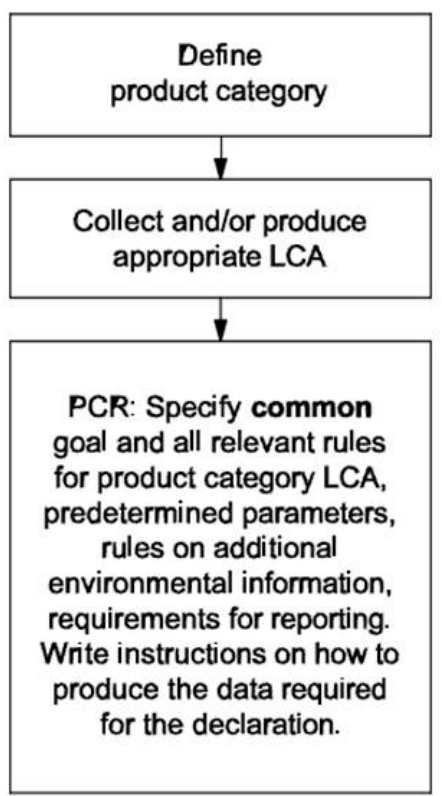




\section{PCR System Boundaries}

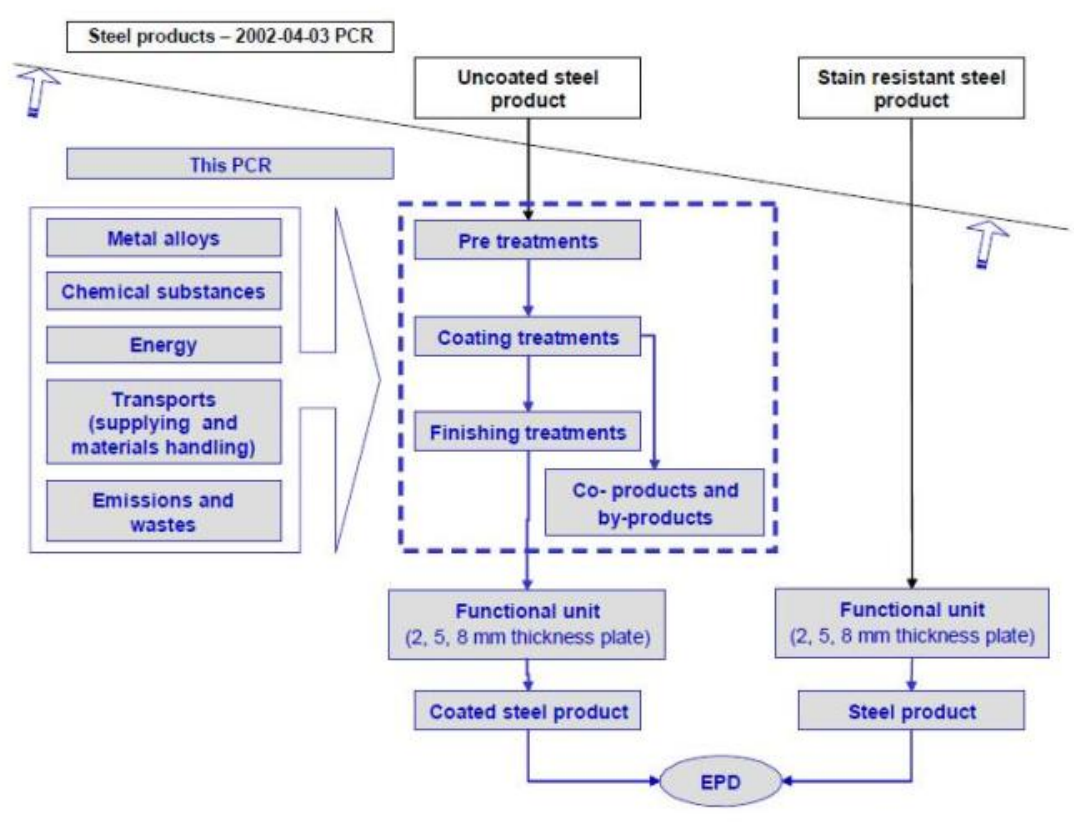

\section{Life Cycle Impact Assessment Metal Insulated Panels}

- Goal and Scope of the Study

- Cradle to Grave

- Cradle to Gate

- Cradle to Cradle

Figure 1: System Boundaries

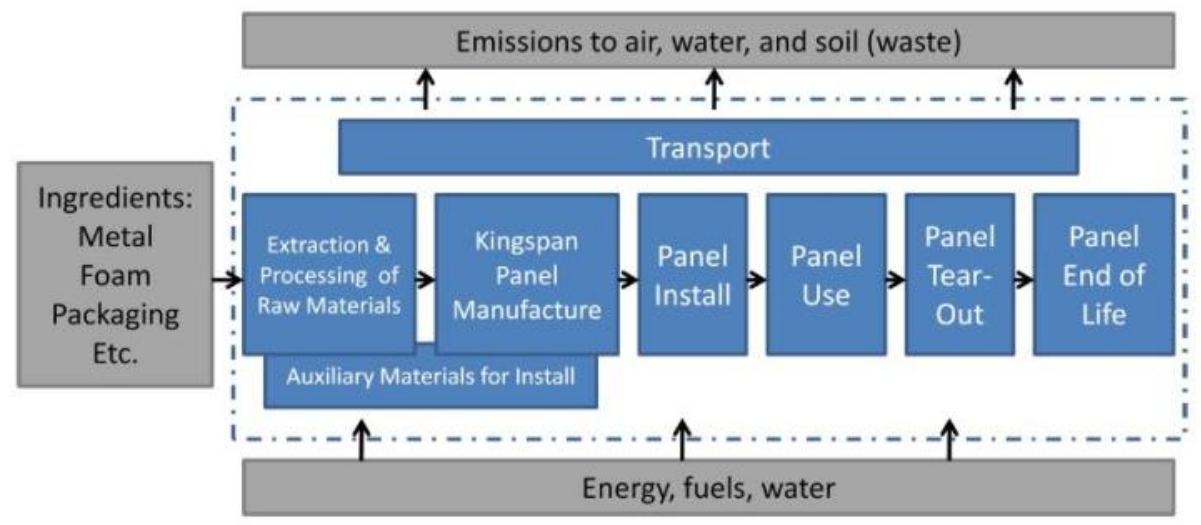




\section{Life Cycle Impact Assessment Methodology \& Impact Categories}

- TRACI (Tool for the Reduction and Assessment of Chemical and Other Environmental Impacts) Impact Categories

http://www.epa.gov/nrmrl/std/sab/traci/

- Environmental Impact Characterizations:

o Global Warming Potential (GWP) [kg CO2 eq];

o Acidification Potential (AP) [mol $\mathrm{H}+$ eq];

o Eutrophication Potential (EP) [kg N eq];

o Ozone Depletion Potential (ODP) [kg CFC-11 eq];

o Smog Creation Potential (Smog) [kg NOx eq];

- Environmental Indicators

- IPCC - Intergovernmental Panel on Climate Change

o Primary Energy Demand of fossil energy resources (PED Fossil) [MJ net calorific];

o Primary Energy Demand of renewable resources (PED Renew) [M] net calorific];

o Resource Consumption (e.g. crude oil, coal, nat gas) [MJ net calorific];

\section{EPD Development}

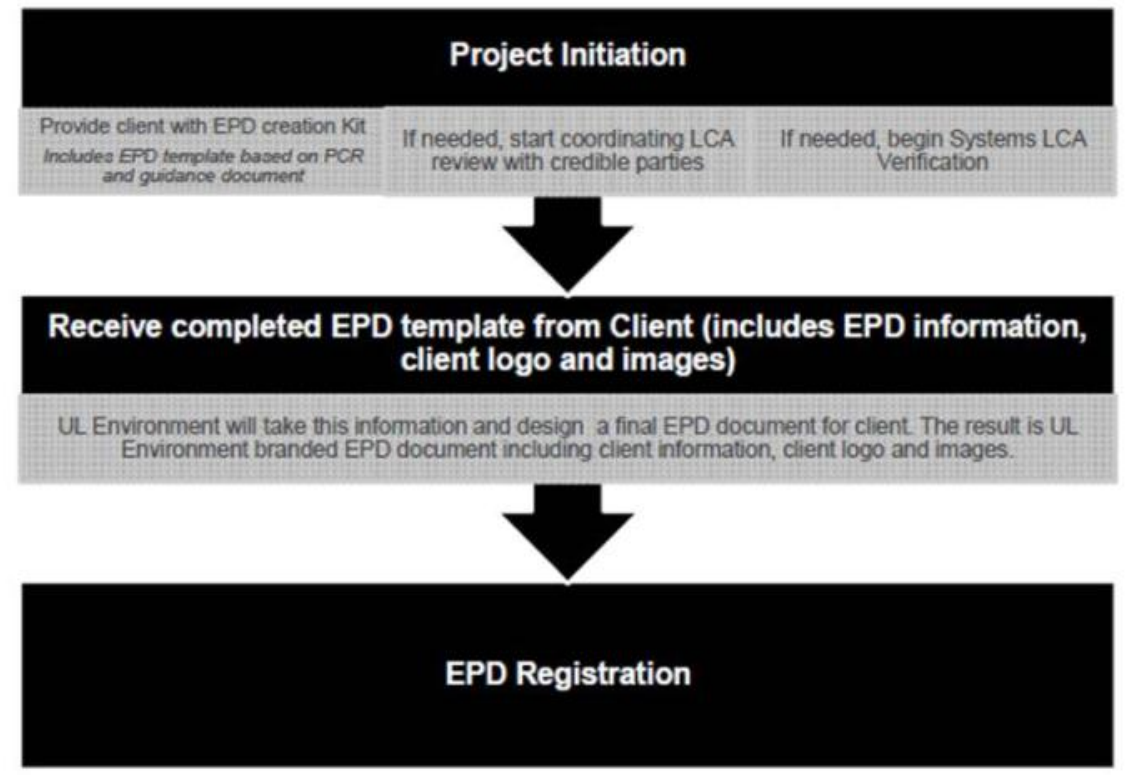




\section{EPDs}

- ISO 14025 for the EPD of building products

- PCR - Product Category Rules (CSI MasterFormat)

- set of specific rules, requirements and guidelines for developing Type III environmental declarations

- Responsibilities of the program operator

- The program operator shall be responsible for the administration of a Type III environmental declaration

- preparing, maintaining and communicating general program instructions;

- publishing the names of the organizations actually involved as interested parties in the program development

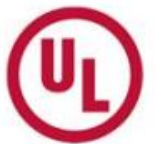

\section{EPD}

An environmental product declaration

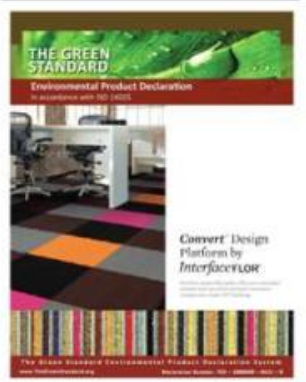

WHERE DO IMPACTS OCCUR?

Across all impact categories, more than $60 \%$ of

the impacts occur in the extraction of raw materials.

"The numbers below are based on the EPD for Convert

products with Type 6,6 Nylon
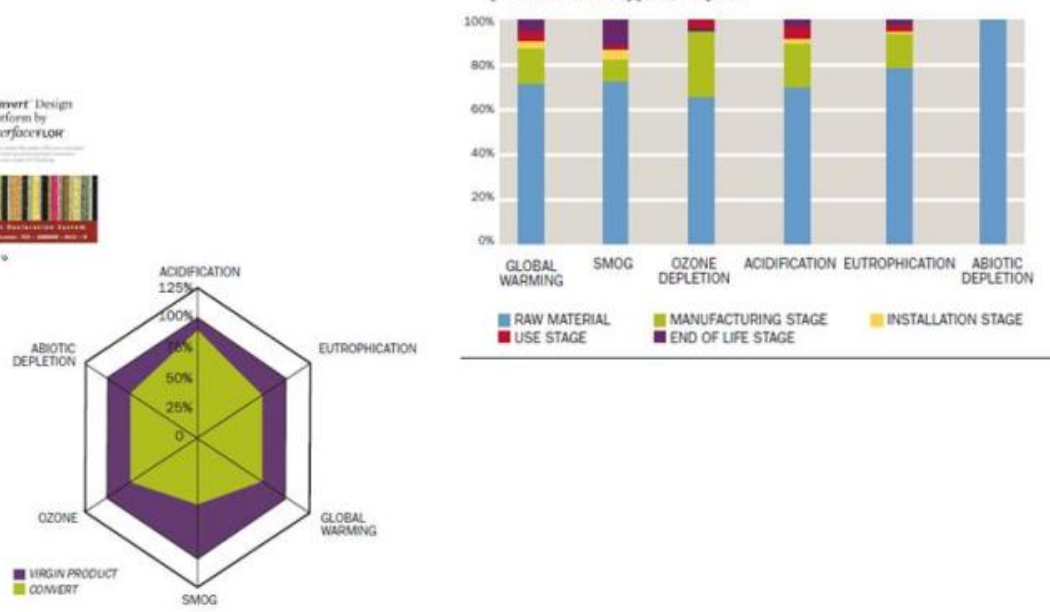


\section{QUESTIONS}

\section{ERDC-CERL Sustainability Product Properties Workshop}

LCA, PCR, EPDS

Paul Bertram, FCSI, CDT, LEED AP

paul.bertram@kingspan.com

Director, Environment \& Sustainability

Kingspan Insulated Panels, North America 
Green Building XML (gbXML): The Open XML Schema for Sustainable Design - John Kennedy

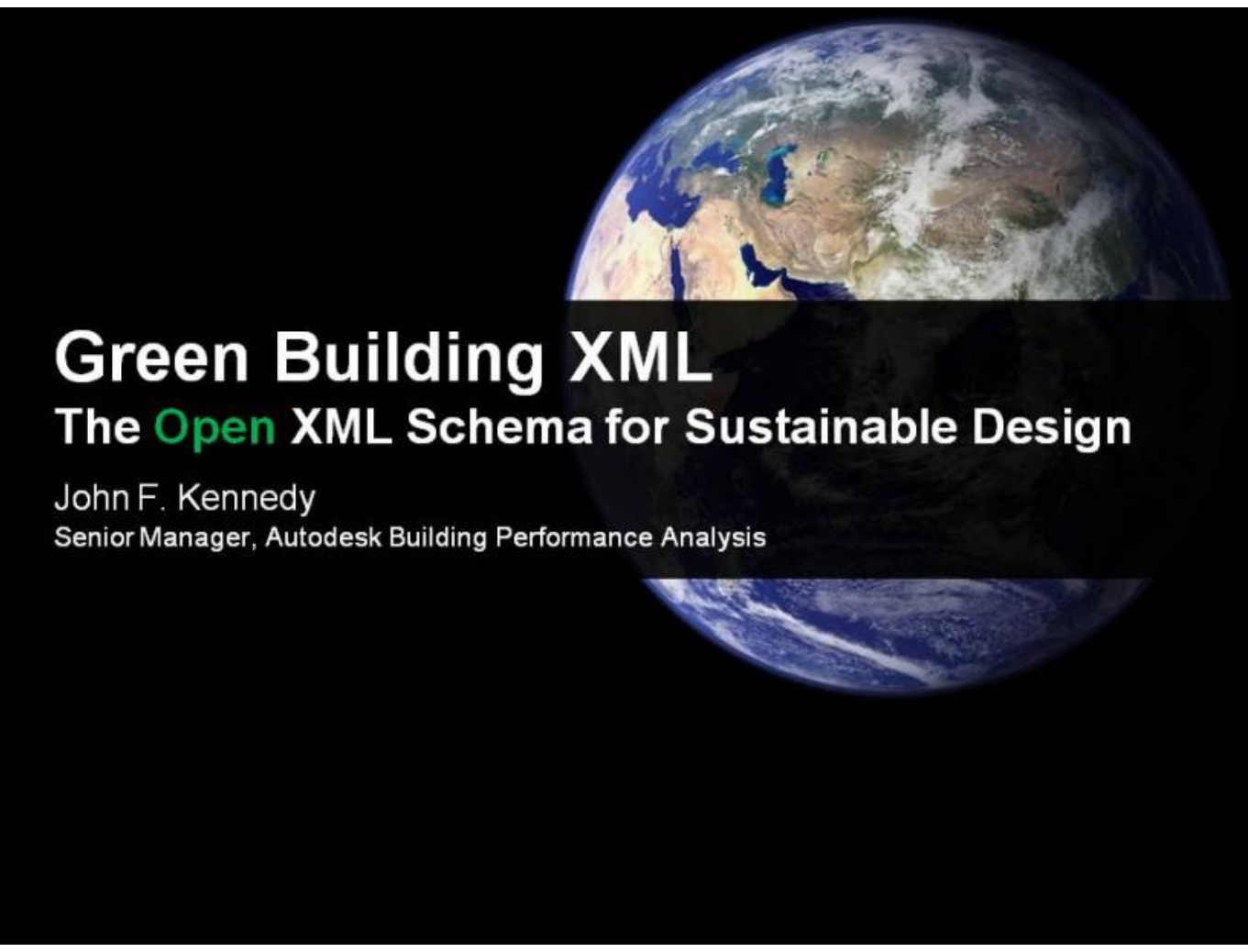

\section{ASHRAE SPC 205}

Title: Standard Representation of Performance Simulation Data for HVAC\&R and Other Facility Equipment

Purpose: To facilitate sharing of equipment characteristics for performance simulation by defining standard representations such as data models, data formats, and automation interfaces.

Scope: This standard applies to data used in the performance simulation of any HVAC\&R or other facility system, equipment, or component.

Chair: Chip Barnaby, cbarnaby@wrightsoft.com 


\section{Green Building XML History}

- Data exchange between 3D-CAD and Green analysis applications

- Development started Dec. 1999

- Published June 2000

- Funding - development and promotion

- California Energy Commission

- Green Building Studio, Inc.

- Pacific Gas \& Electric

\section{Ownership \& Support}

- Non-proprietary open data standard - Not owned by Autodesk or anyone else - Maintained by the industry

- 11 member board

- 1500+ members

- 35+ applications support it

-Bi-annual meetings at ASHRAE's meetings 


\section{gbXML Board Members}
- AirNAB
- Autodesk
- Bentley Systems
- Cadsoft
- Carmel Software
- EDSL
- Greenspace Research
- HVAC Solution
- IES
- Trane
- Wrightsoft

\section{Web-Based Initiatives}

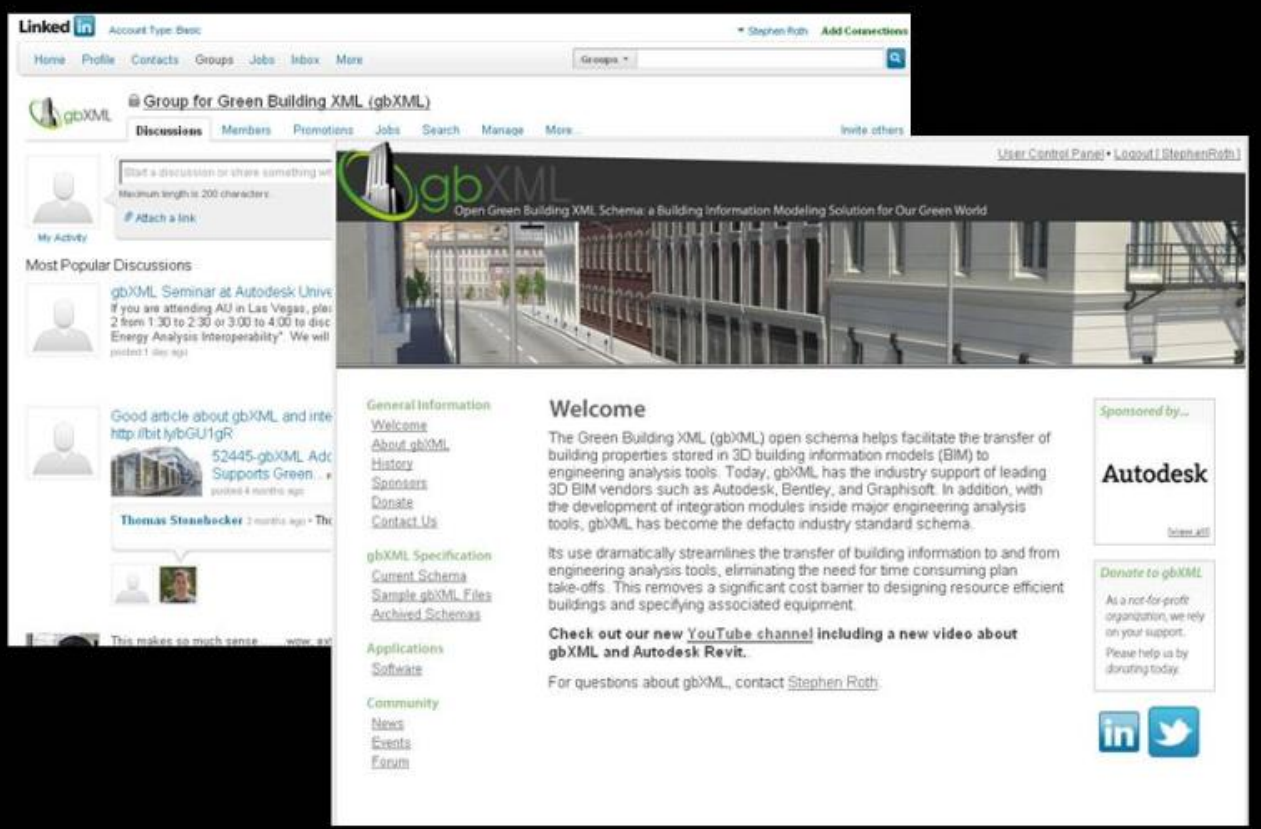




\section{Web-Based Initiatives}

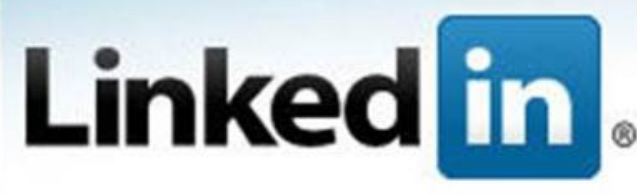

Group for Green Building XML

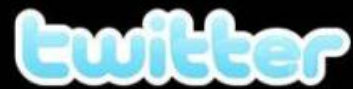

\#gbXML

\section{Main Objective}

- Sustainable Building Analyses

- Minimize human interpretation

- Relieve Pain

- Consistency of data \& analysis

- Next update tighter mapping to COMNET descriptors

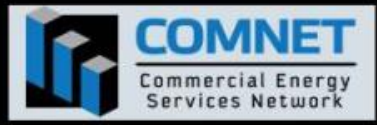




\section{Sustainable Building Analyses}

- Whole building energy use \& costs

- Water use \& costs (indoor, outdoor, and deatchment)

- Carbon emissions

- Heating and cooling load analysio

- LCA

- Renewable energy

- HVAC equipment sizing

- Lighting analysis

- CFD analysis

- Fire analysis

- Solar/shading analysis

- Energy code compliance

- Thermal comfort

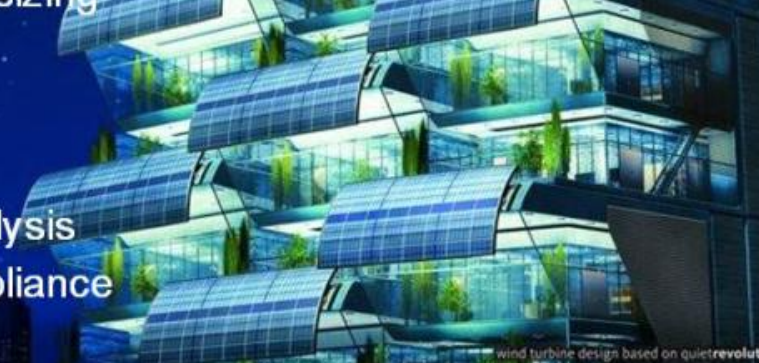

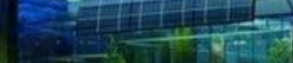

\section{Data Capabilities}

- 3D planar polygon geometry

- 2D rectangular polygon geometry

- Space boundaries $\left(1^{\text {st }} \& 2^{\text {nd }}\right)$

- Opaque constructions and materials

- Thermal and emission properties, recycled content,

- Costs including LCA (embodied, first, and future)

- Fire properties

- Glazing, shades, and their operation

- Internal and external equipment

- Energy, power, efficiencies, water use, physical characteristics

- Costs including LCA (embodied, first, and future)

- Lighting and controls 


\section{Data Capabilities, cont'd.}

- HVAC equipment

- Weather design data

- Ventilation requirements

- Operation schedules

- Occupancy, lighting, equipment, HVAC, temperatures.

- Infiltration

- Transportation types, location, \& schedule

- Vegetation types, location, \& water use.

- Site generation (solar, wind)

- Versioning and change history

- Simulated and measured results

\section{No other open format has these capabilities!}

\section{gbXML Support - BIM and 3D-CAD}

- Autodesk

- AutoCAD Architecture \& MEP

- Revit Architecture \& MEP

- Project Vasari

- LandXplorer

- Bentley

- Architecture

- Building Mechanical Systems

- Speedikon Architectural

- CADSoft

- Envisioneer

- Google

- SketchUp (Greenspace plug-in)

- Graphisoft

- ArchiCAD (Encina plug-in)

- Onuma BIMStorm 


\section{gbXML Support - Analysis}

- Autodesk

- Green Building Studio - DOE-2.2 \& EnergyPlus

- Ecotect Analysis

- DOE-2.2 \& EnergyPlus

- Bentley

- AECosim

- EnergyPlus

- Carmel Software

- EDSL - TAS

- Trane - TRACE 700

- IES VE

- Carrier - HAP

- E4tech Software SA
- CADLine - Cymap

- Elite Software

- EnergySoft - EnergyPro

- blueCAPE - OpenFOAM

- DesignBuilder

- EnergySoft - EnergyPro

- HVAC Solution

- Greenspace Live - Live Energy/EPC

- Solar-Computer GBIS

- DIALux

- LBNL's EnergyPlus GUI

- NREL's OpenStudio

\section{Performance Data - Window}

- Glazing Example

- Actual Manufacturer data

- Analysis ready data

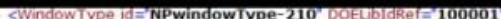
AName>PPG Double Pane SB70xL </Name>

DescriptionsPPG Double Pane SB70XL </Descriptions

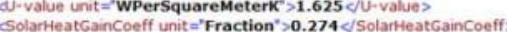

STransmittance type ='Visible'>0.643 $<$ Transmittances

aclaze id ='Glaze-L1-NPwindow Type-210"

description $>$ PPG $\$$ SB70xL Starphire 6</Description

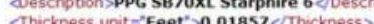

sconductivity unit='WPerMeterk'>1 $>$ Conductivitys

Transmittance type $=$ 'Solar unit $=$ 'Fraction" $>0.28</$ Transmittance $>$ $\left\langle\right.$ Transmittance type $=$ 'Visible' unit $={ }^{\prime}$ Fraction $>0.722</$ Transmittances $<$ Transmittance type $=\mathbf{T R}^{\prime}$ unit="Fraction" $>\mathbf{0}<$ Transmittance $>$

CReflectance type $=$ "ExtSolar" unit $=$ 'Fraction" $>0.499</$ Reflectances CReflectance type ="IntSolar" unit ="Fraction">0.559 </Reflectances CReflectance type $=$ "ExtVisible" unit $=$ "Fraction" $>0.068</$ Reflectance $>$ Reflectance type $=$ 'IntVisible" unit $=$ "Fraction $>0.051<$ Reflect "Emittance type = ExtIR' unit="Fraction" $>0.841</$ Emittances $</$ Glaze>

¿Gap id ='Gas-L2-NPwindowType-210" AName>KRYPTON 3 MM $</$ Name $>$

Description>Krypton</Description

Thickness unit="Feet" $>0.0105$ - Thickness

conductivity unit='wPerMeterk' $>0,1</$ Conductivity $>$

$<$ Gaps

EGlaze id='Glaze-L3-NPwindowType-210"

ANamesPPG CLEAR $6</$ Names

CDESCIDTIOON $>$ PPG CLEAR 6</Description>

STickness unit = Feet' $>0.01857$ - Thickness $>$

(

(1) Transmittance type $=$ - Visible unit = Fraction $>0.886</$ Transmittance

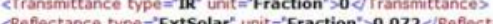
Reflectance $0.0=$ "IntSolar" unit="Fraction" Reflectance type='ExtVisible' unit='Fraction'>0.085 </Reflectances Reflectance type $=$ 'IntVisible" unit="Fraction'>0.085 / /Reflectances $^{\prime}$ Emittance type = "IntrR" unit="Fraction" $>\mathbf{0 . 3 4}</$ Emittance> 〈Glaze> 


\section{Performance Data - Light Fixture}

- Energy

- Photometry

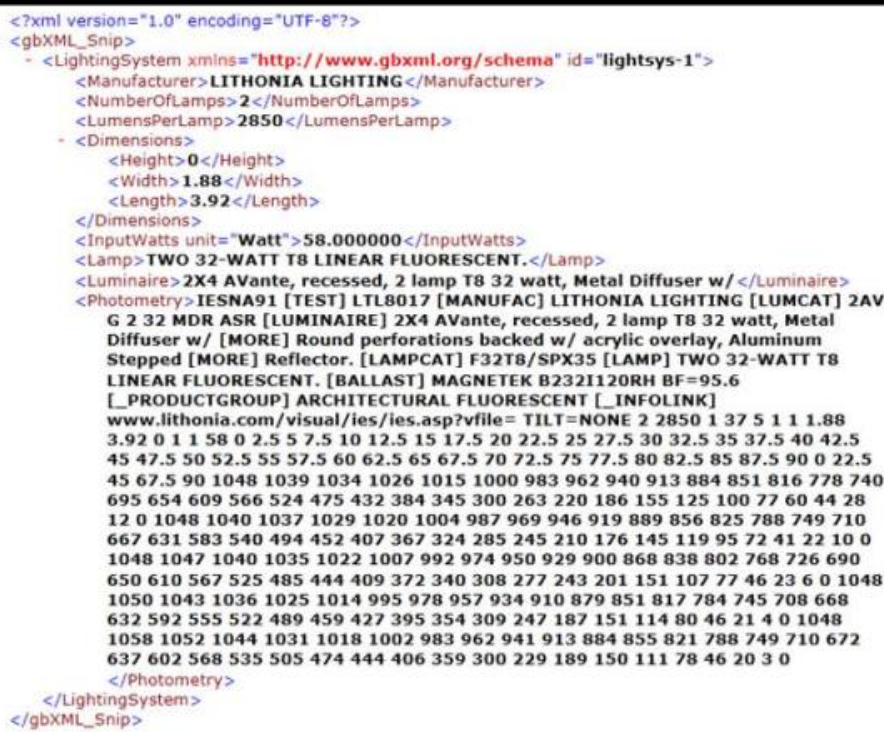

\section{Performance Data - HVAC}

- Energy

- Design Temps

- Capacities

- Part-load data

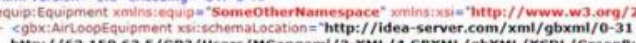

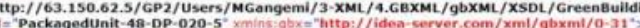

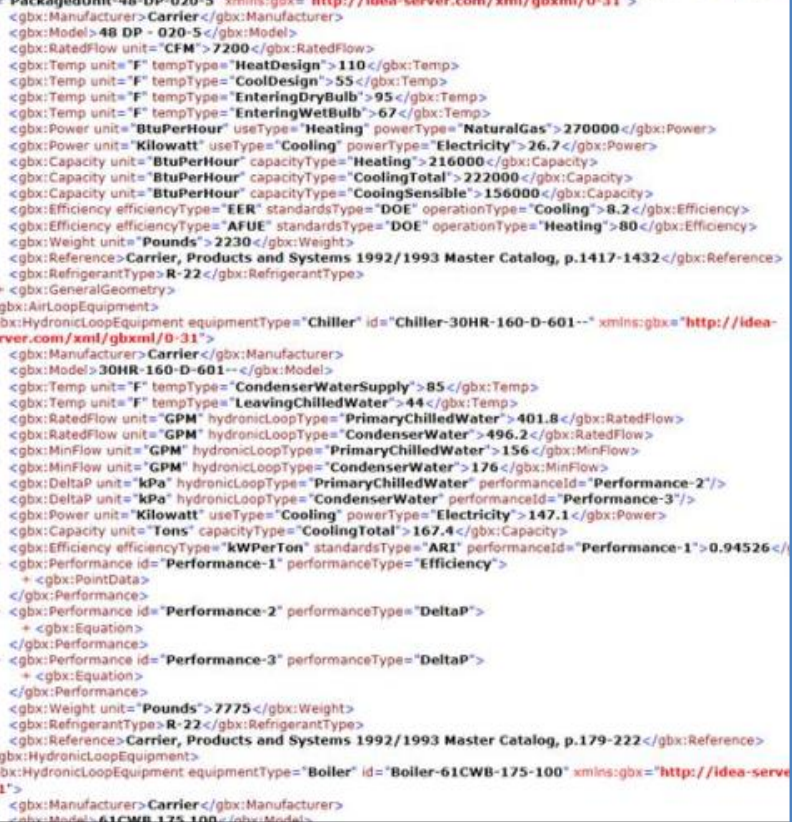




\title{
More Information
}

\author{
Visit www.gbxml.org for \\ schema-related and \\ other information
}

Contact Chair:

Stephen Roth, PE, LEED AP

sroth@carmelsoft.com

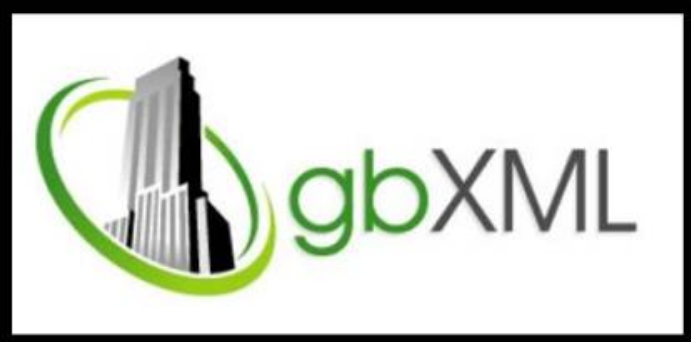


Sustainability Product Properties Discussion - Kristine Fallon and Robert Feldman
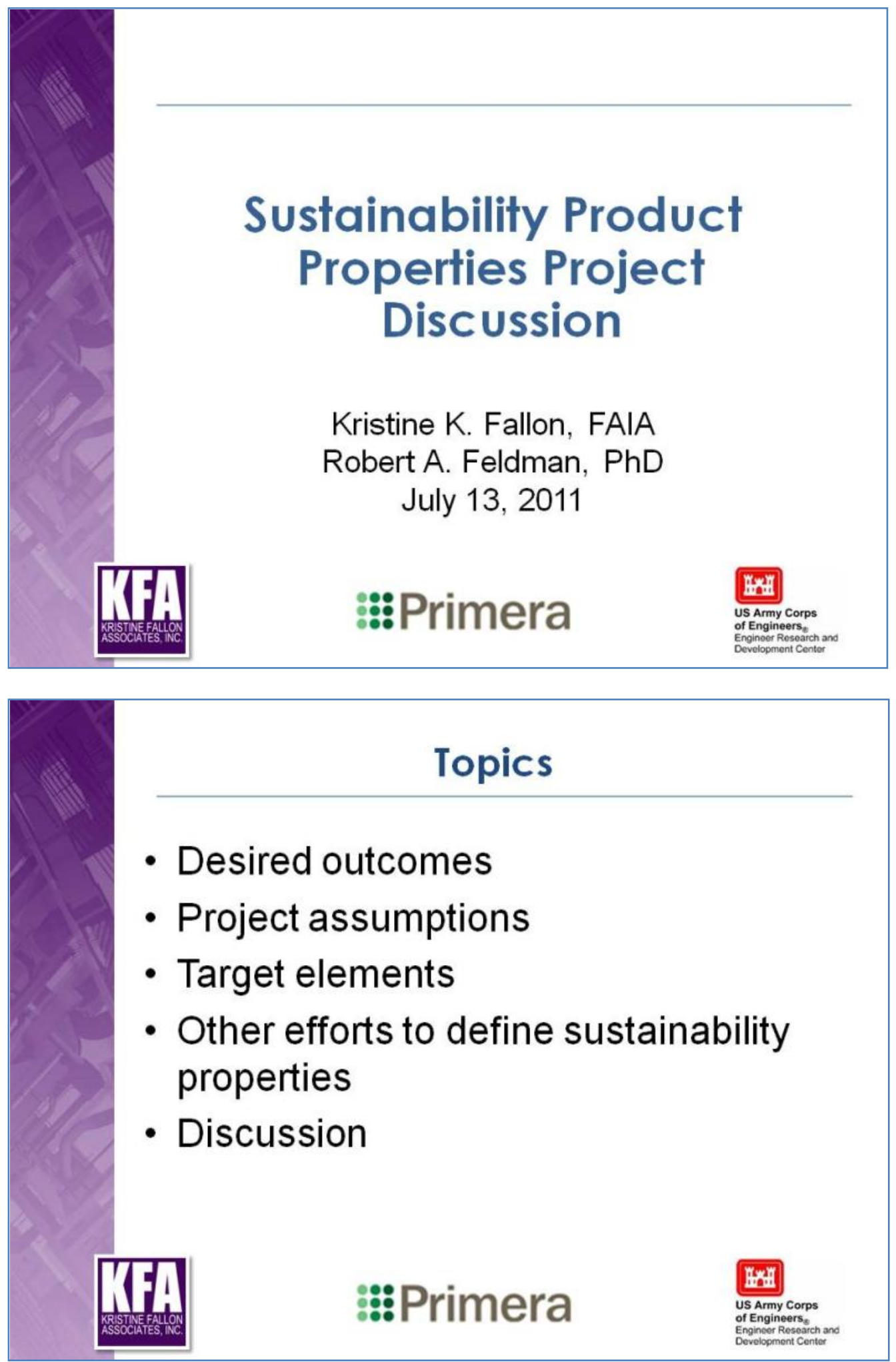


\section{Desired Outcomes}

- Demonstrate need for computable product properties for sustainability analyses

- Identify prior/current work to build upon

- Form working groups to define open source sustainability product properties specifications for architectural, mechanical, electrical and water systems

\section{Project Assumptions}

- Identifying the sustainability properties necessary to selection and analysis of various building products and materials would be useful to the industry

- The goal is to make sustainability assessment and analysis directly computable from a building model (BIM)

- There have been efforts to define necessary/ desired sustainability properties, but for the most part, not in a computable form 

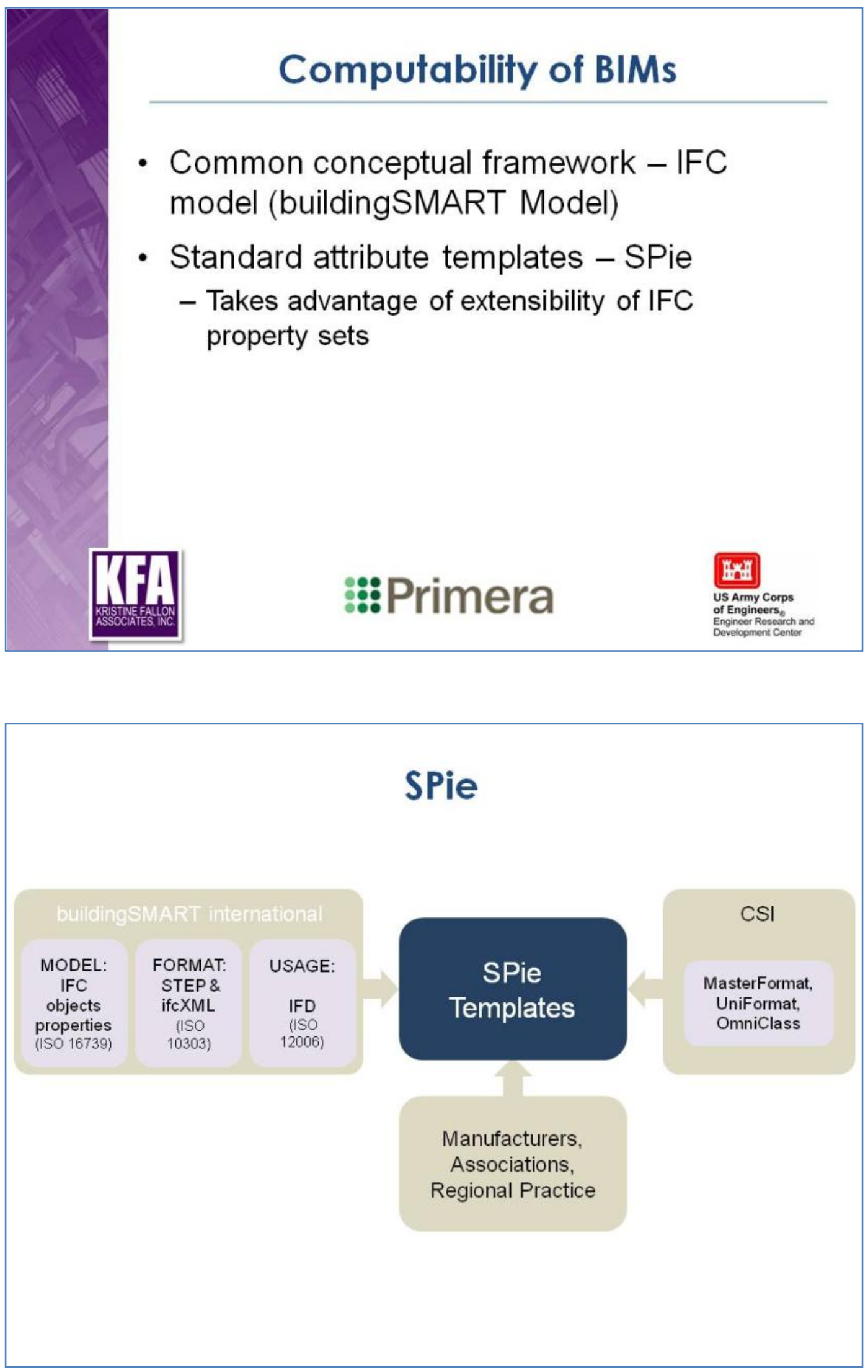

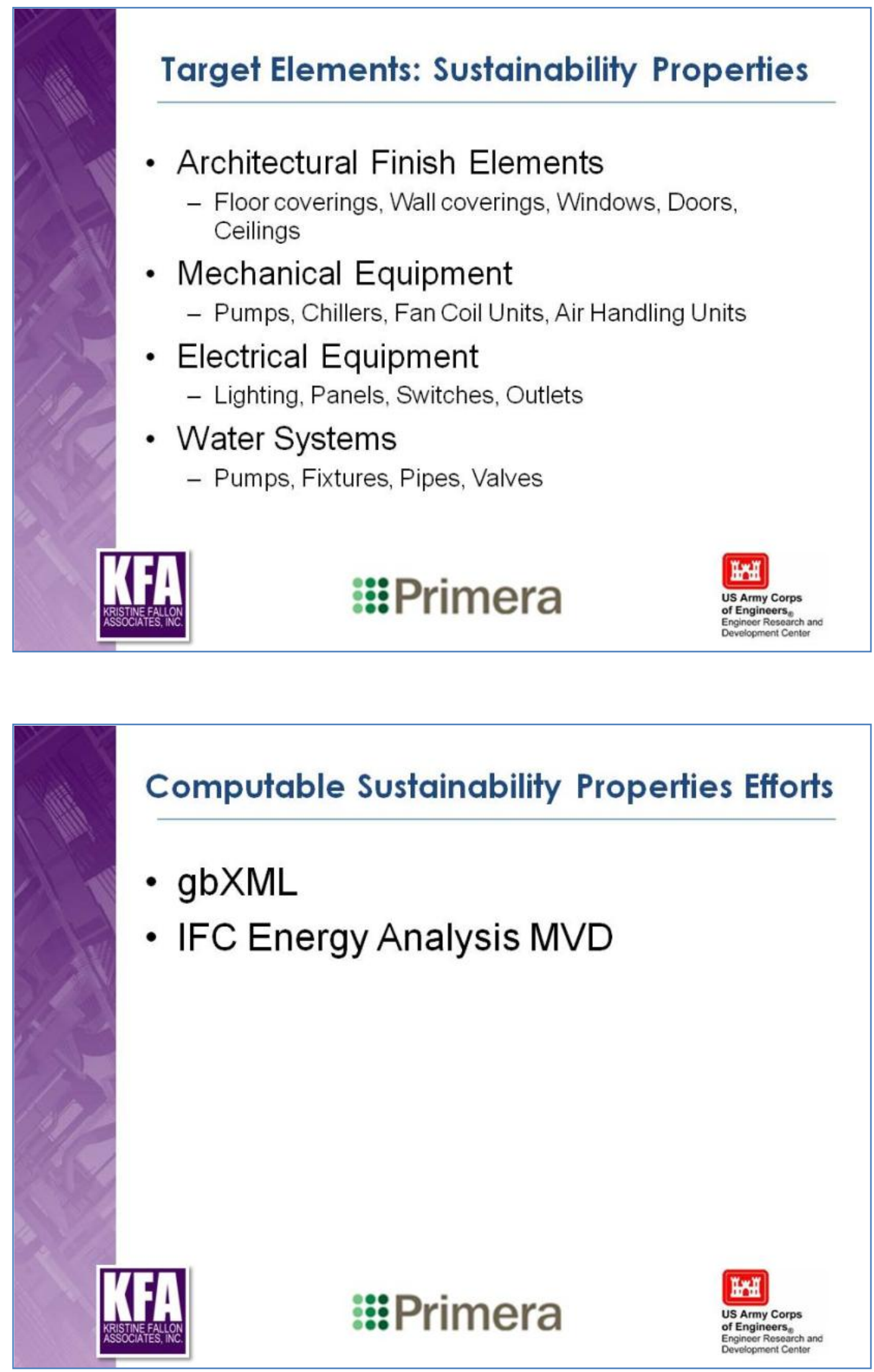

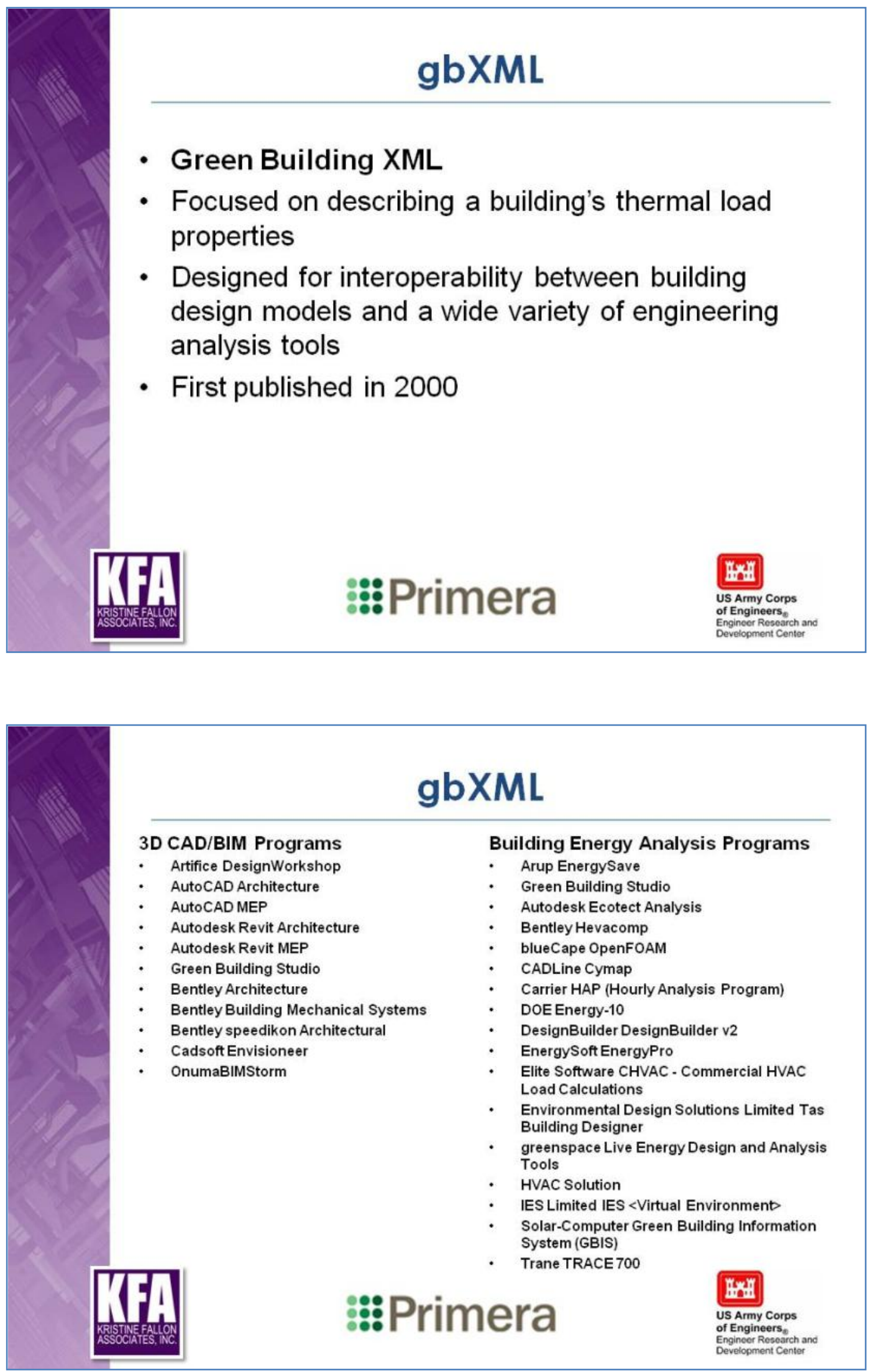


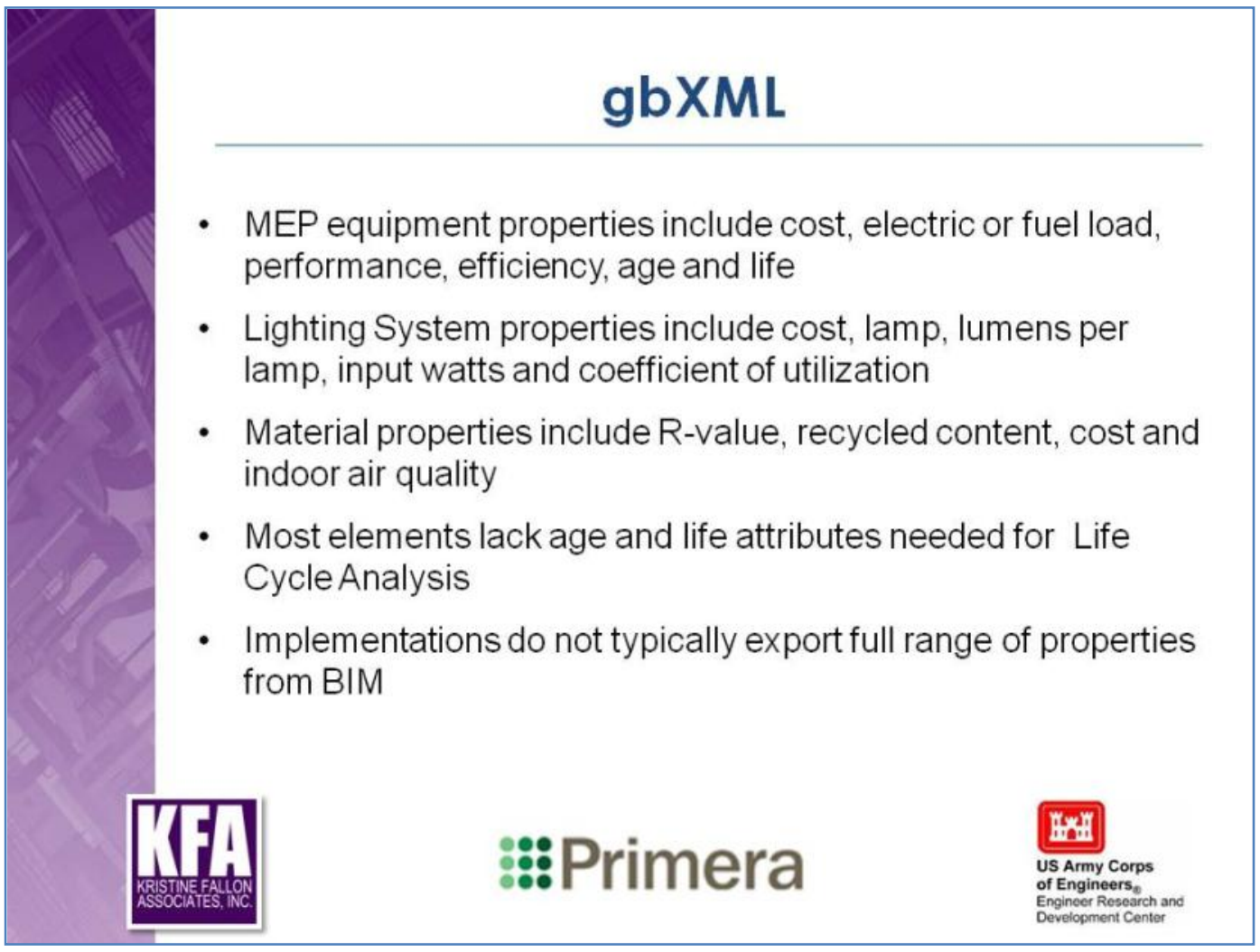

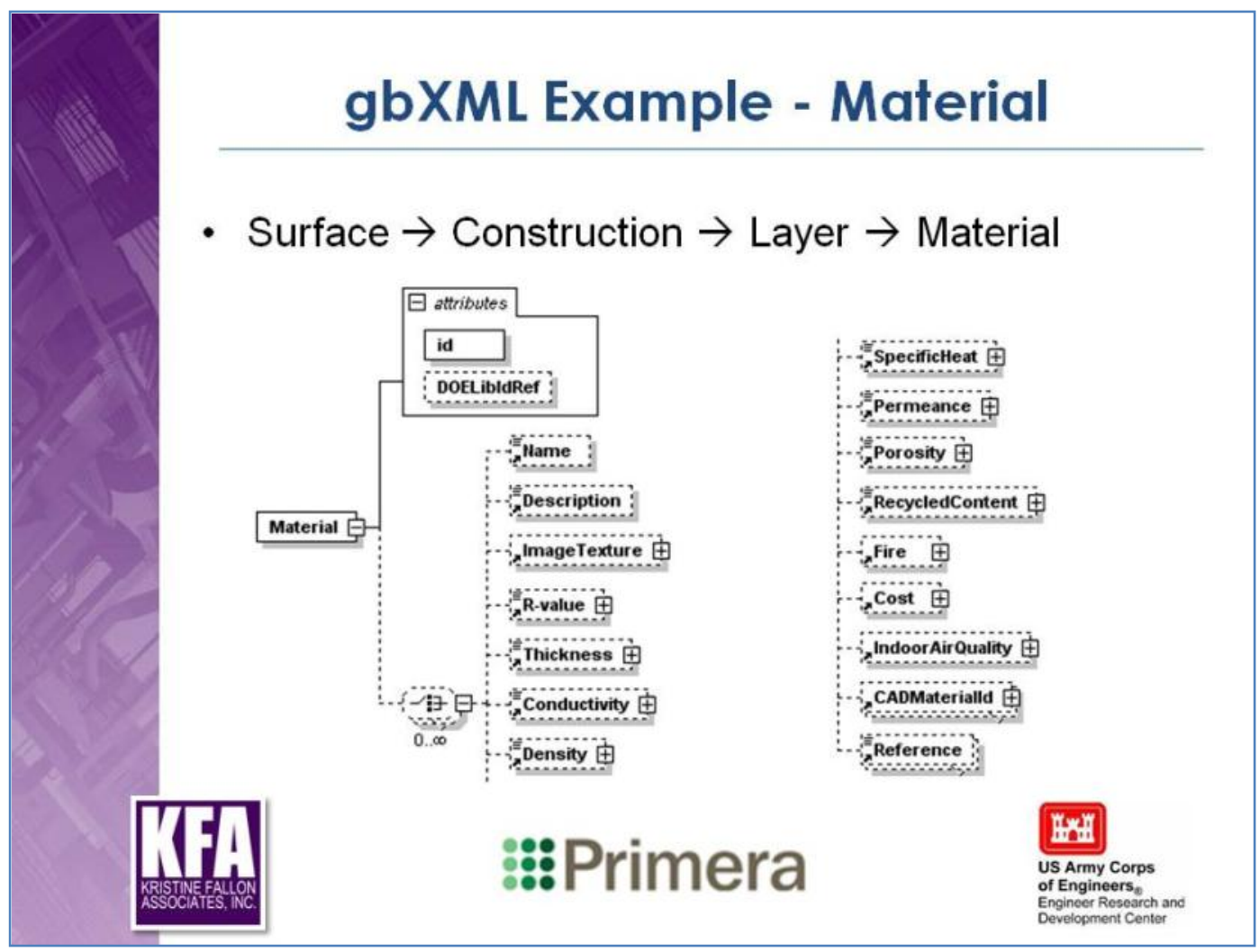




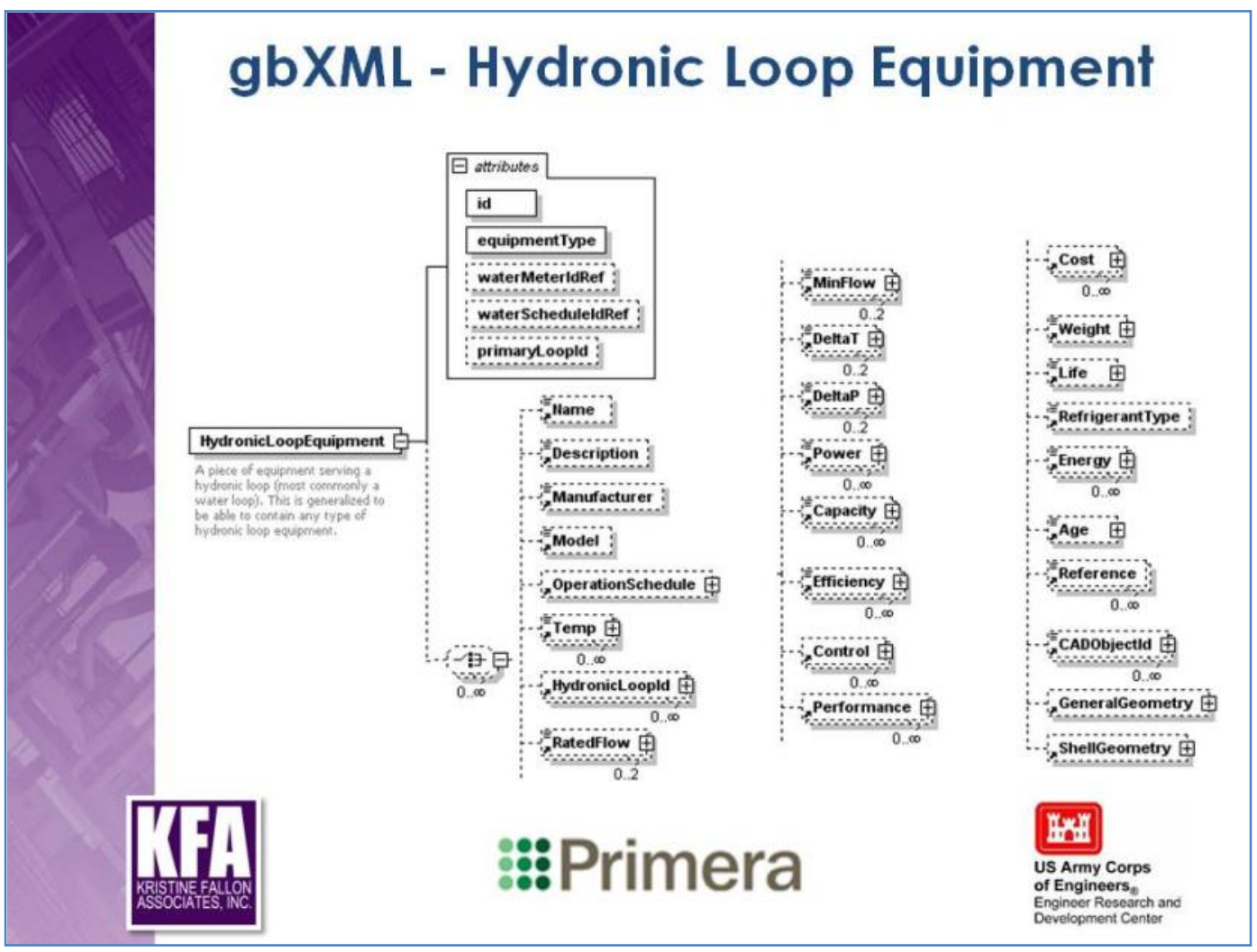

\section{IFC Energy Analysis MVD}

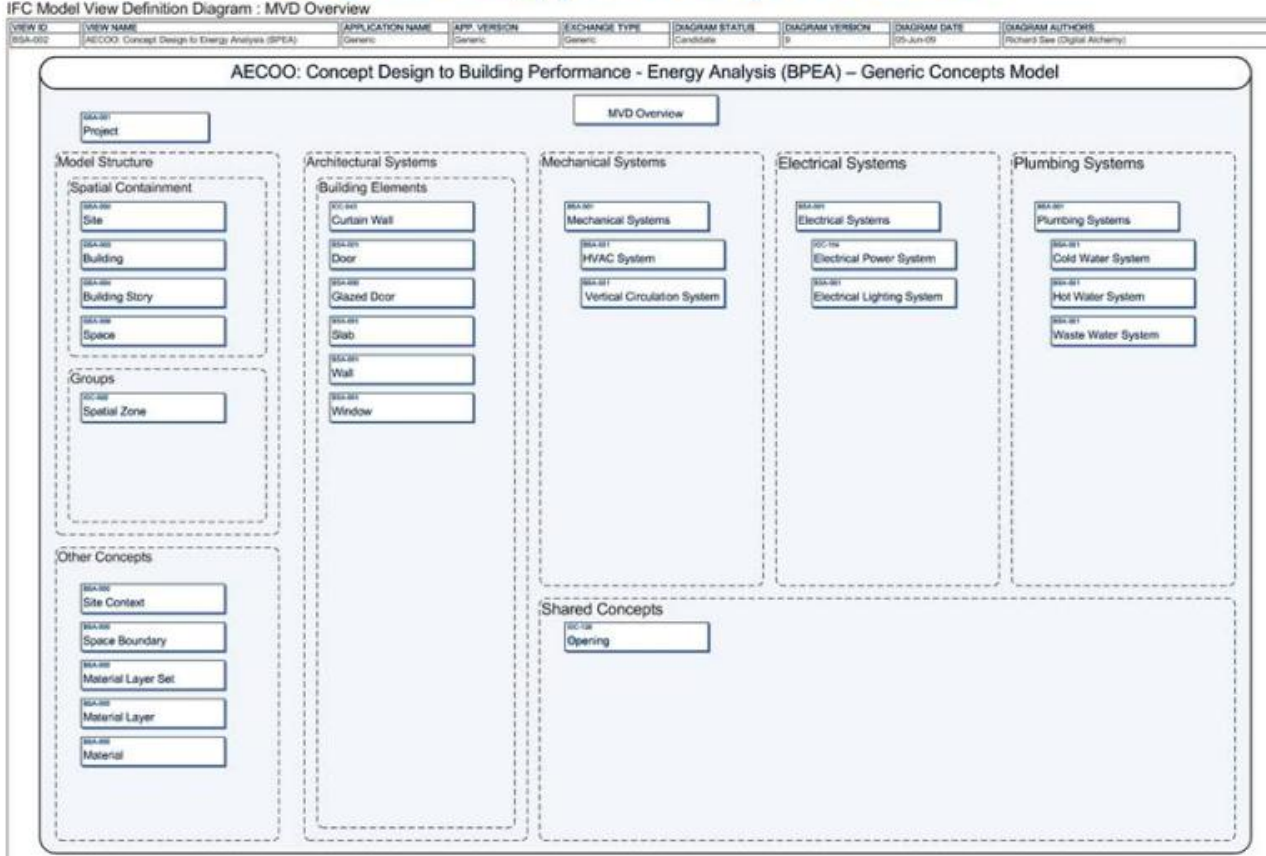

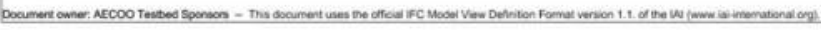




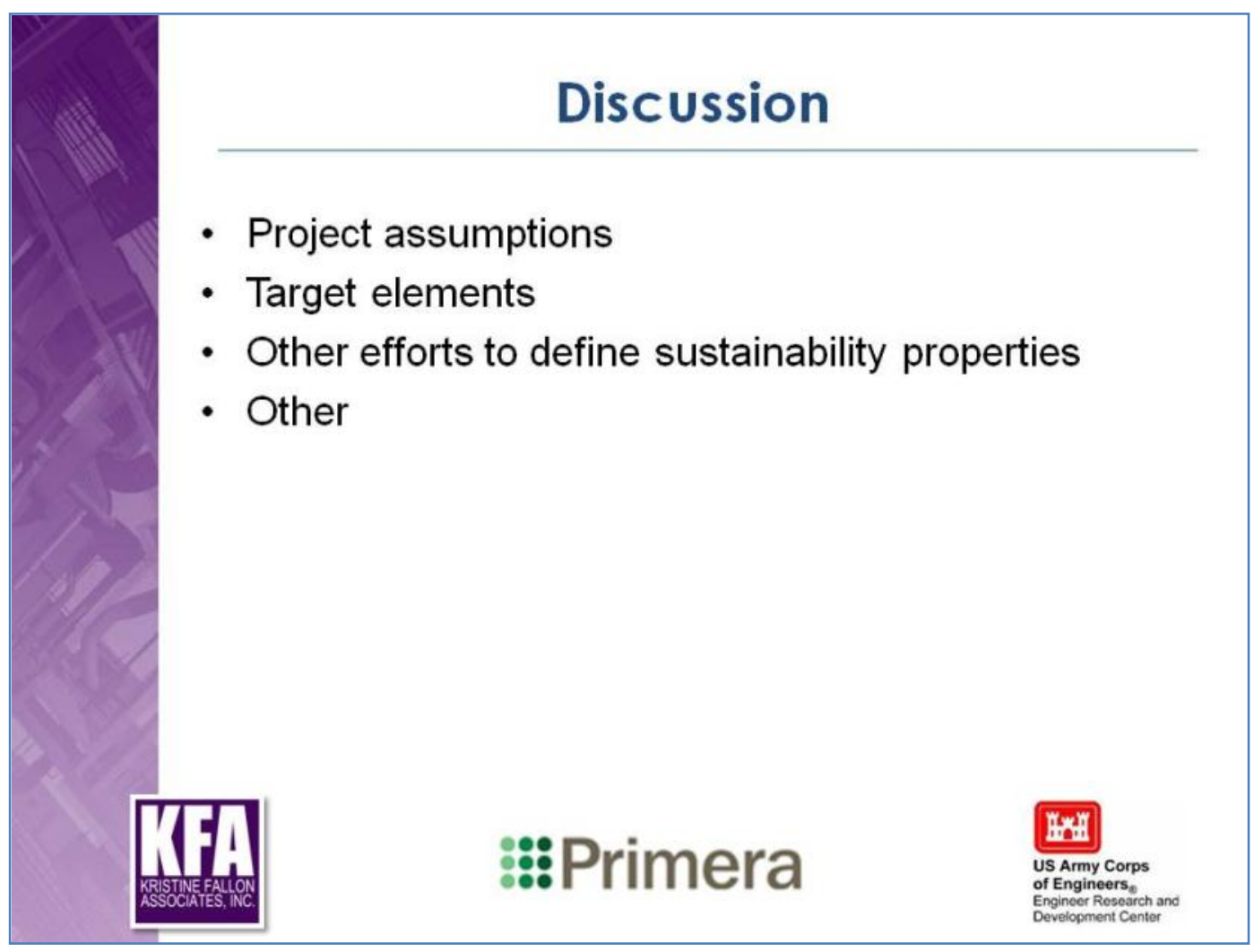




\section{Appendix B: Extended Building Information Templates}

\section{Overview}

Sustainability properties for 56 building elements were identified and incorporated into building property templates for use in BIM models. The templates were populated with real-world product information available from manufacturers, and are reproduced here.

The real-world product information was primarily gathered by downloading the publicly available data from the selected manufacturers' websites. Through this process, it was noted that not all of the necessary sustainability information was readily available for the products. Where the information was not available, there was also an attempt to gather this information by contacting the product manufacturers directly. Where products or properties of products that could not be obtained, this condition is noted.

In addition to where properties were not available, some of the product properties identified by the templates required additional design calculation details in order to provide realistic potential values. For example, concrete pad and strip footings use materials that are typically locally sourced, so the project location needs to be determined before a meaningful value can be entered.

The 56 templates reproduced in this appendix have been updated as completely as possible using the most current information available at the time of writing. 


\section{Templates populated with sustainability and product information}

\begin{tabular}{|c|c|c|c|}
\hline \multicolumn{4}{|l|}{ Chiller_AIRCOOLED_US } \\
\hline $\begin{array}{l}\stackrel{\Phi}{E} \\
\text { ָ }\end{array}$ & 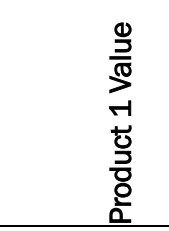 & 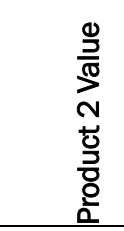 & 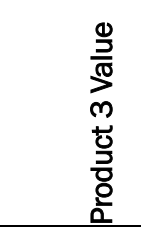 \\
\hline Manufacturer & Thermal Care & Sterling & Trane \\
\hline Model & TSW2OA & 30RB 60 & Series R 80 \\
\hline NominalCapacity & 21 & 63.8 & 75.6 \\
\hline NominalEfficiency & $n / a$ & $\mathrm{n} / \mathrm{a}$ & 18.2 \\
\hline NominalCondensingTemperature & $\mathrm{n} / \mathrm{a}$ & $\mathrm{n} / \mathrm{a}$ & 75 \\
\hline NominalEvaporatingTemperature & $\mathrm{n} / \mathrm{a}$ & $\mathrm{n} / \mathrm{a}$ & 40 \\
\hline NominalHeatRejectionRate & $\mathrm{n} / \mathrm{a}$ & $\mathrm{n} / \mathrm{a}$ & $\mathrm{n} / \mathrm{a}$ \\
\hline NominalPowerConsumption & $\mathrm{n} / \mathrm{a}$ & $\mathrm{n} / \mathrm{a}$ & $\mathrm{n} / \mathrm{a}$ \\
\hline CapacityCurve & $\mathrm{n} / \mathrm{a}$ & $\mathrm{n} / \mathrm{a}$ & $\mathrm{n} / \mathrm{a}$ \\
\hline CoefficientOfPerformanceCurve & $\mathrm{n} / \mathrm{a}$ & $\mathrm{n} / \mathrm{a}$ & $\mathrm{n} / \mathrm{a}$ \\
\hline FullLoadRatioCurve & $\mathrm{n} / \mathrm{a}$ & $\mathrm{n} / \mathrm{a}$ & $\mathrm{n} / \mathrm{a}$ \\
\hline PostConsumerRecoveredContent & $\mathrm{n} / \mathrm{a}$ & $n / a$ & $\mathrm{n} / \mathrm{a}$ \\
\hline TotalRecoveredContent & $\mathrm{n} / \mathrm{a}$ & $\mathrm{n} / \mathrm{a}$ & $\mathrm{n} / \mathrm{a}$ \\
\hline RenewableContent & $\mathrm{n} / \mathrm{a}$ & $\mathrm{n} / \mathrm{a}$ & $\mathrm{n} / \mathrm{a}$ \\
\hline RenewableMaterial & $\mathrm{n} / \mathrm{a}$ & $\mathrm{n} / \mathrm{a}$ & $\mathrm{n} / \mathrm{a}$ \\
\hline BiobasedContent & $\mathrm{n} / \mathrm{a}$ & $\mathrm{n} / \mathrm{a}$ & $\mathrm{n} / \mathrm{a}$ \\
\hline BiobasedMaterial & $\mathrm{n} / \mathrm{a}$ & $\mathrm{n} / \mathrm{a}$ & $\mathrm{n} / \mathrm{a}$ \\
\hline RawMaterialLocation & $\mathrm{n} / \mathrm{a}$ & $\mathrm{n} / \mathrm{a}$ & $\mathrm{n} / \mathrm{a}$ \\
\hline RegionalMaterialContent & $\mathrm{n} / \mathrm{a}$ & $\mathrm{n} / \mathrm{a}$ & $\mathrm{n} / \mathrm{a}$ \\
\hline ManufactureLocation & $\mathrm{n} / \mathrm{a}$ & $\mathrm{n} / \mathrm{a}$ & $\mathrm{n} / \mathrm{a}$ \\
\hline CertifiedContent & $\mathrm{n} / \mathrm{a}$ & $\mathrm{n} / \mathrm{a}$ & $\mathrm{n} / \mathrm{a}$ \\
\hline CertificationType & $\mathrm{n} / \mathrm{a}$ & $\mathrm{n} / \mathrm{a}$ & $\mathrm{n} / \mathrm{a}$ \\
\hline Emissions & $\mathrm{n} / \mathrm{a}$ & $\mathrm{n} / \mathrm{a}$ & $\mathrm{n} / \mathrm{a}$ \\
\hline SNAP & $\mathrm{n} / \mathrm{a}$ & $\mathrm{n} / \mathrm{a}$ & $\mathrm{n} / \mathrm{a}$ \\
\hline ThermalResistance & $\mathrm{n} / \mathrm{a}$ & $\mathrm{n} / \mathrm{a}$ & $\mathrm{n} / \mathrm{a}$ \\
\hline HeatLoad & $\mathrm{n} / \mathrm{a}$ & $\mathrm{n} / \mathrm{a}$ & $\mathrm{n} / \mathrm{a}$ \\
\hline EnergyStar & $\mathrm{n} / \mathrm{a}$ & $\mathrm{n} / \mathrm{a}$ & $\mathrm{n} / \mathrm{a}$ \\
\hline RefrigerantType & HFC-407C & $R-410 A$ & $\mathrm{R}-134 \mathrm{a}$ \\
\hline
\end{tabular}




\section{Covering_CEILING_AcousticalPanelCeilings_US}

\begin{tabular}{|c|c|c|c|}
\hline $\begin{array}{l}\stackrel{0}{\mathbb{E}} \\
\stackrel{\text { I0 }}{z}\end{array}$ & 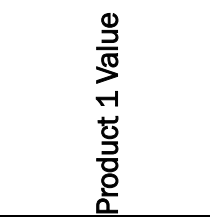 & 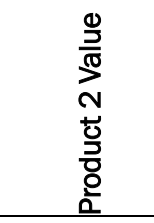 & 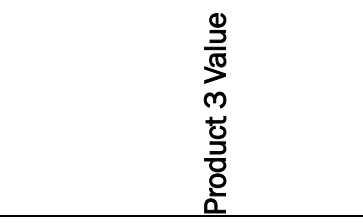 \\
\hline Manufacturer & Armstrong & USG & CertainTeed \\
\hline Model & $\begin{array}{l}\text { Tundra - Beveled } \\
\text { Tegular - } 304 \\
\text { (9/16") }\end{array}$ & "F" Fissured & $\begin{array}{l}\text { Ecophon }{ }^{\circledR} \text { Focus }^{\mathrm{TM}} \mathrm{E} \\
\text { High Density Fiberglass Ceilings } \\
(3 / 4 ")\end{array}$ \\
\hline FireRating & $\mathrm{n} / \mathrm{a}$ & $n / a$ & $\mathrm{n} / \mathrm{a}$ \\
\hline AcousticRating & NRC 0.50 & NRC 0.70 & NRC 0.90 \\
\hline FlammabilityRating & CLASS A & CLASS A & CLASS A \\
\hline FragilityRating & $\mathrm{n} / \mathrm{a}$ & $\mathrm{n} / \mathrm{a}$ & $\mathrm{n} / \mathrm{a}$ \\
\hline SurfaceSpreadOfFlame & 25 & 25 & 25 \\
\hline Combustible & TRUE & TRUE & TRUE \\
\hline IsExternal & FALSE & FALSE & FALSE \\
\hline ThermalTransmittance & $\mathrm{n} / \mathrm{a}$ & $\mathrm{n} / \mathrm{a}$ & $\mathrm{n} / \mathrm{a}$ \\
\hline Permeability & $\mathrm{n} / \mathrm{a}$ & $\mathrm{n} / \mathrm{a}$ & $\mathrm{n} / \mathrm{a}$ \\
\hline PostConsumerRecoveredContent & $\mathrm{n} / \mathrm{a}$ & 71 & 70 \\
\hline TotalRecoveredContent & $\mathrm{n} / \mathrm{a}$ & 71 & 71 \\
\hline RenewableContent & $\mathrm{n} / \mathrm{a}$ & $\mathrm{n} / \mathrm{a}$ & $\mathrm{n} / \mathrm{a}$ \\
\hline RenewableMaterial & $\mathrm{n} / \mathrm{a}$ & $\mathrm{n} / \mathrm{a}$ & $\mathrm{n} / \mathrm{a}$ \\
\hline BiobasedContent & $\mathrm{n} / \mathrm{a}$ & $\mathrm{n} / \mathrm{a}$ & $\mathrm{n} / \mathrm{a}$ \\
\hline BiobasedMaterial & $\mathrm{n} / \mathrm{a}$ & $\mathrm{n} / \mathrm{a}$ & $\mathrm{n} / \mathrm{a}$ \\
\hline RawMaterialLocation & $\mathrm{n} / \mathrm{a}$ & $\mathrm{n} / \mathrm{a}$ & $\mathrm{n} / \mathrm{a}$ \\
\hline RegionalMaterialContent & $\mathrm{n} / \mathrm{a}$ & $n / a$ & $\mathrm{n} / \mathrm{a}$ \\
\hline ManufactureLocation & $\mathrm{n} / \mathrm{a}$ & $\mathrm{n} / \mathrm{a}$ & $\mathrm{n} / \mathrm{a}$ \\
\hline CertifiedContent & $\mathrm{n} / \mathrm{a}$ & $\mathrm{n} / \mathrm{a}$ & $\mathrm{n} / \mathrm{a}$ \\
\hline CertificationType & $\mathrm{n} / \mathrm{a}$ & $\mathrm{n} / \mathrm{a}$ & $\mathrm{n} / \mathrm{a}$ \\
\hline Emissions & $\mathrm{n} / \mathrm{a}$ & 0 & $\mathrm{n} / \mathrm{a}$ \\
\hline SNAP & $\mathrm{n} / \mathrm{a}$ & $\mathrm{n} / \mathrm{a}$ & $\mathrm{n} / \mathrm{a}$ \\
\hline ThermalResistance & 1.7 & 1.7 & $\mathrm{n} / \mathrm{a}$ \\
\hline
\end{tabular}




\begin{tabular}{|c|c|c|c|}
\hline \multicolumn{4}{|c|}{ Covering_CLADDING_AluminumSiding_US } \\
\hline $\begin{array}{l}\stackrel{\mathbb{N}}{\mathbf{T}} \\
\stackrel{\mathbb{N}}{\mathbf{Z}}\end{array}$ & $\begin{array}{l}\frac{0}{D} \\
\frac{D}{D} \\
ㄱ \\
\frac{0}{0} \\
\frac{D}{0} \\
\frac{0}{2}\end{array}$ & $\begin{array}{l}\frac{0}{D} \\
\frac{D}{\pi} \\
\text { N } \\
\frac{0}{2} \\
\frac{D}{0} \\
\frac{0}{2}\end{array}$ & $\begin{array}{l}\frac{0}{D} \\
\frac{D}{0} \\
m \\
\frac{0}{0} \\
\frac{7}{0} \\
\frac{0}{2}\end{array}$ \\
\hline Manufacturer & Petersen Aluminum & Centria & Centria \\
\hline Model & Flush Panel - .032" (Depth 1") & $\begin{array}{l}\text { IW-10A - .040" (Depth 1- } \\
\text { 1/2") }\end{array}$ & $\begin{array}{l}\text { CS-200 - .050" } \\
\text { (Depth 7/8") }\end{array}$ \\
\hline Sustainability & $\mathrm{n} / \mathrm{a}$ & $\mathrm{n} / \mathrm{a}$ & $\mathrm{n} / \mathrm{a}$ \\
\hline FireRating & $\mathrm{n} / \mathrm{a}$ & $\mathrm{n} / \mathrm{a}$ & $\mathrm{n} / \mathrm{a}$ \\
\hline AcousticRating & $\mathrm{n} / \mathrm{a}$ & $\mathrm{n} / \mathrm{a}$ & $\mathrm{n} / \mathrm{a}$ \\
\hline FlammabilityRating & $\mathrm{n} / \mathrm{a}$ & $\mathrm{n} / \mathrm{a}$ & $\mathrm{n} / \mathrm{a}$ \\
\hline FragilityRating & $\mathrm{n} / \mathrm{a}$ & $\mathrm{n} / \mathrm{a}$ & $\mathrm{n} / \mathrm{a}$ \\
\hline SurfaceSpreadOfFlame & $\mathrm{n} / \mathrm{a}$ & $\mathrm{n} / \mathrm{a}$ & $\mathrm{n} / \mathrm{a}$ \\
\hline Combustible & $\mathrm{n} / \mathrm{a}$ & $\mathrm{n} / \mathrm{a}$ & $\mathrm{n} / \mathrm{a}$ \\
\hline IsExternal & TRUE & TRUE & TRUE \\
\hline ThermalTransmittance & $\mathrm{n} / \mathrm{a}$ & $\mathrm{n} / \mathrm{a}$ & $\mathrm{n} / \mathrm{a}$ \\
\hline PostConsumerRecoveredContent & 9.7 & 25.5 & 25.5 \\
\hline TotalRecoveredContent & 92 & 32.3 & 32.3 \\
\hline RenewableContent & $\mathrm{n} / \mathrm{a}$ & $\mathrm{n} / \mathrm{a}$ & $\mathrm{n} / \mathrm{a}$ \\
\hline RenewableMaterial & $\mathrm{n} / \mathrm{a}$ & $\mathrm{n} / \mathrm{a}$ & $\mathrm{n} / \mathrm{a}$ \\
\hline BiobasedContent & $n / a$ & $\mathrm{n} / \mathrm{a}$ & $\mathrm{n} / \mathrm{a}$ \\
\hline BiobasedMaterial & $\mathrm{n} / \mathrm{a}$ & $\mathrm{n} / \mathrm{a}$ & $\mathrm{n} / \mathrm{a}$ \\
\hline RawMaterialLocation & $n / a$ & $\mathrm{n} / \mathrm{a}$ & $\mathrm{n} / \mathrm{a}$ \\
\hline RegionalMaterialContent & $n / a$ & 10 & $\mathrm{n} / \mathrm{a}$ \\
\hline ManufactureLocation & Lewisport, KY & $\mathrm{n} / \mathrm{a}$ & $\mathrm{n} / \mathrm{a}$ \\
\hline CertifiedContent & $n / a$ & $\mathrm{n} / \mathrm{a}$ & $\mathrm{n} / \mathrm{a}$ \\
\hline CertificationType & $\mathrm{n} / \mathrm{a}$ & Cradle to Cradle & $\mathrm{n} / \mathrm{a}$ \\
\hline Emissions & $\mathrm{n} / \mathrm{a}$ & $\mathrm{n} / \mathrm{a}$ & $\mathrm{n} / \mathrm{a}$ \\
\hline SNAP & $\mathrm{n} / \mathrm{a}$ & $\mathrm{n} / \mathrm{a}$ & $\mathrm{n} / \mathrm{a}$ \\
\hline ThermalResistance & $\begin{array}{l}0.85 \text { (if color selected BONE } \\
\text { WHITE) }\end{array}$ & $\mathrm{n} / \mathrm{a}$ & $\mathrm{n} / \mathrm{a}$ \\
\hline
\end{tabular}




\begin{tabular}{|c|c|c|c|}
\hline \multicolumn{4}{|c|}{ Covering_CLADDING_GypsumBoardAssemblies_US } \\
\hline 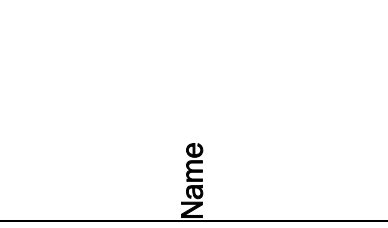 & 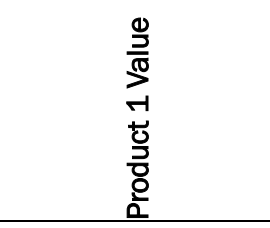 & 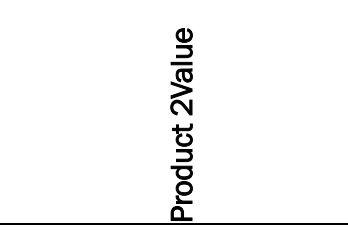 & 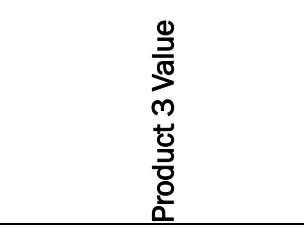 \\
\hline Manufacturer & Georgia Pacific & USG & National Gypsum \\
\hline Model & $\begin{array}{l}\text { Tough Rock Fireguard } \\
\text { Gypsum Board (5/8") }\end{array}$ & $\begin{array}{l}\text { SHEETROCK } ® \text { Brand Gypsum } \\
\text { Panels - firecode core }\left(5 / 8^{\prime \prime}\right)\end{array}$ & $\begin{array}{l}\text { Gold Bond e2XP Extended } \\
\text { Exposure Interior Extreme } \\
(5 / 8 ")\end{array}$ \\
\hline Sustainability & $\mathrm{n} / \mathrm{a}$ & $\mathrm{n} / \mathrm{a}$ & $\mathrm{n} / \mathrm{a}$ \\
\hline FireRating & $\mathrm{n} / \mathrm{a}$ & $\mathrm{n} / \mathrm{a}$ & $\mathrm{n} / \mathrm{a}$ \\
\hline AcousticRating & $\mathrm{n} / \mathrm{a}$ & $\mathrm{n} / \mathrm{a}$ & $\mathrm{n} / \mathrm{a}$ \\
\hline FlammabilityRating & 0 & 0 & $\mathrm{n} / \mathrm{a}$ \\
\hline FragilityRating & 0 & $\mathrm{n} / \mathrm{a}$ & $\mathrm{n} / \mathrm{a}$ \\
\hline SurfaceSpreadOfFlame & 15 & $\mathrm{n} / \mathrm{a}$ & 0 \\
\hline Combustible & FALSE & FALSE & FALSE \\
\hline IsExternal & FALSE & FALSE & FASLE \\
\hline ThermalTransmittance & $\mathrm{n} / \mathrm{a}$ & $\mathrm{n} / \mathrm{a}$ & $\mathrm{n} / \mathrm{a}$ \\
\hline PostConsumerRecoveredContent & 0 & $\mathrm{n} / \mathrm{a}$ & 0 \\
\hline TotalRecoveredContent & $\mathrm{n} / \mathrm{a}$ & $\mathrm{n} / \mathrm{a}$ & $\mathrm{n} / \mathrm{a}$ \\
\hline RenewableContent & $\mathrm{n} / \mathrm{a}$ & $\mathrm{n} / \mathrm{a}$ & $\mathrm{n} / \mathrm{a}$ \\
\hline RenewableMaterial & $\mathrm{n} / \mathrm{a}$ & $\mathrm{n} / \mathrm{a}$ & $\mathrm{n} / \mathrm{a}$ \\
\hline BiobasedContent & $\mathrm{n} / \mathrm{a}$ & $\mathrm{n} / \mathrm{a}$ & $\mathrm{n} / \mathrm{a}$ \\
\hline BiobasedMaterial & $\mathrm{n} / \mathrm{a}$ & $\mathrm{n} / \mathrm{a}$ & $\mathrm{n} / \mathrm{a}$ \\
\hline RawMaterialLocation & $\mathrm{n} / \mathrm{a}$ & $\mathrm{n} / \mathrm{a}$ & $\mathrm{n} / \mathrm{a}$ \\
\hline RegionalMaterialContent & $\mathrm{n} / \mathrm{a}$ & $\mathrm{n} / \mathrm{a}$ & $\mathrm{n} / \mathrm{a}$ \\
\hline ManufactureLocation & $\mathrm{n} / \mathrm{a}$ & $\mathrm{n} / \mathrm{a}$ & $\mathrm{n} / \mathrm{a}$ \\
\hline CertifiedContent & $\mathrm{n} / \mathrm{a}$ & $\mathrm{n} / \mathrm{a}$ & $\mathrm{n} / \mathrm{a}$ \\
\hline CertificationType & $\mathrm{n} / \mathrm{a}$ & $n / a$ & GreenGuard \\
\hline Emissions & $\mathrm{n} / \mathrm{a}$ & $\mathrm{n} / \mathrm{a}$ & none \\
\hline SNAP & $\mathrm{n} / \mathrm{a}$ & $\mathrm{n} / \mathrm{a}$ & $\mathrm{n} / \mathrm{a}$ \\
\hline ThermalResistance & 0.56 & $\mathrm{n} / \mathrm{a}$ & 0.5 \\
\hline
\end{tabular}




\begin{tabular}{|c|c|c|c|}
\hline \multicolumn{4}{|c|}{ Covering_CLADDING_Sheathing_US } \\
\hline 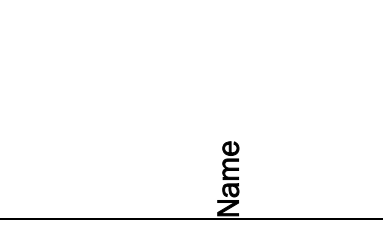 & $\begin{array}{l}\frac{0}{2} \\
\frac{\partial}{\pi} \\
ㄱ \\
\frac{0}{0} \\
\frac{7}{0} \\
\frac{0}{2}\end{array}$ & $\begin{array}{l}\frac{0}{2} \\
\frac{D}{\pi} \\
\mathbb{N} \\
\frac{0}{0} \\
\frac{7}{0} \\
\frac{D}{2}\end{array}$ & 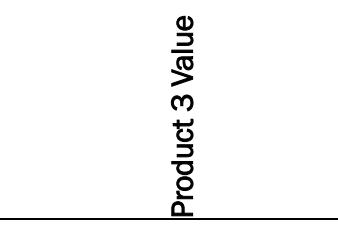 \\
\hline Manufacturer & Georgia Pacific & Georgia Pacific & Georgia Pacific \\
\hline Model & BLUE RIBBON OSB & Plytanium Plywood & Dens Glass Sheathing \\
\hline Sustainability & $n / a$ & $\mathrm{n} / \mathrm{a}$ & $\mathrm{n} / \mathrm{a}$ \\
\hline FireRating & Class III or C & Class III or C & $\mathrm{n} / \mathrm{a}$ \\
\hline AcousticRating & $\mathrm{n} / \mathrm{a}$ & $\mathrm{n} / \mathrm{a}$ & $\mathrm{n} / \mathrm{a}$ \\
\hline FlammabilityRating & 1 & 1 & 0 \\
\hline FragilityRating & $\mathrm{n} / \mathrm{a}$ & $\mathrm{n} / \mathrm{a}$ & $\mathrm{n} / \mathrm{a}$ \\
\hline SurfaceSpreadOfFlame & $76-200$ & $76-200$ & 0 \\
\hline Combustible & TRUE & TRUE & FALSE \\
\hline IsExternal & TRUE & TRUE & TRUE \\
\hline ThermalTransmittance & $\mathrm{n} / \mathrm{a}$ & $\mathrm{n} / \mathrm{a}$ & $\mathrm{n} / \mathrm{a}$ \\
\hline PostConsumerRecoveredContent & $\mathrm{n} / \mathrm{a}$ & $\mathrm{n} / \mathrm{a}$ & 0.2 \\
\hline TotalRecoveredContent & $\mathrm{n} / \mathrm{a}$ & $\mathrm{n} / \mathrm{a}$ & 91.1 \\
\hline RenewableContent & $\mathrm{n} / \mathrm{a}$ & $\mathrm{n} / \mathrm{a}$ & $\mathrm{n} / \mathrm{a}$ \\
\hline RenewableMaterial & $\mathrm{n} / \mathrm{a}$ & $\mathrm{n} / \mathrm{a}$ & $\mathrm{n} / \mathrm{a}$ \\
\hline BiobasedContent & $n / a$ & $\mathrm{n} / \mathrm{a}$ & $\mathrm{n} / \mathrm{a}$ \\
\hline BiobasedMaterial & $\mathrm{n} / \mathrm{a}$ & $\mathrm{n} / \mathrm{a}$ & $\mathrm{n} / \mathrm{a}$ \\
\hline RawMaterialLocation & $\mathrm{n} / \mathrm{a}$ & $\mathrm{n} / \mathrm{a}$ & $\begin{array}{l}\text { Acme, TX; San Marcos Island, } \\
\text { Mexico; Port Hawkesbury, } \\
\text { Nova Scotia; Ft. Dodge, IA; St. } \\
\text { George, UT; Sweetwater, TX; } \\
\text { Centralia, WA; Wheatfield, IN }\end{array}$ \\
\hline RegionalMaterialContent & $n / a$ & $\mathrm{n} / \mathrm{a}$ & $\mathrm{n} / \mathrm{a}$ \\
\hline ManufactureLocation & $\mathrm{n} / \mathrm{a}$ & $\mathrm{n} / \mathrm{a}$ & $\mathrm{n} / \mathrm{a}$ \\
\hline CertifiedContent & $n / a$ & $n / a$ & $\mathrm{n} / \mathrm{a}$ \\
\hline CertificationType & $\begin{array}{l}\text { Sustainable } \\
\text { Forestry Initiative, } \\
\text { NAHB Research } \\
\text { Center }\end{array}$ & $\begin{array}{l}\text { Sustainable } \\
\text { Forestry Initiative, } \\
\text { NAHB Research } \\
\text { Center }\end{array}$ & $\mathrm{n} / \mathrm{a}$ \\
\hline Emissions & none & none & $\mathrm{n} / \mathrm{a}$ \\
\hline SNAP & $\mathrm{n} / \mathrm{a}$ & $\mathrm{n} / \mathrm{a}$ & $\mathrm{n} / \mathrm{a}$ \\
\hline ThermalResistance & 0.77 & 0.77 & 0.67 \\
\hline
\end{tabular}




\begin{tabular}{|c|c|c|c|}
\hline \multicolumn{4}{|c|}{ Covering_FLOORING_CeramicTiling_US } \\
\hline $\begin{array}{l}\stackrel{0}{E} \\
\stackrel{\mathbb{\pi}}{\mathbf{L}}\end{array}$ & $\begin{array}{l}\frac{0}{2} \\
\frac{\partial}{\pi} \\
ㄱ \\
\frac{0}{0} \\
\frac{7}{0} \\
\frac{0}{2}\end{array}$ & 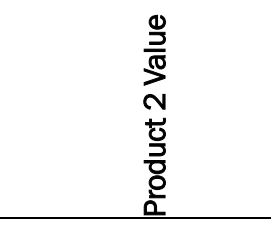 & $\begin{array}{l}\frac{0}{2} \\
\frac{D}{\pi} \\
\text { m } \\
\frac{ \pm}{2} \\
\frac{0}{0} \\
\frac{0}{2}\end{array}$ \\
\hline Manufacturer & Daltile & StonePeak & StonePeak \\
\hline Model & $\begin{array}{l}\text { Willow Branch } \\
\text { SD92 }\end{array}$ & $\begin{array}{l}\text { THESTANDARD - Beige } \\
\text { (Porcelain) }\end{array}$ & $\begin{array}{l}\text { PARKLAND - Acadia } \\
\text { (Porcelain) }\end{array}$ \\
\hline Sustainability & $\mathrm{n} / \mathrm{a}$ & $\mathrm{n} / \mathrm{a}$ & $\mathrm{n} / \mathrm{a}$ \\
\hline Sealants & $\mathrm{n} / \mathrm{a}$ & $\mathrm{n} / \mathrm{a}$ & $\mathrm{n} / \mathrm{a}$ \\
\hline FireRating & $\mathrm{n} / \mathrm{a}$ & $\mathrm{n} / \mathrm{a}$ & $\mathrm{n} / \mathrm{a}$ \\
\hline AcousticRating & $\mathrm{n} / \mathrm{a}$ & $\mathrm{n} / \mathrm{a}$ & $\mathrm{n} / \mathrm{a}$ \\
\hline FlammabilityRating & $\mathrm{n} / \mathrm{a}$ & $\mathrm{n} / \mathrm{a}$ & $\mathrm{n} / \mathrm{a}$ \\
\hline FragilityRating & $\mathrm{n} / \mathrm{a}$ & $\mathrm{n} / \mathrm{a}$ & $\mathrm{n} / \mathrm{a}$ \\
\hline SurfaceSpreadOfFlame & $\mathrm{n} / \mathrm{a}$ & $\mathrm{n} / \mathrm{a}$ & $\mathrm{n} / \mathrm{a}$ \\
\hline Combustible & $\mathrm{n} / \mathrm{a}$ & $\mathrm{n} / \mathrm{a}$ & $\mathrm{n} / \mathrm{a}$ \\
\hline IsExternal & $\mathrm{n} / \mathrm{a}$ & $\mathrm{n} / \mathrm{a}$ & $\mathrm{n} / \mathrm{a}$ \\
\hline ThermalTransmittance & $\mathrm{n} / \mathrm{a}$ & $\mathrm{n} / \mathrm{a}$ & $\mathrm{n} / \mathrm{a}$ \\
\hline PostConsumerRecoveredContent & 17.6 & $\mathrm{n} / \mathrm{a}$ & $\mathrm{n} / \mathrm{a}$ \\
\hline TotaIRecoveredContent & 37.4 & 28 & 97 \\
\hline RenewableContent & $\mathrm{n} / \mathrm{a}$ & $\mathrm{n} / \mathrm{a}$ & $\mathrm{n} / \mathrm{a}$ \\
\hline RenewableMaterial & $\mathrm{n} / \mathrm{a}$ & $\mathrm{n} / \mathrm{a}$ & $\mathrm{n} / \mathrm{a}$ \\
\hline BiobasedContent & $\mathrm{n} / \mathrm{a}$ & $\mathrm{n} / \mathrm{a}$ & $\mathrm{n} / \mathrm{a}$ \\
\hline BiobasedMaterial & $\mathrm{n} / \mathrm{a}$ & $\mathrm{n} / \mathrm{a}$ & $\mathrm{n} / \mathrm{a}$ \\
\hline RawMaterialLocation & $\mathrm{n} / \mathrm{a}$ & $\mathrm{n} / \mathrm{a}$ & $\mathrm{n} / \mathrm{a}$ \\
\hline RegionalMaterialContent & $n / a$ & $\mathrm{n} / \mathrm{a}$ & $\mathrm{n} / \mathrm{a}$ \\
\hline ManufactureLocation & Monterrey, Mexico & $\mathrm{n} / \mathrm{a}$ & $\mathrm{n} / \mathrm{a}$ \\
\hline CertifiedContent & $\mathrm{n} / \mathrm{a}$ & $\mathrm{n} / \mathrm{a}$ & $\mathrm{n} / \mathrm{a}$ \\
\hline CertificationType & $\mathrm{n} / \mathrm{a}$ & GreenGuard & GreenGuard \\
\hline Emissions & none & none & none \\
\hline SNAP & $\mathrm{n} / \mathrm{a}$ & $\mathrm{n} / \mathrm{a}$ & $\mathrm{n} / \mathrm{a}$ \\
\hline ThermalResistance & $n / a$ & $n / a$ & $n / a$ \\
\hline
\end{tabular}


Covering_FLOORING_ResilientTileFlooring_US

\begin{tabular}{|c|c|c|c|}
\hline 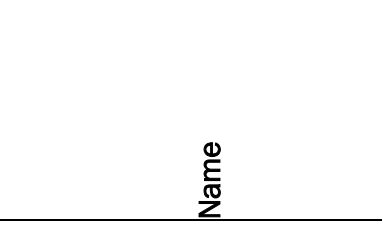 & $\begin{array}{l}\frac{0}{2} \\
\frac{D}{\pi} \\
ㄱ \\
\frac{1}{0} \\
\frac{0}{0} \\
\frac{0}{0}\end{array}$ & 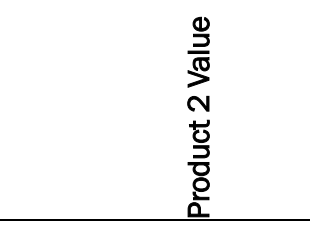 & 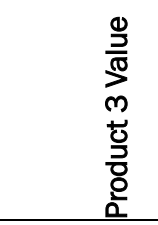 \\
\hline Manufacturer & MANNINGTON & ARMSTRONG & JOHNSONITE \\
\hline Model & Essentials (VCT) & $\begin{array}{l}\text { Standard Excelon Imperial } \\
\text { Texture (VCT) }\end{array}$ & Space \\
\hline Sustainability & $\mathrm{n} / \mathrm{a}$ & $n / a$ & $n / a$ \\
\hline FireRating & not_defined & Class 1 & Class 1 \\
\hline AcousticRating & $n / a$ & $\mathrm{n} / \mathrm{a}$ & $\mathrm{n} / \mathrm{a}$ \\
\hline FlammabilityRating & not_defined & Class 1 & Class 1 \\
\hline FragilityRating & not_defined & $\mathrm{n} / \mathrm{a}$ & $\mathrm{n} / \mathrm{a}$ \\
\hline SurfaceSpreadOfFlame & $\mathrm{n} / \mathrm{a}$ & $\mathrm{n} / \mathrm{a}$ & $\mathrm{n} / \mathrm{a}$ \\
\hline Combustible & not_defined & $\mathrm{n} / \mathrm{a}$ & $\mathrm{n} / \mathrm{a}$ \\
\hline IsExternal & FALSE & FALSE & FALSE \\
\hline ThermalTransmittance & $\mathrm{n} / \mathrm{a}$ & $\mathrm{n} / \mathrm{a}$ & $\mathrm{n} / \mathrm{a}$ \\
\hline PostConsumerRecoveredContent & $\mathrm{n} / \mathrm{a}$ & $\mathrm{n} / \mathrm{a}$ & 0 \\
\hline TotalRecoveredContent & $\mathrm{n} / \mathrm{a}$ & 1 & 35 \\
\hline RenewableContent & $\mathrm{n} / \mathrm{a}$ & $\mathrm{n} / \mathrm{a}$ & 0 \\
\hline RenewableMaterial & $\mathrm{n} / \mathrm{a}$ & $\mathrm{n} / \mathrm{a}$ & $\mathrm{n} / \mathrm{a}$ \\
\hline BiobasedContent & $\mathrm{n} / \mathrm{a}$ & $n / a$ & $n / a$ \\
\hline BiobasedMaterial & $n / a$ & $\mathrm{n} / \mathrm{a}$ & $\mathrm{n} / \mathrm{a}$ \\
\hline RawMaterialLocation & $\mathrm{n} / \mathrm{a}$ & $\mathrm{n} / \mathrm{a}$ & $\mathrm{n} / \mathrm{a}$ \\
\hline RegionalMaterialContent & $\mathrm{n} / \mathrm{a}$ & $\mathrm{n} / \mathrm{a}$ & $n / a$ \\
\hline ManufactureLocation & Salem, NJ & Jackson, MS & Imported \\
\hline CertifiedContent & $\mathrm{n} / \mathrm{a}$ & $n / a$ & $\mathrm{n} / \mathrm{a}$ \\
\hline CertificationType & SCS & SCS & SCS \\
\hline Emissions & $\mathrm{n} / \mathrm{a}$ & $\mathrm{n} / \mathrm{a}$ & $\mathrm{n} / \mathrm{a}$ \\
\hline SNAP & $n / a$ & $n / a$ & $n / a$ \\
\hline ThermalResistance & $\mathrm{n} / \mathrm{a}$ & $\mathrm{n} / \mathrm{a}$ & $\mathrm{n} / \mathrm{a}$ \\
\hline
\end{tabular}




\begin{tabular}{|c|c|c|c|}
\hline \multicolumn{4}{|c|}{ Covering_FLOORING_SheetCarpeting_US } \\
\hline $\begin{array}{l}\stackrel{\Phi}{E} \\
\underset{\boldsymbol{D}}{\mathbf{z}}\end{array}$ & 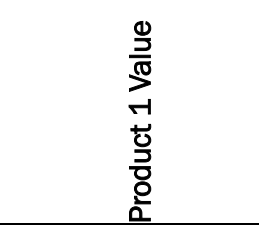 & 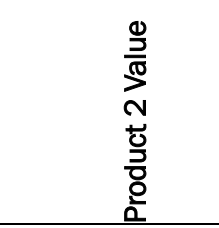 & 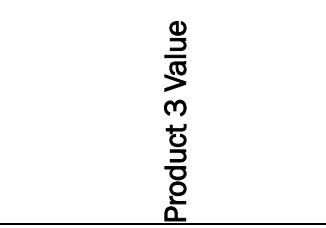 \\
\hline Manufacturer & Mohawk (Broadloom) & Atlas (Broadloom) & Shaw (Broadloom) \\
\hline Model & 0 & EP52 Bamboo & $\begin{array}{l}\text { core } 5 A 178 \text { - alterNature - } \\
\text { balsa } 78103\end{array}$ \\
\hline Sustainability & $\mathrm{n} / \mathrm{a}$ & $\mathrm{n} / \mathrm{a}$ & $\mathrm{n} / \mathrm{a}$ \\
\hline MaterialsYarn & $\begin{array}{l}\text { EverStrand Revive } \\
\text { Polyester }\end{array}$ & nylon type 6,6 & Eco Solution Q Nylon \\
\hline FireRating & $\mathrm{n} / \mathrm{a}$ & Class 1 & Class 1 \\
\hline AcousticRating & $\mathrm{n} / \mathrm{a}$ & $\mathrm{n} / \mathrm{a}$ & $\mathrm{n} / \mathrm{a}$ \\
\hline FlammabilityRating & $\mathrm{n} / \mathrm{a}$ & $\mathrm{n} / \mathrm{a}$ & $\mathrm{n} / \mathrm{a}$ \\
\hline FragilityRating & $\mathrm{n} / \mathrm{a}$ & $\mathrm{n} / \mathrm{a}$ & $\mathrm{n} / \mathrm{a}$ \\
\hline SurfaceSpreadOfFlame & $\mathrm{n} / \mathrm{a}$ & $\mathrm{n} / \mathrm{a}$ & $\mathrm{n} / \mathrm{a}$ \\
\hline Combustible & $\mathrm{n} / \mathrm{a}$ & $\mathrm{n} / \mathrm{a}$ & $\mathrm{n} / \mathrm{a}$ \\
\hline IsExternal & $\mathrm{n} / \mathrm{a}$ & $\mathrm{n} / \mathrm{a}$ & $\mathrm{n} / \mathrm{a}$ \\
\hline ThermalTransmittance & $\mathrm{n} / \mathrm{a}$ & $\mathrm{n} / \mathrm{a}$ & $\mathrm{n} / \mathrm{a}$ \\
\hline PostConsumerRecoveredContent & $n / a$ & 10 & 11.4 \\
\hline TotaIRecoveredContent & $n / a$ & 10 & 20.5 \\
\hline RenewableContent & $\mathrm{n} / \mathrm{a}$ & $\mathrm{n} / \mathrm{a}$ & $\mathrm{n} / \mathrm{a}$ \\
\hline RenewableMaterial & $n / a$ & $\mathrm{n} / \mathrm{a}$ & $n / a$ \\
\hline BiobasedContent & $n / a$ & $n / a$ & $n / a$ \\
\hline BiobasedMaterial & $\mathrm{n} / \mathrm{a}$ & $\mathrm{n} / \mathrm{a}$ & $n / a$ \\
\hline RawMaterialLocation & $\mathrm{n} / \mathrm{a}$ & $\mathrm{n} / \mathrm{a}$ & $n / a$ \\
\hline RegionalMaterialContent & $\mathrm{n} / \mathrm{a}$ & $\mathrm{n} / \mathrm{a}$ & $\mathrm{n} / \mathrm{a}$ \\
\hline ManufactureLocation & $\mathrm{n} / \mathrm{a}$ & $\mathrm{n} / \mathrm{a}$ & $n / a$ \\
\hline CertifiedContent & $\mathrm{n} / \mathrm{a}$ & $\mathrm{n} / \mathrm{a}$ & $n / a$ \\
\hline CertificationType & $\mathrm{n} / \mathrm{a}$ & $\mathrm{n} / \mathrm{a}$ & $\begin{array}{l}\text { MBDC Cradle to Cradle, NSF } \\
\text { 140; CRI green label plus; } \\
\text { LEED }\end{array}$ \\
\hline Emissions & $\mathrm{n} / \mathrm{a}$ & $\mathrm{n} / \mathrm{a}$ & none \\
\hline SNAP & $\mathrm{n} / \mathrm{a}$ & $\mathrm{n} / \mathrm{a}$ & $\mathrm{n} / \mathrm{a}$ \\
\hline ThermalResistance & $\mathrm{n} / \mathrm{a}$ & $\mathrm{n} / \mathrm{a}$ & $\mathrm{n} / \mathrm{a}$ \\
\hline MaterialsBacking & $\mathrm{n} / \mathrm{a}$ & $\mathrm{n} / \mathrm{a}$ & $\mathrm{n} / \mathrm{a}$ \\
\hline VaporPermeability & $\mathrm{n} / \mathrm{a}$ & $\mathrm{n} / \mathrm{a}$ & $\mathrm{n} / \mathrm{a}$ \\
\hline Adhesives & $\mathrm{n} / \mathrm{a}$ & $\mathrm{n} / \mathrm{a}$ & $\mathrm{n} / \mathrm{a}$ \\
\hline
\end{tabular}




\section{Covering_FLOORING_TileCarpeting_US}

\begin{tabular}{|c|c|c|c|}
\hline 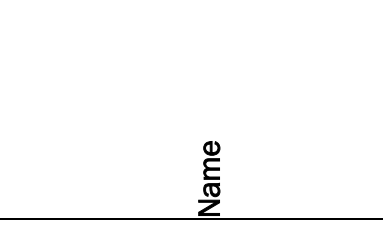 & 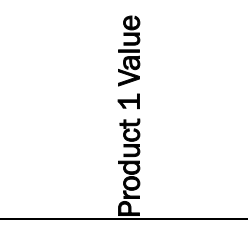 & 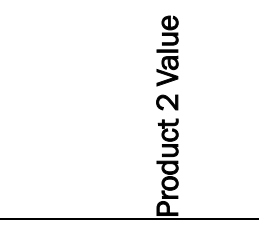 & 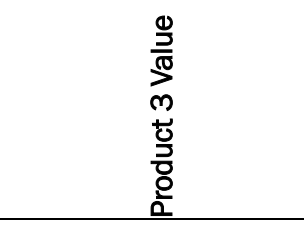 \\
\hline Manufacturer & Atlas & InterfaceFlor & Patcraft \\
\hline Model & Millot & Cubic Colors & Flex and Yield \\
\hline Sustainability & $\mathrm{n} / \mathrm{a}$ & $\mathrm{n} / \mathrm{a}$ & $\mathrm{n} / \mathrm{a}$ \\
\hline MaterialsYarn & nylon type 6,6 & Type 6 Nylon & Nylon 6 \\
\hline FireRating & $\mathrm{n} / \mathrm{a}$ & $\mathrm{n} / \mathrm{a}$ & $\mathrm{n} / \mathrm{a}$ \\
\hline AcousticRating & $\mathrm{n} / \mathrm{a}$ & $\mathrm{n} / \mathrm{a}$ & $\mathrm{n} / \mathrm{a}$ \\
\hline FlammabilityRating & Class 1 & Class 1 & Class I \\
\hline FragilityRating & $\mathrm{n} / \mathrm{a}$ & $\mathrm{n} / \mathrm{a}$ & $\mathrm{n} / \mathrm{a}$ \\
\hline SurfaceSpreadOfFlame & Class 1 & Class 1 & Class I \\
\hline Combustible & TRUE & TRUE & TRUE \\
\hline IsExternal & FALSE & FALSE & FALSE \\
\hline ThermalTransmittance & $\mathrm{n} / \mathrm{a}$ & $\mathrm{n} / \mathrm{a}$ & $\mathrm{n} / \mathrm{a}$ \\
\hline PostConsumerRecoveredContent & 0 & 4 & 11.4 \\
\hline TotalRecoveredContent & 24 & 56 & 44 \\
\hline RenewableContent & $\mathrm{n} / \mathrm{a}$ & $n / a$ & $\mathrm{n} / \mathrm{a}$ \\
\hline RenewableMaterial & $\mathrm{n} / \mathrm{a}$ & $\mathrm{n} / \mathrm{a}$ & $\mathrm{n} / \mathrm{a}$ \\
\hline BiobasedContent & $\mathrm{n} / \mathrm{a}$ & $\mathrm{n} / \mathrm{a}$ & 0 \\
\hline BiobasedMaterial & $\mathrm{n} / \mathrm{a}$ & $n / a$ & $\mathrm{n} / \mathrm{a}$ \\
\hline RawMaterialLocation & $\mathrm{n} / \mathrm{a}$ & $\mathrm{n} / \mathrm{a}$ & $\mathrm{n} / \mathrm{a}$ \\
\hline RegionalMaterialContent & $\mathrm{n} / \mathrm{a}$ & $\mathrm{n} / \mathrm{a}$ & $\mathrm{n} / \mathrm{a}$ \\
\hline ManufactureLocation & $\begin{array}{l}\text { Los Angeles, CA } \\
90040\end{array}$ & LaGrange, GA 30240 & USA \\
\hline CertifiedContent & yes & yes & yes \\
\hline CertificationType & NSF & NSF-140 & Cradle to Cradle, NSF 140 \\
\hline Emissions & $\mathrm{n} / \mathrm{a}$ & none & $\mathrm{n} / \mathrm{a}$ \\
\hline SNAP & $\mathrm{n} / \mathrm{a}$ & $\mathrm{n} / \mathrm{a}$ & $\mathrm{n} / \mathrm{a}$ \\
\hline ThermalResistance & $\mathrm{n} / \mathrm{a}$ & $n / a$ & $\mathrm{n} / \mathrm{a}$ \\
\hline MaterialsBacking & $\begin{array}{l}\text { Polyurethane } \\
\text { cushion tile backing } \\
\text { system }\end{array}$ & GlasBac Tile & $\begin{array}{l}\text { Non-woven Synthetic and } \\
\text { EcoWorx® Tile }\end{array}$ \\
\hline VaporPermeability & $\mathrm{n} / \mathrm{a}$ & $\mathrm{n} / \mathrm{a}$ & $\mathrm{n} / \mathrm{a}$ \\
\hline Adhesives & $\mathrm{n} / \mathrm{a}$ & $\mathrm{n} / \mathrm{a}$ & $\mathrm{n} / \mathrm{a}$ \\
\hline
\end{tabular}




\begin{tabular}{|c|c|c|c|}
\hline Covering_FLOORING_WoodSt & pandPlankFlooring_US & & \\
\hline 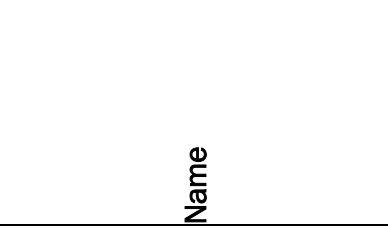 & 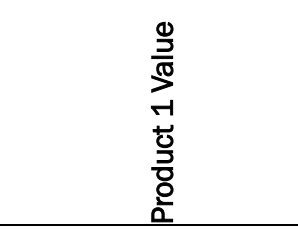 & 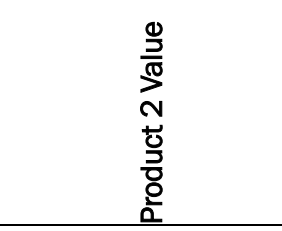 & $\begin{array}{l}\frac{0}{2} \\
\frac{0}{\pi} \\
\text { m } \\
\frac{0}{0} \\
\frac{D}{0} \\
\frac{0}{2}\end{array}$ \\
\hline Manufacturer & ARMSTRONG & MANNINGTON & SHAW \\
\hline Model & 5" - Century Farm Maple & 5" - American Maple & 3.25" Maple CA223 \\
\hline Sustainability & $n / a$ & $n / a$ & $n / a$ \\
\hline Materials & 7-ply_engineered_wood & 5-ply_engineered_wood & 3-ply_engineered_wood \\
\hline WoodSpecies & Maple & Maple & Maple \\
\hline WoodSpeciesNote & $\mathrm{n} / \mathrm{a}$ & $\mathrm{n} / \mathrm{a}$ & $\mathrm{n} / \mathrm{a}$ \\
\hline FireRating & $\mathrm{n} / \mathrm{a}$ & Class 1 & Class 1 \\
\hline AcousticRating & $\mathrm{n} / \mathrm{a}$ & less than 50 & $\mathrm{n} / \mathrm{a}$ \\
\hline FlammabilityRating & 1 & Class 1 & Class 1 \\
\hline FragilityRating & $\mathrm{n} / \mathrm{a}$ & $\mathrm{n} / \mathrm{a}$ & $\mathrm{n} / \mathrm{a}$ \\
\hline SurfaceSpreadOfFlame & $\mathrm{n} / \mathrm{a}$ & Class 1 & Class 1 \\
\hline Combustible & TRUE & TRUE & TRUE \\
\hline IsExternal & FALSE & FALSE & FALSE \\
\hline ThermalTransmittance & $\mathrm{n} / \mathrm{a}$ & $\mathrm{n} / \mathrm{a}$ & $\mathrm{n} / \mathrm{a}$ \\
\hline PostConsumerRecoveredContent & $\mathrm{n} / \mathrm{a}$ & $\mathrm{n} / \mathrm{a}$ & $\mathrm{n} / \mathrm{a}$ \\
\hline TotalRecoveredContent & $\mathrm{n} / \mathrm{a}$ & $n / a$ & $n / a$ \\
\hline RenewableContent & $\mathrm{n} / \mathrm{a}$ & $\mathrm{n} / \mathrm{a}$ & $n / a$ \\
\hline RenewableMaterial & $n / a$ & $n / a$ & $n / a$ \\
\hline BiobasedContent & $n / a$ & $n / a$ & $n / a$ \\
\hline BiobasedMaterial & $\mathrm{n} / \mathrm{a}$ & $\mathrm{n} / \mathrm{a}$ & $\mathrm{n} / \mathrm{a}$ \\
\hline RawMaterialLocation & $n / a$ & $\mathrm{n} / \mathrm{a}$ & $\mathrm{n} / \mathrm{a}$ \\
\hline RegionalMaterialContent & $n / a$ & $n / a$ & $n / a$ \\
\hline ManufactureLocation & $n / a$ & $\mathrm{n} / \mathrm{a}$ & USA \\
\hline CertifiedContent & unknown & unknown & yes \\
\hline CertificationType & $\mathrm{n} / \mathrm{a}$ & $\mathrm{n} / \mathrm{a}$ & $\begin{array}{l}\text { Cradle to Cradle, } \\
\text { Greenguard }\end{array}$ \\
\hline Emissions & $\mathrm{n} / \mathrm{a}$ & $\mathrm{n} / \mathrm{a}$ & $\mathrm{n} / \mathrm{a}$ \\
\hline SNAP & $\mathrm{n} / \mathrm{a}$ & $\mathrm{n} / \mathrm{a}$ & $\mathrm{n} / \mathrm{a}$ \\
\hline ThermalResistance & $n / a$ & $n / a$ & $n / a$ \\
\hline
\end{tabular}




\section{Covering_INSULATION_BlanketInsulation_US}

\begin{tabular}{|c|c|c|c|}
\hline $\begin{array}{l}\stackrel{0}{E} \\
\underset{\mathbb{W}}{Z}\end{array}$ & 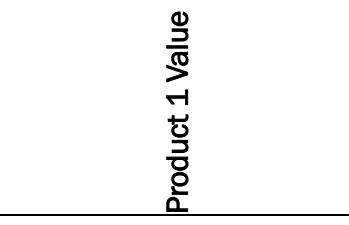 & 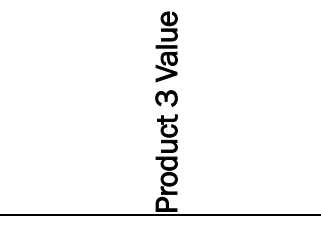 & 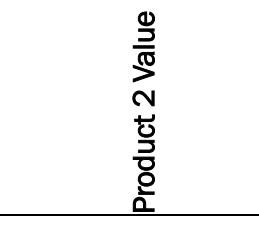 \\
\hline Manufacturer & Certainteed & Owens Corning & Bonded Logic Inc \\
\hline Model & $\begin{array}{l}\text { Unfaced CertaPro }{ }^{\mathrm{TM}} \\
\text { Commercial AcoustaTherm }{ }^{\mathrm{TM}} \\
\text { Batts -5.5" }\end{array}$ & $\begin{array}{l}\text { ProPink FastBatt Insulation } \\
\text { - Kraft Faced }\end{array}$ & $\begin{array}{l}\text { Unfaced UltraTouch } \\
\text { Denim Insulation - 5.5' }\end{array}$ \\
\hline Sustainability & $\mathrm{n} / \mathrm{a}$ & $\mathrm{n} / \mathrm{a}$ & $n / a$ \\
\hline FireRating & 0 & $\mathrm{n} / \mathrm{a}$ & $\mathrm{n} / \mathrm{a}$ \\
\hline AcousticRating & $\mathrm{n} / \mathrm{a}$ & 51 & 57 \\
\hline FlammabilityRating & Class 1 & 0 & Class 1 \\
\hline FragilityRating & $\mathrm{n} / \mathrm{a}$ & $\mathrm{n} / \mathrm{a}$ & $n / a$ \\
\hline SurfaceSpreadOfFlame & Class 1 & $\mathrm{n} / \mathrm{a}$ & Class 1 \\
\hline Combustible & FALSE & FALSE & TRUE \\
\hline IsExternal & FALSE & FALSE & FALSE \\
\hline ThermalTransmittance & $\mathrm{n} / \mathrm{a}$ & $\mathrm{n} / \mathrm{a}$ & $n / a$ \\
\hline PostConsumerRecoveredContent & $\mathrm{n} / \mathrm{a}$ & 20 & 80 \\
\hline TotalRecoveredContent & 35 & 50 & 80 \\
\hline RenewableContent & $\mathrm{n} / \mathrm{a}$ & $\mathrm{n} / \mathrm{a}$ & 70 \\
\hline RenewableMaterial & $\mathrm{n} / \mathrm{a}$ & $\mathrm{n} / \mathrm{a}$ & Cotton \\
\hline BiobasedContent & $\mathrm{n} / \mathrm{a}$ & $\mathrm{n} / \mathrm{a}$ & 70 \\
\hline BiobasedMaterial & $\mathrm{n} / \mathrm{a}$ & $\mathrm{n} / \mathrm{a}$ & Cotton \\
\hline RawMaterialLocation & $\mathrm{n} / \mathrm{a}$ & $\mathrm{n} / \mathrm{a}$ & Brownsville, TX \\
\hline RegionalMaterialContent & $\mathrm{n} / \mathrm{a}$ & $\mathrm{n} / \mathrm{a}$ & $\mathrm{n} / \mathrm{a}$ \\
\hline ManufactureLocation & $\mathrm{n} / \mathrm{a}$ & Toledo, $\mathrm{OH}$ & Chandler, AZ \\
\hline CertifiedContent & $\mathrm{n} / \mathrm{a}$ & $\mathrm{n} / \mathrm{a}$ & $n / a$ \\
\hline CertificationType & Greenguard & SCS, Greenguard & $\mathrm{n} / \mathrm{a}$ \\
\hline Emissions & $\mathrm{n} / \mathrm{a}$ & $\mathrm{n} / \mathrm{a}$ & $n / a$ \\
\hline SNAP & $\mathrm{n} / \mathrm{a}$ & $\mathrm{n} / \mathrm{a}$ & $n / a$ \\
\hline ThermalResistance & 21 & 19 & 21 \\
\hline Carcinogenic & 0 & Group 3 & $n / a$ \\
\hline FormaldehydeFree & no & $\mathrm{n} / \mathrm{a}$ & $n / a$ \\
\hline
\end{tabular}




\begin{tabular}{|c|c|c|c|}
\hline \multicolumn{4}{|c|}{ Covering_INSULATION_Boardlnsulation_US } \\
\hline 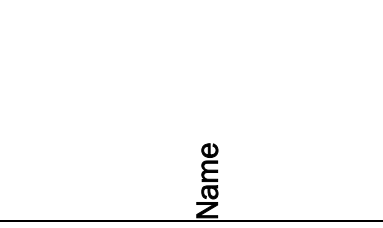 & 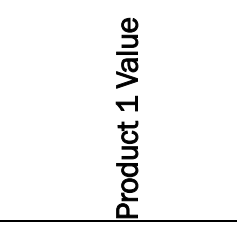 & 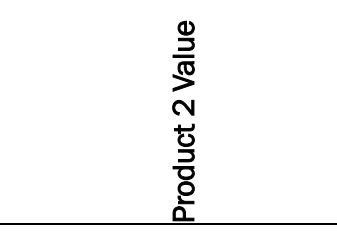 & 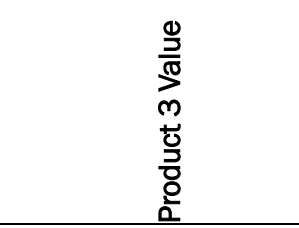 \\
\hline Manufacturer & Atlas & OwensCorning & Firestone \\
\hline Model & $\begin{array}{l}\text { Thermal Star Rigid - } \\
\text { Expanded } \\
\text { Polystyrene EPS } \\
\text { (closed-cell) }\end{array}$ & $\begin{array}{l}\text { FOAMULAR Extruded } \\
\text { Polystyrene XPS (closed-cell) }\end{array}$ & $\begin{array}{l}\text { RESISTA Polyisocyanurate } \\
\text { (closed-cell) }\end{array}$ \\
\hline Adhesives & $\mathrm{n} / \mathrm{a}$ & $\mathrm{n} / \mathrm{a}$ & $\mathrm{n} / \mathrm{a}$ \\
\hline AdhesivesNote & $\mathrm{n} / \mathrm{a}$ & $\mathrm{n} / \mathrm{a}$ & $\mathrm{n} / \mathrm{a}$ \\
\hline FireRating & 2 & 1 & 1 \\
\hline AcousticRating & $\mathrm{n} / \mathrm{a}$ & $\mathrm{n} / \mathrm{a}$ & $\mathrm{n} / \mathrm{a}$ \\
\hline FlammabilityRating & 2 & 1 & 1 \\
\hline FragilityRating & $\mathrm{n} / \mathrm{a}$ & $\mathrm{n} / \mathrm{a}$ & $\mathrm{n} / \mathrm{a}$ \\
\hline SurfaceSpreadOfFlame & $\mathrm{n} / \mathrm{a}$ & 5 & 1 \\
\hline Combustible & $\mathrm{n} / \mathrm{a}$ & $\mathrm{n} / \mathrm{a}$ & $\mathrm{n} / \mathrm{a}$ \\
\hline IsExternal & FALSE & FALSE & FALSE \\
\hline ThermalTransmittance & $\mathrm{n} / \mathrm{a}$ & $\mathrm{n} / \mathrm{a}$ & $\mathrm{n} / \mathrm{a}$ \\
\hline PostConsumerRecoveredContent & 0 & 0 & 0 \\
\hline TotalRecoveredContent & up to 100 & 20 & 5 \\
\hline RenewableContent & $\mathrm{n} / \mathrm{a}$ & $\mathrm{n} / \mathrm{a}$ & $\mathrm{n} / \mathrm{a}$ \\
\hline RenewableMaterial & $\mathrm{n} / \mathrm{a}$ & $\mathrm{n} / \mathrm{a}$ & $\mathrm{n} / \mathrm{a}$ \\
\hline BiobasedContent & $\mathrm{n} / \mathrm{a}$ & $\mathrm{n} / \mathrm{a}$ & $\mathrm{n} / \mathrm{a}$ \\
\hline BiobasedMaterial & $\mathrm{n} / \mathrm{a}$ & $\mathrm{n} / \mathrm{a}$ & $\mathrm{n} / \mathrm{a}$ \\
\hline RawMaterialLocation & $\mathrm{n} / \mathrm{a}$ & $\mathrm{n} / \mathrm{a}$ & $\mathrm{n} / \mathrm{a}$ \\
\hline RegionalMaterialContent & $\mathrm{n} / \mathrm{a}$ & $\mathrm{n} / \mathrm{a}$ & $\mathrm{n} / \mathrm{a}$ \\
\hline ManufactureLocation & $\mathrm{n} / \mathrm{a}$ & $\mathrm{n} / \mathrm{a}$ & $n / a$ \\
\hline CertifiedContent & $\mathrm{n} / \mathrm{a}$ & $\mathrm{n} / \mathrm{a}$ & $\mathrm{n} / \mathrm{a}$ \\
\hline CertificationType & $\mathrm{n} / \mathrm{a}$ & SCS & $\mathrm{n} / \mathrm{a}$ \\
\hline Emissions & $n / a$ & $\mathrm{n} / \mathrm{a}$ & $\mathrm{n} / \mathrm{a}$ \\
\hline SNAP & $\mathrm{n} / \mathrm{a}$ & $\mathrm{n} / \mathrm{a}$ & $\mathrm{n} / \mathrm{a}$ \\
\hline ThermalResistance & $3.9 /$ inch & $5 /$ inch & $6 /$ inch \\
\hline Carcinogenic & $n / a$ & $\mathrm{n} / \mathrm{a}$ & Class 3 \\
\hline FormaldehydeFree & $n / a$ & yes & yes \\
\hline
\end{tabular}


Covering_INSULATION_PolymerBasedExteriorInsulationandFinishSystem_US

\begin{tabular}{|c|c|c|c|}
\hline $\begin{array}{l}\stackrel{0}{E} \\
\text { ָ0 } \\
\end{array}$ & $\begin{array}{l}\frac{0}{2} \\
\frac{\pi}{\pi} \\
\\
\frac{1}{0} \\
\frac{0}{0} \\
\frac{2}{2}\end{array}$ & $\begin{array}{l}\frac{0}{2} \\
\frac{\pi}{10} \\
\text { N } \\
\frac{d}{2} \\
\frac{0}{0} \\
\frac{2}{2}\end{array}$ & $\begin{array}{l}\frac{0}{2} \\
\frac{1}{10} \\
m \\
\frac{0}{0} \\
\frac{7}{0} \\
\frac{0}{2}\end{array}$ \\
\hline Manufacturer & Senergy & Dryvit & Sto Corp. \\
\hline Model & Senerflex Classic PB & Outsulation X System & StoTherm Lotusan NExT \\
\hline BaseCoat & $\begin{array}{l}100 \% \text { acrylic base } \\
\text { coat, field-mixed with } \\
\text { Portland } \\
\text { cement }\end{array}$ & $\begin{array}{l}\text { liquid polymer-based material, } \\
\text { which is field mixed with Portland } \\
\text { cement intended for high moisture } \\
\text { areas }\end{array}$ & $\begin{array}{l}\text { Sto BTS Plus-one- } \\
\text { component polymer } \\
\text { modified cement based } \\
\text { high build base coat with } \\
\text { less than } 33 \text { percent } \\
\text { portland cement content } \\
\text { by weight }\end{array}$ \\
\hline FinishCoat & $\begin{array}{l}100 \% \text { acrylic resin } \\
\text { finish; air cured, } \\
\text { compatible with Base } \\
\text { Coat }\end{array}$ & $\begin{array}{l}\text { Water based, } 100 \% \text { acrylic finish } \\
\text { containing } 20 \% \text { by volume post } \\
\text { consumer recycled content and } \\
\text { formulated with DPR chemistry }\end{array}$ & $\begin{array}{l}\text { Stolit@Lotusan }{ }^{\circledR} \text {-Acrylic } \\
\text { based textured wall coating } \\
\text { with Lotus-Effect }{ }^{\circledR} \text {, } \\
\text { pronounced self-cleaning } \\
\text { performance. }\end{array}$ \\
\hline FireRating & $\mathrm{n} / \mathrm{a}$ & $\mathrm{n} / \mathrm{a}$ & $\mathrm{n} / \mathrm{a}$ \\
\hline AcousticRating & $\mathrm{n} / \mathrm{a}$ & $\mathrm{n} / \mathrm{a}$ & $\mathrm{n} / \mathrm{a}$ \\
\hline FlammabilityRating & $\mathrm{n} / \mathrm{a}$ & $\mathrm{n} / \mathrm{a}$ & $\mathrm{n} / \mathrm{a}$ \\
\hline FragilityRating & $\mathrm{n} / \mathrm{a}$ & $\mathrm{n} / \mathrm{a}$ & $\mathrm{n} / \mathrm{a}$ \\
\hline SurfaceSpreadOfFlame & $\mathrm{n} / \mathrm{a}$ & CLASS A & $\mathrm{n} / \mathrm{a}$ \\
\hline Combustible & $\mathrm{n} / \mathrm{a}$ & $\mathrm{n} / \mathrm{a}$ & $\mathrm{n} / \mathrm{a}$ \\
\hline IsExternal & TRUE & TRUE & TRUE \\
\hline ThermalTransmittance & $\mathrm{n} / \mathrm{a}$ & $\mathrm{n} / \mathrm{a}$ & $\mathrm{n} / \mathrm{a}$ \\
\hline PostConsumerRecoveredContent & $\mathrm{n} / \mathrm{a}$ & $\mathrm{n} / \mathrm{a}$ & $\mathrm{n} / \mathrm{a}$ \\
\hline TotalRecoveredContent & $\mathrm{n} / \mathrm{a}$ & $\mathrm{n} / \mathrm{a}$ & $\mathrm{n} / \mathrm{a}$ \\
\hline RenewableContent & $\mathrm{n} / \mathrm{a}$ & $\mathrm{n} / \mathrm{a}$ & $\mathrm{n} / \mathrm{a}$ \\
\hline RenewableMaterial & $\mathrm{n} / \mathrm{a}$ & $\mathrm{n} / \mathrm{a}$ & $\mathrm{n} / \mathrm{a}$ \\
\hline BiobasedContent & $\mathrm{n} / \mathrm{a}$ & $\mathrm{n} / \mathrm{a}$ & $\mathrm{n} / \mathrm{a}$ \\
\hline BiobasedMaterial & $\mathrm{n} / \mathrm{a}$ & $\mathrm{n} / \mathrm{a}$ & $\mathrm{n} / \mathrm{a}$ \\
\hline RawMaterialLocation & $\mathrm{n} / \mathrm{a}$ & $\mathrm{n} / \mathrm{a}$ & $\mathrm{n} / \mathrm{a}$ \\
\hline RegionalMaterialContent & $\mathrm{n} / \mathrm{a}$ & $\mathrm{n} / \mathrm{a}$ & $\mathrm{n} / \mathrm{a}$ \\
\hline ManufactureLocation & $\mathrm{n} / \mathrm{a}$ & $\mathrm{n} / \mathrm{a}$ & $\mathrm{n} / \mathrm{a}$ \\
\hline CertifiedContent & $\mathrm{n} / \mathrm{a}$ & $\mathrm{n} / \mathrm{a}$ & $\mathrm{n} / \mathrm{a}$ \\
\hline CertificationType & $\mathrm{n} / \mathrm{a}$ & $\mathrm{n} / \mathrm{a}$ & $\mathrm{n} / \mathrm{a}$ \\
\hline Emissions & $\mathrm{n} / \mathrm{a}$ & $\mathrm{n} / \mathrm{a}$ & $\mathrm{n} / \mathrm{a}$ \\
\hline SNAP & $\mathrm{n} / \mathrm{a}$ & $\mathrm{n} / \mathrm{a}$ & $\mathrm{n} / \mathrm{a}$ \\
\hline ThermalResistance & 18.97 & 20 & 28.3 \\
\hline Carcinogenic & $\mathrm{n} / \mathrm{a}$ & $\mathrm{n} / \mathrm{a}$ & $\mathrm{n} / \mathrm{a}$ \\
\hline FormaldehydeFree & $\mathrm{n} / \mathrm{a}$ & $\mathrm{n} / \mathrm{a}$ & $\mathrm{n} / \mathrm{a}$ \\
\hline
\end{tabular}




\begin{tabular}{|c|c|c|c|}
\hline \multicolumn{4}{|c|}{ Covering_MEMBRANE_AirBarriers_US } \\
\hline $\begin{array}{l}\stackrel{0}{E} \\
\stackrel{\mathbb{\pi}}{\mathbf{Z}}\end{array}$ & $\begin{array}{l}\frac{0}{2} \\
\frac{1}{\pi} \\
\frac{1}{1} \\
\frac{0}{0} \\
\frac{7}{0} \\
\frac{0}{2}\end{array}$ & 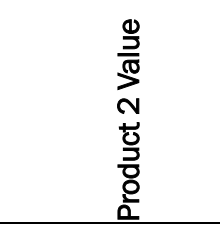 & 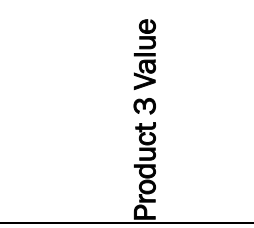 \\
\hline Manufacturer & GRACE & PROSOC & HOHMANN BARNARD \\
\hline Model & $\begin{array}{l}\text { PERM-A-BARRIER ALUMINUM } \\
\text { WALL MEMBRANE - air and } \\
\text { moisture barrier - SELF ADHERED }\end{array}$ & $\begin{array}{l}\text { R-GUARD - Air and } \\
\text { moisture barrier - } \\
\text { FLUID APPLIED }\end{array}$ & Textroflash Liquid \\
\hline FireRating & $\mathrm{n} / \mathrm{a}$ & $\mathrm{n} / \mathrm{a}$ & $\mathrm{n} / \mathrm{a}$ \\
\hline AcousticRating & $\mathrm{n} / \mathrm{a}$ & $n / a$ & $n / a$ \\
\hline FlammabilityRating & $\mathrm{n} / \mathrm{a}$ & $\mathrm{n} / \mathrm{a}$ & $\mathrm{n} / \mathrm{a}$ \\
\hline FragilityRating & $\mathrm{n} / \mathrm{a}$ & $n / a$ & $n / a$ \\
\hline SurfaceSpreadOfFlame & $\mathrm{n} / \mathrm{a}$ & $\mathrm{n} / \mathrm{a}$ & $\mathrm{n} / \mathrm{a}$ \\
\hline Combustible & $\mathrm{n} / \mathrm{a}$ & $\mathrm{n} / \mathrm{a}$ & $n / a$ \\
\hline IsExternal & $\mathrm{n} / \mathrm{a}$ & $\mathrm{n} / \mathrm{a}$ & $\mathrm{n} / \mathrm{a}$ \\
\hline ThermalTransmittance & $\mathrm{n} / \mathrm{a}$ & $n / a$ & $n / a$ \\
\hline PostConsumerRecoveredContent & $\mathrm{n} / \mathrm{a}$ & $\mathrm{n} / \mathrm{a}$ & $\mathrm{n} / \mathrm{a}$ \\
\hline TotalRecoveredContent & $\mathrm{n} / \mathrm{a}$ & $\mathrm{n} / \mathrm{a}$ & $n / a$ \\
\hline RenewableContent & $\mathrm{n} / \mathrm{a}$ & $\mathrm{n} / \mathrm{a}$ & $\mathrm{n} / \mathrm{a}$ \\
\hline RenewableMaterial & $\mathrm{n} / \mathrm{a}$ & $\mathrm{n} / \mathrm{a}$ & $n / a$ \\
\hline BiobasedContent & $\mathrm{n} / \mathrm{a}$ & $\mathrm{n} / \mathrm{a}$ & $\mathrm{n} / \mathrm{a}$ \\
\hline BiobasedMaterial & $\mathrm{n} / \mathrm{a}$ & $\mathrm{n} / \mathrm{a}$ & $\mathrm{n} / \mathrm{a}$ \\
\hline RawMaterialLocation & $\mathrm{n} / \mathrm{a}$ & $\mathrm{n} / \mathrm{a}$ & $\mathrm{n} / \mathrm{a}$ \\
\hline RegionalMaterialContent & $\mathrm{n} / \mathrm{a}$ & $\mathrm{n} / \mathrm{a}$ & $n / a$ \\
\hline ManufactureLocation & $\mathrm{n} / \mathrm{a}$ & $\mathrm{n} / \mathrm{a}$ & $\mathrm{n} / \mathrm{a}$ \\
\hline CertifiedContent & $\mathrm{n} / \mathrm{a}$ & $\mathrm{n} / \mathrm{a}$ & $n / a$ \\
\hline CertificationType & $\mathrm{n} / \mathrm{a}$ & $n / a$ & $\mathrm{n} / \mathrm{a}$ \\
\hline Emissions & $\mathrm{n} / \mathrm{a}$ & $\mathrm{n} / \mathrm{a}$ & none \\
\hline SNAP & $\mathrm{n} / \mathrm{a}$ & $\mathrm{n} / \mathrm{a}$ & $\mathrm{n} / \mathrm{a}$ \\
\hline ThermalResistance & $\mathrm{n} / \mathrm{a}$ & $n / a$ & $n / a$ \\
\hline
\end{tabular}




\begin{tabular}{|c|c|c|c|}
\hline \multicolumn{4}{|c|}{ Covering_MEMBRANE_EthylenePropyleneDieneMonomerRoofing_US } \\
\hline $\begin{array}{l}\stackrel{0}{E} \\
\stackrel{\mathbb{\pi}}{\mathbf{Z}} \\
\end{array}$ & 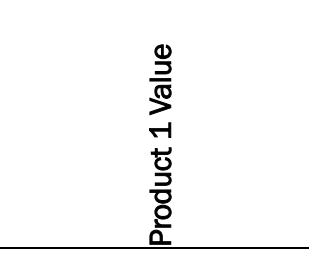 & $\begin{array}{l}\frac{0}{2} \\
\frac{2}{10} \\
\text { N } \\
\frac{0}{2} \\
\frac{0}{0} \\
\frac{0}{2}\end{array}$ & $\begin{array}{l}\frac{0}{D} \\
\frac{D}{N 0} \\
m \\
\frac{0}{0} \\
\frac{2}{0} \\
\frac{0}{2}\end{array}$ \\
\hline Manufacturer & CARLISLE & FIRESTONE & JOHNS MANVILLE \\
\hline Model & $\begin{array}{l}\text { Sure-Seal Dusted Non- } \\
\text { Reinforced - Fully adhered }\end{array}$ & $\begin{array}{l}\text { RubberGard Low Slope } \\
\text { Fire Retardant }\end{array}$ & $\begin{array}{l}\text { JM EPDM Nonreinforced } \\
\text { Roofing Membrane - } 90 \text { FR }\end{array}$ \\
\hline Sustainability & $\mathrm{n} / \mathrm{a}$ & $\mathrm{n} / \mathrm{a}$ & $\mathrm{n} / \mathrm{a}$ \\
\hline Membrane & 45 mils non-reinforced & 60 mils non-reinforced & 90 mils non-reinforced \\
\hline Ballast & $\mathrm{n} / \mathrm{a}$ & $\mathrm{n} / \mathrm{a}$ & $\mathrm{n} / \mathrm{a}$ \\
\hline CoverBoardOverInsulation & notedefined & notedefined & notedefined \\
\hline Insulation & notedefined & notedefined & notedefined \\
\hline InsulationProfile & notedefined & notedefined & notedefined \\
\hline InsulationSubstrateBoard & notedefined & notedefined & notedefined \\
\hline VaporRetarder & notedefined & notedefined & notedefined \\
\hline FireRating & $\mathrm{n} / \mathrm{a}$ & $\mathrm{n} / \mathrm{a}$ & $n / a$ \\
\hline AcousticRating & $\mathrm{n} / \mathrm{a}$ & $\mathrm{n} / \mathrm{a}$ & $n / a$ \\
\hline FlammabilityRating & $\mathrm{n} / \mathrm{a}$ & $\mathrm{n} / \mathrm{a}$ & $n / a$ \\
\hline FragilityRating & $\mathrm{n} / \mathrm{a}$ & $\mathrm{n} / \mathrm{a}$ & $\mathrm{n} / \mathrm{a}$ \\
\hline SurfaceSpreadOfFlame & $\mathrm{n} / \mathrm{a}$ & $\mathrm{n} / \mathrm{a}$ & $\mathrm{n} / \mathrm{a}$ \\
\hline Combustible & $\mathrm{n} / \mathrm{a}$ & $\mathrm{n} / \mathrm{a}$ & $\mathrm{n} / \mathrm{a}$ \\
\hline IsExternal & TRUE & TRUE & TRUE \\
\hline ThermalTransmittance & $\mathrm{n} / \mathrm{a}$ & $\mathrm{n} / \mathrm{a}$ & $\mathrm{n} / \mathrm{a}$ \\
\hline PostConsumerRecoveredContent & 0.03 & 0 & $\mathrm{n} / \mathrm{a}$ \\
\hline TotalRecoveredContent & $\mathrm{n} / \mathrm{a}$ & $\mathrm{n} / \mathrm{a}$ & $\mathrm{n} / \mathrm{a}$ \\
\hline RenewableContent & $\mathrm{n} / \mathrm{a}$ & $\mathrm{n} / \mathrm{a}$ & $\mathrm{n} / \mathrm{a}$ \\
\hline RenewableMaterial & $\mathrm{n} / \mathrm{a}$ & $\mathrm{n} / \mathrm{a}$ & $\mathrm{n} / \mathrm{a}$ \\
\hline BiobasedContent & $\mathrm{n} / \mathrm{a}$ & $\mathrm{n} / \mathrm{a}$ & $\mathrm{n} / \mathrm{a}$ \\
\hline BiobasedMaterial & $\mathrm{n} / \mathrm{a}$ & $\mathrm{n} / \mathrm{a}$ & $\mathrm{n} / \mathrm{a}$ \\
\hline RawMaterialLocation & $\mathrm{n} / \mathrm{a}$ & $\mathrm{n} / \mathrm{a}$ & $\mathrm{n} / \mathrm{a}$ \\
\hline RegionalMaterialContent & $\mathrm{n} / \mathrm{a}$ & $\mathrm{n} / \mathrm{a}$ & $\mathrm{n} / \mathrm{a}$ \\
\hline ManufactureLocation & $\begin{array}{l}\text { Carlisle, PA and } \\
\text { Greenville, IL }\end{array}$ & Prescott, AR & $\mathrm{n} / \mathrm{a}$ \\
\hline CertifiedContent & $\mathrm{n} / \mathrm{a}$ & $\mathrm{n} / \mathrm{a}$ & $\mathrm{n} / \mathrm{a}$ \\
\hline CertificationType & $\mathrm{n} / \mathrm{a}$ & $\mathrm{n} / \mathrm{a}$ & $\mathrm{n} / \mathrm{a}$ \\
\hline Emissions & $\mathrm{n} / \mathrm{a}$ & $\mathrm{n} / \mathrm{a}$ & $\mathrm{n} / \mathrm{a}$ \\
\hline SNAP & $\mathrm{n} / \mathrm{a}$ & $\mathrm{n} / \mathrm{a}$ & $\mathrm{n} / \mathrm{a}$ \\
\hline ThermalResistance & $\mathrm{n} / \mathrm{a}$ & $\mathrm{n} / \mathrm{a}$ & $\mathrm{n} / \mathrm{a}$ \\
\hline
\end{tabular}




\begin{tabular}{|c|c|c|c|}
\hline \multicolumn{4}{|c|}{ Covering_MEMBRANE_Painting_US } \\
\hline 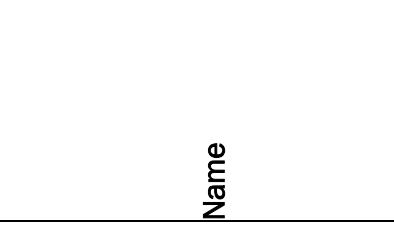 & 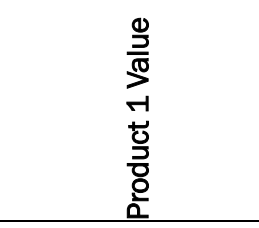 & 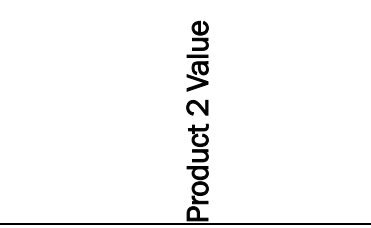 & $\begin{array}{l}\frac{0}{2} \\
\frac{D}{0} \\
m \\
\frac{0}{0} \\
\frac{0}{0} \\
\frac{0}{2}\end{array}$ \\
\hline Manufacturer & PPG & Benjamin Moore & Sherwin-Williams \\
\hline Model & $\begin{array}{l}\text { OLYMPIC } ₫ \text { Premium } \\
\text { Interior Oil Based } \\
\text { Wood Stain } 44500\end{array}$ & $\begin{array}{l}\text { Aura Waterborne Interior Paint - } \\
\text { Matte Finish (522) }\end{array}$ & $\begin{array}{l}\text { Harmony® Interior } \\
\text { Acrylic Latex - Semi- } \\
\text { Gloss }\end{array}$ \\
\hline Sustainability & 0 & 0 & 0 \\
\hline ApplicationSurface & $\begin{array}{l}\text { interior_unfinished_w } \\
\text { ood_surfaces }\end{array}$ & $\mathrm{n} / \mathrm{a}$ & $\mathrm{n} / \mathrm{a}$ \\
\hline PrimaryCoatingType & Alkyd / Oil Resin & 100\% Acrylic & Latex \\
\hline PrimaryPaintSystem & $\mathrm{n} / \mathrm{a}$ & two_finish_coats & $\begin{array}{l}\text { primer_plus_two_finish_ } \\
\text { coats }\end{array}$ \\
\hline FireRating & $\mathrm{n} / \mathrm{a}$ & $\mathrm{n} / \mathrm{a}$ & $\mathrm{n} / \mathrm{a}$ \\
\hline AcousticRating & $\mathrm{n} / \mathrm{a}$ & $\mathrm{n} / \mathrm{a}$ & $\mathrm{n} / \mathrm{a}$ \\
\hline FlammabilityRating & 2 & $n / a$ & $\mathrm{n} / \mathrm{a}$ \\
\hline FragilityRating & $\mathrm{n} / \mathrm{a}$ & $n / a$ & $\mathrm{n} / \mathrm{a}$ \\
\hline SurfaceSpreadOfFlame & $\mathrm{n} / \mathrm{a}$ & $\mathrm{n} / \mathrm{a}$ & $\mathrm{n} / \mathrm{a}$ \\
\hline Combustible & TRUE & FALSE & FALSE \\
\hline IsExternal & FALSE & FALSE & FALSE \\
\hline ThermalTransmittance & $n / a$ & $\mathrm{n} / \mathrm{a}$ & $\mathrm{n} / \mathrm{a}$ \\
\hline PostConsumerRecoveredContent & $\mathrm{n} / \mathrm{a}$ & $\mathrm{n} / \mathrm{a}$ & $\mathrm{n} / \mathrm{a}$ \\
\hline TotalRecoveredContent & $n / a$ & $n / a$ & $n / a$ \\
\hline RenewableContent & $\mathrm{n} / \mathrm{a}$ & $\mathrm{n} / \mathrm{a}$ & $\mathrm{n} / \mathrm{a}$ \\
\hline RenewableMaterial & $n / a$ & $n / a$ & $\mathrm{n} / \mathrm{a}$ \\
\hline BiobasedContent & $\mathrm{n} / \mathrm{a}$ & $\mathrm{n} / \mathrm{a}$ & $\mathrm{n} / \mathrm{a}$ \\
\hline BiobasedMaterial & $n / a$ & $n / a$ & $\mathrm{n} / \mathrm{a}$ \\
\hline RawMaterialLocation & $\mathrm{n} / \mathrm{a}$ & $\mathrm{n} / \mathrm{a}$ & $\mathrm{n} / \mathrm{a}$ \\
\hline RegionalMaterialContent & $n / a$ & $n / a$ & $\mathrm{n} / \mathrm{a}$ \\
\hline ManufactureLocation & 0 & 0 & 0 \\
\hline CertifiedContent & $\mathrm{n} / \mathrm{a}$ & $n / a$ & $\mathrm{n} / \mathrm{a}$ \\
\hline CertificationType & $\mathrm{n} / \mathrm{a}$ & Green Promise & GreenSure \\
\hline Emissions & $240 \mathrm{~g} / \mathrm{L}$ & VOC $50 \mathrm{~g} / \mathrm{L}$ & VOC $0 \mathrm{~g} / \mathrm{L}$ \\
\hline SNAP & $n / a$ & $n / a$ & $n / a$ \\
\hline ThermalResistance & $\mathrm{n} / \mathrm{a}$ & $n / a$ & $\mathrm{n} / \mathrm{a}$ \\
\hline Conductivity & 0 & $n / a$ & $\mathrm{n} / \mathrm{a}$ \\
\hline Density & $7.84 \mathrm{lb} / \mathrm{gal}$ & 10.0 - 12.1 (lbs/gal) & $10.51 \mathrm{lb} / \mathrm{gal}$ \\
\hline SpecificHeat & 0 & $n / a$ & $n / a$ \\
\hline
\end{tabular}


Covering_ROOFING_AsphaltShingles_US

\begin{tabular}{|c|c|c|c|}
\hline 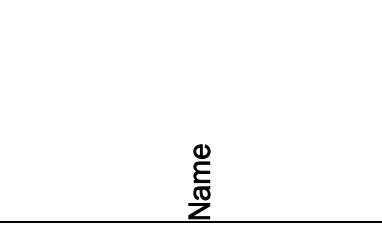 & $\begin{array}{l}\frac{0}{\partial} \\
\frac{\partial}{\pi} \\
ㄱ \\
\frac{1}{0} \\
\frac{0}{0} \\
\frac{0}{2}\end{array}$ & 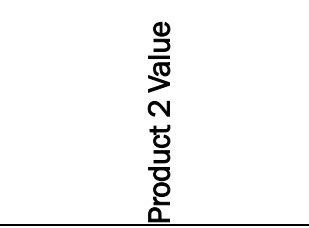 & 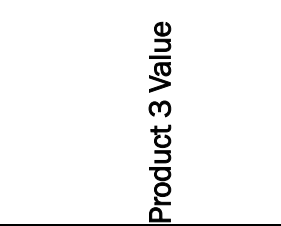 \\
\hline Manufacturer & OWENS CORNING & GAF & CERTAIN TEED \\
\hline Model & $\begin{array}{l}\text { DURATION SHINGLE - ESTATE } \\
\text { GRAY }\end{array}$ & COOL WEATHERED WOOD & $\begin{array}{l}\text { LANDMARK SOLARIS } \\
\text { PLATINUM - COSTAL TAN }\end{array}$ \\
\hline FireRating & CLASS A & CLASS A & CLASS A \\
\hline AcousticRating & $\mathrm{n} / \mathrm{a}$ & $\mathrm{n} / \mathrm{a}$ & $\mathrm{n} / \mathrm{a}$ \\
\hline FlammabilityRating & $\mathrm{n} / \mathrm{a}$ & $\mathrm{n} / \mathrm{a}$ & $\mathrm{n} / \mathrm{a}$ \\
\hline FragilityRating & $\mathrm{n} / \mathrm{a}$ & $\mathrm{n} / \mathrm{a}$ & $n / a$ \\
\hline SurfaceSpreadOfFlame & $\mathrm{n} / \mathrm{a}$ & $\mathrm{n} / \mathrm{a}$ & $\mathrm{n} / \mathrm{a}$ \\
\hline Combustible & $\mathrm{n} / \mathrm{a}$ & $\mathrm{n} / \mathrm{a}$ & $\mathrm{n} / \mathrm{a}$ \\
\hline IsExternal & $\mathrm{n} / \mathrm{a}$ & $\mathrm{n} / \mathrm{a}$ & $n / a$ \\
\hline ThermalTransmittance & $\mathrm{n} / \mathrm{a}$ & $\mathrm{n} / \mathrm{a}$ & $\mathrm{n} / \mathrm{a}$ \\
\hline PostConsumerRecoveredContent & $\mathrm{n} / \mathrm{a}$ & $\mathrm{n} / \mathrm{a}$ & $\mathrm{n} / \mathrm{a}$ \\
\hline TotalRecoveredContent & $\mathrm{n} / \mathrm{a}$ & $\mathrm{n} / \mathrm{a}$ & $n / a$ \\
\hline RenewableContent & $\mathrm{n} / \mathrm{a}$ & $\mathrm{n} / \mathrm{a}$ & $\mathrm{n} / \mathrm{a}$ \\
\hline RenewableMaterial & $\mathrm{n} / \mathrm{a}$ & $\mathrm{n} / \mathrm{a}$ & $\mathrm{n} / \mathrm{a}$ \\
\hline BiobasedContent & $\mathrm{n} / \mathrm{a}$ & $\mathrm{n} / \mathrm{a}$ & $\mathrm{n} / \mathrm{a}$ \\
\hline BiobasedMaterial & $\mathrm{n} / \mathrm{a}$ & $\mathrm{n} / \mathrm{a}$ & $\mathrm{n} / \mathrm{a}$ \\
\hline RawMaterialLocation & $\mathrm{n} / \mathrm{a}$ & $\mathrm{n} / \mathrm{a}$ & $\mathrm{n} / \mathrm{a}$ \\
\hline RegionalMaterialContent & $\mathrm{n} / \mathrm{a}$ & $\mathrm{n} / \mathrm{a}$ & $\mathrm{n} / \mathrm{a}$ \\
\hline ManufactureLocation & $\mathrm{n} / \mathrm{a}$ & $\mathrm{n} / \mathrm{a}$ & $\mathrm{n} / \mathrm{a}$ \\
\hline CertifiedContent & $\mathrm{n} / \mathrm{a}$ & $\mathrm{n} / \mathrm{a}$ & $\mathrm{n} / \mathrm{a}$ \\
\hline CertificationType & $\mathrm{n} / \mathrm{a}$ & $\mathrm{n} / \mathrm{a}$ & $\mathrm{n} / \mathrm{a}$ \\
\hline Emissions & $\mathrm{n} / \mathrm{a}$ & $\mathrm{n} / \mathrm{a}$ & $\mathrm{n} / \mathrm{a}$ \\
\hline SNAP & $\mathrm{n} / \mathrm{a}$ & $\mathrm{n} / \mathrm{a}$ & $\mathrm{n} / \mathrm{a}$ \\
\hline ThermalResistance & $\mathrm{n} / \mathrm{a}$ & $\mathrm{n} / \mathrm{a}$ & $\mathrm{n} / \mathrm{a}$ \\
\hline Exposure & $5-5 / 8 "$ & $5-5 / 8 "$ & $55 / 8 "$ \\
\hline EnergyStar & no & yes & yes \\
\hline SolarReflectanceFront & $\mathrm{n} / \mathrm{a}$ & 0.26 & 0.4 \\
\hline
\end{tabular}




\begin{tabular}{|c|c|c|c|}
\hline \multicolumn{4}{|c|}{ Covering_ROOFING_SheetMetalRoofing_US } \\
\hline $\begin{array}{l}\stackrel{0}{E} \\
\text { ָ } \\
\end{array}$ & $\begin{array}{l}\frac{0}{2} \\
\frac{\pi}{\pi} \\
-1 \\
\frac{1}{0} \\
\frac{D}{0} \\
\frac{2}{2}\end{array}$ & 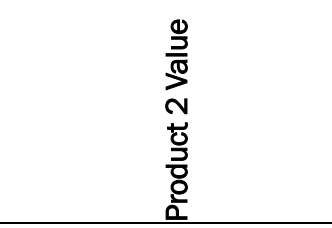 & $\begin{array}{l}\frac{0}{2} \\
\frac{\pi}{\pi} \\
\text { m } \\
\stackrel{0}{0} \\
\frac{0}{0} \\
\frac{0}{2}\end{array}$ \\
\hline Manufacturer & PAC-CLAD & FIRESTONE & ATAS \\
\hline Model & $\begin{array}{l}\text { TITE-LOC STANDING } \\
\text { SEAM - PRE-FINISHED } \\
\text { ALUMINUM - ALMOND }\end{array}$ & $\begin{array}{l}\text { UC-3 STANDING SEAM -PRE- } \\
\text { FINISHED ALUMINUM }\end{array}$ & $\begin{array}{l}\text { FLR154 - 2" Field-Lok } \\
\text { Panel - PREFINISHED } \\
\text { ALUMINUM - } \\
\text { SANDSTONE }\end{array}$ \\
\hline Sustainability & $\mathrm{n} / \mathrm{a}$ & $\mathrm{n} / \mathrm{a}$ & $\mathrm{n} / \mathrm{a}$ \\
\hline FireRating & CLASS A & CLASS A & $\mathrm{n} / \mathrm{a}$ \\
\hline AcousticRating & $\mathrm{n} / \mathrm{a}$ & $\mathrm{n} / \mathrm{a}$ & $\mathrm{n} / \mathrm{a}$ \\
\hline FlammabilityRating & $\mathrm{n} / \mathrm{a}$ & $\mathrm{n} / \mathrm{a}$ & ASTM E 84 \\
\hline FragilityRating & $\mathrm{n} / \mathrm{a}$ & $\mathrm{n} / \mathrm{a}$ & $\mathrm{n} / \mathrm{a}$ \\
\hline SurfaceSpreadOfFlame & $\mathrm{n} / \mathrm{a}$ & $\mathrm{n} / \mathrm{a}$ & $\mathrm{n} / \mathrm{a}$ \\
\hline Combustible & $\mathrm{n} / \mathrm{a}$ & $\mathrm{n} / \mathrm{a}$ & $\mathrm{n} / \mathrm{a}$ \\
\hline IsExternal & $\mathrm{n} / \mathrm{a}$ & $\mathrm{n} / \mathrm{a}$ & $\mathrm{n} / \mathrm{a}$ \\
\hline ThermalTransmittance & $\mathrm{n} / \mathrm{a}$ & $\mathrm{n} / \mathrm{a}$ & $\mathrm{n} / \mathrm{a}$ \\
\hline PostConsumerRecoveredContent & $\mathrm{n} / \mathrm{a}$ & 1.6 & 1.6 \\
\hline TotalRecoveredContent & $\mathrm{n} / \mathrm{a}$ & 51.5 & 51.5 \\
\hline RenewableContent & $\mathrm{n} / \mathrm{a}$ & $\mathrm{n} / \mathrm{a}$ & $\mathrm{n} / \mathrm{a}$ \\
\hline RenewableMaterial & $\mathrm{n} / \mathrm{a}$ & $\mathrm{n} / \mathrm{a}$ & $\mathrm{n} / \mathrm{a}$ \\
\hline BiobasedContent & $\mathrm{n} / \mathrm{a}$ & $n / a$ & $\mathrm{n} / \mathrm{a}$ \\
\hline BiobasedMaterial & $\mathrm{n} / \mathrm{a}$ & $\mathrm{n} / \mathrm{a}$ & $\mathrm{n} / \mathrm{a}$ \\
\hline RawMaterialLocation & $\mathrm{n} / \mathrm{a}$ & $\mathrm{n} / \mathrm{a}$ & $\mathrm{n} / \mathrm{a}$ \\
\hline RegionalMaterialContent & $\mathrm{n} / \mathrm{a}$ & $\mathrm{n} / \mathrm{a}$ & $\mathrm{n} / \mathrm{a}$ \\
\hline ManufactureLocation & Elk Grove Village, IL & $\begin{array}{l}\text { Anoka, MN } \\
\text { College Park, GA } \\
\text { Morrisville, PA } \\
\text { Las Vegas, NV } \\
\text { Warren, MI }\end{array}$ & $\mathrm{n} / \mathrm{a}$ \\
\hline CertifiedContent & $\mathrm{n} / \mathrm{a}$ & $\mathrm{n} / \mathrm{a}$ & $\mathrm{n} / \mathrm{a}$ \\
\hline CertificationType & $\mathrm{n} / \mathrm{a}$ & $\mathrm{n} / \mathrm{a}$ & $\mathrm{n} / \mathrm{a}$ \\
\hline Emissions & $\mathrm{n} / \mathrm{a}$ & $\mathrm{n} / \mathrm{a}$ & $n / a$ \\
\hline SNAP & $\mathrm{n} / \mathrm{a}$ & $\mathrm{n} / \mathrm{a}$ & $\mathrm{n} / \mathrm{a}$ \\
\hline ThermalResistance & $\mathrm{n} / \mathrm{a}$ & $\mathrm{n} / \mathrm{a}$ & $\mathrm{n} / \mathrm{a}$ \\
\hline
\end{tabular}




\begin{tabular}{|c|c|c|c|}
\hline \multicolumn{4}{|c|}{ Covering_ROOFING_VegetatedProtectedMembraneRoofing_US } \\
\hline $\begin{array}{l}\stackrel{0}{E} \\
\stackrel{\mathbb{\pi}}{Z}\end{array}$ & $\begin{array}{l}\frac{0}{2} \\
\frac{1}{\pi} \\
ㄱ \\
\frac{0}{2} \\
\frac{0}{0} \\
\frac{0}{0}\end{array}$ & 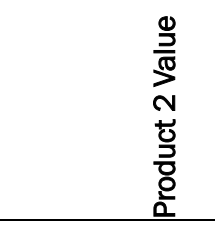 & $\begin{array}{l}\frac{0}{2} \\
\frac{0}{\pi} \\
m \\
\text { m } \\
\frac{0}{0} \\
\frac{0}{0}\end{array}$ \\
\hline Manufacturer & XeroFlor & Roof Meadow & Firestone \\
\hline Model & $\begin{array}{l}\text { XF300+XT green roof } \\
\text { system - extensive }\end{array}$ & Type III - extensive & $\begin{array}{l}\text { Skyscape Vegetative } \\
\text { Roof System - Intensive }\end{array}$ \\
\hline Sustainability & $\mathrm{n} / \mathrm{a}$ & 0 & 0 \\
\hline Membrane & polyethylene_20_mil & as_selected & Fully_Adhered_EPDM \\
\hline Ballast & $\mathrm{n} / \mathrm{a}$ & $\mathrm{n} / \mathrm{a}$ & $\mathrm{n} / \mathrm{a}$ \\
\hline CoverBoardOverlnsulation & $\mathrm{n} / \mathrm{a}$ & $\mathrm{n} / \mathrm{a}$ & $\begin{array}{l}\text { ISOGARD_HD_cover_bo } \\
\text { ard }\end{array}$ \\
\hline Insulation & $\mathrm{n} / \mathrm{a}$ & $\mathrm{n} / \mathrm{a}$ & ISO_95+ \\
\hline InsulationProfile & $\mathrm{n} / \mathrm{a}$ & $\mathrm{n} / \mathrm{a}$ & $\mathrm{n} / \mathrm{a}$ \\
\hline GrowingMedium & as_selected & as_selected & as_selected \\
\hline PlantMaterials & extensive & extensive & intensive \\
\hline FireRating & $\mathrm{n} / \mathrm{a}$ & $\mathrm{n} / \mathrm{a}$ & $\mathrm{n} / \mathrm{a}$ \\
\hline AcousticRating & $\mathrm{n} / \mathrm{a}$ & $\mathrm{n} / \mathrm{a}$ & $\mathrm{n} / \mathrm{a}$ \\
\hline FlammabilityRating & $\mathrm{n} / \mathrm{a}$ & $\mathrm{n} / \mathrm{a}$ & $\mathrm{n} / \mathrm{a}$ \\
\hline FragilityRating & $\mathrm{n} / \mathrm{a}$ & $\mathrm{n} / \mathrm{a}$ & $\mathrm{n} / \mathrm{a}$ \\
\hline SurfaceSpreadOfFlame & $\mathrm{n} / \mathrm{a}$ & $\mathrm{n} / \mathrm{a}$ & $\mathrm{n} / \mathrm{a}$ \\
\hline Combustible & $\mathrm{n} / \mathrm{a}$ & $\mathrm{n} / \mathrm{a}$ & $\mathrm{n} / \mathrm{a}$ \\
\hline IsExternal & TRUE & $\mathrm{n} / \mathrm{a}$ & $\mathrm{n} / \mathrm{a}$ \\
\hline ThermalTransmittance & 0 & 0 & $\mathrm{n} / \mathrm{a}$ \\
\hline PostConsumerRecoveredContent & $\mathrm{n} / \mathrm{a}$ & $\mathrm{n} / \mathrm{a}$ & 0 \\
\hline TotalRecoveredContent & $\mathrm{n} / \mathrm{a}$ & $\mathrm{n} / \mathrm{a}$ & 1 \\
\hline RenewableContent & $\mathrm{n} / \mathrm{a}$ & $\mathrm{n} / \mathrm{a}$ & $\mathrm{n} / \mathrm{a}$ \\
\hline RenewableMaterial & organic_mulch & $\mathrm{n} / \mathrm{a}$ & $\mathrm{n} / \mathrm{a}$ \\
\hline BiobasedContent & $\mathrm{n} / \mathrm{a}$ & $\mathrm{n} / \mathrm{a}$ & $\mathrm{n} / \mathrm{a}$ \\
\hline BiobasedMaterial & $\mathrm{n} / \mathrm{a}$ & $\mathrm{n} / \mathrm{a}$ & $\mathrm{n} / \mathrm{a}$ \\
\hline RawMaterialLocation & $\mathrm{n} / \mathrm{a}$ & $\mathrm{n} / \mathrm{a}$ & $\mathrm{n} / \mathrm{a}$ \\
\hline RegionalMaterialContent & $\mathrm{n} / \mathrm{a}$ & $\mathrm{n} / \mathrm{a}$ & $\mathrm{n} / \mathrm{a}$ \\
\hline ManufactureLocation & $\mathrm{n} / \mathrm{a}$ & $\mathrm{n} / \mathrm{a}$ & $\mathrm{n} / \mathrm{a}$ \\
\hline CertifiedContent & $\mathrm{n} / \mathrm{a}$ & $\mathrm{n} / \mathrm{a}$ & $\mathrm{n} / \mathrm{a}$ \\
\hline CertificationType & $\mathrm{n} / \mathrm{a}$ & $\mathrm{n} / \mathrm{a}$ & $\mathrm{n} / \mathrm{a}$ \\
\hline Emissions & $\mathrm{n} / \mathrm{a}$ & $\mathrm{n} / \mathrm{a}$ & $\mathrm{n} / \mathrm{a}$ \\
\hline SNAP & $\mathrm{n} / \mathrm{a}$ & $\mathrm{n} / \mathrm{a}$ & $\mathrm{n} / \mathrm{a}$ \\
\hline ThermalResistance & $\mathrm{n} / \mathrm{a}$ & $\mathrm{n} / \mathrm{a}$ & $\mathrm{n} / \mathrm{a}$ \\
\hline
\end{tabular}


CurtainWall_USERDEFINED_AluminumFramedEntrancesandStorefronts_US

\begin{tabular}{|c|c|c|c|}
\hline 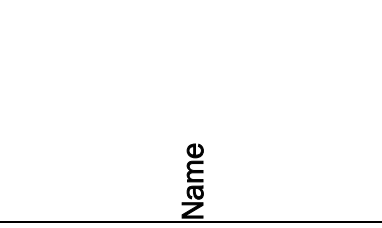 & 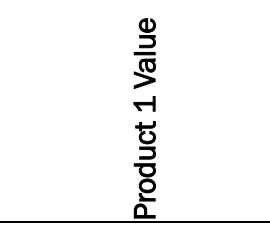 & $\begin{array}{l}\frac{0}{2} \\
\frac{\pi}{\pi} \\
\text { N } \\
\frac{d}{2} \\
\frac{2}{0} \\
\frac{0}{2}\end{array}$ & $\begin{array}{l}\frac{0}{2} \\
\frac{1}{\pi} \\
\frac{0}{m} \\
\frac{0}{0} \\
\frac{0}{0} \\
\frac{0}{2}\end{array}$ \\
\hline Manufacturer & US Aluminum & Kawneer & Tubelite \\
\hline Model & $\begin{array}{l}\text { Storefront Series } 400 \text { - } \\
\text { Center Glazed }\end{array}$ & $\begin{array}{l}\text { Storefront Trifab } \AA \text { VersaGlaze } \AA \\
451 / 451 T\end{array}$ & $\begin{array}{l}\text { Storefront } 14000 \\
\text { Series }\end{array}$ \\
\hline Sustainability & $n / a$ & $\mathrm{n} / \mathrm{a}$ & $n / a$ \\
\hline Glazing & as_selected & as_selected & as_selected \\
\hline GlazingColor & as_selected & as_selected & as_selected \\
\hline AcousticRating & $\mathrm{n} / \mathrm{a}$ & $\mathrm{n} / \mathrm{a}$ & 32 \\
\hline FireRating & $\mathrm{n} / \mathrm{a}$ & $\mathrm{n} / \mathrm{a}$ & $\mathrm{n} / \mathrm{a}$ \\
\hline Combustible & FALSE & FALSE & FALSE \\
\hline SurfaceSpreadOfFlame & $n / a$ & $\mathrm{n} / \mathrm{a}$ & $n / a$ \\
\hline ThermalTransmittance & $\mathrm{n} / \mathrm{a}$ & $\mathrm{n} / \mathrm{a}$ & 0.6 \\
\hline IsExternal & TRUE & TRUE & TRUE \\
\hline PostConsumerRecoveredContent & $n / a$ & $n / a$ & $\mathrm{n} / \mathrm{a}$ \\
\hline TotalRecoveredContent & $n / a$ & $n / a$ & $\mathrm{n} / \mathrm{a}$ \\
\hline RenewableContent & $n / a$ & $\mathrm{n} / \mathrm{a}$ & $\mathrm{n} / \mathrm{a}$ \\
\hline RenewableMaterial & $n / a$ & $n / a$ & $n / a$ \\
\hline BiobasedContent & $n / a$ & $n / a$ & $\mathrm{n} / \mathrm{a}$ \\
\hline BiobasedMaterial & $n / a$ & $\mathrm{n} / \mathrm{a}$ & $n / a$ \\
\hline RawMaterialLocation & $n / a$ & $n / a$ & $n / a$ \\
\hline RegionalMaterialContent & $\mathrm{n} / \mathrm{a}$ & $\mathrm{n} / \mathrm{a}$ & $n / a$ \\
\hline ManufactureLocation & $n / a$ & $\mathrm{n} / \mathrm{a}$ & $n / a$ \\
\hline CertifiedContent & $\mathrm{n} / \mathrm{a}$ & $\mathrm{n} / \mathrm{a}$ & $n / a$ \\
\hline CertificationType & $n / a$ & $\mathrm{n} / \mathrm{a}$ & $n / a$ \\
\hline Emissions & $\mathrm{n} / \mathrm{a}$ & $\mathrm{n} / \mathrm{a}$ & $n / a$ \\
\hline SNAP & $n / a$ & $\mathrm{n} / \mathrm{a}$ & $\mathrm{n} / \mathrm{a}$ \\
\hline ThermalResistance & $n / a$ & $\mathrm{n} / \mathrm{a}$ & $\mathrm{n} / \mathrm{a}$ \\
\hline
\end{tabular}


CurtainWall_USERDEFINED_GlazedAluminumCurtainWalls_US

\begin{tabular}{|c|c|c|c|}
\hline $\begin{array}{l}\stackrel{0}{E} \\
\text { त) } \\
\end{array}$ & 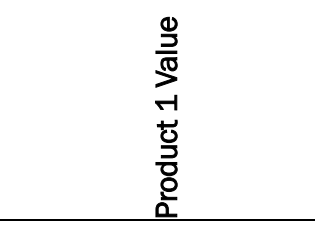 & $\begin{array}{l}\frac{0}{2} \\
\frac{D}{D} \\
\mathbb{N} \\
\frac{0}{2} \\
\frac{0}{0} \\
\frac{0}{2}\end{array}$ & $\begin{array}{l}\frac{0}{\partial} \\
\frac{D}{D} \\
\text { m } \\
\frac{0}{2} \\
\frac{0}{0} \\
\frac{0}{2}\end{array}$ \\
\hline Manufacturer & US Aluminum & Kawneer & Tubelite \\
\hline Model & Series 2100 Curtain Wall & 1600 Wall System 5 & 400 Series Curtainwall \\
\hline Sustainability & $n / a$ & $n / a$ & $n / a$ \\
\hline PrimaryComponents & $\begin{array}{l}\text { extruded_aluminum_frami } \\
\text { ng }\end{array}$ & $\begin{array}{l}\text { extruded_aluminum_frami } \\
\text { ng }\end{array}$ & extruded_aluminum_framing \\
\hline Materials & ther & therma & 0 \\
\hline Glazing & $\mathrm{n} / \mathrm{a}$ & $\mathrm{n} / \mathrm{a}$ & $\mathrm{n} / \mathrm{a}$ \\
\hline GlazingColor & as_selected & as_selected & as_selected \\
\hline AcousticRating & $\mathrm{n} / \mathrm{a}$ & $n / a$ & $n / a$ \\
\hline FireRating & $\mathrm{n} / \mathrm{a}$ & $\mathrm{n} / \mathrm{a}$ & $\mathrm{n} / \mathrm{a}$ \\
\hline Combustible & FALSE & FALSE & FALSE \\
\hline SurfaceSpreadOfFlame & $\mathrm{n} / \mathrm{a}$ & $\mathrm{n} / \mathrm{a}$ & $\mathrm{n} / \mathrm{a}$ \\
\hline ThermalTransmittance & $\mathrm{n} / \mathrm{a}$ & $n / a$ & $\mathrm{n} / \mathrm{a}$ \\
\hline IsExternal & TRUE & TRUE & TRUE \\
\hline PostConsumerRecoveredContent & $\mathrm{n} / \mathrm{a}$ & $\mathrm{n} / \mathrm{a}$ & $n / a$ \\
\hline TotalRecoveredContent & $\mathrm{n} / \mathrm{a}$ & $\mathrm{n} / \mathrm{a}$ & $\mathrm{n} / \mathrm{a}$ \\
\hline RenewableContent & $\mathrm{n} / \mathrm{a}$ & $\mathrm{n} / \mathrm{a}$ & $\mathrm{n} / \mathrm{a}$ \\
\hline RenewableMaterial & $\mathrm{n} / \mathrm{a}$ & $\mathrm{n} / \mathrm{a}$ & $\mathrm{n} / \mathrm{a}$ \\
\hline BiobasedContent & $\mathrm{n} / \mathrm{a}$ & $\mathrm{n} / \mathrm{a}$ & $\mathrm{n} / \mathrm{a}$ \\
\hline BiobasedMaterial & $\mathrm{n} / \mathrm{a}$ & $\mathrm{n} / \mathrm{a}$ & $\mathrm{n} / \mathrm{a}$ \\
\hline RawMaterialLocation & $\mathrm{n} / \mathrm{a}$ & $\mathrm{n} / \mathrm{a}$ & $\mathrm{n} / \mathrm{a}$ \\
\hline RegionalMaterialContent & $\mathrm{n} / \mathrm{a}$ & $\mathrm{n} / \mathrm{a}$ & $\mathrm{n} / \mathrm{a}$ \\
\hline ManufactureLocation & $\mathrm{n} / \mathrm{a}$ & $\mathrm{n} / \mathrm{a}$ & $\mathrm{n} / \mathrm{a}$ \\
\hline CertifiedContent & $\mathrm{n} / \mathrm{a}$ & $\mathrm{n} / \mathrm{a}$ & $\mathrm{n} / \mathrm{a}$ \\
\hline CertificationType & $\mathrm{n} / \mathrm{a}$ & $\mathrm{n} / \mathrm{a}$ & $\mathrm{n} / \mathrm{a}$ \\
\hline Emissions & $\mathrm{n} / \mathrm{a}$ & $\mathrm{n} / \mathrm{a}$ & $\mathrm{n} / \mathrm{a}$ \\
\hline SNAP & $\mathrm{n} / \mathrm{a}$ & $\mathrm{n} / \mathrm{a}$ & $\mathrm{n} / \mathrm{a}$ \\
\hline ThermalResistance & $\mathrm{n} / \mathrm{a}$ & $\mathrm{n} / \mathrm{a}$ & $\mathrm{n} / \mathrm{a}$ \\
\hline
\end{tabular}




\begin{tabular}{|c|c|c|c|}
\hline \multicolumn{4}{|c|}{ Door_DOOR_AluminumDoorsandFrames_US } \\
\hline $\begin{array}{l}\stackrel{0}{E} \\
\text { ָٓ }\end{array}$ & 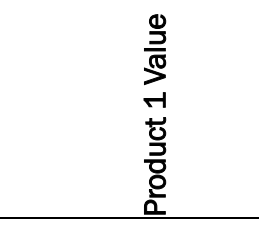 & 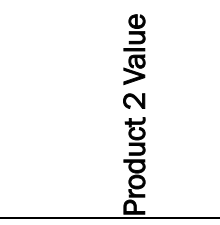 & $\begin{array}{l}\frac{0}{2} \\
\frac{1}{10} \\
\text { m } \\
\frac{0}{0} \\
\frac{D}{0} \\
\frac{0}{2}\end{array}$ \\
\hline Manufacturer & US Aluminum & Kawneer & Tubelite \\
\hline Model & $\begin{array}{l}\text { Durafront Series } 800 \\
\text { Medium Stile Door }\end{array}$ & 0 & Thermal Block \\
\hline ConstructionType & $\mathrm{n} / \mathrm{a}$ & $\mathrm{n} / \mathrm{a}$ & $\mathrm{n} / \mathrm{a}$ \\
\hline Sustainability & $\mathrm{n} / \mathrm{a}$ & $\mathrm{n} / \mathrm{a}$ & $\mathrm{n} / \mathrm{a}$ \\
\hline Manufacturers & $\mathrm{n} / \mathrm{a}$ & $\mathrm{n} / \mathrm{a}$ & $\mathrm{n} / \mathrm{a}$ \\
\hline Materials & $\mathrm{n} / \mathrm{a}$ & $\mathrm{n} / \mathrm{a}$ & $\begin{array}{l}\text { aluminum_extrusions_ast } \\
\text { m_b_221_6063_t5_alloy }\end{array}$ \\
\hline DoorType & glazed_aluminum & glazed_aluminum & glazed_aluminum \\
\hline Glazing & $\mathrm{n} / \mathrm{a}$ & $\mathrm{n} / \mathrm{a}$ & $\mathrm{n} / \mathrm{a}$ \\
\hline FireRating & $\mathrm{n} / \mathrm{a}$ & $\mathrm{n} / \mathrm{a}$ & $\mathrm{n} / \mathrm{a}$ \\
\hline AcousticRating & $\mathrm{n} / \mathrm{a}$ & $\mathrm{n} / \mathrm{a}$ & $\mathrm{n} / \mathrm{a}$ \\
\hline IsExternal & TRUE & TRUE & TRUE \\
\hline Infiltration & $.06 \mathrm{cfm}$ & $.06 \mathrm{cfm}$ & $.3 \mathrm{cfm}$ \\
\hline ThermalTransmittance & $\mathrm{n} / \mathrm{a}$ & 0.62 & 0.651 \\
\hline GlazingAreaFraction & $\mathrm{n} / \mathrm{a}$ & $\mathrm{n} / \mathrm{a}$ & $\mathrm{n} / \mathrm{a}$ \\
\hline FireExit & TRUE & TRUE & TRUE \\
\hline SmokeStop & $\mathrm{n} / \mathrm{a}$ & $\mathrm{n} / \mathrm{a}$ & $\mathrm{n} / \mathrm{a}$ \\
\hline PostConsumerRecoveredContent & $n / a$ & $\mathrm{n} / \mathrm{a}$ & $\mathrm{n} / \mathrm{a}$ \\
\hline TotalRecoveredContent & $\mathrm{n} / \mathrm{a}$ & $\mathrm{n} / \mathrm{a}$ & 0.8 \\
\hline RenewableContent & $\mathrm{n} / \mathrm{a}$ & $\mathrm{n} / \mathrm{a}$ & $\mathrm{n} / \mathrm{a}$ \\
\hline RenewableMaterial & $\mathrm{n} / \mathrm{a}$ & $\mathrm{n} / \mathrm{a}$ & $\mathrm{n} / \mathrm{a}$ \\
\hline BiobasedContent & $\mathrm{n} / \mathrm{a}$ & $\mathrm{n} / \mathrm{a}$ & $\mathrm{n} / \mathrm{a}$ \\
\hline BiobasedMaterial & $\mathrm{n} / \mathrm{a}$ & $\mathrm{n} / \mathrm{a}$ & $\mathrm{n} / \mathrm{a}$ \\
\hline RawMaterialLocation & $n / a$ & $n / a$ & $\mathrm{n} / \mathrm{a}$ \\
\hline RegionalMaterialContent & $\mathrm{n} / \mathrm{a}$ & $\mathrm{n} / \mathrm{a}$ & $\mathrm{n} / \mathrm{a}$ \\
\hline ManufactureLocation & $\mathrm{n} / \mathrm{a}$ & $\mathrm{n} / \mathrm{a}$ & $\mathrm{n} / \mathrm{a}$ \\
\hline CertifiedContent & $\mathrm{n} / \mathrm{a}$ & $\mathrm{n} / \mathrm{a}$ & $\mathrm{n} / \mathrm{a}$ \\
\hline CertificationType & $\mathrm{n} / \mathrm{a}$ & $n / a$ & $\mathrm{n} / \mathrm{a}$ \\
\hline Emissions & $\mathrm{n} / \mathrm{a}$ & $\mathrm{n} / \mathrm{a}$ & $\mathrm{n} / \mathrm{a}$ \\
\hline SNAP & $n / a$ & $n / a$ & $\mathrm{n} / \mathrm{a}$ \\
\hline ThermalResistance & $\mathrm{n} / \mathrm{a}$ & $\mathrm{n} / \mathrm{a}$ & $\mathrm{n} / \mathrm{a}$ \\
\hline
\end{tabular}


Door_DOOR_FlushWoodDoors_US

\begin{tabular}{|c|c|c|c|}
\hline $\begin{array}{l}\stackrel{0}{E} \\
\text { ֻٓ } \\
\end{array}$ & $\begin{array}{l}\frac{0}{2} \\
\frac{D}{\pi} \\
ㄱ \\
\frac{1}{0} \\
\frac{0}{0} \\
\frac{0}{2}\end{array}$ & 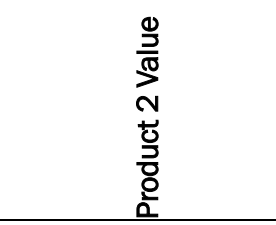 & $\begin{array}{l}\frac{0}{2} \\
\frac{2}{\pi} \\
m \\
\frac{1}{0} \\
\frac{\partial}{0} \\
\frac{0}{2}\end{array}$ \\
\hline Manufacturer & Algoma Hardwoods Inc & Algoma Hardwoods Inc & Jeld-Wen \\
\hline Model & FSC UF Free PC-5 & 3/4 Hour UF Free & $\begin{array}{l}\text { Custom Wood All Panel } \\
\text { Exterior Door - W42H }\end{array}$ \\
\hline ConstructionType & 0 & 0 & 0 \\
\hline Sustainability & $\mathrm{n} / \mathrm{a}$ & $\mathrm{n} / \mathrm{a}$ & $\mathrm{n} / \mathrm{a}$ \\
\hline Glazing & $n / a$ & $n / a$ & $n / a$ \\
\hline Frames & wood & wood & wood \\
\hline FaceMaterials & birch_veneer & birch_veneer & solid pine \\
\hline FireRating & 0 & $3 / 4$ hour & 0 \\
\hline AcousticRating & $\mathrm{n} / \mathrm{a}$ & $\mathrm{n} / \mathrm{a}$ & $\mathrm{n} / \mathrm{a}$ \\
\hline SecurityRating & $n / a$ & $\mathrm{n} / \mathrm{a}$ & $n / a$ \\
\hline IsExternal & FALSE & FALSE & $n / a$ \\
\hline Infiltration & $n / a$ & $\mathrm{n} / \mathrm{a}$ & $n / a$ \\
\hline ThermalTransmittance & $n / a$ & $\mathrm{n} / \mathrm{a}$ & $n / a$ \\
\hline GlazingAreaFraction & $n / a$ & $n / a$ & $n / a$ \\
\hline FireExit & FALSE & FALSE & FALSE \\
\hline SmokeStop & $n / a$ & $n / a$ & $n / a$ \\
\hline PostConsumerRecoveredContent & 0 & 0 & $\mathrm{n} / \mathrm{a}$ \\
\hline TotaIRecoveredContent & 0.12 & 0.16 & $\mathrm{n} / \mathrm{a}$ \\
\hline RenewableContent & $\mathrm{n} / \mathrm{a}$ & $\mathrm{n} / \mathrm{a}$ & $\mathrm{n} / \mathrm{a}$ \\
\hline RenewableMaterial & $\mathrm{n} / \mathrm{a}$ & $\mathrm{n} / \mathrm{a}$ & $\mathrm{n} / \mathrm{a}$ \\
\hline BiobasedContent & $\mathrm{n} / \mathrm{a}$ & $\mathrm{n} / \mathrm{a}$ & $\mathrm{n} / \mathrm{a}$ \\
\hline BiobasedMaterial & $\mathrm{n} / \mathrm{a}$ & $\mathrm{n} / \mathrm{a}$ & $\mathrm{n} / \mathrm{a}$ \\
\hline RawMaterialLocation & varies & varies & $\mathrm{n} / \mathrm{a}$ \\
\hline RegionalMaterialContent & 0.83 & 0 & $\mathrm{n} / \mathrm{a}$ \\
\hline ManufactureLocation & Algoma, WI & Algoma, WI & $\mathrm{n} / \mathrm{a}$ \\
\hline CertifiedContent & yes & yes & $\mathrm{n} / \mathrm{a}$ \\
\hline CertificationType & FSC & $\mathrm{n} / \mathrm{a}$ & $\mathrm{n} / \mathrm{a}$ \\
\hline Emissions & $\mathrm{n} / \mathrm{a}$ & $\mathrm{n} / \mathrm{a}$ & $\mathrm{n} / \mathrm{a}$ \\
\hline SNAP & $\mathrm{n} / \mathrm{a}$ & $\mathrm{n} / \mathrm{a}$ & $\mathrm{n} / \mathrm{a}$ \\
\hline ThermalResistance & $\mathrm{n} / \mathrm{a}$ & $\mathrm{n} / \mathrm{a}$ & $\mathrm{n} / \mathrm{a}$ \\
\hline CoreConstruction & lumber_core & lumber_core & $\mathrm{n} / \mathrm{a}$ \\
\hline Adhesive & $\mathrm{n} / \mathrm{a}$ & $\mathrm{n} / \mathrm{a}$ & $\mathrm{n} / \mathrm{a}$ \\
\hline
\end{tabular}




\begin{tabular}{|c|c|c|c|}
\hline \multicolumn{4}{|c|}{ Door_DOOR_HollowMetalDoorsandFrames_US } \\
\hline$\underset{\stackrel{0}{E}}{\stackrel{\mathbb{N}}{Z}}$ & 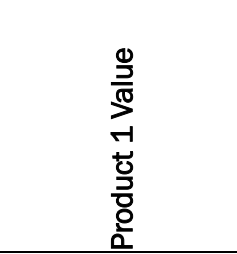 & 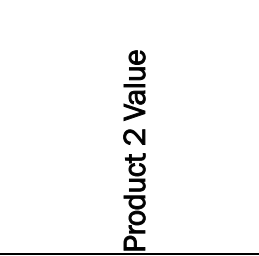 & 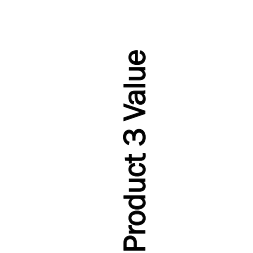 \\
\hline Manufacturer & CECO & CECO & CECO \\
\hline Model & Regent & Legion & Imperial \\
\hline ConstructionType & Hollow Metal & Hollow Metal & Hollow Metal \\
\hline Sustainability & $\mathrm{n} / \mathrm{a}$ & $\mathrm{n} / \mathrm{a}$ & $\mathrm{n} / \mathrm{a}$ \\
\hline Glazing & $\mathrm{n} / \mathrm{a}$ & $\mathrm{n} / \mathrm{a}$ & $\mathrm{n} / \mathrm{a}$ \\
\hline DoorMaterialsInterior & $\begin{array}{l}20 \text { gauge steel } \\
\text { face sheet }\end{array}$ & $\begin{array}{l}18 \text { gauge steel face } \\
\text { sheet }\end{array}$ & $\begin{array}{l}16 \text { gauge steel face } \\
\text { sheet }\end{array}$ \\
\hline FrameMaterialsInterior & 16 gauge steel & 16 gauge steel & 16 gauge steel \\
\hline FrameType & Standard Frame & Standard Frame & Standard Frame \\
\hline FireRating & $\begin{array}{l}20 \min , 45 \min , 1 \\
\text { hour, } 11 / 2 \text { hour, } \\
\text { or } 3 \text { hour }\end{array}$ & $\begin{array}{l}20 \min , 45 \min , 1 \\
\text { hour, } 11 / 2 \text { hour, or } 3 \\
\text { hour }\end{array}$ & $\begin{array}{l}20 \min , 45 \min , 1 \\
\text { hour, } 11 / 2 \text { hour, or } 3 \\
\text { hour }\end{array}$ \\
\hline AcousticRating & $\begin{array}{l}\text { Meet ANSI standar } \\
\text { S12.20-2002 } \\
\text { (STC) }\end{array}$ & $\begin{array}{l}\text { Meet ANSI standar } \\
\text { S12.20-2002 (STC) }\end{array}$ & $\mathrm{n} / \mathrm{a}$ \\
\hline IsExternal & FALSE & FALSE & FALSE \\
\hline Infiltration & $\mathrm{n} / \mathrm{a}$ & $\mathrm{n} / \mathrm{a}$ & $\mathrm{n} / \mathrm{a}$ \\
\hline ThermalTransmittance & $\mathrm{n} / \mathrm{a}$ & $\mathrm{n} / \mathrm{a}$ & $\mathrm{n} / \mathrm{a}$ \\
\hline GlazingAreaFraction & $n / a$ & $n / a$ & $\mathrm{n} / \mathrm{a}$ \\
\hline FireExit & TRUE & TRUE & FALSE \\
\hline SmokeStop & TRUE & TRUE & FALSE \\
\hline PostConsumerRecoveredContent & $\begin{array}{l}22.9 \% \text { Doors, } \\
23.6 \% \text { frames. }\end{array}$ & $\begin{array}{l}22.9 \% \text { Doors, } 23.6 \% \\
\text { frames. }\end{array}$ & $\begin{array}{l}22.9 \% \text { Doors, } 23.6 \% \\
\text { frames. }\end{array}$ \\
\hline TotalRecoveredContent & $\begin{array}{l}26.1 \% \text { Doors, } \\
26.9 \% \text { frames. }\end{array}$ & $\begin{array}{l}26.1 \% \text { Doors, } 26.9 \% \\
\text { frames. }\end{array}$ & $\begin{array}{l}26.1 \% \text { Doors, } 26.9 \% \\
\text { frames. }\end{array}$ \\
\hline RenewableContent & $n / a$ & $\mathrm{n} / \mathrm{a}$ & $\mathrm{n} / \mathrm{a}$ \\
\hline RenewableMaterial & $\mathrm{n} / \mathrm{a}$ & $n / a$ & $\mathrm{n} / \mathrm{a}$ \\
\hline BiobasedContent & $\mathrm{n} / \mathrm{a}$ & $n / a$ & $\mathrm{n} / \mathrm{a}$ \\
\hline BiobasedMaterial & $\mathrm{n} / \mathrm{a}$ & $\mathrm{n} / \mathrm{a}$ & $\mathrm{n} / \mathrm{a}$ \\
\hline RawMaterialLocation & $\mathrm{n} / \mathrm{a}$ & $n / a$ & $\mathrm{n} / \mathrm{a}$ \\
\hline RegionalMaterialContent & 1 & 1 & 1 \\
\hline ManufactureLocation & Milan, TN & Milan, TN & Milan, TN \\
\hline CertifiedContent & $n / a$ & $n / a$ & $\mathrm{n} / \mathrm{a}$ \\
\hline CertificationType & $\mathrm{n} / \mathrm{a}$ & $\mathrm{n} / \mathrm{a}$ & $\mathrm{n} / \mathrm{a}$ \\
\hline Emissions & No VOC & No VOC & No VOC \\
\hline SNAP & $n / a$ & $n / a$ & $\mathrm{n} / \mathrm{a}$ \\
\hline ThermalResistance & $n / a$ & $n / a$ & $\mathrm{n} / \mathrm{a}$ \\
\hline
\end{tabular}




\begin{tabular}{|c|c|c|c|}
\hline \multicolumn{4}{|c|}{ Door_DOOR_HollowMetalDoorsandFrames_US } \\
\hline $\begin{array}{l}\stackrel{0}{E} \\
\stackrel{\mathbb{\pi}}{Z}\end{array}$ & 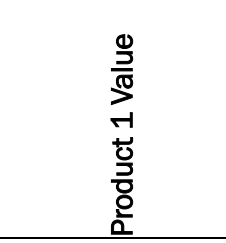 & $\begin{array}{l}\frac{0}{2} \\
\frac{\pi}{\pi} \\
\text { న } \\
\frac{1}{2} \\
\frac{2}{0} \\
\frac{0}{2}\end{array}$ & 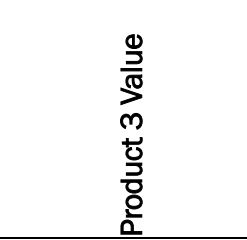 \\
\hline DoorMaterialsExterior & $\begin{array}{l}20 \text { gauge steel } \\
\text { face sheet }\end{array}$ & $\begin{array}{l}18 \text { guage steel face } \\
\text { Sheet }\end{array}$ & $\begin{array}{l}16 \text { gauge steel face } \\
\text { sheet }\end{array}$ \\
\hline FrameMaterialsExterior & 16 gauge steel & 16 gauge steel & 16 gauge \\
\hline FrameConstruction & $\begin{array}{l}\text { Knocked_down or } \\
\text { set up and welded }\end{array}$ & $\begin{array}{l}\text { Knocked_down or set } \\
\text { up and welded }\end{array}$ & $\begin{array}{l}\text { Knocked_down or set } \\
\text { up and welded }\end{array}$ \\
\hline CoreMaterial & $\mathrm{n} / \mathrm{a}$ & $\mathrm{n} / \mathrm{a}$ & $\mathrm{n} / \mathrm{a}$ \\
\hline CoreConstruction & $\begin{array}{l}\text { non-insulated } \\
\text { honeycomb }\end{array}$ & insulated polystyrene & $\begin{array}{l}\text { insulated } \\
\text { polyurethane }\end{array}$ \\
\hline Louvers & $\mathrm{n} / \mathrm{a}$ & $\mathrm{n} / \mathrm{a}$ & $\mathrm{n} / \mathrm{a}$ \\
\hline LouverFireRating & $\mathrm{n} / \mathrm{a}$ & $n / a$ & $\mathrm{n} / \mathrm{a}$ \\
\hline SmokeRating & $\mathrm{n} / \mathrm{a}$ & $\mathrm{n} / \mathrm{a}$ & $\mathrm{n} / \mathrm{a}$ \\
\hline
\end{tabular}




\begin{tabular}{|c|c|c|c|}
\hline \multicolumn{4}{|c|}{ ElectricDistributionBoard_DISTRIBUTIONBOARD_DistributionPanel_US } \\
\hline $\begin{array}{l}\stackrel{\Phi}{E} \\
\stackrel{\mathbb{\pi}}{Z}\end{array}$ & 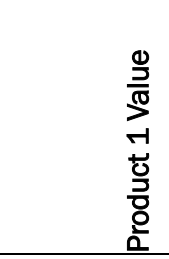 & 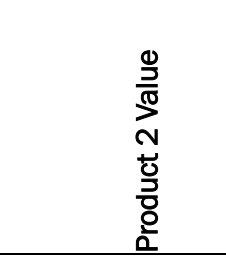 & 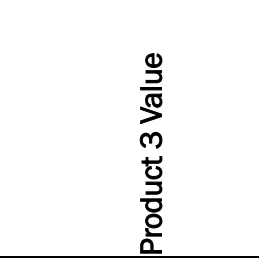 \\
\hline Manufacturer & $\begin{array}{l}\text { GE Industrial } \\
\text { Solutions }\end{array}$ & Schneider Electric & Siemens Industry, Inc. \\
\hline Model & - & - & - \\
\hline PostConsumerRecoveredContent & $\mathrm{n} / \mathrm{a}$ & $\mathrm{n} / \mathrm{a}$ & $\mathrm{n} / \mathrm{a}$ \\
\hline TotalRecoveredContent & $\mathrm{n} / \mathrm{a}$ & $\mathrm{n} / \mathrm{a}$ & $\mathrm{n} / \mathrm{a}$ \\
\hline RenewableContent & $\mathrm{n} / \mathrm{a}$ & $\mathrm{n} / \mathrm{a}$ & $\mathrm{n} / \mathrm{a}$ \\
\hline RenewableMaterial & $\mathrm{n} / \mathrm{a}$ & $\mathrm{n} / \mathrm{a}$ & $\mathrm{n} / \mathrm{a}$ \\
\hline BiobasedContent & $\mathrm{n} / \mathrm{a}$ & $\mathrm{n} / \mathrm{a}$ & $\mathrm{n} / \mathrm{a}$ \\
\hline BiobasedMaterial & $\mathrm{n} / \mathrm{a}$ & $\mathrm{n} / \mathrm{a}$ & $\mathrm{n} / \mathrm{a}$ \\
\hline RawMaterialLocation & $\mathrm{n} / \mathrm{a}$ & $\mathrm{n} / \mathrm{a}$ & $\mathrm{n} / \mathrm{a}$ \\
\hline RegionalMaterialContent & $\mathrm{n} / \mathrm{a}$ & $\mathrm{n} / \mathrm{a}$ & $n / a$ \\
\hline ManufactureLocation & $\mathrm{n} / \mathrm{a}$ & $\mathrm{n} / \mathrm{a}$ & $\mathrm{n} / \mathrm{a}$ \\
\hline CertifiedContent & $\mathrm{n} / \mathrm{a}$ & $\mathrm{n} / \mathrm{a}$ & $n / a$ \\
\hline CertificationType & $\mathrm{n} / \mathrm{a}$ & $\mathrm{n} / \mathrm{a}$ & $\mathrm{n} / \mathrm{a}$ \\
\hline Emissions & $\mathrm{n} / \mathrm{a}$ & $\mathrm{n} / \mathrm{a}$ & $\mathrm{n} / \mathrm{a}$ \\
\hline SNAP & $\mathrm{n} / \mathrm{a}$ & $\mathrm{n} / \mathrm{a}$ & $\mathrm{n} / \mathrm{a}$ \\
\hline ThermalResistance & $\mathrm{n} / \mathrm{a}$ & $\mathrm{n} / \mathrm{a}$ & $\mathrm{n} / \mathrm{a}$ \\
\hline HeatLoad & $\mathrm{n} / \mathrm{a}$ & $\mathrm{n} / \mathrm{a}$ & $\mathrm{n} / \mathrm{a}$ \\
\hline EnergyStar & $\mathrm{n} / \mathrm{a}$ & $\mathrm{n} / \mathrm{a}$ & $\mathrm{n} / \mathrm{a}$ \\
\hline
\end{tabular}




\begin{tabular}{|c|c|c|c|}
\hline \multicolumn{4}{|c|}{ ElectricDistributionBoard_SWITCHBOARD_DistributionPanel_US } \\
\hline 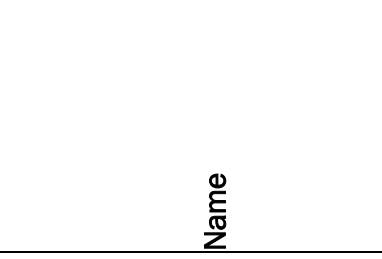 & 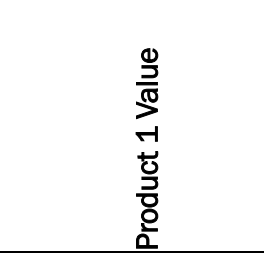 & $\begin{array}{l}\frac{0}{D} \\
\frac{\pi}{\pi} \\
\frac{1}{0} \\
\frac{0}{0} \\
\frac{0}{2}\end{array}$ & $\begin{array}{l}\frac{0}{2} \\
\frac{\pi}{\pi} \\
m \\
\frac{1}{0} \\
\frac{D}{0} \\
\frac{0}{2}\end{array}$ \\
\hline Manufacturer & Siemens Industry, Inc. & GE Industrial Solutions & Schneider Electric \\
\hline Model & 0 & $\begin{array}{l}\text { Spectra Series } \\
\text { Switchboard AV25000A }\end{array}$ & $\begin{array}{l}\text { Power-Style } \\
\text { Commercial Multi- } \\
\text { Metering }\end{array}$ \\
\hline PostConsumerRecoveredContent & $\mathrm{n} / \mathrm{a}$ & $\mathrm{n} / \mathrm{a}$ & $\mathrm{n} / \mathrm{a}$ \\
\hline TotalRecoveredContent & $\mathrm{n} / \mathrm{a}$ & $\mathrm{n} / \mathrm{a}$ & $\mathrm{n} / \mathrm{a}$ \\
\hline RenewableContent & $\mathrm{n} / \mathrm{a}$ & $\mathrm{n} / \mathrm{a}$ & $\mathrm{n} / \mathrm{a}$ \\
\hline RenewableMaterial & $\mathrm{n} / \mathrm{a}$ & $\mathrm{n} / \mathrm{a}$ & $\mathrm{n} / \mathrm{a}$ \\
\hline BiobasedContent & $\mathrm{n} / \mathrm{a}$ & $\mathrm{n} / \mathrm{a}$ & $\mathrm{n} / \mathrm{a}$ \\
\hline BiobasedMaterial & $\mathrm{n} / \mathrm{a}$ & $\mathrm{n} / \mathrm{a}$ & $\mathrm{n} / \mathrm{a}$ \\
\hline RawMaterialLocation & $\mathrm{n} / \mathrm{a}$ & $\mathrm{n} / \mathrm{a}$ & $\mathrm{n} / \mathrm{a}$ \\
\hline RegionalMaterialContent & $\mathrm{n} / \mathrm{a}$ & $n / a$ & $n / a$ \\
\hline ManufactureLocation & $\mathrm{n} / \mathrm{a}$ & $\mathrm{n} / \mathrm{a}$ & $\mathrm{n} / \mathrm{a}$ \\
\hline CertifiedContent & $\mathrm{n} / \mathrm{a}$ & $\mathrm{n} / \mathrm{a}$ & $\mathrm{n} / \mathrm{a}$ \\
\hline CertificationType & $\mathrm{n} / \mathrm{a}$ & $\mathrm{n} / \mathrm{a}$ & $\mathrm{n} / \mathrm{a}$ \\
\hline Emissions & $\mathrm{n} / \mathrm{a}$ & $\mathrm{n} / \mathrm{a}$ & $\mathrm{n} / \mathrm{a}$ \\
\hline SNAP & $\mathrm{n} / \mathrm{a}$ & $\mathrm{n} / \mathrm{a}$ & $\mathrm{n} / \mathrm{a}$ \\
\hline ThermalResistance & $\mathrm{n} / \mathrm{a}$ & $\mathrm{n} / \mathrm{a}$ & $\mathrm{n} / \mathrm{a}$ \\
\hline HeatLoad & $\mathrm{n} / \mathrm{a}$ & $\mathrm{n} / \mathrm{a}$ & $\mathrm{n} / \mathrm{a}$ \\
\hline EnergyStar & $\mathrm{n} / \mathrm{a}$ & $\mathrm{n} / \mathrm{a}$ & $\mathrm{n} / \mathrm{a}$ \\
\hline
\end{tabular}




\begin{tabular}{|c|c|c|c|}
\hline \multicolumn{4}{|l|}{ Fan_CENTRIFUGALAIRFOIL_US } \\
\hline 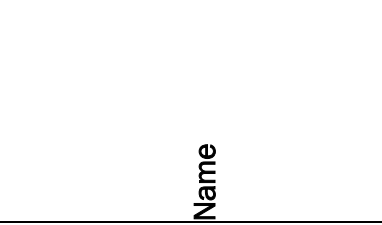 & 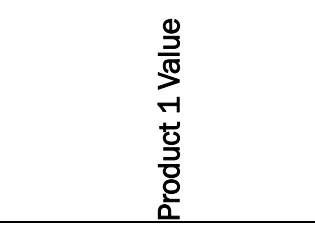 & 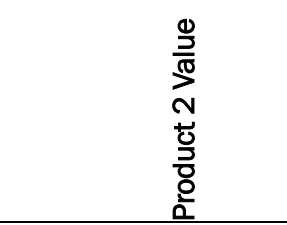 & $\begin{array}{l}\frac{0}{2} \\
\frac{D}{\pi} \\
m \\
\frac{ \pm}{2} \\
\frac{0}{0} \\
\frac{0}{2}\end{array}$ \\
\hline Manufacturer & AIR CONTROL INDUSTRIES & $\begin{array}{l}\text { TWIN CITY FANS and } \\
\text { BLOWERS }\end{array}$ & $\begin{array}{l}\text { Industrial Air } \\
\text { Technology Corp. }\end{array}$ \\
\hline Model & Centrifugal Fan VBL5 & BAF-DW & AF Airfoil Single Wide \\
\hline NominalAirFlowRate & 165 & $\mathrm{n} / \mathrm{a}$ & 2000 \\
\hline NominalTotalPressure & 1.6 & $\mathrm{n} / \mathrm{a}$ & 2.5 \\
\hline NominalStaticPressure & 1.5 & $\mathrm{n} / \mathrm{a}$ & $\mathrm{n} / \mathrm{a}$ \\
\hline NominalPowerRate & $\mathrm{n} / \mathrm{a}$ & $\mathrm{n} / \mathrm{a}$ & $\mathrm{n} / \mathrm{a}$ \\
\hline EfficiencyCurve & $\mathrm{n} / \mathrm{a}$ & $\mathrm{n} / \mathrm{a}$ & $\mathrm{n} / \mathrm{a}$ \\
\hline FractionOfMotorHeatToAirStream & $\mathrm{n} / \mathrm{a}$ & $\mathrm{n} / \mathrm{a}$ & $\mathrm{n} / \mathrm{a}$ \\
\hline PostConsumerRecoveredContent & $n / a$ & $\mathrm{n} / \mathrm{a}$ & $\mathrm{n} / \mathrm{a}$ \\
\hline TotaIRecoveredContent & $\mathrm{n} / \mathrm{a}$ & $\mathrm{n} / \mathrm{a}$ & $\mathrm{n} / \mathrm{a}$ \\
\hline RenewableContent & $\mathrm{n} / \mathrm{a}$ & $\mathrm{n} / \mathrm{a}$ & $\mathrm{n} / \mathrm{a}$ \\
\hline RenewableMaterial & $\mathrm{n} / \mathrm{a}$ & $\mathrm{n} / \mathrm{a}$ & $\mathrm{n} / \mathrm{a}$ \\
\hline BiobasedContent & $n / a$ & $\mathrm{n} / \mathrm{a}$ & $\mathrm{n} / \mathrm{a}$ \\
\hline BiobasedMaterial & $\mathrm{n} / \mathrm{a}$ & $\mathrm{n} / \mathrm{a}$ & $\mathrm{n} / \mathrm{a}$ \\
\hline RawMaterialLocation & $\mathrm{n} / \mathrm{a}$ & $\mathrm{n} / \mathrm{a}$ & $\mathrm{n} / \mathrm{a}$ \\
\hline RegionalMaterialContent & $\mathrm{n} / \mathrm{a}$ & $\mathrm{n} / \mathrm{a}$ & $\mathrm{n} / \mathrm{a}$ \\
\hline ManufactureLocation & $\mathrm{n} / \mathrm{a}$ & Minneapolis, Minnesota & $\mathrm{n} / \mathrm{a}$ \\
\hline CertifiedContent & $n / a$ & $n / a$ & $n / a$ \\
\hline CertificationType & $n / a$ & $n / a$ & $n / a$ \\
\hline Emissions & $\mathrm{n} / \mathrm{a}$ & $n / a$ & $\mathrm{n} / \mathrm{a}$ \\
\hline SNAP & $\mathrm{n} / \mathrm{a}$ & $\mathrm{n} / \mathrm{a}$ & $\mathrm{n} / \mathrm{a}$ \\
\hline ThermalResistance & $\mathrm{n} / \mathrm{a}$ & $\mathrm{n} / \mathrm{a}$ & $\mathrm{n} / \mathrm{a}$ \\
\hline HeatLoad & $n / a$ & $n / a$ & $n / a$ \\
\hline EnergyStar & $\mathrm{n} / \mathrm{a}$ & $\mathrm{n} / \mathrm{a}$ & $\mathrm{n} / \mathrm{a}$ \\
\hline FanEfficiency & $n / a$ & $n / a$ & $n / a$ \\
\hline AirOutput & $\mathrm{n} / \mathrm{a}$ & $\mathrm{n} / \mathrm{a}$ & $\mathrm{n} / \mathrm{a}$ \\
\hline
\end{tabular}


Footing_PAD_FOOTING_US

\begin{tabular}{|c|c|c|c|}
\hline 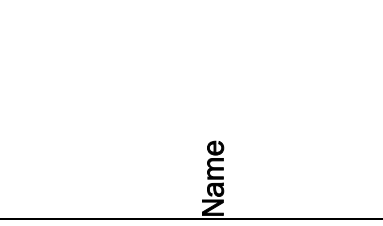 & $\begin{array}{l}\frac{0}{2} \\
\frac{1}{\pi} \\
\frac{1}{2} \\
\frac{1}{0} \\
\frac{0}{0} \\
\frac{0}{2}\end{array}$ & 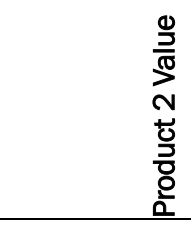 & 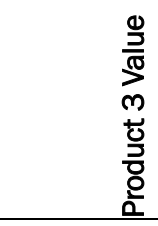 \\
\hline Manufacturer & Lehigh Hanson & Cemex & Holcim \\
\hline \multicolumn{4}{|l|}{ Model } \\
\hline PostConsumerRecoveredContent & $\mathrm{n} / \mathrm{a}$ & $\mathrm{n} / \mathrm{a}$ & $\mathrm{n} / \mathrm{a}$ \\
\hline TotalRecoveredContent & $\mathrm{n} / \mathrm{a}$ & $\mathrm{n} / \mathrm{a}$ & $\mathrm{n} / \mathrm{a}$ \\
\hline RenewableContent & $\mathrm{n} / \mathrm{a}$ & $\mathrm{n} / \mathrm{a}$ & $\mathrm{n} / \mathrm{a}$ \\
\hline RenewableMaterial & $\mathrm{n} / \mathrm{a}$ & $\mathrm{n} / \mathrm{a}$ & $\mathrm{n} / \mathrm{a}$ \\
\hline BiobasedContent & $\mathrm{n} / \mathrm{a}$ & $\mathrm{n} / \mathrm{a}$ & $\mathrm{n} / \mathrm{a}$ \\
\hline BiobasedMaterial & $\mathrm{n} / \mathrm{a}$ & $\mathrm{n} / \mathrm{a}$ & $\mathrm{n} / \mathrm{a}$ \\
\hline RawMaterialLocation & $\mathrm{n} / \mathrm{a}$ & $\mathrm{n} / \mathrm{a}$ & $\mathrm{n} / \mathrm{a}$ \\
\hline RegionalMaterialContent & $n / a$ & $\mathrm{n} / \mathrm{a}$ & $\mathrm{n} / \mathrm{a}$ \\
\hline ManufactureLocation & $\mathrm{n} / \mathrm{a}$ & $\mathrm{n} / \mathrm{a}$ & $\mathrm{n} / \mathrm{a}$ \\
\hline CertifiedContent & $n / a$ & $\mathrm{n} / \mathrm{a}$ & $\mathrm{n} / \mathrm{a}$ \\
\hline CertificationType & $\mathrm{n} / \mathrm{a}$ & $\mathrm{n} / \mathrm{a}$ & $\mathrm{n} / \mathrm{a}$ \\
\hline Emissions & $\mathrm{n} / \mathrm{a}$ & $\mathrm{n} / \mathrm{a}$ & $\mathrm{n} / \mathrm{a}$ \\
\hline SNAP & $\mathrm{n} / \mathrm{a}$ & $\mathrm{n} / \mathrm{a}$ & $\mathrm{n} / \mathrm{a}$ \\
\hline ThermalResistance & $n / a$ & $\mathrm{n} / \mathrm{a}$ & $\mathrm{n} / \mathrm{a}$ \\
\hline
\end{tabular}


Footing_STRIP_FOOTING_US

\begin{tabular}{|c|c|c|c|}
\hline 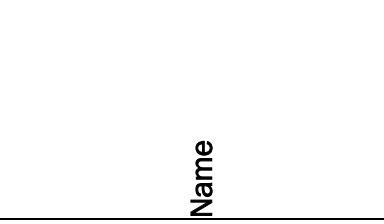 & 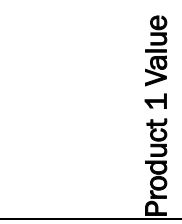 & 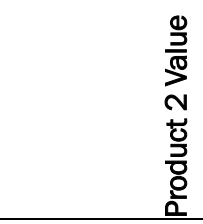 & 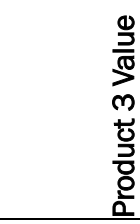 \\
\hline Manufacturer & Lehigh Hanson & Cemex & Holcim \\
\hline \multicolumn{4}{|l|}{ Model } \\
\hline PostConsumerRecoveredContent & n/a & $\mathrm{n} / \mathrm{a}$ & $\mathrm{n} / \mathrm{a}$ \\
\hline TotalRecoveredContent & n/a & $\mathrm{n} / \mathrm{a}$ & $\mathrm{n} / \mathrm{a}$ \\
\hline RenewableContent & $n / a$ & $\mathrm{n} / \mathrm{a}$ & $\mathrm{n} / \mathrm{a}$ \\
\hline RenewableMaterial & $\mathrm{n} / \mathrm{a}$ & $\mathrm{n} / \mathrm{a}$ & $\mathrm{n} / \mathrm{a}$ \\
\hline BiobasedContent & $n / a$ & $\mathrm{n} / \mathrm{a}$ & $\mathrm{n} / \mathrm{a}$ \\
\hline BiobasedMaterial & $n / a$ & $\mathrm{n} / \mathrm{a}$ & $\mathrm{n} / \mathrm{a}$ \\
\hline RawMaterialLocation & $n / a$ & $\mathrm{n} / \mathrm{a}$ & $\mathrm{n} / \mathrm{a}$ \\
\hline RegionalMaterialContent & $n / a$ & $\mathrm{n} / \mathrm{a}$ & $\mathrm{n} / \mathrm{a}$ \\
\hline ManufactureLocation & $n / a$ & $\mathrm{n} / \mathrm{a}$ & $\mathrm{n} / \mathrm{a}$ \\
\hline CertifiedContent & $n / a$ & $\mathrm{n} / \mathrm{a}$ & $\mathrm{n} / \mathrm{a}$ \\
\hline CertificationType & n/a & $\mathrm{n} / \mathrm{a}$ & $\mathrm{n} / \mathrm{a}$ \\
\hline Emissions & n/a & $\mathrm{n} / \mathrm{a}$ & $n / a$ \\
\hline SNAP & $\mathrm{n} / \mathrm{a}$ & $\mathrm{n} / \mathrm{a}$ & $\mathrm{n} / \mathrm{a}$ \\
\hline ThermalResistance & $n / a$ & $\mathrm{n} / \mathrm{a}$ & $n / a$ \\
\hline
\end{tabular}




\begin{tabular}{|c|c|c|c|}
\hline \multicolumn{4}{|l|}{ Lamp_FLUORESCENT_Lamp_US } \\
\hline $\begin{array}{l}\stackrel{0}{E} \\
\stackrel{\mathbb{\pi}}{Z}\end{array}$ & $\begin{array}{l}\frac{0}{2} \\
\frac{D}{\pi} \\
\\
\frac{1}{0} \\
\frac{0}{0} \\
\frac{0}{2}\end{array}$ & 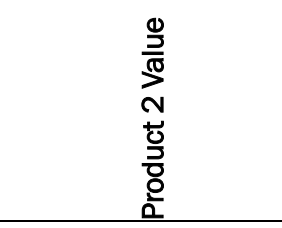 & $\begin{array}{l}\frac{0}{\partial} \\
\frac{D}{D} \\
m \\
\frac{0}{2} \\
\frac{0}{0} \\
\frac{0}{2}\end{array}$ \\
\hline Manufacturer & GE & Philips & OSRAM Slyvania \\
\hline Model & $\begin{array}{l}10322- \\
\text { F32T8XLSPX41HLEC }\end{array}$ & F28T5/850 HE EA 25W & 20919 - T5 PENTRON \\
\hline LampType & linear fluorescent & fluorescent & fluorescent \\
\hline LampBallastType & electronic & electronic & electronic \\
\hline LampCompensationType & $\mathrm{n} / \mathrm{a}$ & $\mathrm{n} / \mathrm{a}$ & $\mathrm{n} / \mathrm{a}$ \\
\hline PostConsumerRecoveredContent & $\mathrm{n} / \mathrm{a}$ & $\mathrm{n} / \mathrm{a}$ & $\mathrm{n} / \mathrm{a}$ \\
\hline TotalRecoveredContent & $\mathrm{n} / \mathrm{a}$ & $\mathrm{n} / \mathrm{a}$ & $\mathrm{n} / \mathrm{a}$ \\
\hline RenewableContent & $\mathrm{n} / \mathrm{a}$ & $\mathrm{n} / \mathrm{a}$ & $\mathrm{n} / \mathrm{a}$ \\
\hline RenewableMaterial & $\mathrm{n} / \mathrm{a}$ & $\mathrm{n} / \mathrm{a}$ & $\mathrm{n} / \mathrm{a}$ \\
\hline BiobasedContent & $\mathrm{n} / \mathrm{a}$ & $\mathrm{n} / \mathrm{a}$ & $n / a$ \\
\hline BiobasedMaterial & $\mathrm{n} / \mathrm{a}$ & $\mathrm{n} / \mathrm{a}$ & $\mathrm{n} / \mathrm{a}$ \\
\hline RawMaterialLocation & $\mathrm{n} / \mathrm{a}$ & $\mathrm{n} / \mathrm{a}$ & $\mathrm{n} / \mathrm{a}$ \\
\hline RegionalMaterialContent & $\mathrm{n} / \mathrm{a}$ & $\mathrm{n} / \mathrm{a}$ & $\mathrm{n} / \mathrm{a}$ \\
\hline ManufactureLocation & $\mathrm{n} / \mathrm{a}$ & $\mathrm{n} / \mathrm{a}$ & $\mathrm{n} / \mathrm{a}$ \\
\hline CertifiedContent & $\mathrm{n} / \mathrm{a}$ & $\mathrm{n} / \mathrm{a}$ & $\mathrm{n} / \mathrm{a}$ \\
\hline CertificationType & TCLP & $\mathrm{n} / \mathrm{a}$ & $n / a$ \\
\hline Emissions & $\mathrm{n} / \mathrm{a}$ & $\mathrm{n} / \mathrm{a}$ & $n / a$ \\
\hline SNAP & $\mathrm{n} / \mathrm{a}$ & $\mathrm{n} / \mathrm{a}$ & $\mathrm{n} / \mathrm{a}$ \\
\hline ThermalResistance & $\mathrm{n} / \mathrm{a}$ & $\mathrm{n} / \mathrm{a}$ & $\mathrm{n} / \mathrm{a}$ \\
\hline HeatLoad & $\mathrm{n} / \mathrm{a}$ & $\mathrm{n} / \mathrm{a}$ & $\mathrm{n} / \mathrm{a}$ \\
\hline EnergyStar & $n / a$ & $\mathrm{n} / \mathrm{a}$ & $\mathrm{n} / \mathrm{a}$ \\
\hline LampEfficacy & 97 & $\mathrm{n} / \mathrm{a}$ & $n / a$ \\
\hline MercuryContent & low & 1.4 & $n / a$ \\
\hline
\end{tabular}




\begin{tabular}{|c|c|c|c|}
\hline \multicolumn{4}{|c|}{ LightFixture_DIRECTIONSOURCE_LightFixture_US } \\
\hline $\begin{array}{l}\stackrel{0}{E} \\
\stackrel{\mathbb{W}}{Z}\end{array}$ & 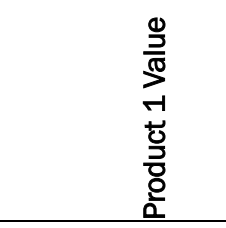 & 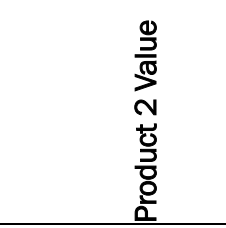 & $\begin{array}{l}\frac{0}{2} \\
\frac{0}{0} \\
m \\
\frac{0}{2} \\
\frac{0}{0} \\
\frac{0}{2}\end{array}$ \\
\hline Manufacturer & ACCULITE & SELUX & $\begin{array}{l}\text { COOPER LIGHTING } \\
\text { METALUX }\end{array}$ \\
\hline Model & T5HO-454 & M125 -2T5 & 2AC LED - $2 X 4$ \\
\hline LampType & T5 FLOURESCENT & T8 FLOURESCENT & LED \\
\hline MaximumPlenumSensibleLoad & $\mathrm{n} / \mathrm{a}$ & $n / a$ & $\mathrm{n} / \mathrm{a}$ \\
\hline MaximumSpaceSensibleLoad & $\mathrm{n} / \mathrm{a}$ & $n / a$ & $\mathrm{n} / \mathrm{a}$ \\
\hline SensibleLoadToRadiant & $\mathrm{n} / \mathrm{a}$ & $\mathrm{n} / \mathrm{a}$ & $\mathrm{n} / \mathrm{a}$ \\
\hline TotalWattage & $233 \mathrm{~W}$ & $75 \mathrm{~W}$ & $45 \mathrm{~W}$ \\
\hline PostConsumerRecoveredContent & $\mathrm{n} / \mathrm{a}$ & $\mathrm{n} / \mathrm{a}$ & $\mathrm{n} / \mathrm{a}$ \\
\hline TotalRecoveredContent & $\mathrm{n} / \mathrm{a}$ & $\mathrm{n} / \mathrm{a}$ & $\mathrm{n} / \mathrm{a}$ \\
\hline RenewableContent & $n / a$ & $n / a$ & $\mathrm{n} / \mathrm{a}$ \\
\hline RenewableMaterial & $\mathrm{n} / \mathrm{a}$ & $\mathrm{n} / \mathrm{a}$ & $\mathrm{n} / \mathrm{a}$ \\
\hline BiobasedContent & $\mathrm{n} / \mathrm{a}$ & $\mathrm{n} / \mathrm{a}$ & $\mathrm{n} / \mathrm{a}$ \\
\hline BiobasedMaterial & $\mathrm{n} / \mathrm{a}$ & $\mathrm{n} / \mathrm{a}$ & $\mathrm{n} / \mathrm{a}$ \\
\hline RawMaterialLocation & $\mathrm{n} / \mathrm{a}$ & $\mathrm{n} / \mathrm{a}$ & $\mathrm{n} / \mathrm{a}$ \\
\hline RegionalMaterialContent & $\mathrm{n} / \mathrm{a}$ & $\mathrm{n} / \mathrm{a}$ & $\mathrm{n} / \mathrm{a}$ \\
\hline ManufactureLocation & $\mathrm{n} / \mathrm{a}$ & $\mathrm{n} / \mathrm{a}$ & $\mathrm{n} / \mathrm{a}$ \\
\hline CertifiedContent & $\mathrm{n} / \mathrm{a}$ & $\mathrm{n} / \mathrm{a}$ & $\mathrm{n} / \mathrm{a}$ \\
\hline CertificationType & $\mathrm{n} / \mathrm{a}$ & $n / a$ & $n / a$ \\
\hline Emissions & $n / a$ & $n / a$ & $n / a$ \\
\hline SNAP & $\mathrm{n} / \mathrm{a}$ & $\mathrm{n} / \mathrm{a}$ & $\mathrm{n} / \mathrm{a}$ \\
\hline ThermalResistance & $n / a$ & $\mathrm{n} / \mathrm{a}$ & $\mathrm{n} / \mathrm{a}$ \\
\hline HeatLoad & $n / a$ & $n / a$ & $\mathrm{n} / \mathrm{a}$ \\
\hline EnergyStar & $\mathrm{n} / \mathrm{a}$ & $\mathrm{n} / \mathrm{a}$ & unknown \\
\hline LuminaireEfficacy & $\mathrm{n} / \mathrm{a}$ & $\mathrm{n} / \mathrm{a}$ & FL75 LPW \\
\hline LuminaireEfficiency & 0.9 & 0.68 & 0.879 \\
\hline BallastType & $\begin{array}{l}\text { Programmed Start } \\
\text { T5HO Electronic }\end{array}$ & electronic & electronic \\
\hline BallastFactor & 1 & Class $\mathrm{P}$ & $\mathrm{n} / \mathrm{a}$ \\
\hline BallastAcousticRating & $\mathrm{n} / \mathrm{a}$ & A & $\mathrm{n} / \mathrm{a}$ \\
\hline BacklightUplightGlare & $\mathrm{n} / \mathrm{a}$ & $n / a$ & $\mathrm{n} / \mathrm{a}$ \\
\hline ControlType & Occupancy Sensor & Occupancy Sensor & Occupancy Sensor \\
\hline
\end{tabular}


Outlet_DATAOUTLET_Outlet_US

\begin{tabular}{|c|c|c|c|}
\hline 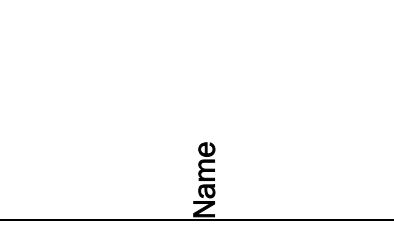 & 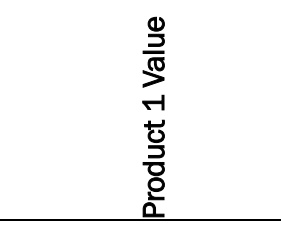 & 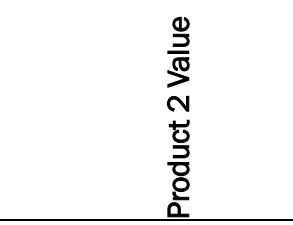 & $\begin{array}{l}\frac{\Phi}{D} \\
\frac{\partial}{\pi} \\
m \\
\frac{0}{J} \\
\frac{D}{0} \\
\frac{0}{2}\end{array}$ \\
\hline Manufacturer & Cyber Link & Cyber Link & Cyber Link \\
\hline Model & $\begin{array}{l}\text { CAT6 Component Rated } \\
\text { Jacks - IC1078L6WH }\end{array}$ & $\begin{array}{l}\text { CAT5E MIG5E+ Keystone } \\
\text { Jacks - K52-152/L90/AL }\end{array}$ & $\begin{array}{l}\text { CAT6 Tool-Less Jacks } \\
\text { K64-203/TL/BL }\end{array}$ \\
\hline PostConsumerRecoveredContent & $\mathrm{n} / \mathrm{a}$ & $\mathrm{n} / \mathrm{a}$ & $\mathrm{n} / \mathrm{a}$ \\
\hline TotalRecoveredContent & $\mathrm{n} / \mathrm{a}$ & $\mathrm{n} / \mathrm{a}$ & $\mathrm{n} / \mathrm{a}$ \\
\hline RenewableContent & $\mathrm{n} / \mathrm{a}$ & $\mathrm{n} / \mathrm{a}$ & $\mathrm{n} / \mathrm{a}$ \\
\hline RenewableMaterial & $\mathrm{n} / \mathrm{a}$ & $\mathrm{n} / \mathrm{a}$ & $\mathrm{n} / \mathrm{a}$ \\
\hline BiobasedContent & $\mathrm{n} / \mathrm{a}$ & $\mathrm{n} / \mathrm{a}$ & $\mathrm{n} / \mathrm{a}$ \\
\hline BiobasedMaterial & $\mathrm{n} / \mathrm{a}$ & $\mathrm{n} / \mathrm{a}$ & $\mathrm{n} / \mathrm{a}$ \\
\hline RawMaterialLocation & $\mathrm{n} / \mathrm{a}$ & $\mathrm{n} / \mathrm{a}$ & $\mathrm{n} / \mathrm{a}$ \\
\hline RegionalMaterialContent & $\mathrm{n} / \mathrm{a}$ & $\mathrm{n} / \mathrm{a}$ & $\mathrm{n} / \mathrm{a}$ \\
\hline ManufactureLocation & $\mathrm{n} / \mathrm{a}$ & $\mathrm{n} / \mathrm{a}$ & $\mathrm{n} / \mathrm{a}$ \\
\hline CertifiedContent & $\mathrm{n} / \mathrm{a}$ & $\mathrm{n} / \mathrm{a}$ & $\mathrm{n} / \mathrm{a}$ \\
\hline CertificationType & $\mathrm{n} / \mathrm{a}$ & $\mathrm{n} / \mathrm{a}$ & $\mathrm{n} / \mathrm{a}$ \\
\hline Emissions & $n / a$ & $n / a$ & $\mathrm{n} / \mathrm{a}$ \\
\hline SNAP & $\mathrm{n} / \mathrm{a}$ & $\mathrm{n} / \mathrm{a}$ & $\mathrm{n} / \mathrm{a}$ \\
\hline ThermalResistance & $\mathrm{n} / \mathrm{a}$ & $\mathrm{n} / \mathrm{a}$ & $\mathrm{n} / \mathrm{a}$ \\
\hline
\end{tabular}




\begin{tabular}{|c|c|c|c|}
\hline \multicolumn{4}{|c|}{ Outlet_POWEROUTLET_Outlet_US } \\
\hline $\begin{array}{l}\stackrel{\Phi}{E} \\
\stackrel{\mathbb{T}}{\mathbf{Z}}\end{array}$ & 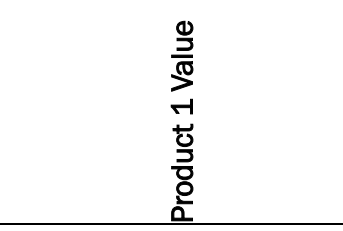 & 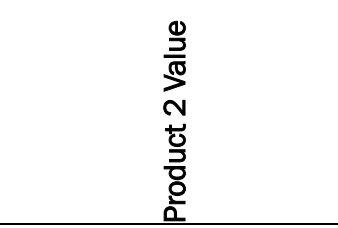 & 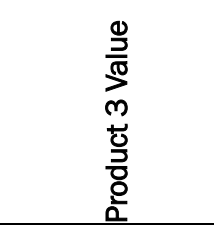 \\
\hline Manufacturer & Leviton & Leviton & Leviton \\
\hline Model & $\begin{array}{l}\text { TBR15 - Narrow Body Duplex } \\
\text { Receptacle } 15 \text { Amp, } 125 \text { Volt, } \\
\text { NEMA 5-15R }\end{array}$ & $\begin{array}{l}\text { MD820-IGG - Lev-Lok Decora } \\
15 \text { Amp Hospital Grade } \\
\text { Straight Blade Isolated } \\
\text { Ground Duplex Receptacle }\end{array}$ & $\begin{array}{l}16262 \text { - Industrial } \\
\text { Grade } 15 \mathrm{~A} / 125 \mathrm{~V} \\
\text { Duplex Decora } \\
\text { Receptacle }\end{array}$ \\
\hline PostConsumerRecoveredContent & $\mathrm{n} / \mathrm{a}$ & $\mathrm{n} / \mathrm{a}$ & $\mathrm{n} / \mathrm{a}$ \\
\hline TotalRecoveredContent & $\mathrm{n} / \mathrm{a}$ & $\mathrm{n} / \mathrm{a}$ & $\mathrm{n} / \mathrm{a}$ \\
\hline RenewableContent & $\mathrm{n} / \mathrm{a}$ & $\mathrm{n} / \mathrm{a}$ & $\mathrm{n} / \mathrm{a}$ \\
\hline RenewableMaterial & $\mathrm{n} / \mathrm{a}$ & $\mathrm{n} / \mathrm{a}$ & $\mathrm{n} / \mathrm{a}$ \\
\hline BiobasedContent & $\mathrm{n} / \mathrm{a}$ & $\mathrm{n} / \mathrm{a}$ & $\mathrm{n} / \mathrm{a}$ \\
\hline BiobasedMaterial & $\mathrm{n} / \mathrm{a}$ & $\mathrm{n} / \mathrm{a}$ & $\mathrm{n} / \mathrm{a}$ \\
\hline RawMaterialLocation & $\mathrm{n} / \mathrm{a}$ & $\mathrm{n} / \mathrm{a}$ & $\mathrm{n} / \mathrm{a}$ \\
\hline RegionalMaterialContent & $\mathrm{n} / \mathrm{a}$ & $\mathrm{n} / \mathrm{a}$ & $\mathrm{n} / \mathrm{a}$ \\
\hline ManufactureLocation & $\mathrm{n} / \mathrm{a}$ & $\mathrm{n} / \mathrm{a}$ & $\mathrm{n} / \mathrm{a}$ \\
\hline CertifiedContent & $\mathrm{n} / \mathrm{a}$ & $\mathrm{n} / \mathrm{a}$ & $\mathrm{n} / \mathrm{a}$ \\
\hline CertificationType & $\mathrm{n} / \mathrm{a}$ & $\mathrm{n} / \mathrm{a}$ & $\mathrm{n} / \mathrm{a}$ \\
\hline Emissions & $\mathrm{n} / \mathrm{a}$ & $\mathrm{n} / \mathrm{a}$ & $\mathrm{n} / \mathrm{a}$ \\
\hline SNAP & $\mathrm{n} / \mathrm{a}$ & $\mathrm{n} / \mathrm{a}$ & $\mathrm{n} / \mathrm{a}$ \\
\hline ThermalResistance & $\mathrm{n} / \mathrm{a}$ & $\mathrm{n} / \mathrm{a}$ & $\mathrm{n} / \mathrm{a}$ \\
\hline
\end{tabular}


Outlet_TELEPHONEOUTLET_Outlet_US

\begin{tabular}{|l|l|l|l|}
\hline & & & \\
& & & \\
& & & \\
& & & \\
& & &
\end{tabular}




\begin{tabular}{|c|c|c|c|}
\hline \multicolumn{4}{|c|}{ PipeSegment_RIGIDSEGMENT_US } \\
\hline $\begin{array}{l}\stackrel{\Phi}{E} \\
\text { ָั } \\
\end{array}$ & 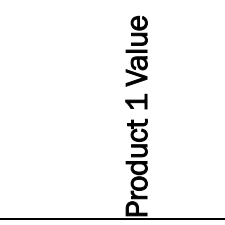 & $\begin{array}{l}\frac{0}{2} \\
\frac{2}{\pi} \\
N \\
\frac{0}{0} \\
\frac{0}{0} \\
\frac{0}{2}\end{array}$ & $\begin{array}{l}\frac{0}{2} \\
\frac{D}{\pi} \\
m \\
\frac{0}{0} \\
\frac{0}{8} \\
\frac{0}{2}\end{array}$ \\
\hline Manufacturer & Harvel & Harvel & Harvel \\
\hline Model & $\begin{array}{l}34100 \text { Clear Rigid } \\
\text { PVC Pipe }\end{array}$ & $\begin{array}{l}34126 \text { - 3" Clear Rigid } \\
\text { Schedule } 80 \text { PVC Pipe }\end{array}$ & $\begin{array}{l}34116 \text { - } 12 \text { " Clear Rigid } \\
\text { Schedule } 40 \text { PVC Pipe }\end{array}$ \\
\hline PostConsumerRecoveredContent & $\mathrm{n} / \mathrm{a}$ & $\mathrm{n} / \mathrm{a}$ & $\mathrm{n} / \mathrm{a}$ \\
\hline TotalRecoveredContent & $\mathrm{n} / \mathrm{a}$ & $\mathrm{n} / \mathrm{a}$ & $\mathrm{n} / \mathrm{a}$ \\
\hline RenewableContent & $\mathrm{n} / \mathrm{a}$ & $\mathrm{n} / \mathrm{a}$ & $\mathrm{n} / \mathrm{a}$ \\
\hline RenewableMaterial & $\mathrm{n} / \mathrm{a}$ & $\mathrm{n} / \mathrm{a}$ & $\mathrm{n} / \mathrm{a}$ \\
\hline BiobasedContent & $\mathrm{n} / \mathrm{a}$ & $\mathrm{n} / \mathrm{a}$ & $\mathrm{n} / \mathrm{a}$ \\
\hline BiobasedMaterial & $\mathrm{n} / \mathrm{a}$ & $\mathrm{n} / \mathrm{a}$ & $\mathrm{n} / \mathrm{a}$ \\
\hline RawMaterialLocation & $\mathrm{n} / \mathrm{a}$ & $\mathrm{n} / \mathrm{a}$ & $\mathrm{n} / \mathrm{a}$ \\
\hline RegionalMaterialContent & $\mathrm{n} / \mathrm{a}$ & $\mathrm{n} / \mathrm{a}$ & $\mathrm{n} / \mathrm{a}$ \\
\hline ManufactureLocation & $\mathrm{n} / \mathrm{a}$ & $\mathrm{n} / \mathrm{a}$ & $\mathrm{n} / \mathrm{a}$ \\
\hline CertifiedContent & $\mathrm{n} / \mathrm{a}$ & $\mathrm{n} / \mathrm{a}$ & $\mathrm{n} / \mathrm{a}$ \\
\hline CertificationType & $\mathrm{n} / \mathrm{a}$ & $\mathrm{n} / \mathrm{a}$ & $\mathrm{n} / \mathrm{a}$ \\
\hline Emissions & $\mathrm{n} / \mathrm{a}$ & $\mathrm{n} / \mathrm{a}$ & $\mathrm{n} / \mathrm{a}$ \\
\hline SNAP & $\mathrm{n} / \mathrm{a}$ & $\mathrm{n} / \mathrm{a}$ & $\mathrm{n} / \mathrm{a}$ \\
\hline ThermalResistance & $\mathrm{n} / \mathrm{a}$ & $\mathrm{n} / \mathrm{a}$ & $\mathrm{n} / \mathrm{a}$ \\
\hline InsulationType & unset & unset & unset \\
\hline
\end{tabular}




\begin{tabular}{|c|c|c|c|}
\hline \multicolumn{4}{|l|}{ Pump_CIRCULATOR_US } \\
\hline $\begin{array}{l}\stackrel{0}{E} \\
\stackrel{\mathbb{\pi}}{\mathbf{Z}}\end{array}$ & 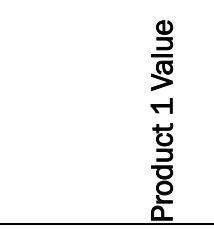 & $\begin{array}{l}\frac{0}{2} \\
\frac{1}{00} \\
\text { N } \\
\frac{1}{0} \\
\frac{2}{0} \\
\frac{0}{2}\end{array}$ & $\begin{array}{l}\frac{0}{J} \\
\frac{\pi}{\pi} \\
m \\
\text { m } \\
\frac{0}{2} \\
\frac{0}{0} \\
\frac{0}{2}\end{array}$ \\
\hline Manufacturer & TACO & GRAINGER & GRUNDFOS \\
\hline Model & GT SERIES PUMP & GRUNDFOS - UP1542-F & ALPHA Pro $25-60 \mathrm{~B}$ \\
\hline PostConsumerRecoveredContent & $\mathrm{n} / \mathrm{a}$ & $\mathrm{n} / \mathrm{a}$ & $\mathrm{n} / \mathrm{a}$ \\
\hline TotalRecoveredContent & $\mathrm{n} / \mathrm{a}$ & $\mathrm{n} / \mathrm{a}$ & $\mathrm{n} / \mathrm{a}$ \\
\hline RenewableContent & $\mathrm{n} / \mathrm{a}$ & $n / a$ & $n / a$ \\
\hline RenewableMaterial & $\mathrm{n} / \mathrm{a}$ & $\mathrm{n} / \mathrm{a}$ & $\mathrm{n} / \mathrm{a}$ \\
\hline BiobasedContent & $n / a$ & $\mathrm{n} / \mathrm{a}$ & $\mathrm{n} / \mathrm{a}$ \\
\hline BiobasedMaterial & $\mathrm{n} / \mathrm{a}$ & $\mathrm{n} / \mathrm{a}$ & $\mathrm{n} / \mathrm{a}$ \\
\hline RawMaterialLocation & $\mathrm{n} / \mathrm{a}$ & $\mathrm{n} / \mathrm{a}$ & $\mathrm{n} / \mathrm{a}$ \\
\hline RegionalMaterialContent & $\mathrm{n} / \mathrm{a}$ & $\mathrm{n} / \mathrm{a}$ & $\mathrm{n} / \mathrm{a}$ \\
\hline ManufactureLocation & $\mathrm{n} / \mathrm{a}$ & $\mathrm{n} / \mathrm{a}$ & $\mathrm{n} / \mathrm{a}$ \\
\hline CertifiedContent & $\mathrm{n} / \mathrm{a}$ & $\mathrm{n} / \mathrm{a}$ & $\mathrm{n} / \mathrm{a}$ \\
\hline CertificationType & $\mathrm{n} / \mathrm{a}$ & $\mathrm{n} / \mathrm{a}$ & $\mathrm{n} / \mathrm{a}$ \\
\hline Emissions & $\mathrm{n} / \mathrm{a}$ & $\mathrm{n} / \mathrm{a}$ & $\mathrm{n} / \mathrm{a}$ \\
\hline SNAP & $\mathrm{n} / \mathrm{a}$ & $\mathrm{n} / \mathrm{a}$ & $\mathrm{n} / \mathrm{a}$ \\
\hline ThermalResistance & $\mathrm{n} / \mathrm{a}$ & $\mathrm{n} / \mathrm{a}$ & $\mathrm{n} / \mathrm{a}$ \\
\hline HeatLoad & $\mathrm{n} / \mathrm{a}$ & $\mathrm{n} / \mathrm{a}$ & $\mathrm{n} / \mathrm{a}$ \\
\hline EnergyStar & $n / a$ & $n / a$ & $n / a$ \\
\hline
\end{tabular}




\begin{tabular}{|c|c|c|c|}
\hline \multicolumn{4}{|c|}{ SanitaryTerminal_BATH_PlumbingFixtures_US } \\
\hline 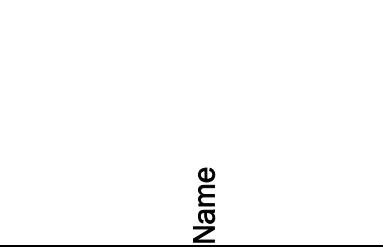 & 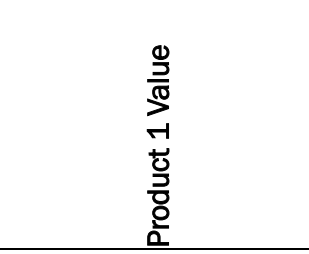 & 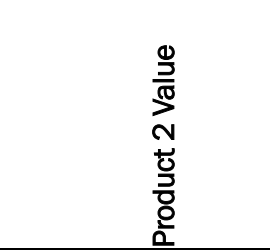 & 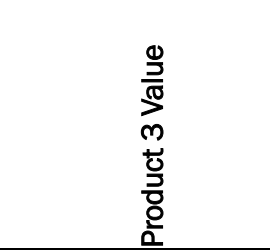 \\
\hline Manufacturer & Delta & American Standard & Kohler \\
\hline Model & $\begin{array}{l}\text { Victorian Monitor }{ }^{\circledR} 18 \\
\text { Series XO Jetted Shower }{ }^{\mathrm{TM}} \\
\text { Trim }\end{array}$ & $\begin{array}{l}\text { Moments FloWise } \\
\text { Bath/Shower Model \#: } \\
\text { T506.508 }\end{array}$ & $\begin{array}{l}\text { Forté multifunction } \\
\text { showerhead - K-10240 }\end{array}$ \\
\hline PostConsumerRecoveredContent & $\mathrm{n} / \mathrm{a}$ & $n / a$ & $\mathrm{n} / \mathrm{a}$ \\
\hline TotaIRecoveredContent & $n / a$ & $n / a$ & $n / a$ \\
\hline RenewableContent & $n / a$ & $\mathrm{n} / \mathrm{a}$ & $n / a$ \\
\hline RenewableMaterial & $n / a$ & $n / a$ & $n / a$ \\
\hline BiobasedContent & $n / a$ & $\mathrm{n} / \mathrm{a}$ & $n / a$ \\
\hline BiobasedMaterial & $\mathrm{n} / \mathrm{a}$ & $\mathrm{n} / \mathrm{a}$ & $\mathrm{n} / \mathrm{a}$ \\
\hline RawMaterialLocation & $n / a$ & $\mathrm{n} / \mathrm{a}$ & $\mathrm{n} / \mathrm{a}$ \\
\hline RegionalMaterialContent & $n / a$ & $\mathrm{n} / \mathrm{a}$ & $n / a$ \\
\hline ManufactureLocation & $\mathrm{n} / \mathrm{a}$ & $\mathrm{n} / \mathrm{a}$ & $\mathrm{n} / \mathrm{a}$ \\
\hline CertifiedContent & $\mathrm{n} / \mathrm{a}$ & $n / a$ & $n / a$ \\
\hline CertificationType & $\mathrm{n} / \mathrm{a}$ & $\mathrm{n} / \mathrm{a}$ & $\mathrm{n} / \mathrm{a}$ \\
\hline Emissions & $\mathrm{n} / \mathrm{a}$ & $\mathrm{n} / \mathrm{a}$ & $n / a$ \\
\hline SNAP & $\mathrm{n} / \mathrm{a}$ & $n / a$ & $n / a$ \\
\hline ThermalResistance & $\mathrm{n} / \mathrm{a}$ & $n / a$ & $n / a$ \\
\hline VolumePerUse & 2.5 & 2 & 1.75 \\
\hline WaterSense & NO & YES & YES \\
\hline
\end{tabular}


SanitaryTerminal_SANITARYFOUNTAIN_PlumbingFixtures_US

\begin{tabular}{|c|c|c|c|}
\hline$\frac{\mathscr{\Phi}}{\mathbb{E}}$ & 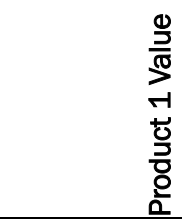 & 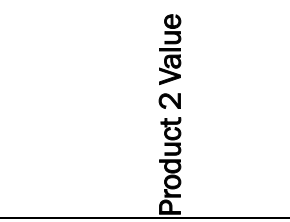 & 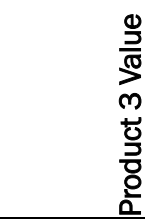 \\
\hline Manufacturer & Haws & Elkay & Oasis \\
\hline Model & H1001.8HPS & $\begin{array}{l}\text { GreenSpec® Listed High } \\
\text { Efficiency Cooler } \\
\text { LRPBGRNM28RAK }\end{array}$ & PG8AC \\
\hline Sustainability & $\mathrm{n} / \mathrm{a}$ & $\mathrm{n} / \mathrm{a}$ & $\mathrm{n} / \mathrm{a}$ \\
\hline PostConsumerRecoveredContent & $\mathrm{n} / \mathrm{a}$ & $\mathrm{n} / \mathrm{a}$ & $\mathrm{n} / \mathrm{a}$ \\
\hline TotalRecoveredContent & $\mathrm{n} / \mathrm{a}$ & $\mathrm{n} / \mathrm{a}$ & $\mathrm{n} / \mathrm{a}$ \\
\hline RenewableContent & $\mathrm{n} / \mathrm{a}$ & $\mathrm{n} / \mathrm{a}$ & $\mathrm{n} / \mathrm{a}$ \\
\hline RenewableMaterial & $\mathrm{n} / \mathrm{a}$ & $\mathrm{n} / \mathrm{a}$ & $\mathrm{n} / \mathrm{a}$ \\
\hline BiobasedContent & $\mathrm{n} / \mathrm{a}$ & $\mathrm{n} / \mathrm{a}$ & $\mathrm{n} / \mathrm{a}$ \\
\hline BiobasedMaterial & $\mathrm{n} / \mathrm{a}$ & $\mathrm{n} / \mathrm{a}$ & $\mathrm{n} / \mathrm{a}$ \\
\hline RawMaterialLocation & $\mathrm{n} / \mathrm{a}$ & $\mathrm{n} / \mathrm{a}$ & $\mathrm{n} / \mathrm{a}$ \\
\hline RegionalMaterialContent & $\mathrm{n} / \mathrm{a}$ & $\mathrm{n} / \mathrm{a}$ & $\mathrm{n} / \mathrm{a}$ \\
\hline ManufactureLocation & $\mathrm{n} / \mathrm{a}$ & $\mathrm{n} / \mathrm{a}$ & $\mathrm{n} / \mathrm{a}$ \\
\hline CertifiedContent & $\mathrm{n} / \mathrm{a}$ & $\mathrm{n} / \mathrm{a}$ & $\mathrm{n} / \mathrm{a}$ \\
\hline CertificationType & $\mathrm{n} / \mathrm{a}$ & $\mathrm{n} / \mathrm{a}$ & $\mathrm{n} / \mathrm{a}$ \\
\hline Emissions & $\mathrm{n} / \mathrm{a}$ & $\mathrm{n} / \mathrm{a}$ & $\mathrm{n} / \mathrm{a}$ \\
\hline SNAP & $\mathrm{n} / \mathrm{a}$ & $\mathrm{n} / \mathrm{a}$ & $\mathrm{n} / \mathrm{a}$ \\
\hline ThermalResistance & $\mathrm{n} / \mathrm{a}$ & $\mathrm{n} / \mathrm{a}$ & $\mathrm{n} / \mathrm{a}$ \\
\hline VolumePerUse & $\mathrm{n} / \mathrm{a}$ & $\mathrm{n} / \mathrm{a}$ & $\mathrm{n} / \mathrm{a}$ \\
\hline WaterSense & NO & NO & NO \\
\hline
\end{tabular}




\begin{tabular}{|c|c|c|c|}
\hline \multicolumn{4}{|c|}{ SanitaryTerminal_SHOWER_PlumbingFixtures_US } \\
\hline $\begin{array}{l}\stackrel{0}{E} \\
\underset{\mathbb{\pi}}{\mathbf{Z}} \\
\end{array}$ & 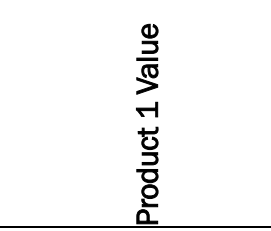 & 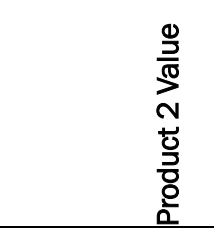 & 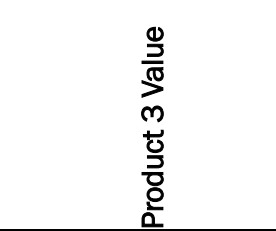 \\
\hline Manufacturer & TОто & DELTA & ТОТО \\
\hline Model & Legato - TS624A & T17230-H2O & Trilogy - TS100AL \\
\hline ShowerType & Single spray & Single spray & Single spray \\
\hline Sustainability & $\mathrm{n} / \mathrm{a}$ & $\mathrm{n} / \mathrm{a}$ & $\mathrm{n} / \mathrm{a}$ \\
\hline PostConsumerRecoveredContent & $\mathrm{n} / \mathrm{a}$ & $\mathrm{n} / \mathrm{a}$ & $\mathrm{n} / \mathrm{a}$ \\
\hline TotalRecoveredContent & $\mathrm{n} / \mathrm{a}$ & $\mathrm{n} / \mathrm{a}$ & $\mathrm{n} / \mathrm{a}$ \\
\hline RenewableContent & $\mathrm{n} / \mathrm{a}$ & $\mathrm{n} / \mathrm{a}$ & $\mathrm{n} / \mathrm{a}$ \\
\hline RenewableMaterial & $\mathrm{n} / \mathrm{a}$ & $\mathrm{n} / \mathrm{a}$ & $\mathrm{n} / \mathrm{a}$ \\
\hline BiobasedContent & $\mathrm{n} / \mathrm{a}$ & $\mathrm{n} / \mathrm{a}$ & $\mathrm{n} / \mathrm{a}$ \\
\hline BiobasedMaterial & $\mathrm{n} / \mathrm{a}$ & $\mathrm{n} / \mathrm{a}$ & $n / a$ \\
\hline RawMaterialLocation & $\mathrm{n} / \mathrm{a}$ & $\mathrm{n} / \mathrm{a}$ & $\mathrm{n} / \mathrm{a}$ \\
\hline RegionalMaterialContent & $\mathrm{n} / \mathrm{a}$ & $\mathrm{n} / \mathrm{a}$ & $\mathrm{n} / \mathrm{a}$ \\
\hline ManufactureLocation & $\mathrm{n} / \mathrm{a}$ & $\mathrm{n} / \mathrm{a}$ & $n / a$ \\
\hline CertifiedContent & $\mathrm{n} / \mathrm{a}$ & $\mathrm{n} / \mathrm{a}$ & $\mathrm{n} / \mathrm{a}$ \\
\hline CertificationType & $\begin{array}{l}\text { IAPMO(cUPC), State of } \\
\text { Massachusetts and } \\
\text { others }\end{array}$ & CSA international & $\begin{array}{l}\text { IAPMO(cUPC), State of } \\
\text { Massachusetts, City of } \\
\text { Los Angeles, and others }\end{array}$ \\
\hline Emissions & $\mathrm{n} / \mathrm{a}$ & $\mathrm{n} / \mathrm{a}$ & $n / a$ \\
\hline SNAP & $\mathrm{n} / \mathrm{a}$ & $\mathrm{n} / \mathrm{a}$ & $\mathrm{n} / \mathrm{a}$ \\
\hline ThermalResistance & $\mathrm{n} / \mathrm{a}$ & $\mathrm{n} / \mathrm{a}$ & $\mathrm{n} / \mathrm{a}$ \\
\hline VolumePerUse & 2.5 GPM & $2.0 \mathrm{GPM}$ & 1.75 GPM \\
\hline WaterSense & No & Yes & Yes \\
\hline
\end{tabular}


SanitaryTerminal_SINK_PlumbingFixtures_US

\begin{tabular}{|c|c|c|c|}
\hline $\begin{array}{l}\stackrel{0}{\mathbb{E}} \\
\stackrel{\mathbb{Z}}{z}\end{array}$ & 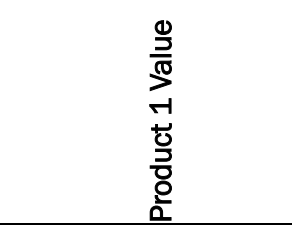 & 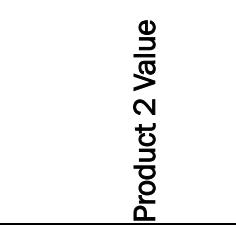 & 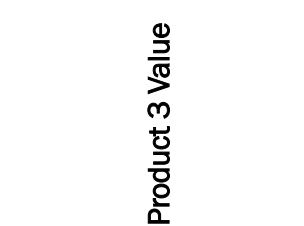 \\
\hline Manufacturer & ТОТО & KOHLER & AMERICAN STANDARD \\
\hline Model & $\begin{array}{l}\text { Kiwami Renesse - } \\
\text { TL170DD }\end{array}$ & Bancroft - K-10579 & 7385.003_V05 - Reliant 3 \\
\hline Sustainability & $\mathrm{n} / \mathrm{a}$ & $\mathrm{n} / \mathrm{a}$ & $\mathrm{n} / \mathrm{a}$ \\
\hline PostConsumerRecoveredContent & $\mathrm{n} / \mathrm{a}$ & $\mathrm{n} / \mathrm{a}$ & $n / a$ \\
\hline TotalRecoveredContent & $\mathrm{n} / \mathrm{a}$ & $\mathrm{n} / \mathrm{a}$ & $n / a$ \\
\hline RenewableContent & $\mathrm{n} / \mathrm{a}$ & $\mathrm{n} / \mathrm{a}$ & $n / a$ \\
\hline RenewableMaterial & $\mathrm{n} / \mathrm{a}$ & $n / a$ & $n / a$ \\
\hline BiobasedContent & $\mathrm{n} / \mathrm{a}$ & $\mathrm{n} / \mathrm{a}$ & $n / a$ \\
\hline BiobasedMaterial & $\mathrm{n} / \mathrm{a}$ & $\mathrm{n} / \mathrm{a}$ & $\mathrm{n} / \mathrm{a}$ \\
\hline RawMaterialLocation & $\mathrm{n} / \mathrm{a}$ & $n / a$ & $n / a$ \\
\hline RegionalMaterialContent & $\mathrm{n} / \mathrm{a}$ & $\mathrm{n} / \mathrm{a}$ & $\mathrm{n} / \mathrm{a}$ \\
\hline ManufactureLocation & $\mathrm{n} / \mathrm{a}$ & $n / a$ & $n / a$ \\
\hline CertifiedContent & $\mathrm{n} / \mathrm{a}$ & $\mathrm{n} / \mathrm{a}$ & $\mathrm{n} / \mathrm{a}$ \\
\hline CertificationType & $\begin{array}{l}\text { IAPMO(cUPC), State of } \\
\text { Massachusetts, City of } \\
\text { Los Angeles, and others }\end{array}$ & unknown & unknown \\
\hline Emissions & $\mathrm{n} / \mathrm{a}$ & $\mathrm{n} / \mathrm{a}$ & $\mathrm{n} / \mathrm{a}$ \\
\hline SNAP & $\mathrm{n} / \mathrm{a}$ & $\mathrm{n} / \mathrm{a}$ & $\mathrm{n} / \mathrm{a}$ \\
\hline ThermalResistance & $\mathrm{n} / \mathrm{a}$ & $\mathrm{n} / \mathrm{a}$ & $\mathrm{n} / \mathrm{a}$ \\
\hline VolumePerUse & $2.2 \mathrm{GPM}$ & $1.5 \mathrm{GPM}$ & 0.5 GPM \\
\hline WaterSense & no & yes & yes \\
\hline WaterTemperatureMax & $\mathrm{n} / \mathrm{a}$ & $n / a$ & $n / a$ \\
\hline WaterTemperatureMin & $\mathrm{n} / \mathrm{a}$ & $n / a$ & $n / a$ \\
\hline
\end{tabular}




\begin{tabular}{|c|c|c|c|}
\hline \multicolumn{4}{|c|}{ SanitaryTerminal_TOILETPAN_PlumbingFixtures_US } \\
\hline $\begin{array}{l}\stackrel{\Xi}{E} \\
\stackrel{\text { (ొ) }}{Z}\end{array}$ & 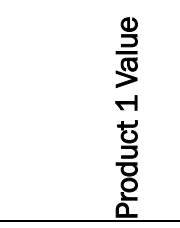 & 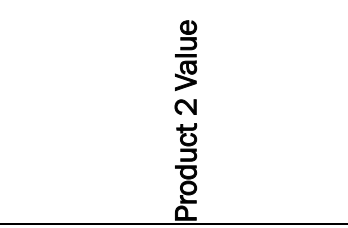 & 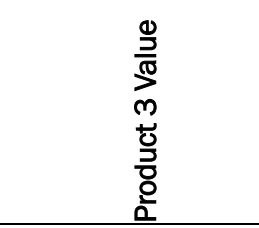 \\
\hline Manufacturer & тОто & тОто & ТОТО \\
\hline Model & $\begin{array}{l}\text { Promenade - } \\
\text { CST423SF(G) }\end{array}$ & $\begin{array}{l}\text { Eco Promenade - } \\
\text { CST423EF(G) }\end{array}$ & Aquia - MS654204MF \\
\hline Sustainability & 0 & 0 & 0 \\
\hline ToiletType & Close Coupled & Close Coupled & One-piece \\
\hline PostConsumerRecoveredContent & $\mathrm{n} / \mathrm{a}$ & $\mathrm{n} / \mathrm{a}$ & $\mathrm{n} / \mathrm{a}$ \\
\hline TotalRecoveredContent & $\mathrm{n} / \mathrm{a}$ & $\mathrm{n} / \mathrm{a}$ & $\mathrm{n} / \mathrm{a}$ \\
\hline RenewableContent & $\mathrm{n} / \mathrm{a}$ & $\mathrm{n} / \mathrm{a}$ & $\mathrm{n} / \mathrm{a}$ \\
\hline RenewableMaterial & $\mathrm{n} / \mathrm{a}$ & $\mathrm{n} / \mathrm{a}$ & $\mathrm{n} / \mathrm{a}$ \\
\hline BiobasedContent & $\mathrm{n} / \mathrm{a}$ & $\mathrm{n} / \mathrm{a}$ & $\mathrm{n} / \mathrm{a}$ \\
\hline BiobasedMaterial & $\mathrm{n} / \mathrm{a}$ & $\mathrm{n} / \mathrm{a}$ & $n / a$ \\
\hline RawMaterialLocation & $n / a$ & $\mathrm{n} / \mathrm{a}$ & $n / a$ \\
\hline RegionalMaterialContent & $n / a$ & $\mathrm{n} / \mathrm{a}$ & $\mathrm{n} / \mathrm{a}$ \\
\hline ManufactureLocation & $n / a$ & $\mathrm{n} / \mathrm{a}$ & $n / a$ \\
\hline CertifiedContent & $\mathrm{n} / \mathrm{a}$ & $\mathrm{n} / \mathrm{a}$ & $\mathrm{n} / \mathrm{a}$ \\
\hline CertificationType & $n / a$ & $\begin{array}{l}\text { IAPMO(cUPC), EPA } \\
\text { Watersense, } \\
\text { State of Massachusetts, City } \\
\text { of Los Angeles, and } \\
\text { others }\end{array}$ & $\begin{array}{l}\text { IAPMO(CUPC } ®), \text { EPA } \\
\text { WaterSense, } \\
\text { State of } \\
\text { Massachusetts, and } \\
\text { others }\end{array}$ \\
\hline Emissions & $\mathrm{n} / \mathrm{a}$ & $\mathrm{n} / \mathrm{a}$ & $\mathrm{n} / \mathrm{a}$ \\
\hline SNAP & $\mathrm{n} / \mathrm{a}$ & $\mathrm{n} / \mathrm{a}$ & $\mathrm{n} / \mathrm{a}$ \\
\hline ThermalResistance & $n / a$ & $n / a$ & $n / a$ \\
\hline VolumePerUse & 1.6 & 1.28 & $1.6 / 0.9$ \\
\hline WaterSense & No & Yes & Yes \\
\hline
\end{tabular}




\begin{tabular}{|c|c|c|c|}
\hline \multicolumn{4}{|c|}{ SanitaryTerminal_URINAL_PlumbingFixtures_US } \\
\hline $\begin{array}{l}\stackrel{\mathbb{E}}{\mathbb{Z}} \\
\stackrel{\mathbf{Z}}{\mathbf{2}}\end{array}$ & 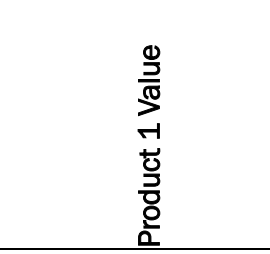 & 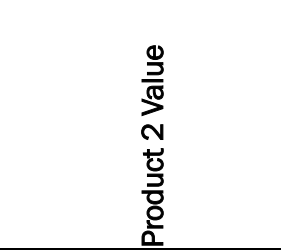 & 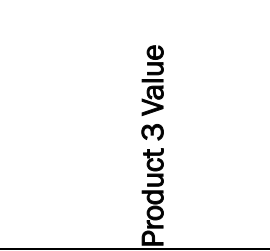 \\
\hline Manufacturer & ТОТО & ТОТО & ТОТО \\
\hline Model & UE930 & UT104E & UT105U(V)(G) \\
\hline Sustainability & $\mathrm{n} / \mathrm{a}$ & $\mathrm{n} / \mathrm{a}$ & $\mathrm{n} / \mathrm{a}$ \\
\hline UrinalType & wall hung & wall hung & wall hung \\
\hline PostConsumerRecoveredContent & $\mathrm{n} / \mathrm{a}$ & $\mathrm{n} / \mathrm{a}$ & $\mathrm{n} / \mathrm{a}$ \\
\hline TotalRecoveredContent & $\mathrm{n} / \mathrm{a}$ & $\mathrm{n} / \mathrm{a}$ & $\mathrm{n} / \mathrm{a}$ \\
\hline RenewableContent & $\mathrm{n} / \mathrm{a}$ & $\mathrm{n} / \mathrm{a}$ & $\mathrm{n} / \mathrm{a}$ \\
\hline RenewableMaterial & $\mathrm{n} / \mathrm{a}$ & $\mathrm{n} / \mathrm{a}$ & $\mathrm{n} / \mathrm{a}$ \\
\hline BiobasedContent & $\mathrm{n} / \mathrm{a}$ & $\mathrm{n} / \mathrm{a}$ & $\mathrm{n} / \mathrm{a}$ \\
\hline BiobasedMaterial & $\mathrm{n} / \mathrm{a}$ & $\mathrm{n} / \mathrm{a}$ & $\mathrm{n} / \mathrm{a}$ \\
\hline RawMaterialLocation & $\mathrm{n} / \mathrm{a}$ & $\mathrm{n} / \mathrm{a}$ & $\mathrm{n} / \mathrm{a}$ \\
\hline RegionalMaterialContent & $n / a$ & $\mathrm{n} / \mathrm{a}$ & $\mathrm{n} / \mathrm{a}$ \\
\hline ManufactureLocation & $n / a$ & $\mathrm{n} / \mathrm{a}$ & $n / a$ \\
\hline CertifiedContent & $n / a$ & $\mathrm{n} / \mathrm{a}$ & $\mathrm{n} / \mathrm{a}$ \\
\hline CertificationType & $\begin{array}{l}\text { IAPMO(cUPC), State of } \\
\text { Massachusetts, City of } \\
\text { Los Angeles }\end{array}$ & $\begin{array}{l}\text { IAPMO(cUPC), State of } \\
\text { Massachusetts, City of } \\
\text { Los Angeles }\end{array}$ & $\begin{array}{l}\text { IAPMO(cUPC), State of } \\
\text { Massachusetts, City of } \\
\text { Los Angeles }\end{array}$ \\
\hline Emissions & $\mathrm{n} / \mathrm{a}$ & $n / a$ & $\mathrm{n} / \mathrm{a}$ \\
\hline SNAP & $\mathrm{n} / \mathrm{a}$ & $n / a$ & $n / a$ \\
\hline ThermalResistance & $n / a$ & $n / a$ & $\mathrm{n} / \mathrm{a}$ \\
\hline VolumePerUse & 1.0 GPF & $0.5 \mathrm{GPF}$ & 0.125 GPF \\
\hline WaterSense & no & no & yes \\
\hline
\end{tabular}




\begin{tabular}{|c|c|c|c|}
\hline SwitchingDevice_DIMMERSW & _US & & \\
\hline 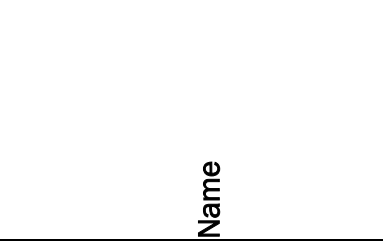 & 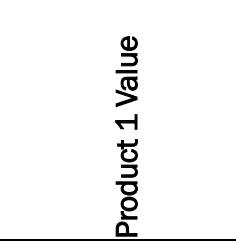 & $\begin{array}{l}\frac{0}{2} \\
\frac{2}{\pi} \\
\text { N } \\
\stackrel{0}{0} \\
\frac{D}{0} \\
\frac{2}{2}\end{array}$ & $\begin{array}{l}\frac{0}{2} \\
\frac{2}{\pi} \\
m \\
\frac{1}{0} \\
\frac{0}{0} \\
\frac{0}{0} \\
\frac{0}{2}\end{array}$ \\
\hline Manufacturer & Leviton & Lutron & Leviton \\
\hline Model & Renoir-26666-31W & Skylark - S-103P & $6602-220$ \\
\hline DimmerType & rocker & rocker & rotary \\
\hline PostConsumerRecoveredContent & $\mathrm{n} / \mathrm{a}$ & $\mathrm{n} / \mathrm{a}$ & $\mathrm{n} / \mathrm{a}$ \\
\hline TotalRecoveredContent & $\mathrm{n} / \mathrm{a}$ & $\mathrm{n} / \mathrm{a}$ & $\mathrm{n} / \mathrm{a}$ \\
\hline RenewableContent & $\mathrm{n} / \mathrm{a}$ & $\mathrm{n} / \mathrm{a}$ & $\mathrm{n} / \mathrm{a}$ \\
\hline RenewableMaterial & $\mathrm{n} / \mathrm{a}$ & $\mathrm{n} / \mathrm{a}$ & $\mathrm{n} / \mathrm{a}$ \\
\hline BiobasedContent & $\mathrm{n} / \mathrm{a}$ & $\mathrm{n} / \mathrm{a}$ & $\mathrm{n} / \mathrm{a}$ \\
\hline BiobasedMaterial & $\mathrm{n} / \mathrm{a}$ & $\mathrm{n} / \mathrm{a}$ & $\mathrm{n} / \mathrm{a}$ \\
\hline RawMaterialLocation & $\mathrm{n} / \mathrm{a}$ & $\mathrm{n} / \mathrm{a}$ & $\mathrm{n} / \mathrm{a}$ \\
\hline RegionalMaterialContent & $\mathrm{n} / \mathrm{a}$ & $n / a$ & $\mathrm{n} / \mathrm{a}$ \\
\hline ManufactureLocation & $\mathrm{n} / \mathrm{a}$ & $\mathrm{n} / \mathrm{a}$ & $\mathrm{n} / \mathrm{a}$ \\
\hline CertifiedContent & $\mathrm{n} / \mathrm{a}$ & $\mathrm{n} / \mathrm{a}$ & $\mathrm{n} / \mathrm{a}$ \\
\hline CertificationType & UL/CSA & $\mathrm{n} / \mathrm{a}$ & non-UL \\
\hline Emissions & $\mathrm{n} / \mathrm{a}$ & $\mathrm{n} / \mathrm{a}$ & $\mathrm{n} / \mathrm{a}$ \\
\hline SNAP & $\mathrm{n} / \mathrm{a}$ & $\mathrm{n} / \mathrm{a}$ & $\mathrm{n} / \mathrm{a}$ \\
\hline ThermalResistance & $\mathrm{n} / \mathrm{a}$ & $\mathrm{n} / \mathrm{a}$ & $\mathrm{n} / \mathrm{a}$ \\
\hline HeatLoad & $n / a$ & $n / a$ & $n / a$ \\
\hline EnergyStar & $n / a$ & $\mathrm{n} / \mathrm{a}$ & $\mathrm{n} / \mathrm{a}$ \\
\hline
\end{tabular}




\begin{tabular}{|c|c|c|c|}
\hline \multicolumn{4}{|c|}{ SwitchingDevice_TOGGLESWITCH_US } \\
\hline $\begin{array}{l}\stackrel{0}{E} \\
\stackrel{\mathbb{\pi}}{Z}\end{array}$ & $\begin{array}{l}\frac{0}{3} \\
\frac{7}{\pi} \\
ㄱ \\
\frac{1}{0} \\
\frac{3}{0} \\
\frac{0}{2}\end{array}$ & 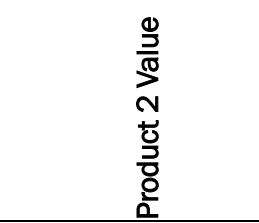 & $\begin{array}{l}\frac{0}{2} \\
\frac{0}{\pi} \\
\text { m } \\
\stackrel{0}{0} \\
\frac{0}{0} \\
\frac{2}{2}\end{array}$ \\
\hline Manufacturer & $\begin{array}{l}\text { GRAINGER - CARLING } \\
\text { TECHNOLOGIES }\end{array}$ & $\begin{array}{l}\text { GRAINGER - CARLING } \\
\text { TECHNOLOGIES }\end{array}$ & $\begin{array}{l}\text { GRAINGER - POWER } \\
\text { FIRST }\end{array}$ \\
\hline Model & 111-16-73 & 2GK51-73 & 2VLU1 \\
\hline SwitchActivation & notknown & notknown & notknown \\
\hline PostConsumerRecoveredContent & $\mathrm{n} / \mathrm{a}$ & $\mathrm{n} / \mathrm{a}$ & $\mathrm{n} / \mathrm{a}$ \\
\hline TotalRecoveredContent & $\mathrm{n} / \mathrm{a}$ & $\mathrm{n} / \mathrm{a}$ & $\mathrm{n} / \mathrm{a}$ \\
\hline RenewableContent & $\mathrm{n} / \mathrm{a}$ & $\mathrm{n} / \mathrm{a}$ & $\mathrm{n} / \mathrm{a}$ \\
\hline RenewableMaterial & $\mathrm{n} / \mathrm{a}$ & $\mathrm{n} / \mathrm{a}$ & $\mathrm{n} / \mathrm{a}$ \\
\hline BiobasedContent & $\mathrm{n} / \mathrm{a}$ & $\mathrm{n} / \mathrm{a}$ & $\mathrm{n} / \mathrm{a}$ \\
\hline BiobasedMaterial & $\mathrm{n} / \mathrm{a}$ & $\mathrm{n} / \mathrm{a}$ & $\mathrm{n} / \mathrm{a}$ \\
\hline RawMaterialLocation & $\mathrm{n} / \mathrm{a}$ & $\mathrm{n} / \mathrm{a}$ & $\mathrm{n} / \mathrm{a}$ \\
\hline RegionalMaterialContent & $\mathrm{n} / \mathrm{a}$ & $\mathrm{n} / \mathrm{a}$ & $\mathrm{n} / \mathrm{a}$ \\
\hline ManufactureLocation & $\mathrm{n} / \mathrm{a}$ & $\mathrm{n} / \mathrm{a}$ & $\mathrm{n} / \mathrm{a}$ \\
\hline CertifiedContent & $\mathrm{n} / \mathrm{a}$ & $\mathrm{n} / \mathrm{a}$ & $\mathrm{n} / \mathrm{a}$ \\
\hline CertificationType & $\mathrm{n} / \mathrm{a}$ & $\mathrm{n} / \mathrm{a}$ & $\mathrm{n} / \mathrm{a}$ \\
\hline Emissions & $\mathrm{n} / \mathrm{a}$ & $\mathrm{n} / \mathrm{a}$ & $\mathrm{n} / \mathrm{a}$ \\
\hline SNAP & $\mathrm{n} / \mathrm{a}$ & $\mathrm{n} / \mathrm{a}$ & $\mathrm{n} / \mathrm{a}$ \\
\hline ThermalResistance & $\mathrm{n} / \mathrm{a}$ & $\mathrm{n} / \mathrm{a}$ & $\mathrm{n} / \mathrm{a}$ \\
\hline HeatLoad & $\mathrm{n} / \mathrm{a}$ & $\mathrm{n} / \mathrm{a}$ & $\mathrm{n} / \mathrm{a}$ \\
\hline EnergyStar & $n / a$ & $n / a$ & $n / a$ \\
\hline
\end{tabular}




\begin{tabular}{|c|c|c|c|}
\hline \multicolumn{4}{|l|}{ Transformer_VOLTAGE_US } \\
\hline $\begin{array}{l}\stackrel{0}{E} \\
\stackrel{\mathbb{\pi}}{Z}\end{array}$ & 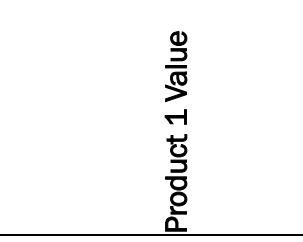 & $\begin{array}{l}\frac{0}{2} \\
\frac{\pi}{\pi} \\
\text { N } \\
\frac{d}{0} \\
\frac{D}{0} \\
\frac{0}{2}\end{array}$ & 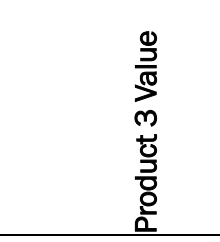 \\
\hline Manufacturer & DCACPOWER INVERTERS & Voltage Converters & 220 CONVERTERS \\
\hline Model & vc3000W & MS10G8 & THG-20000 \\
\hline PostConsumerRecoveredContent & $\mathrm{n} / \mathrm{a}$ & $\mathrm{n} / \mathrm{a}$ & $n / a$ \\
\hline TotaIRecoveredContent & $\mathrm{n} / \mathrm{a}$ & $\mathrm{n} / \mathrm{a}$ & $\mathrm{n} / \mathrm{a}$ \\
\hline RenewableContent & $\mathrm{n} / \mathrm{a}$ & $\mathrm{n} / \mathrm{a}$ & $n / a$ \\
\hline RenewableMaterial & $\mathrm{n} / \mathrm{a}$ & $\mathrm{n} / \mathrm{a}$ & $n / a$ \\
\hline BiobasedContent & $\mathrm{n} / \mathrm{a}$ & $\mathrm{n} / \mathrm{a}$ & $n / a$ \\
\hline BiobasedMaterial & $\mathrm{n} / \mathrm{a}$ & $\mathrm{n} / \mathrm{a}$ & $n / a$ \\
\hline RawMaterialLocation & $\mathrm{n} / \mathrm{a}$ & $\mathrm{n} / \mathrm{a}$ & $\mathrm{n} / \mathrm{a}$ \\
\hline RegionalMaterialContent & $\mathrm{n} / \mathrm{a}$ & $\mathrm{n} / \mathrm{a}$ & $n / a$ \\
\hline ManufactureLocation & $\mathrm{n} / \mathrm{a}$ & $\mathrm{n} / \mathrm{a}$ & $n / a$ \\
\hline CertifiedContent & $\mathrm{n} / \mathrm{a}$ & $\mathrm{n} / \mathrm{a}$ & $\mathrm{n} / \mathrm{a}$ \\
\hline CertificationType & $\mathrm{n} / \mathrm{a}$ & $\mathrm{n} / \mathrm{a}$ & $\mathrm{n} / \mathrm{a}$ \\
\hline Emissions & $\mathrm{n} / \mathrm{a}$ & $\mathrm{n} / \mathrm{a}$ & $\mathrm{n} / \mathrm{a}$ \\
\hline HeatLoad & $\mathrm{n} / \mathrm{a}$ & $\mathrm{n} / \mathrm{a}$ & $\mathrm{n} / \mathrm{a}$ \\
\hline EnergyStar & $\mathrm{n} / \mathrm{a}$ & $\mathrm{n} / \mathrm{a}$ & $\mathrm{n} / \mathrm{a}$ \\
\hline EISAEfficiency & $\mathrm{n} / \mathrm{a}$ & $\mathrm{n} / \mathrm{a}$ & $\mathrm{n} / \mathrm{a}$ \\
\hline TransformerFillType & $\mathrm{n} / \mathrm{a}$ & $\mathrm{n} / \mathrm{a}$ & $\mathrm{n} / \mathrm{a}$ \\
\hline AcousticRating & $n / a$ & $\mathrm{n} / \mathrm{a}$ & $n / a$ \\
\hline
\end{tabular}




\begin{tabular}{|c|c|c|c|}
\hline \multicolumn{4}{|c|}{ UnitaryEquipment_AIRHANDLER_US } \\
\hline $\begin{array}{l}\stackrel{\mathbb{E}}{\mathbf{N}} \\
\text { Z }\end{array}$ & 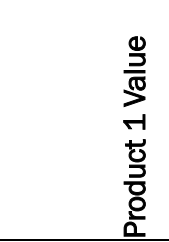 & 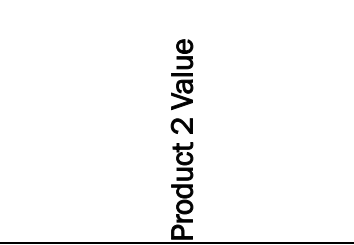 & 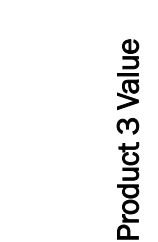 \\
\hline Manufacturer & Lennox & Trane & Carrier \\
\hline Model & TSA240S4D & $\begin{array}{l}\text { Performance Climate Changer } \\
\text { Air Handler }\end{array}$ & 39L18 AERO \\
\hline PostConsumerRecoveredContent & $\mathrm{n} / \mathrm{a}$ & $\mathrm{n} / \mathrm{a}$ & $\mathrm{n} / \mathrm{a}$ \\
\hline TotalRecoveredContent & $\mathrm{n} / \mathrm{a}$ & $n / a$ & $n / a$ \\
\hline RenewableContent & $\mathrm{n} / \mathrm{a}$ & $\mathrm{n} / \mathrm{a}$ & $\mathrm{n} / \mathrm{a}$ \\
\hline RenewableMaterial & $\mathrm{n} / \mathrm{a}$ & $\mathrm{n} / \mathrm{a}$ & $\mathrm{n} / \mathrm{a}$ \\
\hline BiobasedContent & $\mathrm{n} / \mathrm{a}$ & $\mathrm{n} / \mathrm{a}$ & $\mathrm{n} / \mathrm{a}$ \\
\hline BiobasedMaterial & $\mathrm{n} / \mathrm{a}$ & $\mathrm{n} / \mathrm{a}$ & $\mathrm{n} / \mathrm{a}$ \\
\hline RawMaterialLocation & $\mathrm{n} / \mathrm{a}$ & $\mathrm{n} / \mathrm{a}$ & $n / a$ \\
\hline RegionalMaterialContent & $\mathrm{n} / \mathrm{a}$ & $\mathrm{n} / \mathrm{a}$ & $\mathrm{n} / \mathrm{a}$ \\
\hline ManufactureLocation & $\mathrm{n} / \mathrm{a}$ & $\mathrm{n} / \mathrm{a}$ & $\mathrm{n} / \mathrm{a}$ \\
\hline CertifiedContent & $\mathrm{n} / \mathrm{a}$ & $\mathrm{n} / \mathrm{a}$ & $\mathrm{n} / \mathrm{a}$ \\
\hline CertificationType & $\mathrm{n} / \mathrm{a}$ & $\mathrm{n} / \mathrm{a}$ & $\mathrm{n} / \mathrm{a}$ \\
\hline Emissions & $\mathrm{n} / \mathrm{a}$ & $n / a$ & $\mathrm{n} / \mathrm{a}$ \\
\hline SNAP & $\mathrm{n} / \mathrm{a}$ & $n / a$ & $n / a$ \\
\hline ThermalResistance & $\mathrm{n} / \mathrm{a}$ & $n / a$ & $n / a$ \\
\hline HeatLoad & $n / a$ & $n / a$ & $n / a$ \\
\hline EnergyStar & $\mathrm{n} / \mathrm{a}$ & $n / a$ & $\mathrm{n} / \mathrm{a}$ \\
\hline NominalCoolingCapacity & $\mathrm{n} / \mathrm{a}$ & $n / a$ & 9000 \\
\hline CoolingCapacity & 236000 & $n / a$ & $n / a$ \\
\hline Economizer & $n / a$ & $\mathrm{n} / \mathrm{a}$ & $\mathrm{n} / \mathrm{a}$ \\
\hline SupplyFanMotorPower & $\mathrm{n} / \mathrm{a}$ & $n / a$ & $n / a$ \\
\hline SupplyFanCapacity & $n / a$ & $n / a$ & $n / a$ \\
\hline ReturnFanMotorPower & $\mathrm{n} / \mathrm{a}$ & $\mathrm{n} / \mathrm{a}$ & $n / a$ \\
\hline ReturnFanCapacity & $\mathrm{n} / \mathrm{a}$ & $\mathrm{n} / \mathrm{a}$ & $\mathrm{n} / \mathrm{a}$ \\
\hline
\end{tabular}




\begin{tabular}{|c|c|c|c|}
\hline \multicolumn{4}{|l|}{ Valve_FAUCET_US } \\
\hline $\begin{array}{l}\stackrel{0}{E} \\
\stackrel{\mathbb{\pi}}{\mathbf{Z}} \\
\end{array}$ & 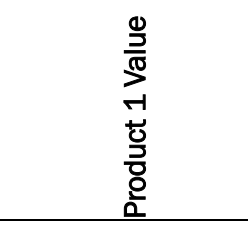 & 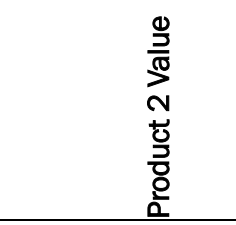 & $\begin{array}{l}\frac{0}{J} \\
\frac{D}{\pi} \\
m \\
\text { m } \\
\frac{0}{0} \\
\frac{0}{0} \\
\frac{0}{2}\end{array}$ \\
\hline Manufacturer & American Standard & Kohler & Delta \\
\hline Model & $\begin{array}{l}7500.170 \text { Centerset } \\
\text { Lavatory }\end{array}$ & $\begin{array}{l}\text { Sculpted Touchless } \\
\text { lavatory faucet } \\
\text { - K-13461 }\end{array}$ & $\begin{array}{l}\text { Trinsic Single Handle Pull- } \\
\text { Down Bar/Prep Faucet } \\
\text { Featuring Touch } 20 \AA \\
\text { Technology }\end{array}$ \\
\hline FaucetType & $\mathrm{n} / \mathrm{a}$ & $\mathrm{n} / \mathrm{a}$ & $\mathrm{n} / \mathrm{a}$ \\
\hline FaucetOperation & leverhandle & other & $n / a$ \\
\hline FaucetFunction & mixed & 0 & 0 \\
\hline PostConsumerRecoveredContent & $\mathrm{n} / \mathrm{a}$ & $\mathrm{n} / \mathrm{a}$ & $\mathrm{n} / \mathrm{a}$ \\
\hline TotalRecoveredContent & $\mathrm{n} / \mathrm{a}$ & $\mathrm{n} / \mathrm{a}$ & $\mathrm{n} / \mathrm{a}$ \\
\hline RenewableContent & $\mathrm{n} / \mathrm{a}$ & $\mathrm{n} / \mathrm{a}$ & $\mathrm{n} / \mathrm{a}$ \\
\hline RenewableMaterial & $\mathrm{n} / \mathrm{a}$ & $\mathrm{n} / \mathrm{a}$ & $\mathrm{n} / \mathrm{a}$ \\
\hline BiobasedContent & $\mathrm{n} / \mathrm{a}$ & $\mathrm{n} / \mathrm{a}$ & $\mathrm{n} / \mathrm{a}$ \\
\hline BiobasedMaterial & $\mathrm{n} / \mathrm{a}$ & $\mathrm{n} / \mathrm{a}$ & $\mathrm{n} / \mathrm{a}$ \\
\hline RawMaterialLocation & $\mathrm{n} / \mathrm{a}$ & $\mathrm{n} / \mathrm{a}$ & $\mathrm{n} / \mathrm{a}$ \\
\hline RegionalMaterialContent & $\mathrm{n} / \mathrm{a}$ & $\mathrm{n} / \mathrm{a}$ & $\mathrm{n} / \mathrm{a}$ \\
\hline ManufactureLocation & $\mathrm{n} / \mathrm{a}$ & $\mathrm{n} / \mathrm{a}$ & $\mathrm{n} / \mathrm{a}$ \\
\hline CertifiedContent & $\mathrm{n} / \mathrm{a}$ & $\mathrm{n} / \mathrm{a}$ & $\mathrm{n} / \mathrm{a}$ \\
\hline CertificationType & $\mathrm{n} / \mathrm{a}$ & $n / a$ & $n / a$ \\
\hline Emissions & $\mathrm{n} / \mathrm{a}$ & $\mathrm{n} / \mathrm{a}$ & $\mathrm{n} / \mathrm{a}$ \\
\hline SNAP & $n / a$ & $n / a$ & $n / a$ \\
\hline ThermalResistance & $\mathrm{n} / \mathrm{a}$ & $\mathrm{n} / \mathrm{a}$ & $n / a$ \\
\hline OperatingPressureMaximum & $\mathrm{n} / \mathrm{a}$ & $n / a$ & $n / a$ \\
\hline
\end{tabular}




\begin{tabular}{|c|c|c|c|}
\hline \multicolumn{4}{|l|}{ Valve_FLUSHING_US } \\
\hline $\begin{array}{l}\stackrel{\Xi}{E} \\
\stackrel{\mathbb{N}}{\mathbf{Z}}\end{array}$ & 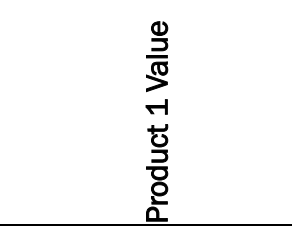 & $\begin{array}{l}\frac{0}{2} \\
\frac{\pi}{\pi} \\
\text { N } \\
\frac{1}{2} \\
\frac{0}{0} \\
\frac{0}{2}\end{array}$ & $\begin{array}{l}\frac{0}{2} \\
\frac{\pi}{0} \\
m \\
\frac{0}{2} \\
\frac{0}{0} \\
\frac{0}{2}\end{array}$ \\
\hline Manufacturer & Delta & American Standard & Kohler \\
\hline Model & $\begin{array}{l}\text { 81T201HWA-DF - DUAL } \\
\text { FLUSH Hard wire FLUSH } \\
\text { VALVE }\end{array}$ & $\begin{array}{l}\text { Selectronic FloWise toilet } \\
\text { Flush Valve - Battery } \\
\text { Powered }\end{array}$ & $\begin{array}{l}\text { WAVE } 1.28 \text { gpf exposed } \\
\text { toilet flushometer - K- } \\
10673\end{array}$ \\
\hline ValvePattern & $\mathrm{n} / \mathrm{a}$ & $\mathrm{n} / \mathrm{a}$ & $\mathrm{n} / \mathrm{a}$ \\
\hline ValveOperation & $\mathrm{n} / \mathrm{a}$ & $\mathrm{n} / \mathrm{a}$ & $\mathrm{n} / \mathrm{a}$ \\
\hline ValveMechanism & $\mathrm{n} / \mathrm{a}$ & $\mathrm{n} / \mathrm{a}$ & $\mathrm{n} / \mathrm{a}$ \\
\hline WorkingPressure & $\mathrm{n} / \mathrm{a}$ & 25 & 0 \\
\hline FlowCoefficient & $\mathrm{n} / \mathrm{a}$ & $\mathrm{n} / \mathrm{a}$ & $n / a$ \\
\hline FlushingRate & 1.6 & 1.28 & 1.28 \\
\hline HasIntegralShutOffDevice & $\mathrm{n} / \mathrm{a}$ & $\mathrm{n} / \mathrm{a}$ & $\mathrm{n} / \mathrm{a}$ \\
\hline IsHighPressure & $\mathrm{n} / \mathrm{a}$ & $\mathrm{n} / \mathrm{a}$ & $n / a$ \\
\hline PostConsumerRecoveredContent & $\mathrm{n} / \mathrm{a}$ & $\mathrm{n} / \mathrm{a}$ & $\mathrm{n} / \mathrm{a}$ \\
\hline TotalRecoveredContent & $\mathrm{n} / \mathrm{a}$ & $\mathrm{n} / \mathrm{a}$ & $n / a$ \\
\hline RenewableContent & $\mathrm{n} / \mathrm{a}$ & $\mathrm{n} / \mathrm{a}$ & $\mathrm{n} / \mathrm{a}$ \\
\hline RenewableMaterial & $\mathrm{n} / \mathrm{a}$ & $\mathrm{n} / \mathrm{a}$ & $n / a$ \\
\hline BiobasedContent & $\mathrm{n} / \mathrm{a}$ & $\mathrm{n} / \mathrm{a}$ & $\mathrm{n} / \mathrm{a}$ \\
\hline BiobasedMaterial & $\mathrm{n} / \mathrm{a}$ & $\mathrm{n} / \mathrm{a}$ & $\mathrm{n} / \mathrm{a}$ \\
\hline RawMaterialLocation & $\mathrm{n} / \mathrm{a}$ & $\mathrm{n} / \mathrm{a}$ & $n / a$ \\
\hline RegionalMaterialContent & $\mathrm{n} / \mathrm{a}$ & $\mathrm{n} / \mathrm{a}$ & $n / a$ \\
\hline ManufactureLocation & $\mathrm{n} / \mathrm{a}$ & $\mathrm{n} / \mathrm{a}$ & $\mathrm{n} / \mathrm{a}$ \\
\hline CertifiedContent & $\mathrm{n} / \mathrm{a}$ & $\mathrm{n} / \mathrm{a}$ & $n / a$ \\
\hline CertificationType & $\mathrm{n} / \mathrm{a}$ & $\mathrm{n} / \mathrm{a}$ & $\mathrm{n} / \mathrm{a}$ \\
\hline Emissions & $\mathrm{n} / \mathrm{a}$ & $\mathrm{n} / \mathrm{a}$ & $\mathrm{n} / \mathrm{a}$ \\
\hline SNAP & $\mathrm{n} / \mathrm{a}$ & $\mathrm{n} / \mathrm{a}$ & $\mathrm{n} / \mathrm{a}$ \\
\hline ThermalResistance & $\mathrm{n} / \mathrm{a}$ & $\mathrm{n} / \mathrm{a}$ & $\mathrm{n} / \mathrm{a}$ \\
\hline OperatingPressureMaximum & $\mathrm{n} / \mathrm{a}$ & 80 & $\mathrm{n} / \mathrm{a}$ \\
\hline
\end{tabular}


Valve_ISOLATING_US

\begin{tabular}{|c|c|c|c|}
\hline $\begin{array}{l}\stackrel{0}{E} \\
\text { ָ } \\
\end{array}$ & 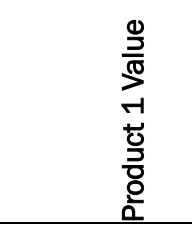 & 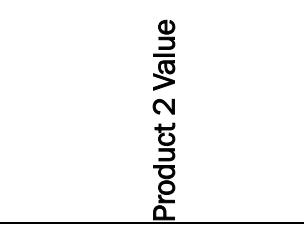 & 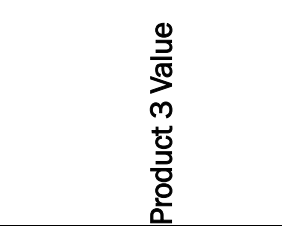 \\
\hline Manufacturer & Honeywell & Buckling Pin Technology & Buckling Pin Technology \\
\hline Model & V5047A1021/U & $\begin{array}{l}\text { Model F-B - Butterfly Valve } \\
\text { Type ESV }\end{array}$ & $\begin{array}{l}\text { Model E-B Inline, Ball } \\
\text { Valve Type ESV }\end{array}$ \\
\hline ValvePattern & two-way & notknown & notknown \\
\hline ValveOperation & notknown & notknown & notknown \\
\hline ValveMechanism & notknown & butterfly & ball \\
\hline WorkingPressure & $\mathrm{n} / \mathrm{a}$ & $\mathrm{n} / \mathrm{a}$ & $\mathrm{n} / \mathrm{a}$ \\
\hline PostConsumerRecoveredContent & $\mathrm{n} / \mathrm{a}$ & $\mathrm{n} / \mathrm{a}$ & $\mathrm{n} / \mathrm{a}$ \\
\hline TotalRecoveredContent & $\mathrm{n} / \mathrm{a}$ & $\mathrm{n} / \mathrm{a}$ & $\mathrm{n} / \mathrm{a}$ \\
\hline RenewableContent & $\mathrm{n} / \mathrm{a}$ & $\mathrm{n} / \mathrm{a}$ & $\mathrm{n} / \mathrm{a}$ \\
\hline RenewableMaterial & $\mathrm{n} / \mathrm{a}$ & $\mathrm{n} / \mathrm{a}$ & $\mathrm{n} / \mathrm{a}$ \\
\hline BiobasedContent & $\mathrm{n} / \mathrm{a}$ & $\mathrm{n} / \mathrm{a}$ & $\mathrm{n} / \mathrm{a}$ \\
\hline BiobasedMaterial & $n / a$ & $\mathrm{n} / \mathrm{a}$ & $\mathrm{n} / \mathrm{a}$ \\
\hline RawMaterialLocation & $\mathrm{n} / \mathrm{a}$ & $\mathrm{n} / \mathrm{a}$ & $\mathrm{n} / \mathrm{a}$ \\
\hline RegionalMaterialContent & $\mathrm{n} / \mathrm{a}$ & $\mathrm{n} / \mathrm{a}$ & $\mathrm{n} / \mathrm{a}$ \\
\hline ManufactureLocation & $\mathrm{n} / \mathrm{a}$ & $\mathrm{n} / \mathrm{a}$ & $\mathrm{n} / \mathrm{a}$ \\
\hline CertifiedContent & $n / a$ & $\mathrm{n} / \mathrm{a}$ & $\mathrm{n} / \mathrm{a}$ \\
\hline CertificationType & $n / a$ & $\mathrm{n} / \mathrm{a}$ & $\mathrm{n} / \mathrm{a}$ \\
\hline Emissions & $\mathrm{n} / \mathrm{a}$ & $n / a$ & $n / a$ \\
\hline SNAP & $n / a$ & $n / a$ & $\mathrm{n} / \mathrm{a}$ \\
\hline ThermalResistance & $n / a$ & $n / a$ & $\mathrm{n} / \mathrm{a}$ \\
\hline OperatingPressureMaximum & 1034 & $\mathrm{n} / \mathrm{a}$ & $\mathrm{n} / \mathrm{a}$ \\
\hline
\end{tabular}




\begin{tabular}{|c|c|c|c|}
\hline \multicolumn{4}{|l|}{ Valve_STOPCOCK_US } \\
\hline $\begin{array}{l}\stackrel{0}{E} \\
\text { ゙ָ } \\
\end{array}$ & 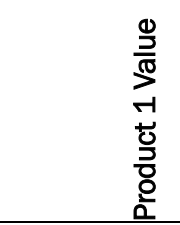 & 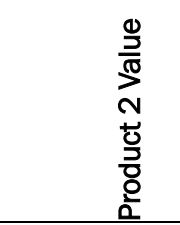 & $\begin{array}{l}\frac{0}{2} \\
\frac{2}{\pi} \\
m \\
m \\
\frac{0}{0} \\
\frac{7}{0} \\
\frac{0}{2}\end{array}$ \\
\hline Manufacturer & COLE-PALMER & COLE-PALMER & Merit Medical \\
\hline Model & WU-30600-06 & WU-30600-00 & U1SNP \\
\hline ValvePattern & $\mathrm{n} / \mathrm{a}$ & $\mathrm{n} / \mathrm{a}$ & $\mathrm{n} / \mathrm{a}$ \\
\hline ValveOperation & $n / a$ & $n / a$ & $\mathrm{n} / \mathrm{a}$ \\
\hline ValveMechanism & $\mathrm{n} / \mathrm{a}$ & $\mathrm{n} / \mathrm{a}$ & $\mathrm{n} / \mathrm{a}$ \\
\hline WorkingPressure & $n / a$ & $n / a$ & $n / a$ \\
\hline PostConsumerRecoveredContent & $\mathrm{n} / \mathrm{a}$ & $\mathrm{n} / \mathrm{a}$ & $\mathrm{n} / \mathrm{a}$ \\
\hline TotalRecoveredContent & $\mathrm{n} / \mathrm{a}$ & $\mathrm{n} / \mathrm{a}$ & $\mathrm{n} / \mathrm{a}$ \\
\hline RenewableContent & $n / a$ & $\mathrm{n} / \mathrm{a}$ & $\mathrm{n} / \mathrm{a}$ \\
\hline RenewableMaterial & $\mathrm{n} / \mathrm{a}$ & $\mathrm{n} / \mathrm{a}$ & $\mathrm{n} / \mathrm{a}$ \\
\hline BiobasedContent & $n / a$ & $\mathrm{n} / \mathrm{a}$ & $n / a$ \\
\hline BiobasedMaterial & $\mathrm{n} / \mathrm{a}$ & $\mathrm{n} / \mathrm{a}$ & $\mathrm{n} / \mathrm{a}$ \\
\hline RawMaterialLocation & $\mathrm{n} / \mathrm{a}$ & $\mathrm{n} / \mathrm{a}$ & $\mathrm{n} / \mathrm{a}$ \\
\hline RegionalMaterialContent & $\mathrm{n} / \mathrm{a}$ & $\mathrm{n} / \mathrm{a}$ & $\mathrm{n} / \mathrm{a}$ \\
\hline ManufactureLocation & $n / a$ & $\mathrm{n} / \mathrm{a}$ & $\mathrm{n} / \mathrm{a}$ \\
\hline CertifiedContent & $\mathrm{n} / \mathrm{a}$ & $\mathrm{n} / \mathrm{a}$ & $\mathrm{n} / \mathrm{a}$ \\
\hline CertificationType & $\mathrm{n} / \mathrm{a}$ & $n / a$ & $\mathrm{n} / \mathrm{a}$ \\
\hline Emissions & $\mathrm{n} / \mathrm{a}$ & $\mathrm{n} / \mathrm{a}$ & $\mathrm{n} / \mathrm{a}$ \\
\hline SNAP & $\mathrm{n} / \mathrm{a}$ & $n / a$ & $\mathrm{n} / \mathrm{a}$ \\
\hline ThermalResistance & $\mathrm{n} / \mathrm{a}$ & $\mathrm{n} / \mathrm{a}$ & $\mathrm{n} / \mathrm{a}$ \\
\hline OperatingPressureMaximum & 0 & 0 & 1200 \\
\hline
\end{tabular}


Wall_USERDEFINED_BrickMasonry_US

\begin{tabular}{|c|c|c|c|}
\hline $\begin{array}{l}\stackrel{0}{E} \\
\text { ָ } \\
\end{array}$ & $\begin{array}{l}\frac{0}{2} \\
\frac{\partial}{\pi} \\
ㄱ \\
\frac{1}{0} \\
\frac{0}{0} \\
\frac{0}{2}\end{array}$ & 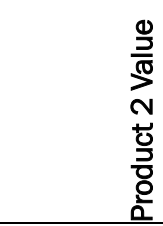 & $\begin{array}{l}\frac{0}{2} \\
\frac{1}{\pi} \\
m \\
\frac{0}{2} \\
\frac{0}{0} \\
\frac{0}{2}\end{array}$ \\
\hline Manufacturer & Acme Brick & Belden Brick & Cloud Ceramics \\
\hline Model & Modular & Utility & King \\
\hline Sustainability & $\mathrm{n} / \mathrm{a}$ & $\mathrm{n} / \mathrm{a}$ & $\mathrm{n} / \mathrm{a}$ \\
\hline FireRating & $\mathrm{n} / \mathrm{a}$ & $\mathrm{n} / \mathrm{a}$ & $\mathrm{n} / \mathrm{a}$ \\
\hline Combustible & FALSE & FALSE & FALSE \\
\hline SurfaceSpreadOfFlame & $\mathrm{n} / \mathrm{a}$ & $\mathrm{n} / \mathrm{a}$ & $\mathrm{n} / \mathrm{a}$ \\
\hline ThermalTransmittance & 0.41 & 0.41 & 0.41 \\
\hline IsExternal & TRUE & TRUE & TRUE \\
\hline PostConsumerRecoveredContent & $\mathrm{n} / \mathrm{a}$ & $\mathrm{n} / \mathrm{a}$ & $\mathrm{n} / \mathrm{a}$ \\
\hline TotalRecoveredContent & $\mathrm{n} / \mathrm{a}$ & $\mathrm{n} / \mathrm{a}$ & $\mathrm{n} / \mathrm{a}$ \\
\hline RenewableContent & $n / a$ & $n / a$ & $n / a$ \\
\hline RenewableMaterial & $\mathrm{n} / \mathrm{a}$ & $\mathrm{n} / \mathrm{a}$ & $\mathrm{n} / \mathrm{a}$ \\
\hline BiobasedContent & $\mathrm{n} / \mathrm{a}$ & $n / a$ & $\mathrm{n} / \mathrm{a}$ \\
\hline BiobasedMaterial & $\mathrm{n} / \mathrm{a}$ & $n / a$ & $n / a$ \\
\hline RawMaterialLocation & $\mathrm{n} / \mathrm{a}$ & $\mathrm{n} / \mathrm{a}$ & $\mathrm{n} / \mathrm{a}$ \\
\hline RegionalMaterialContent & $\mathrm{n} / \mathrm{a}$ & $n / a$ & $n / a$ \\
\hline ManufactureLocation & $\mathrm{n} / \mathrm{a}$ & $n / a$ & $n / a$ \\
\hline CertifiedContent & $\mathrm{n} / \mathrm{a}$ & $n / a$ & $n / a$ \\
\hline CertificationType & $\mathrm{n} / \mathrm{a}$ & $n / a$ & $n / a$ \\
\hline Emissions & $\mathrm{n} / \mathrm{a}$ & $n / a$ & $n / a$ \\
\hline SNAP & $\mathrm{n} / \mathrm{a}$ & $n / a$ & $n / a$ \\
\hline ThermalResistance & $\mathrm{n} / \mathrm{a}$ & $\mathrm{n} / \mathrm{a}$ & $\mathrm{n} / \mathrm{a}$ \\
\hline
\end{tabular}




\begin{tabular}{|c|c|c|c|}
\hline \multicolumn{4}{|c|}{ Wall_USERDEFINED_ConcreteUnitMasonry_US } \\
\hline 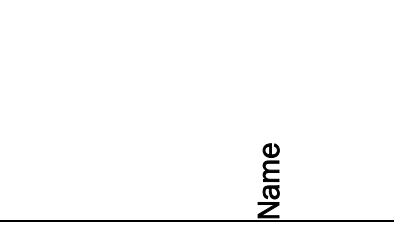 & 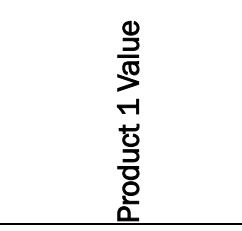 & 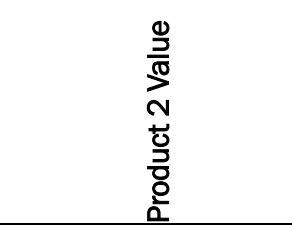 & $\begin{array}{l}\frac{0}{2} \\
\frac{\pi}{00} \\
m \\
\frac{0}{0} \\
\frac{2}{0} \\
\frac{2}{2}\end{array}$ \\
\hline Manufacturer & County Materials & Anchor & Trenwyth \\
\hline Model & $\begin{array}{l}\text { Old World Tumbled - } \\
4 \times 8 \times 16\end{array}$ & Standard CMU - 8X8X16 & $\begin{array}{l}\text { Verastone Plus recycled } \\
\text { filled and polished ground } \\
\text { face masonry units - } \\
8 \times 8 \times 16\end{array}$ \\
\hline Sustainability & $\mathrm{n} / \mathrm{a}$ & $\mathrm{n} / \mathrm{a}$ & $\mathrm{n} / \mathrm{a}$ \\
\hline AcousticRating & $\mathrm{n} / \mathrm{a}$ & $\mathrm{n} / \mathrm{a}$ & $\mathrm{n} / \mathrm{a}$ \\
\hline FireRating & $\mathrm{n} / \mathrm{a}$ & 1 & 3 \\
\hline Combustible & FALSE & FALSE & FALSE \\
\hline SurfaceSpreadOfFlame & $\mathrm{n} / \mathrm{a}$ & $\mathrm{n} / \mathrm{a}$ & $\mathrm{n} / \mathrm{a}$ \\
\hline ThermalTransmittance & not_defined & 0.39 & 0.416666667 \\
\hline IsExternal & TRUE & TRUE & TRUE \\
\hline PostConsumerRecoveredContent & $\mathrm{n} / \mathrm{a}$ & $\mathrm{n} / \mathrm{a}$ & $\mathrm{n} / \mathrm{a}$ \\
\hline TotalRecoveredContent & $n / a$ & $n / a$ & $n / a$ \\
\hline RenewableContent & $n / a$ & $n / a$ & $n / a$ \\
\hline RenewableMaterial & $n / a$ & $n / a$ & $n / a$ \\
\hline BiobasedContent & $n / a$ & $n / a$ & $n / a$ \\
\hline BiobasedMaterial & $\mathrm{n} / \mathrm{a}$ & $n / a$ & $n / a$ \\
\hline RawMaterialLocation & $n / a$ & $n / a$ & $n / a$ \\
\hline RegionalMaterialContent & $\mathrm{n} / \mathrm{a}$ & $n / a$ & $n / a$ \\
\hline ManufactureLocation & $\mathrm{n} / \mathrm{a}$ & $n / a$ & $n / a$ \\
\hline CertifiedContent & $n / a$ & $n / a$ & $n / a$ \\
\hline CertificationType & $\mathrm{n} / \mathrm{a}$ & $\mathrm{n} / \mathrm{a}$ & $\mathrm{n} / \mathrm{a}$ \\
\hline Emissions & $n / a$ & $n / a$ & $n / a$ \\
\hline SNAP & $n / a$ & $n / a$ & $n / a$ \\
\hline ThermalResistance & $n / a$ & $n / a$ & $n / a$ \\
\hline
\end{tabular}




\begin{tabular}{|c|c|c|c|}
\hline \multicolumn{4}{|c|}{ Window_SKYLIGHT_UnitSkylights_US } \\
\hline $\begin{array}{l}\stackrel{\mathbb{N}}{\mathbf{T}} \\
\stackrel{\mathbb{\pi}}{\mathbf{2}}\end{array}$ & 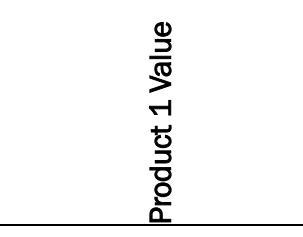 & $\begin{array}{l}\frac{0}{2} \\
\frac{\pi}{0} \\
\text { N } \\
\frac{1}{0} \\
\frac{D}{0} \\
\frac{0}{2}\end{array}$ & 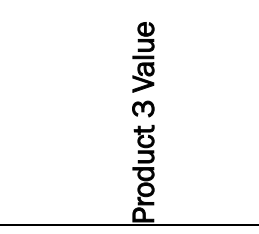 \\
\hline Manufacturer & VELUX America Inc. & Wasco & Acralight \\
\hline Model & $\begin{array}{l}\text { FIXED CURB MOUNT } \\
\text { SKYLIGHT }\end{array}$ & Pinnacle 300 & 8484 \\
\hline Sustainability & $\mathrm{n} / \mathrm{a}$ & $\mathrm{n} / \mathrm{a}$ & $\mathrm{n} / \mathrm{a}$ \\
\hline Type & $\begin{array}{l}\text { single_units_rectangular_ } \\
\text { shape }\end{array}$ & $\begin{array}{l}\text { single_unit_pyramidal_ } \\
\text { shape }\end{array}$ & $\begin{array}{l}\text { single_unit_square_sh } \\
\text { ape }\end{array}$ \\
\hline Glazing & 0 & $\begin{array}{l}\text { insulated_glass_lamin } \\
\text { ated_inner_lite_heat_s } \\
\text { trengthened_exterior_li } \\
\text { te }\end{array}$ & acrylic_plastic_clear \\
\hline PlasticDomeType & notdefined & notdefined & double_dome_sealed \\
\hline AcousticRating & $\mathrm{n} / \mathrm{a}$ & $\mathrm{n} / \mathrm{a}$ & $\mathrm{n} / \mathrm{a}$ \\
\hline FireRating & $\mathrm{n} / \mathrm{a}$ & $\mathrm{n} / \mathrm{a}$ & $\mathrm{n} / \mathrm{a}$ \\
\hline IsExternal & TRUE & TRUE & TRUE \\
\hline Infiltration & $0.04 \mathrm{cfm}$ & $0.06 \mathrm{cfm}$ & $\mathrm{n} / \mathrm{a}$ \\
\hline ThermalTransmittance & $\mathrm{n} / \mathrm{a}$ & $n / a$ & $\mathrm{n} / \mathrm{a}$ \\
\hline GlazingAreaFraction & $\mathrm{n} / \mathrm{a}$ & $\mathrm{n} / \mathrm{a}$ & $\mathrm{n} / \mathrm{a}$ \\
\hline SmokeStop & FALSE & FALSE & FALSE \\
\hline GlassLayers & 0 & 2 & 2 \\
\hline GlassThickness1 & 0 & $3 / 8^{\prime \prime}$ & $\mathrm{n} / \mathrm{a}$ \\
\hline GlassThickness2 & 0 & $1 / 4^{\prime \prime}$ & $\mathrm{n} / \mathrm{a}$ \\
\hline GlassThickness3 & $\mathrm{n} / \mathrm{a}$ & $\mathrm{n} / \mathrm{a}$ & $\mathrm{n} / \mathrm{a}$ \\
\hline FillGas & $\mathrm{n} / \mathrm{a}$ & $\mathrm{n} / \mathrm{a}$ & $\mathrm{n} / \mathrm{a}$ \\
\hline GlassColorExterior & clear & clear & clear \\
\hline GlassColorlnterior & clear & clear & clear \\
\hline VisibleLightReflectance & $\mathrm{n} / \mathrm{a}$ & $\mathrm{n} / \mathrm{a}$ & $\mathrm{n} / \mathrm{a}$ \\
\hline VisibleLightTransmittance & 0.52 & $\mathrm{n} / \mathrm{a}$ & $\mathrm{n} / \mathrm{a}$ \\
\hline SolarAbsorption & $\mathrm{n} / \mathrm{a}$ & $\mathrm{n} / \mathrm{a}$ & $\mathrm{n} / \mathrm{a}$ \\
\hline SolarReflectance & $\mathrm{n} / \mathrm{a}$ & $\mathrm{n} / \mathrm{a}$ & $\mathrm{n} / \mathrm{a}$ \\
\hline SolarTransmittance & $\mathrm{n} / \mathrm{a}$ & $\mathrm{n} / \mathrm{a}$ & $\mathrm{n} / \mathrm{a}$ \\
\hline SolarHeatGainTransmittance & 0.26 & $\mathrm{n} / \mathrm{a}$ & $\mathrm{n} / \mathrm{a}$ \\
\hline ShadingCoefficient & $\mathrm{n} / \mathrm{a}$ & $\mathrm{n} / \mathrm{a}$ & $\mathrm{n} / \mathrm{a}$ \\
\hline ThermalTransmittanceSummer & $\mathrm{n} / \mathrm{a}$ & $\mathrm{n} / \mathrm{a}$ & $\mathrm{n} / \mathrm{a}$ \\
\hline ThermalTransmittanceWinter & $\mathrm{n} / \mathrm{a}$ & $\mathrm{n} / \mathrm{a}$ & $\mathrm{n} / \mathrm{a}$ \\
\hline PostConsumerRecoveredContent & $\mathrm{n} / \mathrm{a}$ & $\mathrm{n} / \mathrm{a}$ & $\mathrm{n} / \mathrm{a}$ \\
\hline TotalRecoveredContent & $\mathrm{n} / \mathrm{a}$ & $\mathrm{n} / \mathrm{a}$ & $\mathrm{n} / \mathrm{a}$ \\
\hline
\end{tabular}


Window_SKYLIGHT_UnitSkylights_US

\begin{tabular}{|c|c|c|c|}
\hline 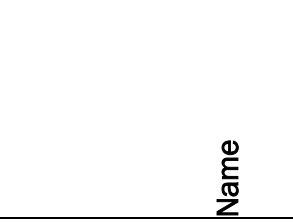 & 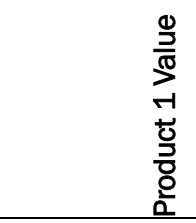 & 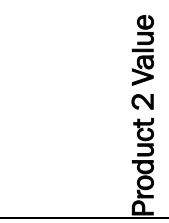 & 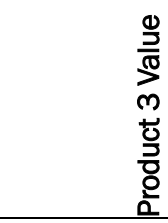 \\
\hline RenewableContent & $n / a$ & $\mathrm{n} / \mathrm{a}$ & $\mathrm{n} / \mathrm{a}$ \\
\hline RenewableMaterial & $n / a$ & $n / a$ & $\mathrm{n} / \mathrm{a}$ \\
\hline BiobasedContent & $n / a$ & $n / a$ & $\mathrm{n} / \mathrm{a}$ \\
\hline BiobasedMaterial & $n / a$ & $n / a$ & $\mathrm{n} / \mathrm{a}$ \\
\hline RawMaterialLocation & $\mathrm{n} / \mathrm{a}$ & $\mathrm{n} / \mathrm{a}$ & $\mathrm{n} / \mathrm{a}$ \\
\hline RegionalMaterialContent & $n / a$ & $n / a$ & $n / a$ \\
\hline ManufactureLocation & $n / a$ & $n / a$ & $\mathrm{n} / \mathrm{a}$ \\
\hline CertifiedContent & $n / a$ & $n / a$ & $\mathrm{n} / \mathrm{a}$ \\
\hline CertificationType & $n / a$ & $n / a$ & $n / a$ \\
\hline Emissions & $\mathrm{n} / \mathrm{a}$ & $n / a$ & $\mathrm{n} / \mathrm{a}$ \\
\hline SNAP & $\mathrm{n} / \mathrm{a}$ & $n / a$ & n/a \\
\hline ThermalResistance & $n / a$ & $n / a$ & $\mathrm{n} / \mathrm{a}$ \\
\hline
\end{tabular}




\begin{tabular}{|c|c|c|c|}
\hline \multicolumn{4}{|c|}{ Window_WINDOW_AluminumWindows_US } \\
\hline $\begin{array}{l}\stackrel{0}{E} \\
\text { ֻٓ } \\
\end{array}$ & 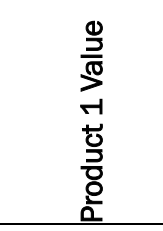 & 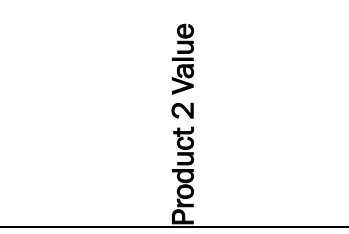 & $\begin{array}{l}\frac{0}{D} \\
\frac{D}{D} \\
m \\
\frac{0}{0} \\
\frac{D}{0} \\
\frac{0}{2}\end{array}$ \\
\hline Manufacturer & YKKap & Traco & Kawneer \\
\hline Model & YVS 400 TU & TR-9400 (AW-PG55-H) & $\begin{array}{l}\text { Series AA } \AA 3350 \\
\text { IsoPortTM }\end{array}$ \\
\hline Sustainability & $\mathrm{n} / \mathrm{a}$ & $\mathrm{n} / \mathrm{a}$ & $\mathrm{n} / \mathrm{a}$ \\
\hline Glazing & $\begin{array}{l}1 " \text { Insulating } \\
\text { glass }\end{array}$ & $\begin{array}{l}\text { PPG -SUNGATE } 400 \text { (2) Clear } \\
+ \text { Clear - 3/4" Insulating glass }\end{array}$ & $\begin{array}{l}\text { PPG - SOLARBAN 70XL } \\
(2)+\text { Clear - 1" insulating } \\
\text { glass }\end{array}$ \\
\hline AcousticRating & 35 STC & $n / a$ & 34 STC \\
\hline FireRating & $n / a$ & $n / a$ & $n / a$ \\
\hline IsExternal & TRUE & TRUE & TRUE \\
\hline Infiltration & 0.3 & 0.3 & 0.3 \\
\hline ThermalTransmittance & 0.53 & 0.52 & 0.48 \\
\hline GlazingAreaFraction & $\mathrm{n} / \mathrm{a}$ & $\mathrm{n} / \mathrm{a}$ & $\mathrm{n} / \mathrm{a}$ \\
\hline SmokeStop & $\mathrm{n} / \mathrm{a}$ & $\mathrm{n} / \mathrm{a}$ & $\mathrm{n} / \mathrm{a}$ \\
\hline GlassLayers & 1 & 2 & 2 \\
\hline GlassThickness1 & $.25 "$ & 0.25 & $.25 "$ \\
\hline GlassThickness2 & $\mathrm{n} / \mathrm{a}$ & $.25 "$ & $.25 "$ \\
\hline GlassThickness3 & $\mathrm{n} / \mathrm{a}$ & $\mathrm{n} / \mathrm{a}$ & $\mathrm{n} / \mathrm{a}$ \\
\hline FillGas & $\mathrm{n} / \mathrm{a}$ & air & argon \\
\hline VisibleLightReflectance & 0.09 & 0.14 & 0.12 \\
\hline VisibleLightTransmittance & 0.89 & 0.76 & 0.64 \\
\hline SolarAbsorption & $n / a$ & $\mathrm{n} / \mathrm{a}$ & $n / a$ \\
\hline SolarReflectance & 7 & 16 & 52 \\
\hline SolarTransmittance & 77 & 51 & 25 \\
\hline SolarHeatGainTransmittance & 0.82 & 0.6 & 0.27 \\
\hline ShadingCoefficient & 0 & 0.69 & 0.32 \\
\hline ThermalTransmittanceSummer & 0.93 & 0.31 & 0.26 \\
\hline ThermalTransmittanceWinter & 1.02 & 0.32 & 0.28 \\
\hline PostConsumerRecoveredContent & $\mathrm{n} / \mathrm{a}$ & $\mathrm{n} / \mathrm{a}$ & $\mathrm{n} / \mathrm{a}$ \\
\hline TotalRecoveredContent & $\mathrm{n} / \mathrm{a}$ & $\mathrm{n} / \mathrm{a}$ & $\mathrm{n} / \mathrm{a}$ \\
\hline RenewableContent & $\mathrm{n} / \mathrm{a}$ & $\mathrm{n} / \mathrm{a}$ & $\mathrm{n} / \mathrm{a}$ \\
\hline RenewableMaterial & $\mathrm{n} / \mathrm{a}$ & $\mathrm{n} / \mathrm{a}$ & $\mathrm{n} / \mathrm{a}$ \\
\hline BiobasedContent & $\mathrm{n} / \mathrm{a}$ & $\mathrm{n} / \mathrm{a}$ & $\mathrm{n} / \mathrm{a}$ \\
\hline BiobasedMaterial & $\mathrm{n} / \mathrm{a}$ & $\mathrm{n} / \mathrm{a}$ & $\mathrm{n} / \mathrm{a}$ \\
\hline RawMaterialLocation & $\mathrm{n} / \mathrm{a}$ & $\mathrm{n} / \mathrm{a}$ & $\mathrm{n} / \mathrm{a}$ \\
\hline RegionalMaterialContent & $\mathrm{n} / \mathrm{a}$ & $n / a$ & $n / a$ \\
\hline
\end{tabular}


Window_WINDOW_AluminumWindows_US

\begin{tabular}{|c|c|c|c|}
\hline $\begin{array}{l}\stackrel{0}{E} \\
\stackrel{\mathbb{\pi}}{Z}\end{array}$ & 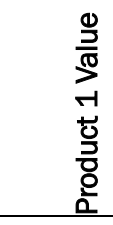 & 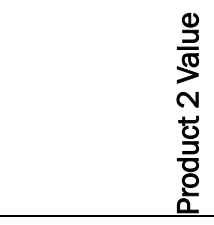 & $\begin{array}{l}\frac{0}{2} \\
\frac{1}{\pi} \\
m \\
\frac{0}{0} \\
\frac{2}{0} \\
\frac{0}{2}\end{array}$ \\
\hline ManufactureLocation & $\mathrm{n} / \mathrm{a}$ & $\mathrm{n} / \mathrm{a}$ & $n / a$ \\
\hline CertifiedContent & $\mathrm{n} / \mathrm{a}$ & $\mathrm{n} / \mathrm{a}$ & $\mathrm{n} / \mathrm{a}$ \\
\hline CertificationType & $\mathrm{n} / \mathrm{a}$ & $\mathrm{n} / \mathrm{a}$ & $\mathrm{n} / \mathrm{a}$ \\
\hline Emissions & $\mathrm{n} / \mathrm{a}$ & $\mathrm{n} / \mathrm{a}$ & $n / a$ \\
\hline SNAP & $\mathrm{n} / \mathrm{a}$ & $\mathrm{n} / \mathrm{a}$ & $n / a$ \\
\hline ThermalResistance & $\mathrm{n} / \mathrm{a}$ & $\mathrm{n} / \mathrm{a}$ & $\mathrm{n} / \mathrm{a}$ \\
\hline WaterInfiltration & 15 psf & $15 \mathrm{psf}$ & $n / a$ \\
\hline UVTransmittance & 0.29 & $\mathrm{n} / \mathrm{a}$ & $\mathrm{n} / \mathrm{a}$ \\
\hline
\end{tabular}




\begin{tabular}{|c|c|c|c|}
\hline \multicolumn{4}{|c|}{ Window_WINDOW_VinylWindows_US } \\
\hline 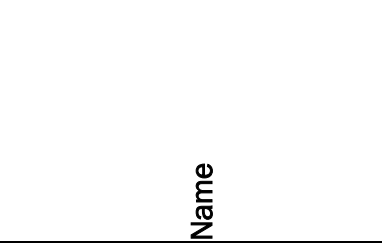 & 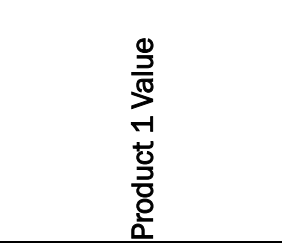 & $\begin{array}{l}\frac{0}{2} \\
\frac{\pi}{10} \\
\text { N } \\
\frac{1}{0} \\
\frac{2}{2} \\
\frac{0}{2}\end{array}$ & $\begin{array}{l}\frac{0}{2} \\
\frac{\pi}{00} \\
m \\
\frac{1}{0} \\
\frac{0}{0} \\
\frac{0}{2}\end{array}$ \\
\hline Manufacturer & Pella & Jeld-wen & Serious Energy, Inc. \\
\hline Model & $\begin{array}{l}350 \text { Series - vent with } \\
\text { foam insulation }\end{array}$ & $\begin{array}{l}\text { PremiumVinyl Double-Hung - } \\
\text { Triple Glaze Low-E } 366 \text { Argon }\end{array}$ & $\begin{array}{l}\text { Heavy Commercial } 7000 \\
\text { Series - fiberglass Picture } \\
\text { (fixed) }\end{array}$ \\
\hline Sustainability & $\mathrm{n} / \mathrm{a}$ & $\mathrm{n} / \mathrm{a}$ & $\mathrm{n} / \mathrm{a}$ \\
\hline Glazing & $\begin{array}{l}\text { insulating_glass_with_l } \\
\text { ow_e_coating }\end{array}$ & $\begin{array}{l}\text { insulating_glass_with_low_e } \\
\text { _coating }\end{array}$ & $\begin{array}{l}\text { insulating_glass_with_low_e } \\
\text { _coating }\end{array}$ \\
\hline GlazingColor & clear & clear & clear \\
\hline AcousticRating & $\mathrm{n} / \mathrm{a}$ & 35 & 34 \\
\hline FireRating & $\mathrm{n} / \mathrm{a}$ & $\mathrm{n} / \mathrm{a}$ & $\mathrm{n} / \mathrm{a}$ \\
\hline SecurityRating & $\mathrm{n} / \mathrm{a}$ & $\mathrm{n} / \mathrm{a}$ & 10 \\
\hline IsExternal & TRUE & TRUE & TRUE \\
\hline Infiltration & 0.3 & $\mathrm{n} / \mathrm{a}$ & 0.01 \\
\hline ThermalTransmittance & $\mathrm{n} / \mathrm{a}$ & $\mathrm{n} / \mathrm{a}$ & 0.38 \\
\hline GlazingAreaFraction & $\mathrm{n} / \mathrm{a}$ & $\mathrm{n} / \mathrm{a}$ & $\mathrm{n} / \mathrm{a}$ \\
\hline SmokeStop & FALSE & FALSE & FALSE \\
\hline GlassLayers & 2 & 3 & 2 \\
\hline GlassThickness1 & 5 & 4.8 & $\mathrm{n} / \mathrm{a}$ \\
\hline GlassThickness2 & 5 & 6.4 & $\mathrm{n} / \mathrm{a}$ \\
\hline GlassThickness3 & $\mathrm{n} / \mathrm{a}$ & $\mathrm{n} / \mathrm{a}$ & $\mathrm{n} / \mathrm{a}$ \\
\hline FillGas & argon & argon & $\mathrm{n} / \mathrm{a}$ \\
\hline GlassColor & $\mathrm{n} / \mathrm{a}$ & $\mathrm{n} / \mathrm{a}$ & $\mathrm{n} / \mathrm{a}$ \\
\hline VisibleLightReflectance & $\mathrm{n} / \mathrm{a}$ & $\mathrm{n} / \mathrm{a}$ & 16 \\
\hline VisibleLightTransmittance & 48 & 0.4 & 56 \\
\hline SolarAbsorption & $\mathrm{n} / \mathrm{a}$ & $\mathrm{n} / \mathrm{a}$ & $\mathrm{n} / \mathrm{a}$ \\
\hline SolarReflectance & $\mathrm{n} / \mathrm{a}$ & $\mathrm{n} / \mathrm{a}$ & 34 \\
\hline SolarTransmittance & $\mathrm{n} / \mathrm{a}$ & $\mathrm{n} / \mathrm{a}$ & 25 \\
\hline SolarHeatGainTransmittance & 0.27 & 0.17 & 0.22 \\
\hline ShadingCoefficient & $\mathrm{n} / \mathrm{a}$ & $\mathrm{n} / \mathrm{a}$ & $\mathrm{n} / \mathrm{a}$ \\
\hline ThermalTransmittanceSummer & $\mathrm{n} / \mathrm{a}$ & $\mathrm{n} / \mathrm{a}$ & 0.09 \\
\hline ThermalTransmittanceWinter & $n / a$ & $\mathrm{n} / \mathrm{a}$ & 0.08 \\
\hline PostConsumerRecoveredContent & $\mathrm{n} / \mathrm{a}$ & 0 & 0 \\
\hline TotalRecoveredContent & $\mathrm{n} / \mathrm{a}$ & 10 & 10 \\
\hline RenewableContent & $n / a$ & $\mathrm{n} / \mathrm{a}$ & $\mathrm{n} / \mathrm{a}$ \\
\hline RenewableMaterial & $n / a$ & $\mathrm{n} / \mathrm{a}$ & $n / a$ \\
\hline
\end{tabular}




\begin{tabular}{|c|c|c|c|}
\hline \multicolumn{4}{|c|}{ Window_WINDOW_VinylWindows_US } \\
\hline $\begin{array}{l}\stackrel{\Phi}{E} \\
\underset{\mathbb{Z}}{Z}\end{array}$ & 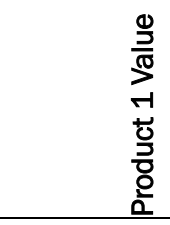 & $\begin{array}{l}\frac{0}{3} \\
\frac{0}{\pi} \\
\mathbb{N} \\
\frac{0}{2} \\
\frac{7}{0} \\
\frac{0}{2}\end{array}$ & 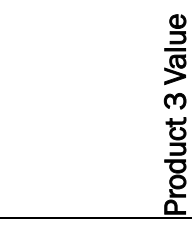 \\
\hline BiobasedContent & $\mathrm{n} / \mathrm{a}$ & $\mathrm{n} / \mathrm{a}$ & $\mathrm{n} / \mathrm{a}$ \\
\hline BiobasedMaterial & $\mathrm{n} / \mathrm{a}$ & $\mathrm{n} / \mathrm{a}$ & $\mathrm{n} / \mathrm{a}$ \\
\hline RawMaterialLocation & $\mathrm{n} / \mathrm{a}$ & $\mathrm{n} / \mathrm{a}$ & $\mathrm{n} / \mathrm{a}$ \\
\hline RegionalMaterialContent & $\mathrm{n} / \mathrm{a}$ & $\mathrm{n} / \mathrm{a}$ & $\mathrm{n} / \mathrm{a}$ \\
\hline ManufactureLocation & $\mathrm{n} / \mathrm{a}$ & $\mathrm{n} / \mathrm{a}$ & $\mathrm{n} / \mathrm{a}$ \\
\hline CertifiedContent & $\mathrm{n} / \mathrm{a}$ & $\mathrm{n} / \mathrm{a}$ & $n / a$ \\
\hline CertificationType & Hallmark & $\begin{array}{l}\text { Energy_Star, } \\
\text { Buy_American_Act_Complia } \\
\text { nt, CARB - } \\
\text { Airborne_Toxic_Control_Mea } \\
\text { sure }\end{array}$ & $\mathrm{n} / \mathrm{a}$ \\
\hline Emissions & $n / a$ & $\mathrm{n} / \mathrm{a}$ & $\mathrm{n} / \mathrm{a}$ \\
\hline SNAP & $\mathrm{n} / \mathrm{a}$ & $\mathrm{n} / \mathrm{a}$ & $\mathrm{n} / \mathrm{a}$ \\
\hline ThermalResistance & 0 & 0.3 & $\mathrm{n} / \mathrm{a}$ \\
\hline WaterInfiltration & 4.6 & $\mathrm{n} / \mathrm{a}$ & 15 \\
\hline UVTransmittance & $\mathrm{n} / \mathrm{a}$ & $\mathrm{n} / \mathrm{a}$ & $<1$ \\
\hline
\end{tabular}


Window_WINDOW_WoodWindows_US

\begin{tabular}{|c|c|c|c|}
\hline $\begin{array}{l}\stackrel{\Phi}{E} \\
\underset{\mathbb{\pi}}{\mathbf{D}}\end{array}$ & 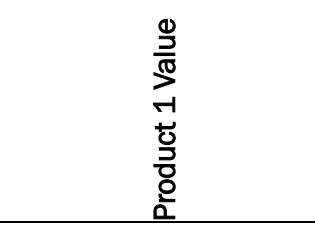 & $\begin{array}{l}\frac{0}{2} \\
\frac{2}{\pi} \\
\text { N } \\
\frac{0}{2} \\
\frac{5}{0} \\
\frac{0}{2}\end{array}$ & $\begin{array}{l}\frac{0}{2} \\
\frac{2}{\pi} \\
m \\
\frac{0}{0} \\
\frac{0}{0} \\
\frac{0}{2}\end{array}$ \\
\hline Manufacturer & Pella & Andersen & Jeld-Wen \\
\hline Model & $\begin{array}{l}\text { Double-hung Designer } \\
\text { Series }\end{array}$ & $\begin{array}{l}400 \text { Series Casement - } \\
\text { CR155 }\end{array}$ & Siteline EX Clad 1003 \\
\hline Sustainability & $\mathrm{n} / \mathrm{a}$ & $n / a$ & 0 \\
\hline Glazing & $\begin{array}{l}\text { insulating_glass_with_low_ } \\
\text { e_coating }\end{array}$ & $\begin{array}{l}\text { insulating_glass_with_low_ } \\
\text { e_coating }\end{array}$ & $\begin{array}{l}\text { insulating_glass_with_I } \\
\text { ow_e_coating }\end{array}$ \\
\hline GlazingColor & clear_glass & clear_glass & clear_glass \\
\hline AcousticRating & 30 & 26 & 35 \\
\hline FireRating & $\mathrm{n} / \mathrm{a}$ & $\mathrm{n} / \mathrm{a}$ & $\mathrm{n} / \mathrm{a}$ \\
\hline IsExternal & TRUE & TRUE & TRUE \\
\hline Infiltration & 0.3 & $\mathrm{n} / \mathrm{a}$ & $\mathrm{n} / \mathrm{a}$ \\
\hline ThermalTransmittance & $\mathrm{n} / \mathrm{a}$ & $\mathrm{n} / \mathrm{a}$ & $\mathrm{n} / \mathrm{a}$ \\
\hline GlazingAreaFraction & $\mathrm{n} / \mathrm{a}$ & 0.675324675 & 0 \\
\hline SmokeStop & FALSE & FALSE & FALSE \\
\hline GlassLayers & 2 & 2 & 2 \\
\hline GlassThickness1 & 2.5 & $\mathrm{n} / \mathrm{a}$ & $\mathrm{n} / \mathrm{a}$ \\
\hline GlassThickness2 & 2.5 & $\mathrm{n} / \mathrm{a}$ & $\mathrm{n} / \mathrm{a}$ \\
\hline GlassThickness3 & $\mathrm{n} / \mathrm{a}$ & $\mathrm{n} / \mathrm{a}$ & $\mathrm{n} / \mathrm{a}$ \\
\hline FillGas & none & argon & argon \\
\hline GlassColor & $\mathrm{n} / \mathrm{a}$ & $\mathrm{n} / \mathrm{a}$ & $\mathrm{n} / \mathrm{a}$ \\
\hline VisibleLightReflectance & $\mathrm{n} / \mathrm{a}$ & $\mathrm{n} / \mathrm{a}$ & $\mathrm{n} / \mathrm{a}$ \\
\hline VisibleLightTransmittance & 82 & 73 & $\mathrm{n} / \mathrm{a}$ \\
\hline SolarAbsorption & $\mathrm{n} / \mathrm{a}$ & $\mathrm{n} / \mathrm{a}$ & $\mathrm{n} / \mathrm{a}$ \\
\hline SolarReflectance & $\mathrm{n} / \mathrm{a}$ & $\mathrm{n} / \mathrm{a}$ & $\mathrm{n} / \mathrm{a}$ \\
\hline SolarTransmittance & $\mathrm{n} / \mathrm{a}$ & $\mathrm{n} / \mathrm{a}$ & $\mathrm{n} / \mathrm{a}$ \\
\hline SolarHeatGainTransmittance & 0.78 & 0.43 & 0.28 \\
\hline ShadingCoefficient & 0.9 & 0.5 & $\mathrm{n} / \mathrm{a}$ \\
\hline ThermalTransmittanceSummer & $\mathrm{n} / \mathrm{a}$ & $\mathrm{n} / \mathrm{a}$ & $\mathrm{n} / \mathrm{a}$ \\
\hline ThermalTransmittanceWinter & $\mathrm{n} / \mathrm{a}$ & $\mathrm{n} / \mathrm{a}$ & $\mathrm{n} / \mathrm{a}$ \\
\hline PostConsumerRecoveredContent & $\mathrm{n} / \mathrm{a}$ & 0 & 0 \\
\hline TotalRecoveredContent & $\mathrm{n} / \mathrm{a}$ & 4 & 10 \\
\hline RenewableContent & $\mathrm{n} / \mathrm{a}$ & $\mathrm{n} / \mathrm{a}$ & $\mathrm{n} / \mathrm{a}$ \\
\hline RenewableMaterial & $\mathrm{n} / \mathrm{a}$ & $\mathrm{n} / \mathrm{a}$ & $\mathrm{n} / \mathrm{a}$ \\
\hline BiobasedContent & $\mathrm{n} / \mathrm{a}$ & $\mathrm{n} / \mathrm{a}$ & $\mathrm{n} / \mathrm{a}$ \\
\hline BiobasedMaterial & $\mathrm{n} / \mathrm{a}$ & $\mathrm{n} / \mathrm{a}$ & $\mathrm{n} / \mathrm{a}$ \\
\hline RawMaterialLocation & $\mathrm{n} / \mathrm{a}$ & $\mathrm{n} / \mathrm{a}$ & $\mathrm{n} / \mathrm{a}$ \\
\hline
\end{tabular}


Window_WINDOW_WoodWindows_US

\begin{tabular}{|c|c|c|c|}
\hline $\begin{array}{l}\stackrel{0}{E} \\
\stackrel{\text { I0 }}{z}\end{array}$ & 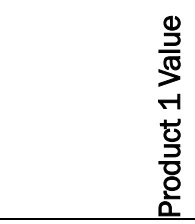 & 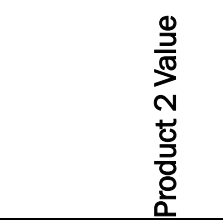 & $\begin{array}{l}\frac{0}{J} \\
\frac{3}{\pi} \\
m \\
\frac{0}{0} \\
\frac{0}{0} \\
\frac{0}{2}\end{array}$ \\
\hline RegionalMaterialContent & $\mathrm{n} / \mathrm{a}$ & n/a & n/a \\
\hline ManufactureLocation & $\mathrm{n} / \mathrm{a}$ & n/a & $n / a$ \\
\hline CertifiedContent & $\mathrm{n} / \mathrm{a}$ & $n / a$ & $\mathrm{n} / \mathrm{a}$ \\
\hline CertificationType & $\mathrm{n} / \mathrm{a}$ & NFRC, Energy_Star & $\begin{array}{l}\text { Energy_Star, } \\
\text { Buy_American_Act_Co } \\
\text { mpliant }\end{array}$ \\
\hline Emissions & $\mathrm{n} / \mathrm{a}$ & $n / a$ & $n / a$ \\
\hline SNAP & $\mathrm{n} / \mathrm{a}$ & $n / a$ & $\mathrm{n} / \mathrm{a}$ \\
\hline ThermalResistance & 0.5 & 0.28 & 0.27 \\
\hline ExteriorCladding & Wood & PVC & aluminum \\
\hline Waterlnfiltration & 7.5 & $n / a$ & $\mathrm{n} / \mathrm{a}$ \\
\hline UVTransmittance & 61 & $n / a$ & $\mathrm{n} / \mathrm{a}$ \\
\hline
\end{tabular}




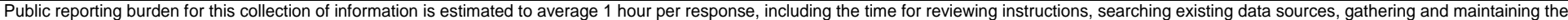

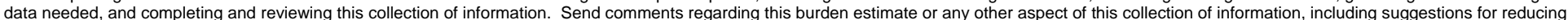

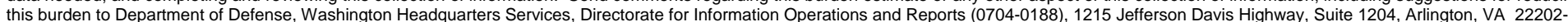

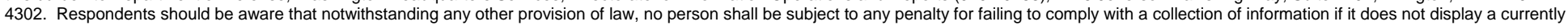
valid OMB control number. PLEASE DO NOT RETURN YOUR FORM TO THE ABOVE ADDRESS.

\begin{tabular}{l|l} 
1. REPORT DATE (DD-MM-YYYY) & 2. REPORT TYPE
\end{tabular}

September 2012

Final

\section{TITLE AND SUBTITLE}

Sustainability Product Properties in Building Information Models

(2)

3. DATES COVERED (From - To)

5a. CONTRACT NUMBER

5b. GRANT NUMBER

5c. PROGRAM ELEMENT NUMBER

\section{AUTHOR(S)}

Kristine K. Fallon, Robert A. Feldman, Julia Greenberger, Gregory R. Williams, Holly J.

Genc, Lourdes M. Gonzalez, and Josh Greenfield

5d. PROJECT NUMBER

CRADA-07-CERL-02

5e. TASK NUMBER

5f. WORK UNIT NUMBER

8. PERFORMING ORGANIZATION REPORT NUMBER

\section{PERFORMING ORGANIZATION NAME(S) AND ADDRESS(ES)}

Kristine Fallon Assocites, Inc.

11 East Adams Street, Suite 1100

Chicago, IL 60603

\section{SPONSORING I MONITORING AGENCY NAME(S) AND ADDRESS(ES)}

US Army Engineer Research and Development Center

Construction Engineering Research Laboratory

P.O. Box 9005

Champaign, IL 61826-9005

\section{DISTRIBUTION / AVAILABILITY STATEMENT}

Approved for public release; distribution is unlimited.

\section{SUPPLEMENTARY NOTES}

\section{ABSTRACT}

There are currently several competing efforts to define and measure sustainability. To date, no single concept of facility sustainability is widely accepted as being definitive because the term is often loosely used to define the particular environmental and social goals of any given sustainability proponent. This work looks beyond an abstract definition of facility sustainability and proposes a set of product properties that can be measured to represent the natural resources consumed to produce and operate facility assets.

Development of this set of sustainability properties included a review of prominent tools and systems for assessing facility sustainability, including contributions by industry experts. The project also included analysis of how sustainability product properties may be integrated with Building Information Modeling (BIM) technology to improve US Army facilities. The report includes sustainability properties for 56 building elements, which have been incorporated into building property templates for use in BIM models.

\section{SUBJECT TERMS}

sustainability, information exchange, product data templates, Construction Operations Building information exchange (COBie),Building Information Modeling (BIM)

\begin{tabular}{|c|c|c|c|c|c|}
\hline \multicolumn{3}{|c|}{ 16. SECURITY CLASSIFICATION OF: } & \multirow{2}{*}{$\begin{array}{l}\text { 17. LIMITATION } \\
\text { OF ABSTRACT }\end{array}$} & \multirow{2}{*}{$\begin{array}{l}\text { 18. NUMBER } \\
\text { OF PAGES } \\
264\end{array}$} & 19a. NAME OF RESPONSIBLE PERSON \\
\hline $\begin{array}{l}\text { a. REPORT } \\
\text { Unclassified }\end{array}$ & $\begin{array}{l}\text { b. ABSTRACT } \\
\text { Unclassified }\end{array}$ & $\begin{array}{l}\text { c. THIS PAGE } \\
\text { Unclassified }\end{array}$ & & & $\begin{array}{l}\text { 19b. TELEPHONE NUMBER } \\
\text { (include area code) }\end{array}$ \\
\hline
\end{tabular}

